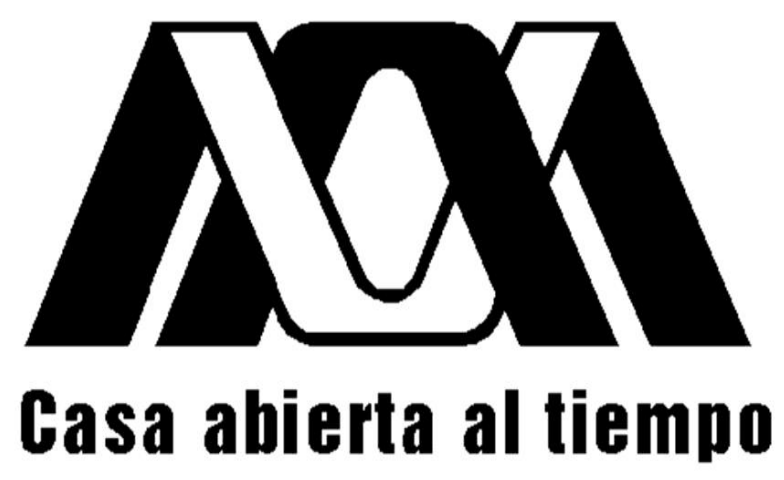

\title{
RESPUESTAS ECOANATÓMICAS Y ECOFISIOLÓGICAS DE DOS ESPECIES DEL GÉNERO Mimosa (LEGUMINOSAE) ANTE EL CAMBIO CLIMÁTICO
} TESIS

Que para obtener el grado de Doctor en Ciencias Biológicas y de la Salud PRESENTA M. en B. SUSANA ADRIANA MONTAÑO ARIAS

Directora: Dra. Sara Lucía Camargo Ricalde Asesora: Dra. Rosaura Grether González Asesor: Dr. David Manuel Díaz Pontones

Junio, 2016 
“El Doctorado en Ciencias Biológicas y de la Salud de la Universidad Autónoma Metropolitana pertenece al Padrón de Posgrados de excelencia del CONACyT y además cuenta con apoyo del mismo Consejo, con el convenio "PFP-20-93" 
Esta tesis se realizó en los laboratorios de Biología y Ecología de Leguminosas, y en Biosistemática de Leguminosas de la Universidad Autónoma Metropolitana Iztapalapa, bajo la tutoría de:

Dra. Sara Lucía Camargo Ricalde (directora, Departamento Biología, UAMI)

Dra. Rosaura Grether González (asesora, Departamento Biología, UAMI)

Dr. David Manuel Díaz Pontones (asesor, Departamento de Ciencias de la Salud, UAMI) 
El jurado designado por las

\section{Divisiones de Ciencias Biológicas y de la Salud}

de las Unidades Cuajimalpa, Iztapalapa y Xochimilco aprobó la tesis que presentó

\section{Susana Adriana Montaño Arias}

\section{El día 15 de junio del año 2016}

Comité Tutoral

Directora: Dra. Sara Lucía Camargo

Ricalde

Asesora Interna: Dra. Rosaura Grether

González

Asesor Interno: Dr. David Manuel Díaz

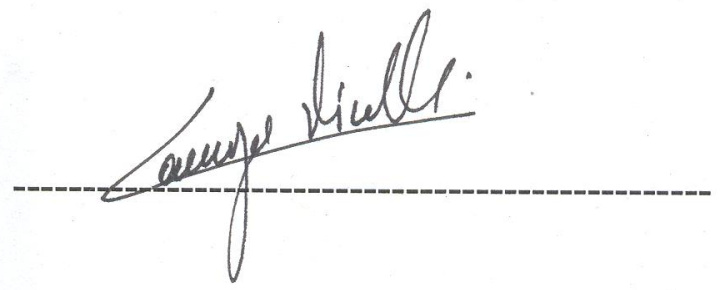

Pontones

Sinodal: Dra. María Hilda Flores Olvera

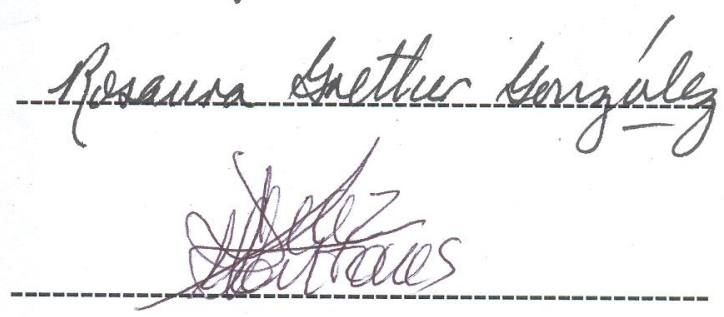

Sinodal: Dra. Silvia Castillo Argüero
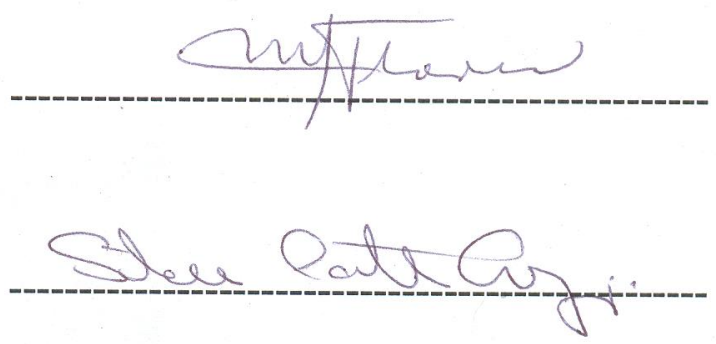


\section{Agradecimientos}

A mis padres: Con todo mi amor, respeto y admiración

Evaristo Genaro Montaño Quezada ${ }^{\dagger}$ y Esperanza Arias Garibay

A mis hermanos

Noé Manuel, Genaro y Ana Georgina

Por su compañía y apoyo

Esta tesis es una contribución a los Proyectos "Biología y Ecología del género Mimosa (Leguminosae-Mimosoideae) en ecosistemas áridos y semiáridos de México: El caso del Valle de Tehuacán-Cuicatlán como un sistema modelo" y "Filogenia Infragenérica de grupos selectos de Mimosa (Leguminosae-Mimosoideae) basada en datos moleculares".

Se agradece a CONACyT-México por la beca otorgada para realizar mis estudios de Doctorado (CVU 228993/Becario 211528).

A mi directora de tesis la Dra. Sara Lucía Camargo Ricalde por brindarme la oportunidad de trabajar en sus proyectos, por enseñarme a hacer investigación, por sus consejos, las múltiples correcciones y críticas y, por sus valiosas aportaciones a mi formación académica. Además, agradezco su ayuda incondicional, por contribuir con ideas y trabajo, por su enorme paciencia y amistad en todo momento del proceso 
de investigación. A mis asesores: Dra. Rosaura Grether González y Dr. David M. Díaz Pontones por su motivación, apoyo, correcciones y críticas a mi trabajo de investigación, todo contribuyó enormemente al buen término de esta tesis. En especial, agradezco a la Dra. Rosaura Grether por creer en mí y darme la oportunidad de ser su estudiante, además, agradezco su enorme paciencia, comprensión y por siempre darme ánimos.

A las Dras. Hilda Flores Olvera y Silvia Castillo Argüero por aceptar ser sinodales, por sus sugerencias y/o recomendaciones que sin duda enriquecieron el contenido de esta tesis.

Quiero agradecer al Dr. Jonh Larsen por asesorarme durante mi estancia de Investigación en el Centro de Investigaciones en Ecosistemas, UNAM.

Al Dr. Noé Montaño y al M. en B. Laurent Martínez Olivares ${ }^{\dagger}$ por su ayuda en las colectas del material de campo. A la Dra. Leticia Pacheco por su compañía, asesoría y ánimo. Al Sr. Elías Ruíz Juárez (No. Económico 19750) de la Carpintería de la UAMI, por su disposición a elaborar las muestras para el estudio macroscópico de la madera.

Por otra parte, agradezco a la Universidad Autónoma Metropolitana y en especial, al Doctorado en Ciencias Biológicas y de la Salud por brindarme apoyo económico durante mis estudios. Asimismo, al Programa de Movilidad Estudiantil "Santander" (ECOES) por la beca otorgada para realizar una estancia de Investigación en el Centro de Investigaciones en Ecosistemas, UNAM, Campus Morelia. 


\section{ÍNDICE}

$\begin{array}{ll}\text { Resumen } & 9\end{array}$

$\begin{array}{ll}\text { Abstract } & 12\end{array}$

Introducción General $\quad 15$

Literatura Citada

$\begin{array}{ll}\text { Objetivo General } & 23\end{array}$

$\begin{array}{ll}\text { Objetivos Particulares } & 23\end{array}$

CAPITULO I Distribución conocida y potencial de Mimosa aculeaticarpa var. aculeaticarpa y M. Iuisana (Leguminosae-Mimosoideae)

Introducción

Antecedentes

Preguntas de Investigación

Hipótesis

Objetivo

Métodos

Resultados

Discusión

Conclusiones

62

Literatura Citada

66

66

CAPITULO II Morfología de la semilla y anatomía de la testa de dos taxa del género Mimosa (Leguminosae-Mimosoideae)

Introducción

Antecedentes

Preguntas de Investigación

Hipótesis

Objetivo

106

Métodos

107

Resultados

107

Discusión

110

Conclusiones

123

Literatura Citada

129

130 
CAPITULO III Efecto de la escarificación y la temperatura en la germinación de dos especies de Mimosa (Leguminosae-Mimosoideae)

Introducción

Antecedentes

Preguntas de Investigación

Hipótesis

Objetivo

Métodos

Resultados

Discusión

Conclusiones

Literatura Citada

Publicación

CAPITULO IV Análisis ecoanatómico de la madera de Mimosa aculeaticarpa var. aculeaticarpa y M. Iuisana (Leguminosae-Mimosoideae)

Introducción

Antecedentes

Preguntas de Investigación

Hipótesis

190

Objetivo

191

Métodos

191

Resultados

191

Discusión

195

Conclusiones

201

Literatura Citada

209

Discusión General

Literatura Citada

Conclusiones Generales

Perspectivas 


\section{RESUMEN}

Una de las predicciones sobre el efecto de cambio climático es que los ecosistemas podrían ampliar o reducir sus áreas de distribución, debido a que los ambientes húmedos podrían convertirse en secos y viceversa; esto como respuesta al grado de tolerancia de los taxa, principalmente vegetales, que los componen. Por ejemplo, dentro de la familia Leguminosae, se considera que el género Mimosa es, potencialmente, capaz de tolerar un amplio rango de variaciones ambientales. Las mimosas mexicanas predominan en ecosistemas cálido-húmedos y cálido-secos, y considerando su importancia biológica y ecológica, se requieren estudios que permitieran establecer el nivel de tolerancia que poseen estas plantas ante las modificaciones que pudiesen darse en los elementos del clima como son la temperatura y la precipitación. Por lo anterior, se generaron mapas de distribución conocida y modelos de distribución potencial de Mimosa aculeaticarpa var. aculeaticarpa (ambiente mésico; amplia distribución, endémica de México) y $M$. luisana (ambiente seco; endémica del Valle de Tehuacán-Cuicatlán, Puebla y Oaxaca), y con el propósito de dar soporte a estos modelos, sobre todo al potencial, se describieron, analizaron, compararon y evaluaron las características morfológicas de sus semillas, la anatomía de la testa y su germinación; así como la anatomía de su madera, obteniéndose, además, los Índices de Vulnerabilidad (IV) y de Mesomorfía (IM), respectivos. Lo anterior, se estableció como fundamento para 
determinar el grado de tolerancia de estos taxa a los posibles cambios de temperatura y precipitación predichos, y para, finalmente, validar dichos modelos. A partir de la depuración y validación de bases de datos de Mimosa (CONABIO, GBIF) y de revisión de herbarios, se determinó, para cada taxon, su distribución conocida y se generaron modelos de distribución potencial con el algoritmo MaxEnt. $M$. aculeaticarpa var. aculeaticarpa tiene amplia distribución en el país; mientras que $M$. luisana presenta una distribución restringida; no obstante, los modelos de distribución potencial indican que ambos taxa podrían ampliar su distribución. Los dos taxa presentan características anatómicas que apoyan la predicción de los modelos; en el caso de la semilla de $M$. aculeaticarpa var. aculeaticarpa, ésta presenta una testa conformada por cutícula, macroesclereidas y parénquima; mientras que la testa de la semilla de $M$. luisana está constituida por cutícula, macroesclereidas, osteoesclereidas y parénquima; por lo que, en ambos casos, la semilla requiere de un método de escarificación para permitir la germinación. Una vez escarificadas, el mayor porcentaje de germinación, independientemente de la temperatura $(5,10,15$, $\left.20,25,30,35,40^{\circ} \mathrm{C}\right)$, lo presenta $M$. luisana $(50-100 \%)$; mientras que a $45^{\circ} \mathrm{C}$, es $M$. aculeaticarpa var. aculeaticarpa quien alcanza el mayor porcentaje (35\%). En el caso de la anatomía de la madera, ésta presenta características que les permitiría, a ambos taxa, adaptarse a variaciones en la precipitación. M. aculeaticarpa var. aculeaticarpa presenta una madera con porosidad anular; mientras que en $M$. luisana, la porosidad es difusa. Ambos taxa presentan elementos de vaso cortos, de diámetro pequeño y sólo los de la madera temprana son de diámetro mediano. El IV más alto (4.05) se determinó en M. aculeaticarpa var. aculeaticarpa; por lo que el IV, 
en conjunto con las características anatómicas de su madera, indican que este taxon es el más vulnerable a la sequía; además de presentar el IM más alto (729.05, menor tolerancia). En cambio, los valores más bajos de los IV (1.42) e IM (226.71), los presentó $M$. luisana, lo que sugiere que este taxon es más resistente a la sequía (mayor tolerancia). De ahí que, si en conjunto se considera la distribución conocida de ambos taxa, así como las predicciones relacionadas con la transformación de los ecosistemas húmedos a secos, entonces es posible sugerir que ambos taxa cuentan con las características biológicas que les permitirían ampliar su distribución, ya que demostraron ser tolerantes a dichos cambios climáticos. Por lo tanto, se propone que ambos taxa pueden ser utilizados en programas de restauración ambiental, respetando su área de distribución conocida; por ejemplo, se propone a M. luisana para restaurar sitios secos del Valle de Tehuacán-Cuicatlán y sitios similares adyacentes, y a $M$. aculeaticarpa var. aculeaticarpa, con una distribución conocida mucho más amplia en México, para lugares mésicos. 


\section{ABSTRACT}

One of the predictions related to the effect of climate change is that ecosystems could expand or reduce their ranges of distribution, as humid environments could become dry and vice versa; this in response to the degree of tolerance of the taxa, mainly plants, which conform them. For instance, within the family Leguminosae, it is considered that genus Mimosa is potentially able to tolerate a wide range of environmental variations. Mexican mimosas dominate in humid-warm and dry-warm ecosystems and, considering their biological and ecological importance, more studies are needed to establish the level of tolerance that these plants could have in relation to the changes that may occur in climatic elements such as temperature and precipitation. Therefore, known distribution maps and potential distribution models of Mimosa aculeaticarpa var. aculeaticarpa (mesic environment, wide distribution, endemic to Mexico) and M. luisana (dry environment, endemic to the Valley of Tehuacán-Cuicatlán, Puebla and Oaxaca states) were generated; hence, in order to support these maps and models, mainly the potential ones, the morphological characteristics of the seeds and the seed cover, and seed germination of both taxa, were described, analyzed, compared and evaluated; as well as the their wood anatomy, getting, in addition, the Vulnerability Index ( $\mathrm{VI})$ and the Mesomorphy Index (MI). With this information, it was possible to establish a basis for determining the degree of tolerance of both taxa to the possible changes predicted in temperature and 
precipitation, and, finally, validate such models. Once, Mimosa data bases (CONABIO, GBIF) were depurated and validated, and the herbaria revision done, the known distribution maps were generated, as well as the potential distribution model using the MaxEnt algorithm. M. aculeaticarpa var. aculeaticarpa is widely distributed in the country; while $M$. luisana has a restricted distribution; besides, the potential distribution models indicate that both taxa may spread their distribution. The two taxa have anatomical features that support the prediction models; in the case of $M$. aculeaticarpa var. aculeaticarpa cover seed, it is formed by a cuticle, macrosclereids and parenchyma; while M. luisana's cover seed, has a cuticle macrosclereids, osteosclereids and parenchyma; thus, in both cases, the seed requires scarification for germination. After scarification, regardless of temperature $(5,10,15,20,25,30$, $35,40{ }^{\circ} \mathrm{C}$ ), the highest germination percentage was recorded on M. luisana (50$100 \%$ ); whereas, at $45{ }^{\circ} \mathrm{C}, \mathrm{M}$. aculeaticarpa var. aculeaticarpa showed the highest percentage of germination (35\%). In relation to the wood anatomy evaluation, both taxa own characteristics that may allow them to adapt to variations in precipitation. $M$. aculeaticarpa var. aculeaticarpa has a ring porous wood; while M. luisana has a diffuse porosity. Both taxa have short vessel elements, with a small diameter and, only in the early wood, the vessel elements have a median diameter. The higher VI (4.05) was determined in M. aculeaticarpa var. aculeaticarpa; consequently, the $\mathrm{VI}$, jointly with the anatomical characteristics of the wood, indicates that this taxon is the most vulnerable to drought; moreover, it also presents the highest IM (729.05, less tolerance). Whereas, the lowest VI (1.42) and MI (226.71) were shown by M. luisana, suggesting that this taxon is more resistant to drought (more tolerance). Hence, if the 
known distribution of both taxa is considered together; as well as the prediction related with the transformation of humid ecosystems to dry ones, then, it is possible to suggest that both taxa have biological characteristics that would allow them to spread their distribution, because they have proved to be tolerant to such climate changes. Therefore, it is proposed that the two taxa may be used in ecological restoration programs, respecting their known range of distribution; for instance, it is possible to propose that $M$. luisana may be used to restore dry sites within the Valley of Tehuacán-Cuicatlán, and similar adjacent sites, and $M$. aculeaticarpa var. aculeaticarpa, with a much wider known distribution in Mexico, for mesic sites. 


\section{INTRODUCCIÓN GENERAL}

El Panel Intergubernamental de Cambio Climático (IPCC) calcula que la superficie terrestre se calentará hasta $5 \stackrel{\circ}{\circ}$ para finales del siglo $\mathrm{XXI}$, lo que implica cambios en la temperatura y precipitación, que variarían geográficamente (Christensen et al., 2007). Por ejemplo, se espera que debido al calentamiento de la superficie del océano, las sequías aumenten en algunos ecosistemas; mientras que en otros, haya una mayor precipitación (Dirmeyer y Shukla, 1996; Peñuelas et al., 2004; Rind et al., 1990).

En términos ecológicos, estos efectos interactivos entre la temperatura y la disponibilidad de agua previstos para las próximas décadas, podrían afectar la distribución de las plantas y, por tanto, la estructura y el funcionamiento de los ecosistemas (Ward et al., 1999; Peñuelas et al., 2004). Estudios experimentales que simulan el calentamiento y la sequía muestran que los taxa modificaran su distribución (Peñuelas et al., 2004), la cual puede ser evaluada mediante modelos predictivos.

Al respecto, Peterson et al. (2011) mencionan que la predicción de la distribución de los taxa se realiza con base en una aproximación de modelación de nicho ecológico, usando el algoritmo de máxima entropía Maxent (Phillips et al., 2006). Sin embargo, los modelos de distribución de los taxa no consideran otros aspectos relevantes relacionados con la biología de los organismos, como son su 
morfología, anatomía, fisiología, crecimiento y reproducción, entre otros, y, particularmente en plantas, su fenología, germinación y establecimiento, ya que estos aspectos muestran el grado de tolerancia de los taxa vegetales a esos cambios y, de ello, depende que los ecosistemas puedan expandirse o contraerse (Parmesan y Yohe, 2003).

Bajo la premisa de que los ecosistemas húmedos cambien a secos y viceversa (Villers, 1998), toman relevancia los taxa que habitan en ambos ambientes y considerando la predominancia del género Mimosa (Leguminosae) en este tipo de ecosistemas en México (Orozco-Almanza et al., 2003) y a su importancia biológica y ecológica (Camargo-Ricalde et al., 2002, 2010; Valiente-Banuet et al., 1991; Valiente-Banuet y Ezcurra, 1991), es importante conocer las respuestas ecoanatómicas y ecofisiológicas de sus taxa, en este caso de $M$. aculeaticarpa Ortega var. aculeaticarpa y de M. luisana Brandegee (Anexo), ante las condiciones actuales de temperatura y/o precipitación para determinar el grado de tolerancia que pudieran presentar ante los posibles cambios ambientales predichos y, de esta manera, sugerir una ampliación o reducción de su distribución.

Como una aproximación, se generaron modelos de distribución conocida y potencial de ambos taxa que permitieron establecer los ecosistemas en los que están o estarían presentes (Capítulo I), apoyado con el estudio de otros aspectos biológicos como son la anatomía de la semilla (Capítulo II), la germinación de las semillas a diferentes temperaturas (Capítulo III) y la anatomía de la madera (Capítulo IV), los cuales permitieron determinar la organización anatómica y el grado de 
tolerancia que presentan estos taxa para validar una ampliación o reducción de su distribución, sugerida por los modelos.

\section{LITERATURA CITADA}

Camargo-Ricalde, S.L., Dhillion S.S. y Grether R. 2002. Community structure of endemic Mimosa species and environmental heterogeneity in a semi-arid Mexican valley. Journal of Vegetation Science 13: 697-704.

Camargo-Ricalde, S.L., Montaño N.M., Reyes-Jaramillo I., Jiménez-González C. y Dhillion S.S. 2010. Effect of mycorrhizae on seedlings of six endemic Mimosa L. species (Leguminosae-Mimosoideae) from the semi-arid Tehuacán-Cuicatlán Valley, Mexico. Trees-Structure and Function 24: 67-78.

Christensen, J.H., Hewitson B., Busuioc A., Chen A., Gao X., Held I., Jones R., Kolli R.K., Kwon W.-T., Laprise, R. Magaña Rueda V., Mearns L., Menéndez C.G., Räisänen J., Rinke A., Sarr A. y Whetton P. 2007. Regional climate projections. En: Solomon S., Qin D., Manning M., Marquis M., Averyt K.B., Tignor M., LeRoy-Miller H. y Chen Z. Eds. Climate Change: The Physical Science Basis. Summary for Policymarkers. Contribution of Working Group I to the Fourth Assessment Report of the Intergovernmental Panel on Climate Change, pp. 847-940, Cambridge University Press, Cambridge. 
Dirmeyer, P.A. y Shukla J. 1996. The effect on regional and global climate of expansion of the worl's deserts. Quarterly Journal of the Royal Meteorological Society 122: 451-482.

Martínez-Bernal, A. y Grether R. 2006. Mimosa. En: Novelo A. y Medina-Lemus R. (eds.). Flora del Valle de Tehuacán-Cuicatlán. Fascículo 44. Instituto de Biología, Universidad Nacional Autónoma de México, México. 1-108 p.

Orozco-Almanza, M.S., Ponce de León-García L., Grether R. y García-Moya E. 2003. Germination of four species of the genus Mimosa (Leguminosae) in a semi-arid zone of Central Mexico. Journal of Arid Environments 55: 75-92.

Parmesan, C. y Yohe G. 2003. A globally coherent fingerprint of climate change impacts across natural systems Nature 421: 37-42.

Peñuelas, J., Sabaté S., Fidella I. y Gracia C. 2004. Efectos del cambio climático sobre los ecosistemas terrestres: observación, experimentación y simulación. En: Valladares, F. 2004. Ecología del bosque mediterráneo en un mundo cambiante. 425-460. Ministerio de Medio Ambiente, EGRAF, S. A., Madrid.

Peterson, A.T., Soberón J., Pearson R.G., Anderson R.P., Martínez-Meyer E., Nakamura M. y Araújo M.B. 2011. Ecological Niches and Geographic Distributions. Princeton University Press. New Jersey. 314 p.

Phillips, S.J., Anderson R.P. y Schapire R.E. 2006. Maximum entropy modelling of species geographic distributions. Ecological Modelling 190: 231-259. 
Rind, D., Goldberg R., Hansen J., Rosenzweig C. y Ruedy R. 1990. Potential evapotranspiration and the likelihood of future drought. Journal of Geophysical Research 95: 9983-10004.

Valiente-Banuet, A. y Ezcurra E. 1991. Shade as a cause of the association between the cactus Neobuxbaumia tetetzo and the nurse shrub Mimosa luisana. Journal of Ecology 79: 961-971.

Valiente-Banuet, A., Vite F. y Zavala-Hurtado J.A. 1991. Interaction between the cactus Neobuxbaumia tetetzo and the nurse shrub Mimosa luisana. Journal of Vegetation Science 2: 11-14.

Ward, J., Tissue D.T., Thomas R.B. y Strain B.R. 1999. Comparative responses of model $\mathrm{C} 3$ y $\mathrm{C} 4$ plants to drought in low and elevated $\mathrm{CO}_{2}$. Global Change Biology 5: 857-867. 
Respuestas ecoanatómicas y ecofisiológicas de dos especies del género Mimosa (Leguminosae) ante el cambio climático

\section{ANEXO}


ANEXO. Características morfológicas de los taxa estudiados

De acuerdo con Martínez-Bernal y Grether (2006), Mimosa aculeaticarpa var. aculeaticarpa se caracteriza por ser un arbusto de 1.5 a $2.5 \mathrm{~m}$ de altura (Figura $1 \mathrm{~A}$ ), con hojas compuestas por 6-16 pares de pinnas, y por 8-16 pares de folíolos. Sus flores son blancas o púrpuras en los lóbulos, éstas se encuentran agrupadas en capítulos solitarios y en fascículos 2-5 (Figura 1B). Forma de 1-15 legumbres por capítulo (Figura 1C), los frutos son dehiscentes y el margen es persistente (Figura 1D).

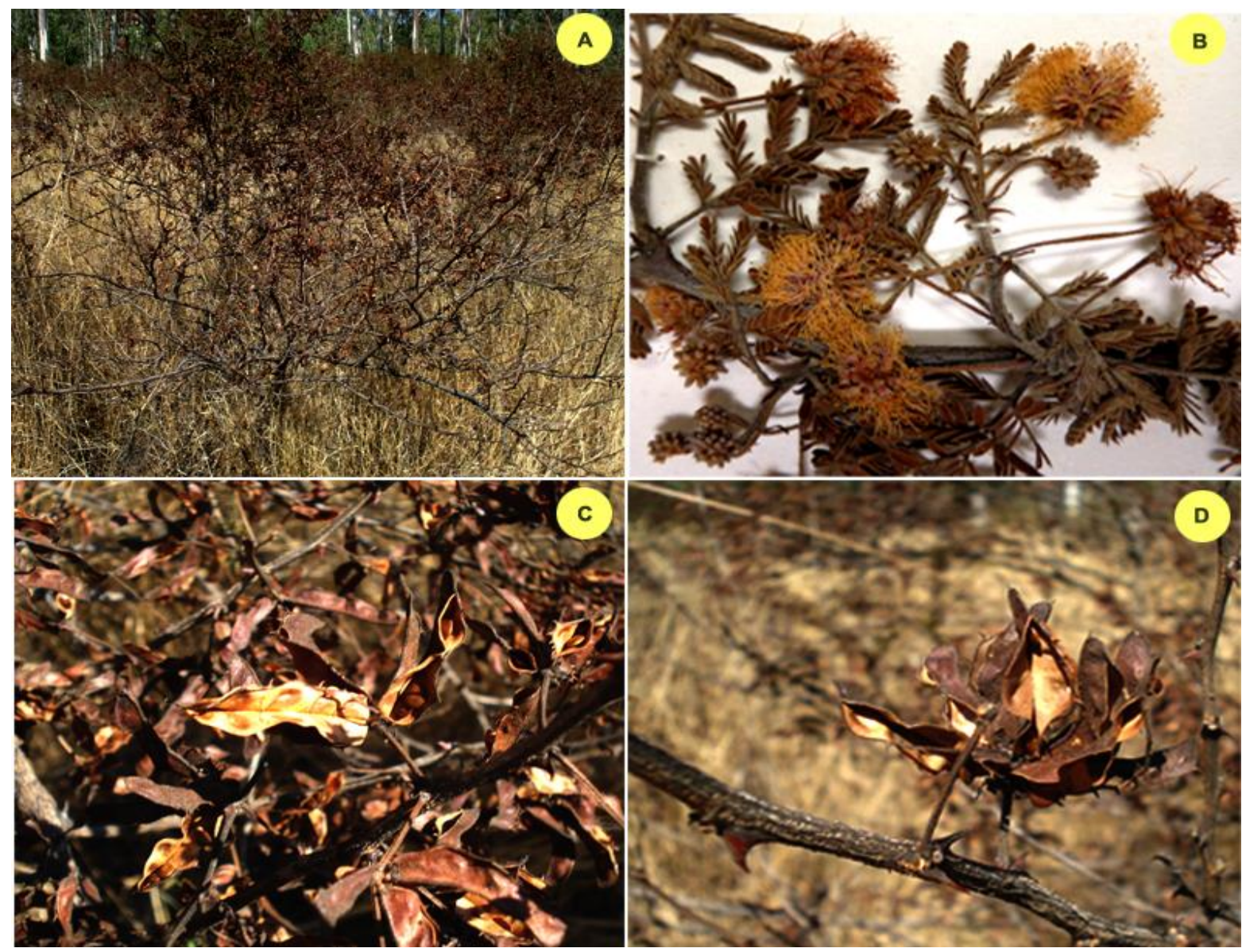

Figura 1. Mimosa aculeaticarpa var. aculeaticarpa. A. Arbusto con frutos; B. Inflorescencias en capítulo; C y D. Frutos maduros dehiscentes. 
Asimismo, de acuerdo con Martínez-Bernal y Grether (2006), Mimosa luisana puede crecer como un arbusto o un árbol de 1.0 a $4.5 \mathrm{~m}$ de altura (Figura 2A), con hojas compuestas por (2-)3-5(-6) pares de pinnas, y por (2-)3-5(-6) pares de folíolos. Sus flores son lilas, éstas se encuentran agrupadas espigas solitarias y en fascículos 2(-3) (Figura 2B). Forma de 2-10 legumbres por espiga (Figura 2C). Cada legumbre se encuentra dividida en 6 o 7 artejos (Figura 2D).
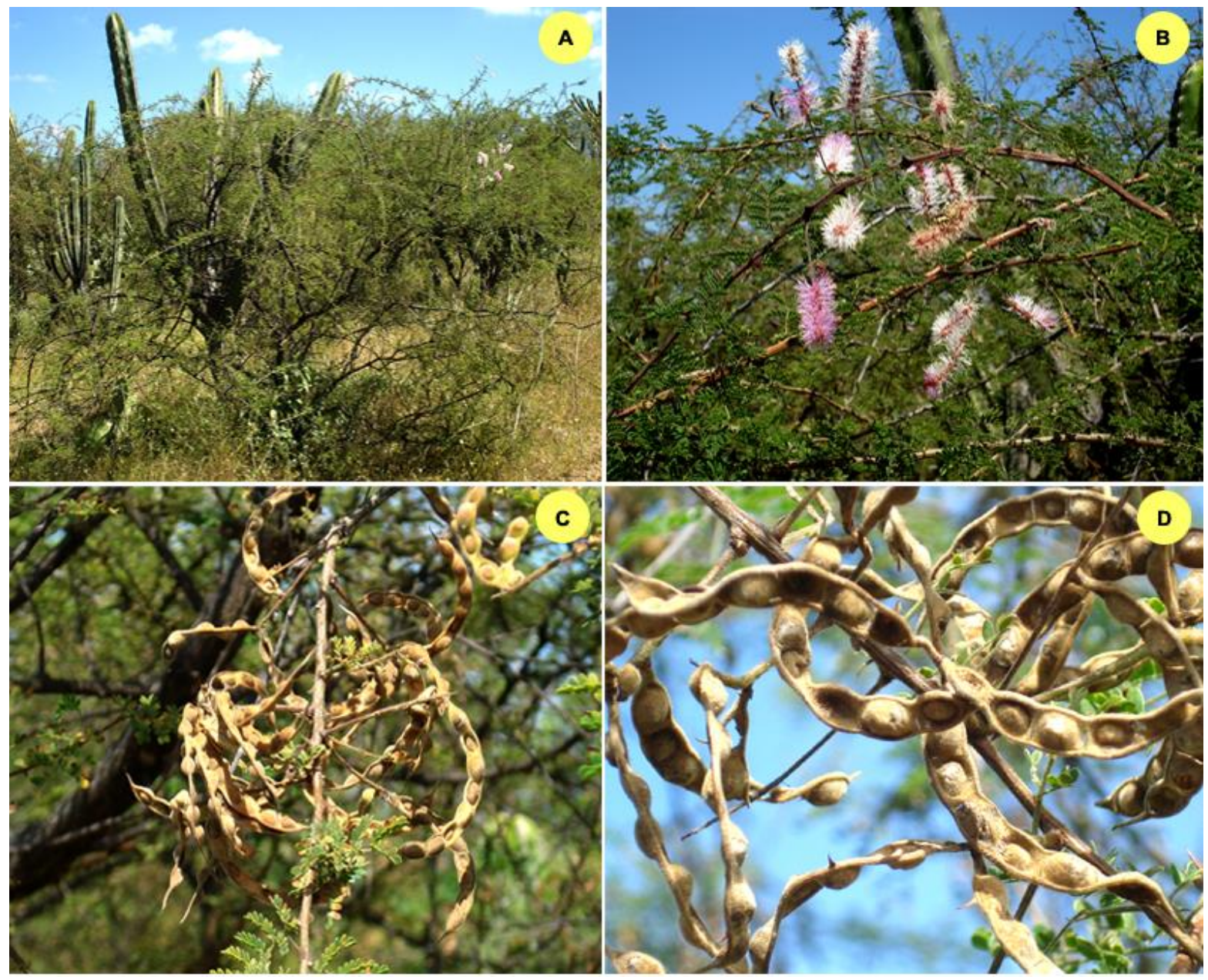

Figura 2. Mimosa luisana. A. Arbusto con inflorescencias; B. Inflorescencias en espiga, jóvenes en color lila y viejas en color rosa pálido; C y D. Frutos maduros divididos en artejos. 


\section{OBJETIVO GENERAL}

A partir de la generación de mapas de distribución conocida y modelos de distribución potencial de dos especies del género Mimosa (Leguminosae), $M$. aculeaticarpa var. aculeaticarpa y M. luisana, evaluar sus respuestas anatómicas y fisiológicas a posibles cambios de temperatura y precipitación, para determinar el grado de tolerancia de dichos taxa a esos cambios y, por lo tanto, sustentar sus modelos de distribución potencial.

\section{OBJETIVOS PARTICULARES}

1. Generar mapas de distribución actual y modelos de distribución potencial de dos taxa de Mimosa (Leguminosae), M. aculeaticarpa var. aculeaticarpa y M. luisana, presentes en México.

2. Describir la morfología y la anatomía de la semilla de los dos taxa del género Mimosa en estudio e inferir sobre sus implicaciones ecológicas.

3. Determinar el efecto de la escarificación y de la temperatura en la germinación de las semillas de los dos taxa del género Mimosa en estudio.

4. Describir la anatomía de la madera de los dos taxa de Mimosa en estudio e inferir sobre sus implicaciones ecológicas. 


\section{CAPÍTULO I}

\section{Distribución conocida y potencial de dos taxa de Mimosa (Leguminosae-Mimosoideae)}

Actual and potential distribution of two taxa of Mimosa (Leguminosae-Mimosoideae)

\section{INTRODUCCIÓN}

El conocimiento de la distribución geográfica de los taxa proporciona información complementaria a la provista por estudios biológicos, ecológicos y sistemáticos, entre otros (Corsi et al., 2000, Hernandez et al., 2006; Loiselle et al., 2003), y es indispensable para el entendimiento de los procesos y patrones de la biodiversidad (Rushton et al., 2004; Wisz et al., 2008), el efecto del cambio climático (Hole et al., 2009; Jeschke et al., 2008; Thomas et al., 2004) y de los sitios con potencial para reintroducir taxa o para su posible restauración ambiental (Kumar y Stohlgren, 2009).

Por otro lado, debido a los constantes problemas que impactan a la biodiversidad (Por ej. deforestación, saqueo de taxa), existe una búsqueda continua de estrategias para la conservación, tanto de los taxa, como de los ecosistemas (Thuiller et al., 2008), una de las estrategias es la modelación de la distribución geográfica.

De acuerdo con Brown (1995) y Lomolino (2005), el factor más importante que determina la distribución de los taxa es el clima; por lo que los parámetros para 
modelar y explicar la distribución son la temperatura y la precipitación (Arudel, 2004; González-Espinosa et al., 2004; Hernández-Pérez, 2011).

Al respecto, se han propuesto diversos algoritmos como el perfil Bioclimático, BIOCLIM (Nix, 1986); Algoritmo Genético, GARP (Stockwell y Peters, 1999); y el de Máxima Entropía, MAXENT (Phillips et al., 2004), que están basados en datos de ocurrencia y/o ausencias que permiten conocer la distribución de los taxa (Elith et al., 2006), y que son considerados herramientas fundamentales en la conservación y la ecología del paisaje (Peterson y Cohoon, 1999). Los algoritmos anteriores se basan en el concepto de nicho ecológico (nicho fundamental) propuesto por Hutchinson (1957); este concepto considera a los factores bióticos y abióticos necesarios para que las poblaciones de un taxon puedan sobrevivir indefinidamente sin la necesidad de migrar (Grinnell, 1917; Hutchinson, 1944). Sin embargo, en muchos casos los taxa no ocupan en su totalidad este nicho, por lo que el espacio utilizado se llama nicho realizado (Schoener, 1989; Soberón y Peterson, 2005).

Por lo anterior, mediante la modelación de la distribución conocida o nicho realizado de un taxon se obtiene información sobre el intervalo ambiental en el que se establece, y con la modelación del nicho fundamental o distribución potencial se reconocen los sitios donde existen las condiciones ambientales propicias para que se establezca dicho taxon y, de esta manera, se pueden estimar los efectos de las variaciones en los parámetros de temperatura y precipitación en la distribución de los taxa (Morales, 2012). Cabe señalar que los efectos a tales variaciones pueden verse 
reflejados desde el nivel específico hasta el nivel ecosistémico (Parmesan y Yohe, 2003; Trejo et al., 2011).

\section{ANTECEDENTES}

La sobreexplotación de la biodiversidad (Maxted y Kell, 2009) y las fluctuaciones en los parámetros climáticos (Cushman, 2006) son las principales causas a las que se les atribuye la pérdida de los taxa, por lo que se requiere de la búsqueda de estrategias que permitan la conservación de la biodiversidad. De acuerdo con Alsos et al. (2009), para conservar un taxon se requiere conocer su respuesta a diferentes condiciones climático-ambientales y, por lo tanto, su capacidad de adaptación debida a los cambios de su entorno.

Para conocer y determinar las condiciones climático-ambientales en las que se localiza un taxon, es necesario conocer su distribución geográfica. Al respecto, existen diversos estudios que analizan la distribución geográfica de los taxa a diferentes escalas: 1) Continental (De la Estrella et al., 2012; Ndayishimiye et al., 2012; Pacheco et al., 2010), ii) Geopolítica, a nivel de país (Bravo, 2011; ContrerasMedina et al., 2010; Núñez-Colín, 2010) o a nivel estatal (Harbert et al., 2014; Hernández-Pérez et al., 2011; Hurtado, 2007; Villaseñor y Téllez, 2004), iii) algunos consideran la Regionalización Biogeográfica; por ejemplo, Sotuyo et al. (2010) analizaron la distribución del complejo Caesalpinia hintonii en la Depresión del Balsas, y Duno-de Stefano et al. (2012) que analizaron los patrones de distribución geográfica de 224 taxa de leguminosas nativas de la Península de Yucatán; y iv) 
otros se basan en las Provincias Florísticas (Ávila-Bello y López-Mata, 2001). Sin embargo, independientemente de la escala, todos utilizan los sistemas de información geográfica (SIG) para mapear la distribución conocida de los taxa; además de emplear algoritmos para modelar la distribución potencial, los cuales requieren conocer las condiciones ambientales del hábitat donde se establece el taxon (Jarvis et al., 2005).

La información sobre las condiciones ambientales en las que se establecen los taxa se puede obtener de: I) Bases de datos, ya sea de herbarios (Duno-de Stefano et al., 2012; Gómez-Mendoza, 2008; Ndayishimiye et al., 2012; Villaseñor y Téllez, 2004), de la Comisión Nacional para el Conocimiento y Uso de la Biodiversidad, CONABIO (Guevara-Escobar et al., 2008; Núñez-Colín, 2010), de Tropicos (Mateo, 2008) y del Nomenclator (Rodríguez-Ochoa, 2014), ii) Consultas de etiquetas de herbarios (Ávila-Bello y López-Mata, 2001; Cruz-Cárdenas et al., 2012; De la Estrella et al., 2012; Hurtado, 2007), y iii) Colectas de campo (Benito de Pando y Peñas de Giles, 2007; Palacios, 2010; Sunil et al., 2009).

Con la información recabada de cualquiera de las fuentes anteriormente mencionadas, se procede a mapear la distribución conocida de los taxa; mientras que para modelar la distribución potencial, además de la información recabada, se requiere el uso de algoritmos que consideren variables climáticas y generen resultados confiables (Grand et al., 2007). Entre los modelos que predicen la distribución potencial encontramos por orden de aparición a: I) El Perfil Bioclimático, BIOCLIM, que calcula los parámetros bioclimáticos para todos los sitios de registro, 
con ellos genera un perfil bioclimático que sintetiza las condiciones climáticas de los sitios analizados y los compara con los atributos climáticos del área de estudio (Fischer et al., 2001), ii) Algoritmo Genético, GARP, el cual proyecta los datos dependiendo de las interacciones, éstas las genera el programa entre las capas ambientales determinadas para el taxon en estudio y los puntos de registro del taxon que se realicen (Hurtado, 2007), iii) Máxima Entropía, MAXENT, que estima la probabilidad de distribución esperada, encontrando la probabilidad de distribución que es más uniforme (entropía máxima), dadas las restricciones de que el valor esperado de cada variable predicativa ambiental se ajuste con su promedio empírico (valores para los datos de registros positivos - Phillips et al., 2006).

De acuerdo con Mateo (2008), BIOCLIM presenta varias desventajas como son: $\imath$ ) Es un método poco flexible, ya que no permite interacciones entre variables; ii) Da la misma importancia a todas las variables; iii) No tienen ningún procedimiento para seleccionar variables; iv) No se puede conocer la influencia de cada variable en el modelo final; v) Tampoco está muy claro cómo puede afectar el empleo de numerosas variables que están altamente correlacionadas en el resultado final de los modelos; vi) Es un método que tiende a sobreajustar; y vii) Es muy susceptible a la presencia de valores atípicos (outliers).

Por otro lado, GARP presenta las siguientes desventajas i) El modelo genera pseudo-asusencias (Soberón y Peterson, 2005); ii) Tiende a cometer errores de comisión (Almazán, 2007), es decir, el modelo predice la presencia de un taxon 
cuando realmente no se ha observado (Mateo, 2008); y iii) Presenta diferentes modelos utilizando los mismos datos (Anderson et al., 2003).

Las limitaciones del algoritmo de MAXENT son realmente las conocidas; es decir, no existe un método de selección de variables, pero permite interacciones entre las variables; asimismo, se puede investigar el efecto de cada una (Mateo, 2008), y funciona con tamaños de muestra pequeños (Hernandez et al., 2006; Mateo, 2008); por lo que es considerado uno de los mejores modelos para predecir la distribución de los taxa (Elith et al., 2006; Hernandez et al., 2006; Herrera, 2012; Phillips y Dudík, 2008; Ramírez-Villegas et al., 2010).

Uno de los parámetros para elegir el algoritmo con el cual trabajar la modelación de la distribución, es el tipo de datos con los que se cuente; es decir, con datos de presencia u ocurrencia (Tsoar et al., 2007), con datos de presencia y ausencia (Elith et al., 2006; Graham et al., 2008; Manel et al., 2001) e, incluso, existen estudios que cuentan, además, con datos de abundancia (Cawsey et al., 2002; Leathwick, 2001; Pearce y Ferrier, 2001). Cabe mencionar que los algoritmos BIOCLIM, GARP y MAXENT, requieren solamente de datos de presencia (Elith et al., 2006; Phillips et al., 2006; Riquelme, 2013) y, aunque son métodos criticados por basarse únicamente en registros de presencia, es importante mencionar que la mayoría de los estudios se basan en este tipo de datos (Mateo et al., 2011), ya que no existen datos de ausencias (P.ej., Graham et al., 2004; Mateo et al., 2010). 
Otro parámetro es el número de datos de presencia (tamaño de la muestra) con los que se cuenta. Al respecto, Mateo (2008) menciona que el tamaño de la muestra tiene una influencia potencial en la consistencia y fiabilidad de los modelos. De manera que la estabilidad y la consistencia de los modelos disminuye según disminuye el tamaño de la muestra; mientras que la fiabilidad final de los modelos debe aumentar con tamaños de muestra mayores (Hernandez et al., 2006; McPherson et al., 2004; Wisz et al., 2008). Franklin (2009) menciona que existe discrepancia entre la cantidad de datos para realizar la modelación de la distribución que va desde 30, 50 y 100 como mínimo, hasta 100 y 500 como máximo.

Cabe señalar que, de acuerdo con Herrera (2012), más allá del número de observaciones, lo importante es contar con ocurrencias del taxon que se encuentren bien distribuidas a lo largo del espacio que se sabe ocupa el mismo. Sin embargo, es importante considerar que, en ocasiones, los registros pueden ser muy limitados, principalmente en taxa de distribución restringida (Pearson et al., 2006), por lo que, muchas veces, se tiene la duda de cuántas observaciones son necesarias para que los resultados de un modelo sean confiables (Herrera, 2012).

Al respecto, Hernandez et al. (2006) reportan que los algoritmos BIOCLIM y GARP requieren de un tamaño de muestra grande. En el caso de BIOCLIM, debe ser superior a 150 registros y, aún con ello, se tiene una baja precisión al momento de predecir la distribución; mientras que GARP, con 75 registros, alcanza su máxima precisión; aunque, con 10 (Stockwell y Peterson, 2002) o 15 registros (Papeş y Gaubert, 2007), se genera un modelo confiable. En el caso de MAXENT, se 
mantiene estable la precisión de la predicción a partir de 5 registros de presencia (Hernandez et al., 2006).

Cabe señalar que, además del tamaño de la muestra, existen otros factores importantes que deben ser considerados; entre ellos destacan la calidad de los datos y la ecología del taxon; es decir, si presenta una distribución amplia o restringida (Mateo, 2008).

Es necesario considerar las limitaciones que tiene el hacer uso de bases de datos, consulta de herbarios (etiquetas/ejemplares) y colectas (datos de campo/ejemplares), o una combinación de las anteriores, ya que lo anterior se verá reflejado en una buena calidad de los datos. De acuerdo con Graham et al. (2004) y con Stein y Wieczorek (2004), las bases de datos deben ser depuradas; es decir, eliminar registros con información incompleta y con errores taxonómicos, entre otros.

Asimismo, para muchas taxa existe una relativa escasez de datos y poca disponibilidad de ellos; además, presentan problemas relacionados con sesgos debido a la limitada accesibilidad de sus sitios (Peterson et al., 1998). Actualmente, los trabajos sobre el modelado de la distribución de taxa mexicanos se consideran escasos (Yberri, 2009). Considerando que, en México, se tienen seis familias representativas debido al número de taxa que presentan (Rzedowski, 1991); entre ellas, la familia Leguminosae, la cual está presente en todos los tipos de vegetación y es de suma importancia económica para el país, por lo que es importante mapear la distribución conocida y la potencial de sus taxa, para evaluar los posibles efectos de 
las variaciones en los regímenes de temperatura y precipitación en la distribución de las mismas.

En México, las leguminosas son una de las familias más amplias y mejor representadas (Sosa y Dávila, 1994); sin embargo, los estudios enfocados en la distribución de sus taxa son escasos. Al respecto, Guevara-Escobar et al. (2008) determinaron la distribución potencial de una selección de taxa arbustivos de leguminosas del bosque tropical caducifolio en el Altiplano Mexicano. Ellos reportan que Pithecellobium dulce (Roxb.) Benth. y Calliandra spp. fueron las leguminosas con mayor área de distribución potencial en el Bajío; mientras que la menor área, pero con alta probabilidad de distribución, se registró para Prosopis laevigata (Willd.) M. C. Johnst., Albizia plurijuga (Standl.) Britt. \& Rose y Leucaena leucocephala (Lam.) de Wit; estas últimas se ubican en la sufamilia Mimosoideae, al igual que Mimosa, siendo este el género más diverso de Mimosoideae en el país (Grether et al., 1996).

El género Mimosa ha sido objeto de múltiples estudios (P. ej. sistemáticos, anatómicos, ecológicos, etc.), por lo que el conocimiento sobre sus taxa es significativo; aunque, el conocimiento relacionado con su distribución es parcial (Grether et al., 2007; Grether et al., 2015; Martínez-Bernal y Grether, 2006), sobre todo en el caso de su distribución potencial.

Por lo anterior, este estudio busca contribuir al conocimiento de la distribución del género Mimosa; en particular, se pretende explorar la distribución conocida y 
potencial de M. aculeaticarpa Ortega var. aculeaticarpa y M. luisana Brandegee, cuya conservación, considero, es prioritaria debido a que son taxa multipropósito (Dhillion et al., 2004; Martínez-Pérez et al., 2006; Pavón et al., 2011), ya que ofrecen múltiples servicios a los ecosistemas y pobladores donde se establecen.

\section{PREGUNTAS DE INVESTIGACIÓN}

¿Cuál es la distribución conocida de Mimosa aculeaticarpa var. aculeaticarpa y $M$. luisana?

¿Cuál es la distribución potencial de Mimosa aculeaticarpa var. aculeaticarpa y $M$. luisana?

\section{HIPÓTESIS}

Si la distribución de los taxa está determinada por factores climáticos como la temperatura, la precipitación; entonces, debido a que el taxon con amplia distribución no tiene preferencia por algún tipo de clima, este ampliará su distribución; mientras que el taxon con distribución restringida, la reducirá.

\section{OBJETIVO}

Determinar la distribución conocida y potencial de Mimosa aculeaticarpa var. aculeaticarpa y M. luisana, ambas endémicas de México. 


\section{MÉTODOS}

\section{Selección de los taxa}

Se eligió a Mimosa aculeaticarpa var. acuelaticarpa y a M. luisana, ambos taxa endémicos de México, pero con diferente distribución. De acuerdo con Grether et al. (2007), M. aculeaticarpa var. acuelaticarpa presenta una amplia distribución en el país, estableciéndose tanto en climas secos como templados; mientras que $M$. luisana es un taxon restringido al Valle de Tehuacán-Cuicatlán, Puebla y Oaxaca, y sólo se establece en climas secos (Martínez-Bernal y Grether, 2006).

\section{Obtención de datos}

Los registros de $M$. aculeaticarpa var. aculeaticarpa y M. luisana fueron extraídos de la base de datos de Leguminosas proporcionada por la Comisión Nacional para el Conocimiento y Uso de la Biodiversidad (CONABIO) y de la base de datos del Herbario Nacional (MEXU).

Asimismo, para la incorporación de datos, se realizó una consulta de ambos taxa en los siguientes herbarios: Herbario Nacional de México (MEXU), del Instituto de Biología, de la Universidad Nacional Autónoma de México; Herbario Metropolitano (UAMIZ), de la Universidad Autónoma Metropolitana-Iztapalapa; Herbario del Centro Regional del Bajío (IEB), del Instituto de Ecología, A.C., Pátzcuaro, Michoacán, y Herbario de la Facultad de Ciencias Naturales (QMEX), de la Universidad Autónoma de Querétaro. Se revisaron los ejemplares para ratificar o rectificar su identificación y 
se extrajeron los datos de las etiquetas de herbario de los mismos. Posteriormente, se elaboró una base de datos para cada taxon en formato de Excel.

\section{Depuración y validación de datos}

Para ambos taxa, se revisaron los 32 campos de la base datos de CONABIO, corrigiendo errores de omisión, tipografía, contexto, redundancia, convención y congruencia, con el fin de que sean comparables con otras bases de datos (P. ej. el Sistema Nacional de Información sobre Biodiversidad (SNIB)). Para corregir los errores, antes mencionados, se establecieron criterios taxonómicos y geográficos mínimos a cumplir por cada registro de la base de datos (Cuadro 1).

Cuadro 1. Criterios taxonómicos y geográficos mínimos a cumplir por cada registro de la base de datos incorporado.

Criterios Taxonómicos

De la base de CONABIO, sólo se tomaron los registros que cuentan con el campo revisado.

\section{Criterios Geográficos}

Revisión de áreas de distribución a priori (municipios, estados), por taxon, definidas con base en la experiencia del especialista, sus publicaciones taxonómicas y florísticas.

En el caso de $M$. aculaeticarpa var. aculeaticarpa, si el Que las localidades no estuvieran repetidas.

registro no presentaba la variedad, éstos se descartaron.

Revisión del nombre de los taxa (ortografía y sinonimia). Que los registros coincidieran con los rangos latitudinales en los que se desarrolla cada taxon.

Revisión del año de publicación del taxon.

Confiabilidad del especialista que determinó el ejemplar.
Que las coordenadas geográficas coincidieran con el sitio de colecta del taxon.

Que los registros georreferenciados correspondieran a localidades en donde previamente había sido observado (colectado) el taxon y en donde se presentan las condiciones para que los taxa pudieran existir. 
Para cada taxon, se revisó su base de datos, de manera que los registros que presentaban coordenadas geográficas, fueron validados con el programa ArcMap ver. 10.2.2 (Análisis espacial), la cobertura de municipios (INEGI, 2005) y el programa Nomenclator (2005). Cuando se detectaron municipios equivocados, se corrigieron y se contabilizaron como puntos validados.

Con base en la experiencia de campo de la especialista en el género, Dra. Rosaura Grether González, y en la literatura especializada, se validó la presencia del taxon en una coordenada dada. De esta forma, se formuló a priori un posible patrón de distribución de cada taxon, de manera que aquellos registros que no se ajustaron al mismo, se consideraron como localidades erróneas.

Lo anterior, permitió detectar registros en lugares equívocos, donde no está o pudo ser confundido con otro taxon, o no fue corroborado por la especialista; por lo tanto, estos datos fueron eliminados.

Debido a que en el manejo de la base de datos es recomendable trabajar con un número menor de registros sin auto-correlación espacial para lograr una mejor calidad de datos para la modelación, los registros con localidades repetidas fueron excluidos, dejando un sólo registro validado.

\section{Distribución conocida}

Una vez depurados los datos, éstos se posicionaron utilizando el programa ArcMap ver. 10.2.2. Asimismo, los datos de presencia se sobre-posicionaron sobre las 
siguientes capas: i) elevación, ii) climas, iii) suelos, iv) provincias biogeográficas y v) cuencas hidrológicas, obtenidas de la página de la CONABIO (http://www.conabio.gob.mx/informacion/gis/, publicadas en 2001), por lo tanto, la clasificación utilizada es la propuesta por CONABIO (2011).

El número de datos de ocurrencia utilizados para mapear la distribución conocida de $M$. aculeaticarpa var. aculeaticarpa fue de 99 y de 50 datos para $M$. luisana.

\section{Distribución potencial}

\section{Modelación de la distribución potencial}

La distribución potencial de ambos taxa fue modelada con base en una aproximación de modelación de nicho ecológico (Peterson et al., 2011), usando el algoritmo de máxima entropía MAXENT (Phillips et al., 2006). Se seleccionó el algoritmo MAXENT porque no se contó con ausencias reales de los taxa (Elith et al., 2010; Peterson et al., 2011).

\section{Validación estadística}

Los registros depurados tanto taxonómica como geográficamente, fueron validados estadísticamente mediante el programa estadístico SPSS (Statistics versión 21 2012, www.ibm.com.analytics/spss). Se identificaron los datos atípicos mediante diagramas de caja (box plot) que muestran las medidas de tendencia central y de dispersión de los datos, producto de un cruce entre los registros (localidades únicas) y las 
coberturas ambientales, lo que permitió reconocer los rangos ambientales en donde han sido registrados los taxa. Así, los registros que presentaron valores fuera de la desviación estándar fueron revisados y validados; sin embargo, cuando no fue posible validarlos, éstos se excluyeron del modelo. Una vez eliminados los datos atípicos, los datos validados se utilizaron para crear el perfil bioclimático de cada taxon mediante estadística descriptiva (valor promedio, máximo, mínimo y desviación estándar), también realizada en el programa SPSS.

Asimismo, para modelar la distribución potencial de ambos taxa, se utilizaron las coberturas obtenidas de Worldclim (http://www.worldclim.org/ - Hijmans et al. 2005), el cual consta de 19 superficies climáticas con información sobre temperatura y precipitación (Cuadro 2), siendo recortadas para México.

Cuadro 2. Variables climáticas (coberturas de Worldclim), utilizadas por MAXENT, para generar los mapas de distribución potencial de los dos taxa de Mimosa estudiados.

\begin{tabular}{|c|c|c|}
\hline No. & Abr. & Cobertura Climática \\
\hline 1 & TPA & Temperatura promedio anual $\left({ }^{\circ} \mathrm{C}\right)$ \\
\hline 2 & ODT & Oscilación diurna de la temperatura $\left({ }^{\circ} \mathrm{C}\right)$ \\
\hline 3 & OAT & Oscilación anual de la temperatura $\left({ }^{\circ} \mathrm{C}\right)$ (cociente entre parámetros 4 y 5 ) \\
\hline 4 & TPPC & Temperatura máxima promedio del período más cálido $\left(^{\circ} \mathrm{C}\right)$ \\
\hline 5 & TPPF & Temperatura mínima promedio del período más frío $\left({ }^{\circ} \mathrm{C}\right)$ \\
\hline 6 & TCLL & Temperatura promedio del cuatrimestre más lluvioso $\left({ }^{\circ} \mathrm{C}\right)$ \\
\hline 7 & TCS & Temperatura promedio del cuatrimestre más seco $\left({ }^{\circ} \mathrm{C}\right)$ \\
\hline 8 & TCC & Temperatura promedio del cuatrimestre más cálido $\left({ }^{\circ} \mathrm{C}\right)$ \\
\hline 9 & TCF & Temperatura promedio del cuatrimestre más frío $\left({ }^{\circ} \mathrm{C}\right)$ \\
\hline 10 & ISO & Isotermalidad $\left({ }^{\circ} \mathrm{C}\right)$ (cociente entre parámetros 2 y 7 ) \\
\hline 11 & EDT & Estacionalidad de la temperatura (coeficiente de variación, en \%) \\
\hline 12 & EP & Estacionalidad de la precipitación (coeficiente de variación, en \%) \\
\hline 13 & PA & Precipitación anual (mm) \\
\hline 14 & PPLL & Precipitación promedio del período más lluvioso (mm) \\
\hline 15 & PPS & Precipitación promedio del período más seco (mm) \\
\hline 16 & PCLL & Precipitación promedio del cuatrimestre más lluvioso (mm) \\
\hline 17 & PCS & Precipitación promedio del cuatrimestre más seco $(\mathrm{mm})$ \\
\hline 18 & PCC & Precipitación promedio del cuatrimestre más cálido (mm) \\
\hline 19 & PCF & Precipitación promedio del cuatrimestre más frío (mm) \\
\hline
\end{tabular}


Para modelar la distribución potencial de ambos taxa de Mimosa en estudio, la selección de variables climáticas se realizó generando un modelo, en MAXENT, con las 19 variables climáticas y mediante la gráfica de Jacknife que crea este algoritmo. Se comparó la ganancia que tendría el modelo con cada una de sus variables y se detectaron cuáles fueron las variables que, al retirarlas o no considerarlas, sesgarían el modelo (Reguerín, 2012). El modelo también podría sesgarse debido a la correlación entre variables; así, se realizó una prueba de correlación Pearson, para detectar las variables independientes (Sokal y Rohlf, 1995) y, explorar la sensibilidad del modelo al ir excluyendo variables.

El coeficiente de correlación de Pearson se llevó a cabo obteniendo un cruce de los registros de cada uno de los taxa y las 19 variables climáticas; de esta manera, además de la selección de variables, también se obtuvo el perfil bioclimático de cada taxon.

\section{Criterio de selección de la región de referencia (M)}

El criterio para modelar la distribución de los taxa de Mimosa en estudio, fue mediante su patrón de distribución geográfica (movilidad=M). Se seleccionó a $M$. aculeaticarpa var. aculeaticarpa, con amplia distribución en México, y M. luisana, con distribución endémica restringida al país (Grether et al., 1996; Grether et al., 2007; Martínez-Bernal y Grether, 2006). 
La región $\mathrm{M}$ fue delimitada considerando límites geográficos naturales, para lo cual, se empleó la cobertura de cuencas hidrológicas para México de la Comisión Nacional del Agua (CNA-México, 1998, Escala: 1:250000), obtenida de la página de la CONABIO (http://www.conabio.gob.mx/informacion/gis/).

\section{Evaluación de los modelos}

Como método de evaluación, se utilizó el área bajo la curva (AUC), el cual ha sido aceptado como un método estándar para evaluar la exactitud de los modelos de distribución (Benito de Pando y Peñas de Giles, 2007; Lobo et al., 2007). El valor utilizado del AUC fue el generado por el algoritmo MAXENT (Reguerín, 2012). De acuerdo con Herrera (2012), los valores del AUC oscilan de 0 a 1; los más cercanos a 1 , representan un ajuste perfecto del modelo; mientras que los más cercanos a 0 , representan un desajuste completo del modelo. Asimismo, se consultaron las clasificaciones propuestas por Burgueño et al. (1995) y Menzaour (2005) para indicar la categoría (malo, bueno, excelente) a la que pertenece el modelo.

\section{RESULTADOS}

La base de datos proporcionada por la CONABIO consta de 7,144 registros para el género Mimosa, de los cuales 353 pertenecen a los taxa estudiados. M. aculeaticarpa var. aculeaticarpa tuvo 281 registros; mientras que 72 corresponden a M. luisana. 


\section{Depuración de las bases de datos; errores taxonómicos y geográficos}

\subsection{Mimosa aculeaticarpa var. aculeaticarpa}

En la base de datos de Mimosa aculeaticarpa var. aculeaticarpa, se detectaron problemas taxonómicos y geográficos. Los problemas taxonómicos hacen referencia a la confusión entre taxa. Por ejemplo, la especialista en el género considera que la variedad biuncifera (base de datos de la CONABIO) es en realidad un taxon diferente. Aunque, Barneby (1991) la considera una variedad de aculeaticarpa.

En la base de datos de la CONABIO, 15 registros pertenecen a la variedad biuncifera; uno más, reporta la variedad lindheimeri (=var. biuncifera, Barneby, 1991), y otro reporta la variedad imparilis (=Mimosa galeotti, Barneby, 1991), por lo que estos 17 registros fueron descartados.

Por otro lado, 221 registros fueron eliminados de la base de datos, ya que no especifican la variedad (aculeaticarpa o desmanthocarpa). Sólo hubo un registro con la variedad desmathocarpa y también fue descartado.

Diez registros de la base de datos de la CONABIO mostraron que este taxon se distribuye en el estado de Tamaulipas y otro en el estado de Chihuahua, por lo que los 11 registros fueron descartados, ya que salen del patrón de distribución del taxon.

Por otra parte, se detectó que dos registros de la misma base de datos presentan municipios equivocados, éstos se corrigieron con ayuda de la especialista 
se tomaron como datos validados. Asimismo, cuatro registros presentaron localidades repetidas y fueron descartados.

Finalmente, la base de datos que originalmente constaba de 281 registros, quedó con sólo 40 registros validados.

\subsection{Mimosa luisana}

En el caso de la base de datos de Mimosa luisana, también presentó errores taxonómicos y geográficos. Debido a errores taxonómicos, solamente se descartó un registro porque le faltan varios datos, entre los que destacan: no hay apellido del colector, el campo de observado o reportado está en blanco, no hay dato de altitud del sitio, no hay fecha de colecta y no hay localidad exacta.

Cuatro registros reportan una distribución en el Distrito Federal, Oaxaca (centro), Michoacán y Durango, respectivamente, y, de acuerdo con la especialista en el género, dichos registros salen del patrón de distribución del taxon, por lo que fueron descartados.

Un registro más fue descartado, ya que, mediante la revisión del ejemplar en el Herbario Metropolitano (UAMIZ), se encontró que éste corresponde a un ejemplar colectado en el municipio de Coxcatlán; sin embargo, la base de datos de CONABIO reporta al ejemplar en el municipio de Caltepec, lo cual no corresponde.

Asimismo, se detectó que cuatro registros presentaron municipios equivocados; se corrigieron con ayuda de la especialista y se tomaron como datos 
validados. Además, 27 registros presentaron localidades repetidas, por lo que fueron descartados.

Finalmente, la base de datos que originalmente constaba de 72 registros, quedó con sólo 38 registros validados.

\section{Adición de registros}

A la base de datos que se elaboró para Mimosa aculeaticarpa var. aculeaticarpa que constaba de 40 registros validados provenientes de la CONABIO, se le adicionaron 59 registros más (99 registros en total), lo que permitió elaborar el patrón de distribución geográfica del taxon. Cabe señalar que los registros se obtuvieron de la siguiente manera: 40 registros del Herbario Regional del Bajío (IEB), 12 registros de la Base de Datos del Herbario Nacional de México (MEXU) y 7 registros fueron tomados directamente de las etiquetas de los ejemplares de Herbario del MEXU; todos los registros fueron validados siguiendo los criterios mínimos a cumplir presentados en el Cuadro 1.

Respecto a la base de datos de Mimosa luisana, ésta constaba de 38 registros validados provenientes de la CONABIO; se le adicionaron 12 registros del IEB (50 registros en total). 


\section{Distribución conocida de los taxa}

\subsection{Mimosa aculeaticarpa var. aculeaticarpa}

Los resultados indican que Mimosa aculeaticarpa var. aculeaticarpa se encuentra presente en 16 estados de la República Mexicana (Cuadro 3; Figura 1). Los estados con el mayor número de registros son: Michoacán (30), Guanajuato (19), Oaxaca (13) y Querétaro (12); mientras que cinco estados (Aguascalientes, Zacatecas, Guerrero, Tlaxcala y Veracruz) sólo presentaron uno.

El análisis de los registros mostró que los individuos de M. aculeaticarpa var. aculeaticarpa se localizan desde los 0 hasta los 2,500 msnm (Figura 2); aunque, el mayor número de localidades (39) se ubica entre 1,500-2,000 msnm (Figura 3). Cabe mencionar que, la capa de elevación maneja rangos de altitudes, por lo que para datos exactos la altitud se tomó directamente de los datos originales, resultando en que este taxon se distribuye entre los 1,900 y $2,700 \mathrm{msnm}$, concordando con lo reportado en la Flora del Bajío (Grether et al., 2007)

Asimismo, se realizó una sobre-posición de las localidades de este taxon con la capa de climas, obteniendo que el mayor número de localidades predominan en un clima árido; no obstante, también se localiza en climas semiáridos, templados y mésicos (Anexo 1 y Figura 4).

La sobre-posición de las coordenadas de las localidades con la capa de suelos indica que la mayoría de las colectas fueron de individuos que se ubican en suelos de tipo regosol éutrico (21 registros), seguido del vertisol crómico (15 
registros), regosol calcárico (14 registros) y del feozem háplico (13 registros; Figuras 5 y 6$)$.

Cuadro 3. México, estados del país donde se ha colectado Mimosa aculeaticarpa var. aculeaticarpa.

\begin{tabular}{|c|c|l|c|}
\hline Estado & $\begin{array}{l}\text { Número de } \\
\text { registros }\end{array}$ & Estado & $\begin{array}{l}\text { Número de } \\
\text { registros }\end{array}$ \\
\hline Aguascalientes & 1 & Nuevo León & 3 \\
\hline Durango & 2 & Oaxaca & 13 \\
\hline Estado de México & 2 & Puebla & 5 \\
\hline Guanajuato & 19 & Querétaro & 12 \\
\hline Guerrero & 1 & San Luís & 3 \\
\hline Hidalgo & 3 & Potosí & 1 \\
\hline Jalisco & 2 & Veracruz & 1 \\
\hline Michoacán & 30 & Zacatecas & 1 \\
\hline
\end{tabular}




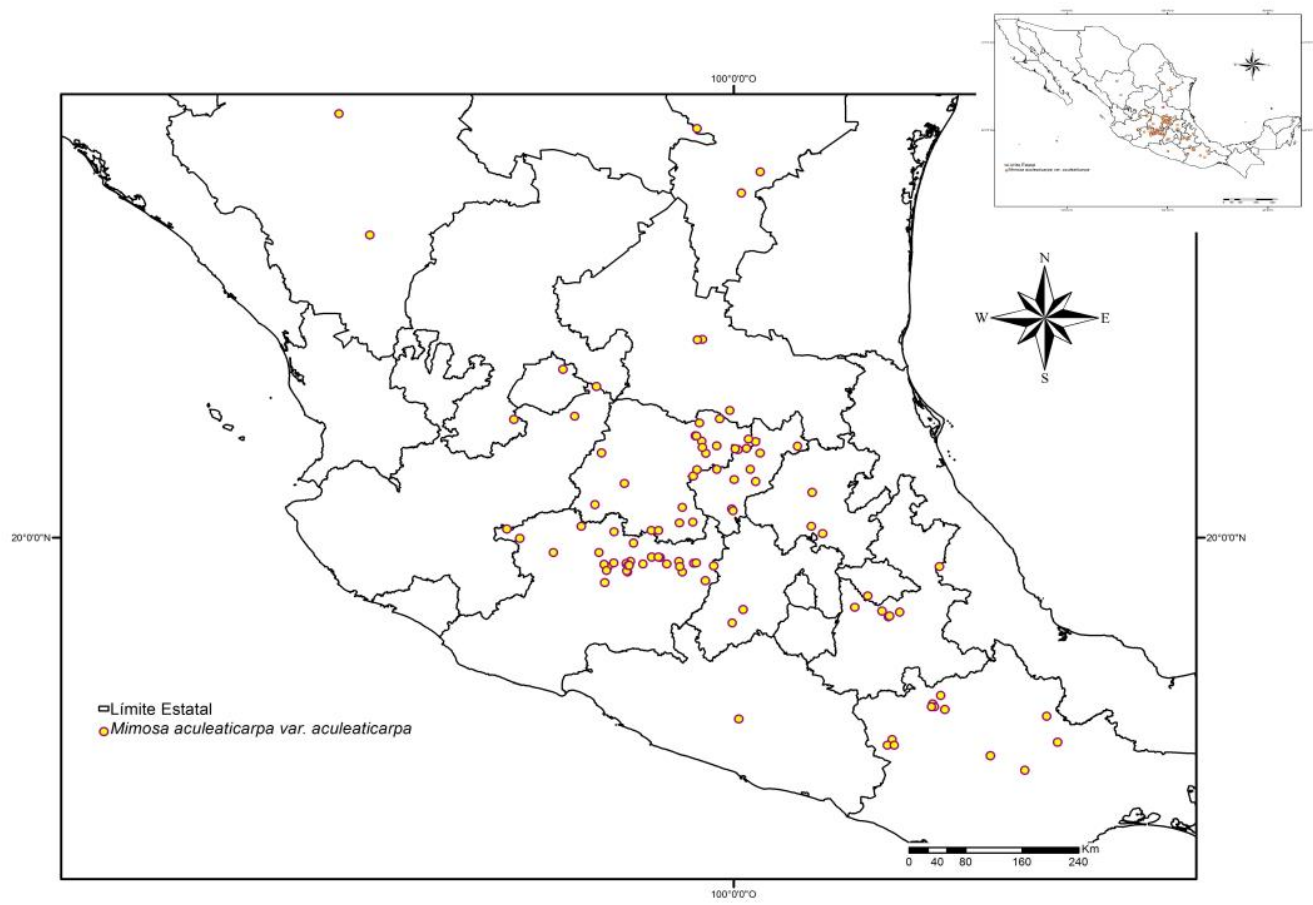

Figura 1. México, localidades de Mimosa aculeaticarpa var. aculeaticarpa.

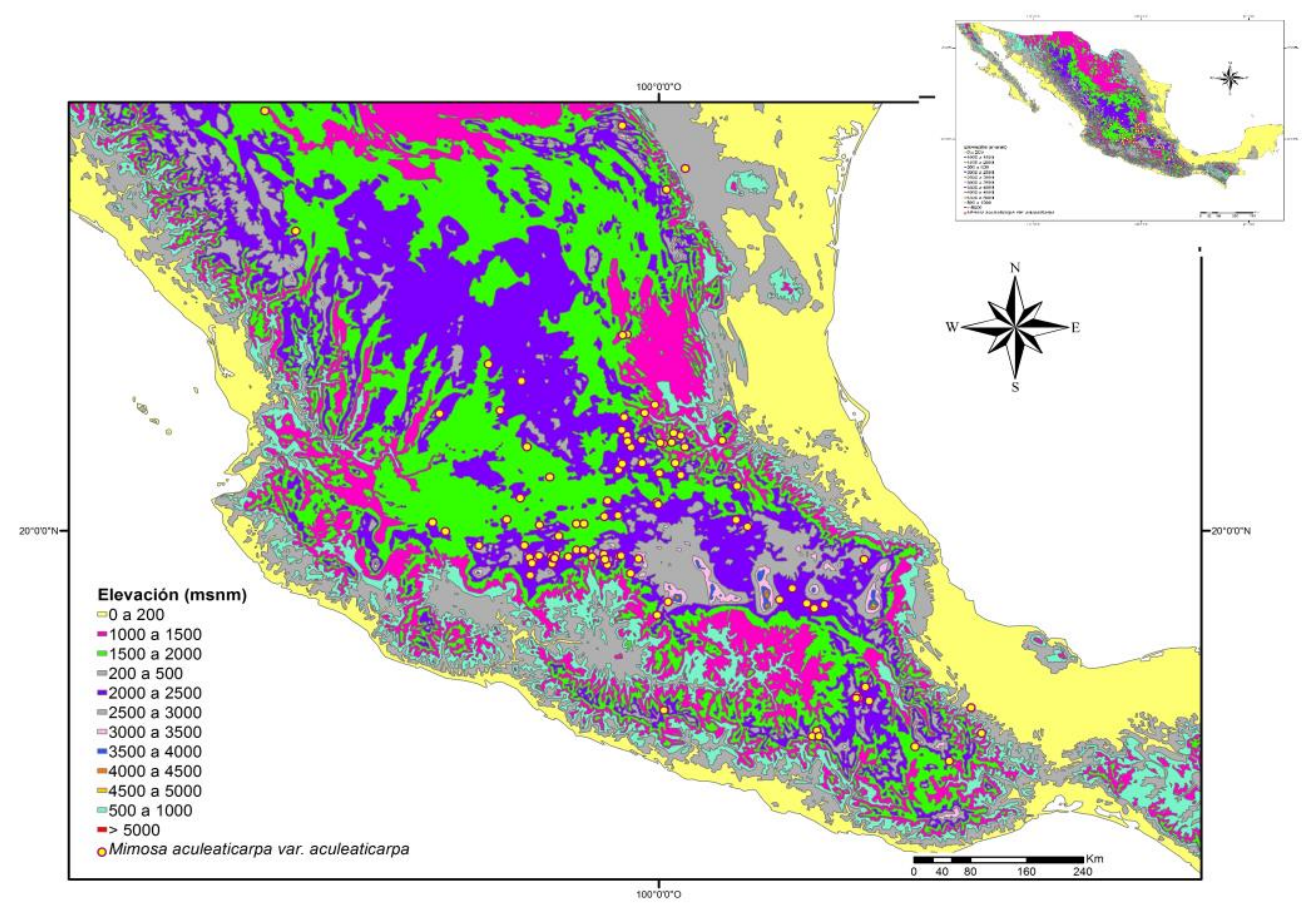

Figura 2. México, elevaciones en las que se localizan los registros de Mimosa aculeaticarpa var. aculeaticarpa. 


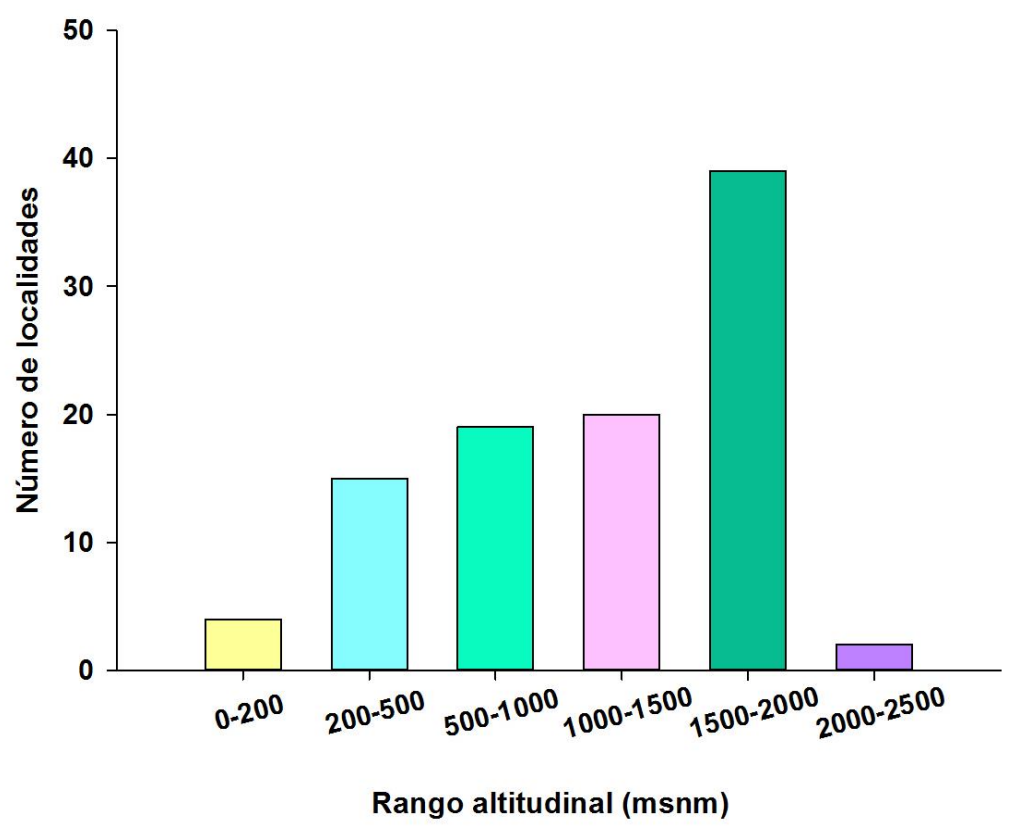

Figura 3. Número de localidades de Mimosa aculeaticarpa var. aculeaticarpa por rango altitudinal.

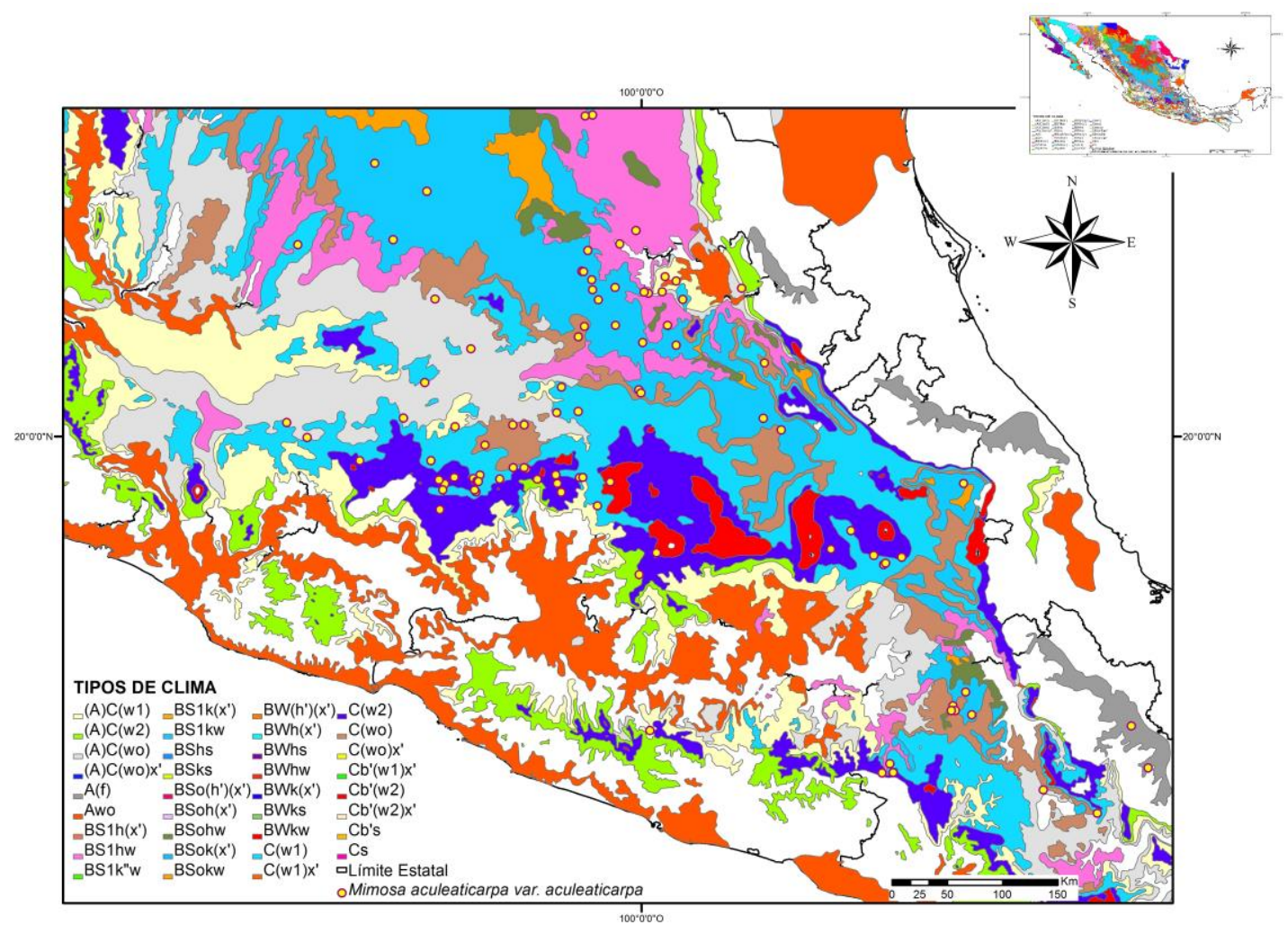

Figura 4. México, climas en los que se localizan los registros de Mimosa aculeaticarpa var. aculeaticarpa. 


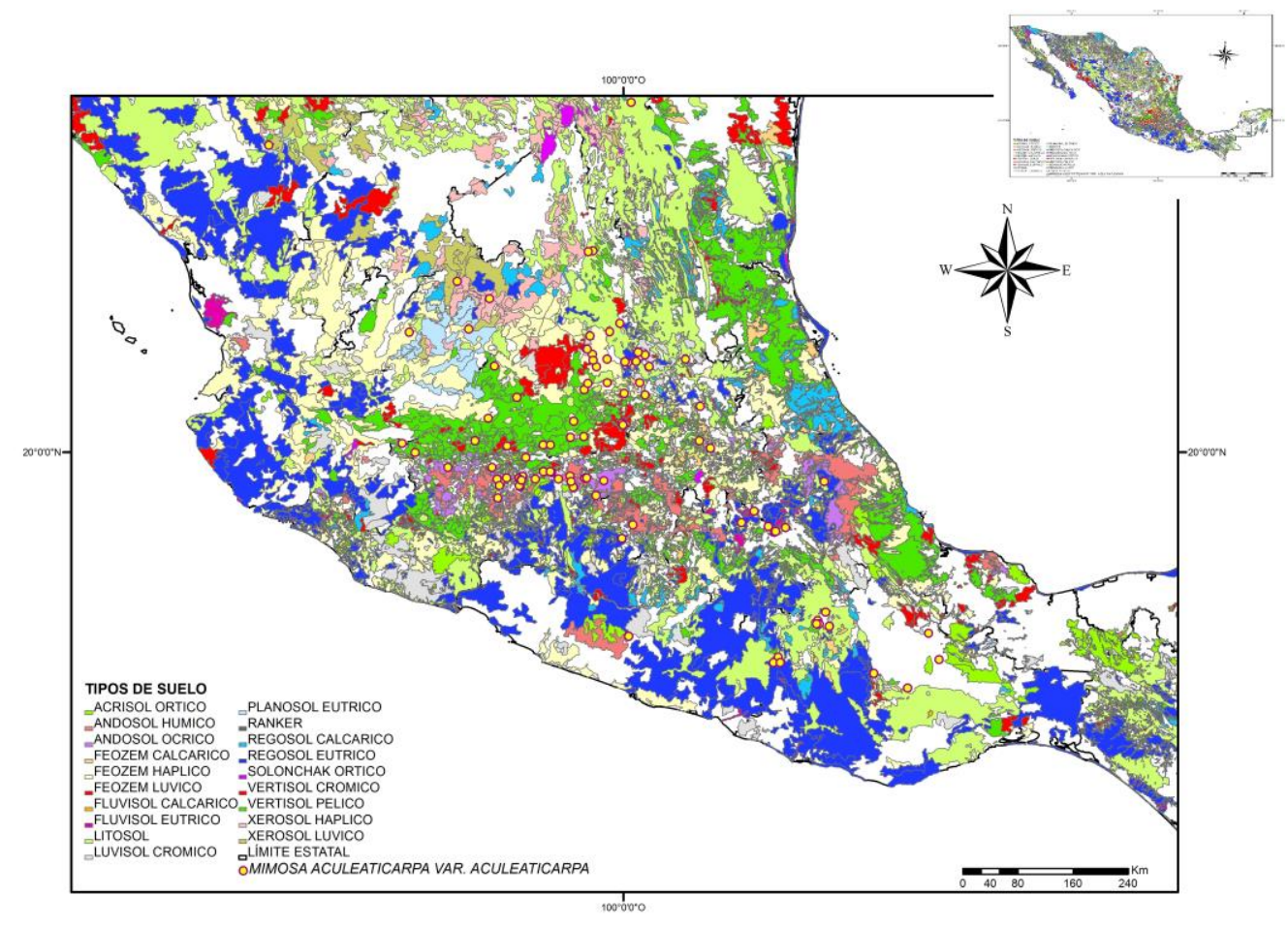

Figura 5. México, suelos en los que se establece Mimosa aculeaticarpa var. aculeaticarpa.

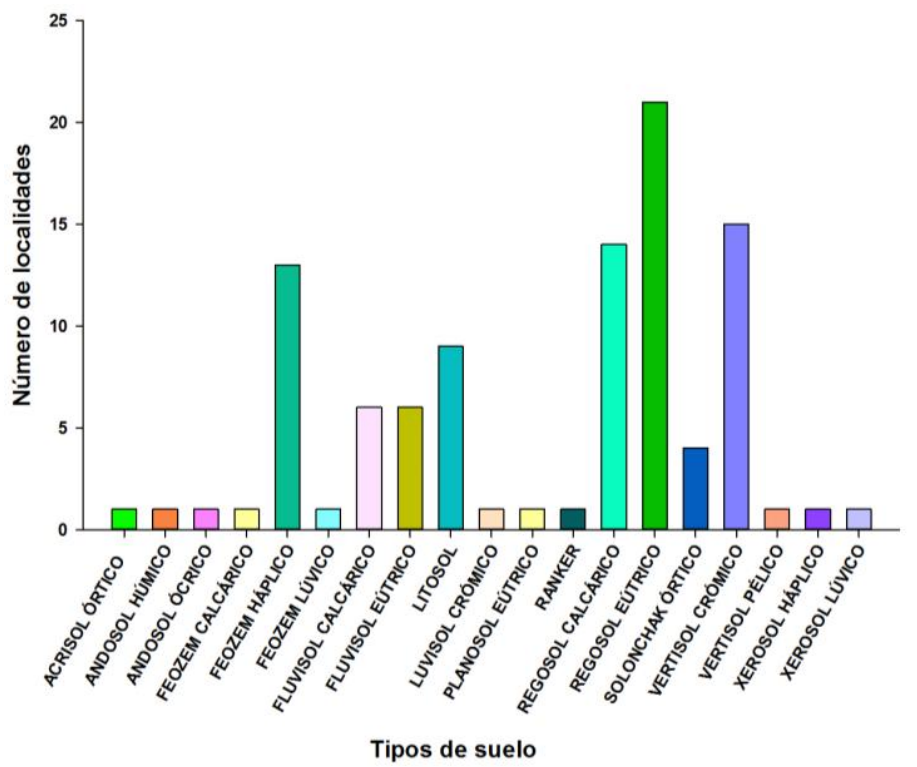

Figura 6. Número de localidades de Mimosa aculeaticarpa var. aculeaticarpa por tipo de suelo. 
Además, los resultados indican que la distribución conocida de M. aculeaticarpa var. aculeaticarpa abarca ocho provincias biogeográficas (CONABIO, 2001): 1) Altiplano Norte, 2) Altiplano Sur, 3) Sierra Madre Oriental 4) Tamaulipeca, 5) Eje Volcánico, 6) Depresión del Balsas, 7) Sierra Madre del Sur, y 8) Golfo de México (Figura 7).

Cabe mencionar que, aunque los resultados indican que el Eje Volcánico es la provincia con el mayor número de localidades (46), seguido del Altiplano Sur (29), no es posible asegurar que el taxon predomina en el estado de Michoacán, debido a la falta de exploración de otros sitios.

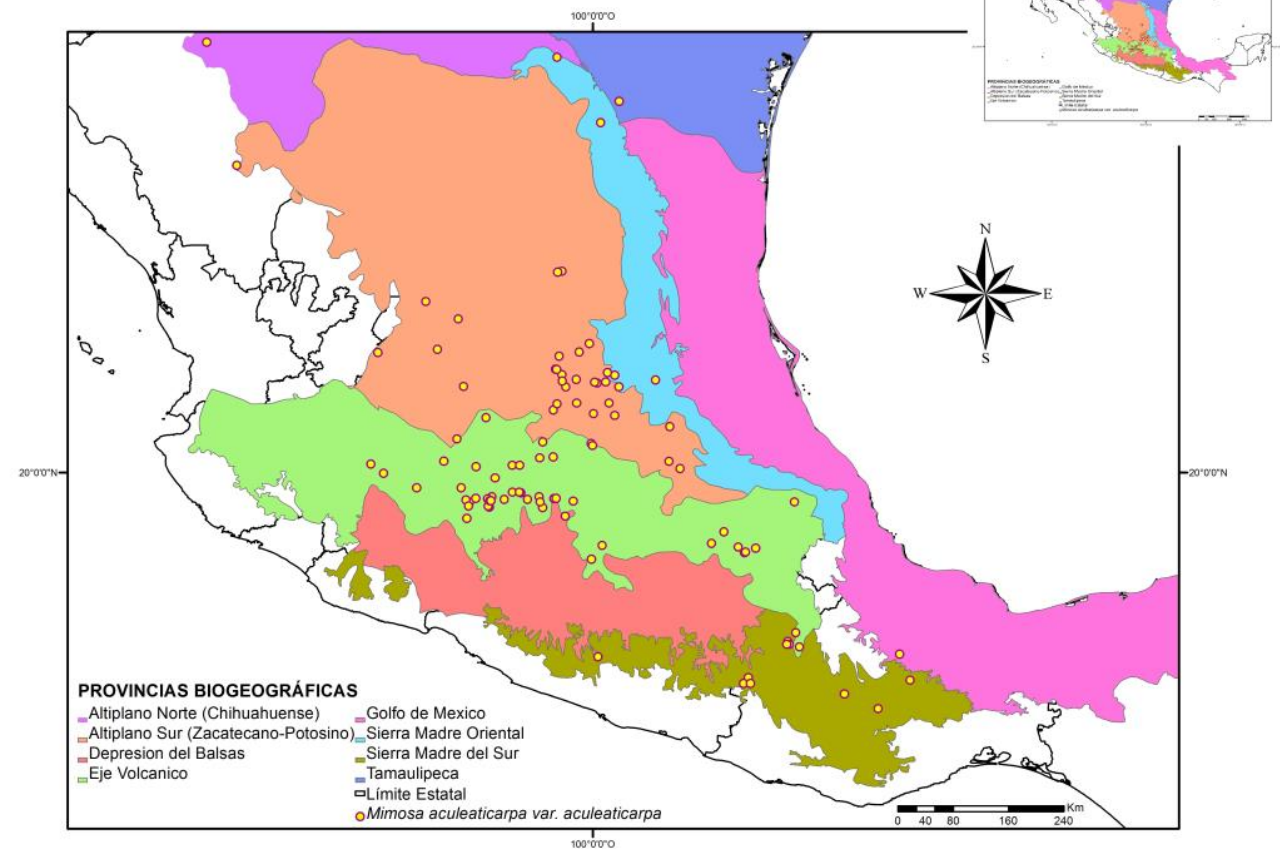

Figura 7. Provincias biogeográficas en las que se localizan los registros de Mimosa aculeaticarpa var. aculeaticarpa. 
Por último, la sobre-posición de las localidades con la capa de cuencas hidrológicas muestra que los sitios están cercanos a una fuente de agua, destacando que el mayor número de colectas se ha realizado en la Cuenca del Río Moctezuma y en la Cuenca del Lago de Pátzcuaro-Cuitzeo y Lago de Yuridia (Figura 8).

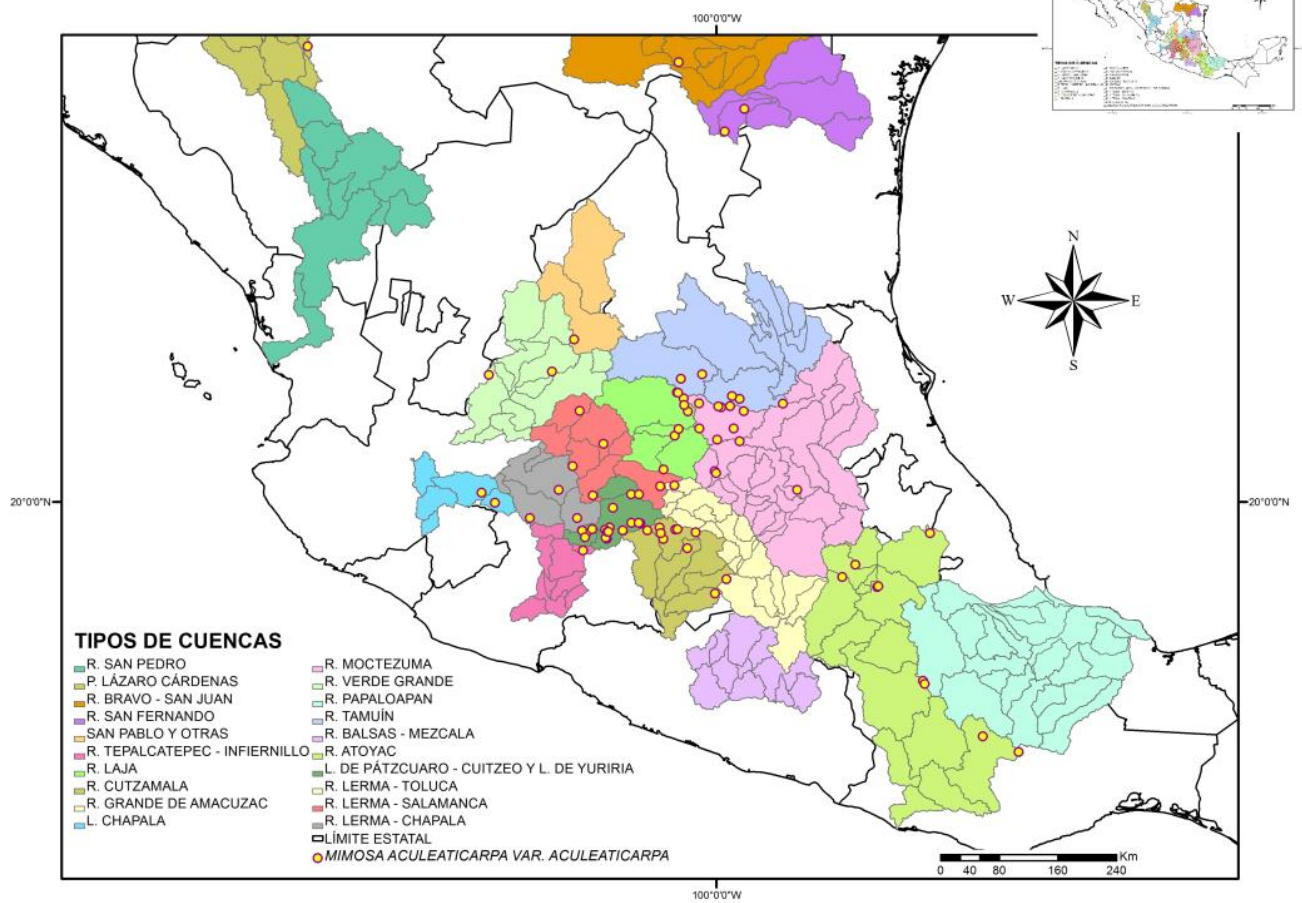

Figura 8. México, cuencas hidrológicas en las que se localizan los registros de Mimosa aculeaticarpa var. aculeaticarpa.

\subsection{Mimosa luisana}

Mimosa luisana es endémica de México, específicamente, su distribución está restringida al Valle de Tehuacán-Cuicatlán, estados de Puebla y Oaxaca. Los resultados indican que el mayor número de colectadas han sido realizadas en el estado de Puebla (Figura 9). 


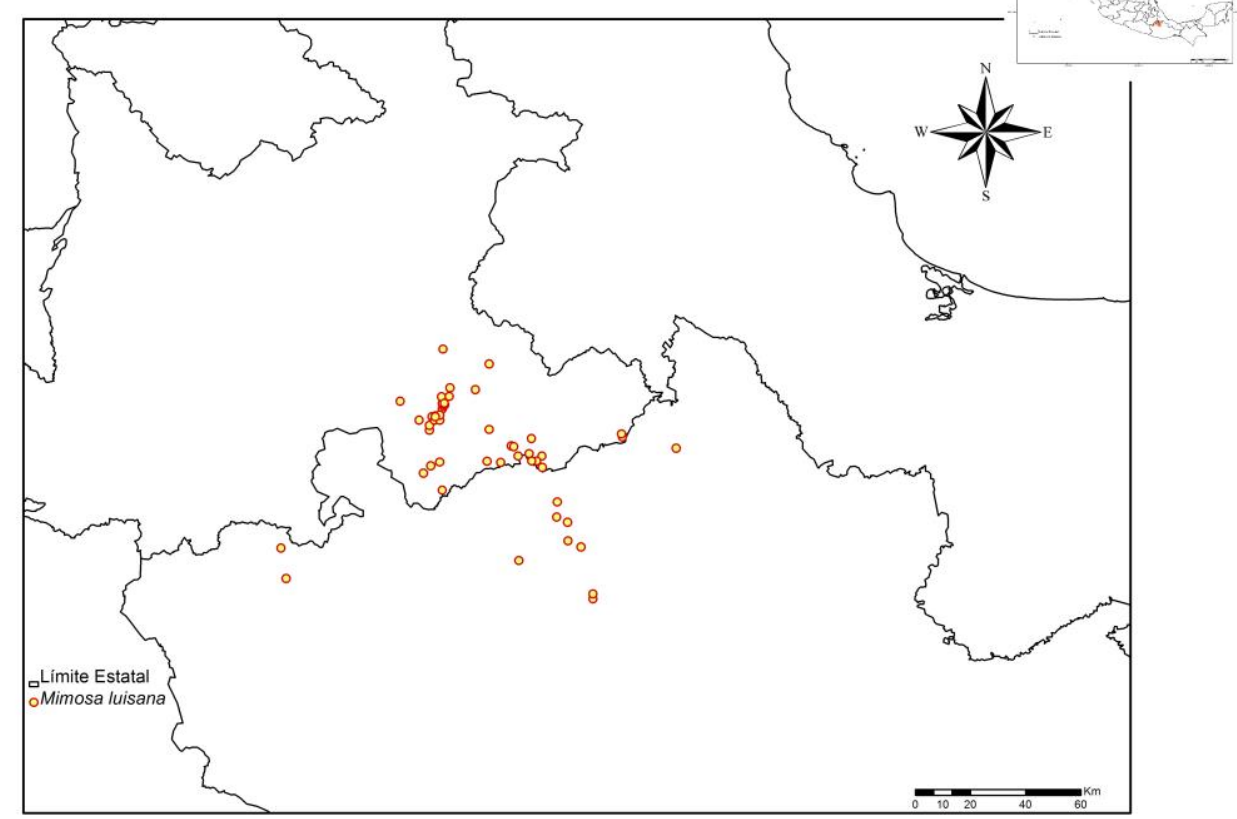

Figura 9. México, localidades de Mimosa luisana en el Valle de Tehuacán-Cuicatlán, Puebla y Oaxaca.

El análisis de los registros obtenidos mostró que los individuos de M. luisana se localizan en el rango que de los 0 hasta los 2,000 msnm (Figuras 10 y 11). El mayor número de localidades (15) se ubica entre 500-1,000 msnm; aunque, 14 localidades se localizan entre 1,500-2,000 msnm. Cabe mencionar que, la capa de elevación maneja rangos de altitudes, por lo que para datos exactos la altitud se tomó directamente de los datos originales, resultando en que este taxon se distribuye entre los 500 y 1,760 msnm, concordando con lo reportado en la Flora del Valle de Tehuacán-Cuicatlán (Martínez-Bernal y Grether, 2006)

La sobre-posición de las localidades de este taxon con la capa de climas, mostró que la mayoría de las localidades están ubicadas en un clima árido (Anexo 2 
y Figura 12). De manera adicional, los resultados muestran que $M$. luisana predominan en suelos de tipo regosol calcárico (Figuras 13 y 14). Asimismo, se observó que el taxon se distribuye principalmente en las siguientes provincias biogeográficas: 1) Eje Volcánico, 2) Oaxaca, y 3) Sierra Madre del Sur (Figura 15).

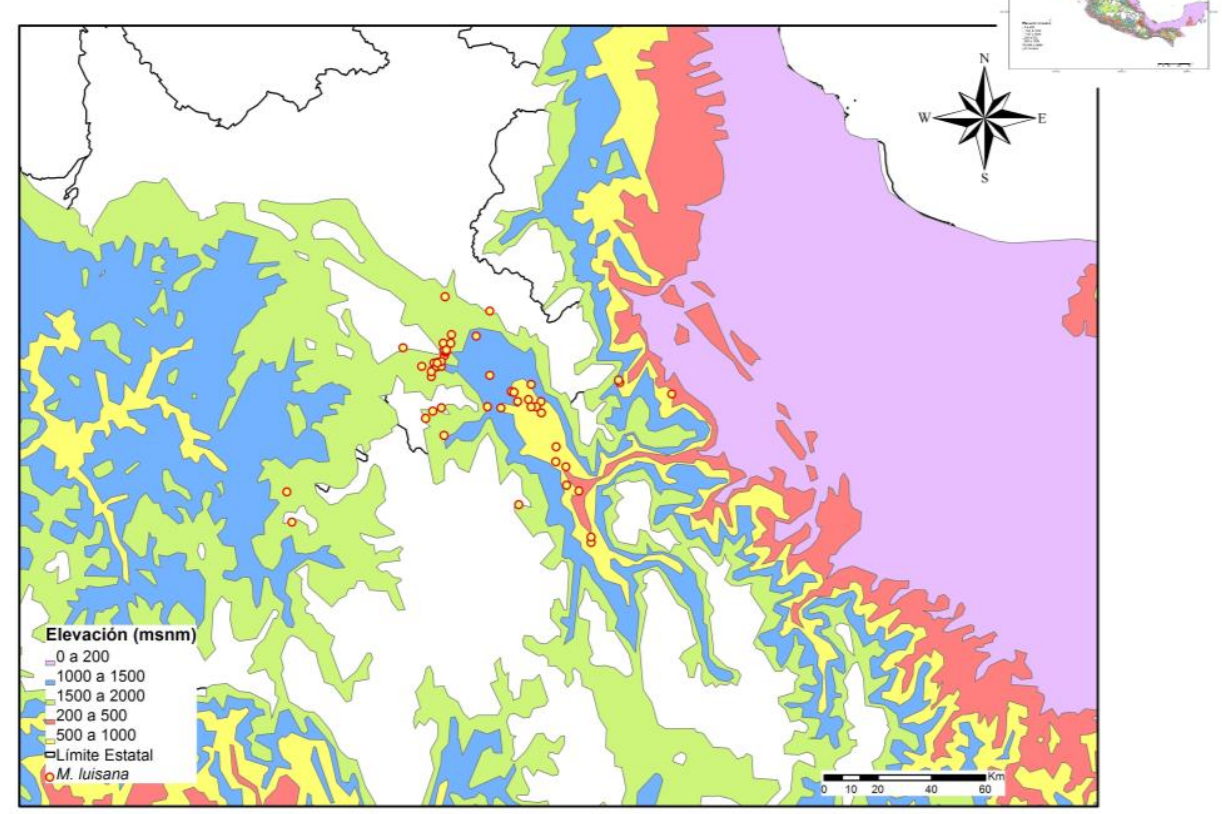

Figura 10. México, elevaciones en las que se localizan los registros de Mimosa luisana. 


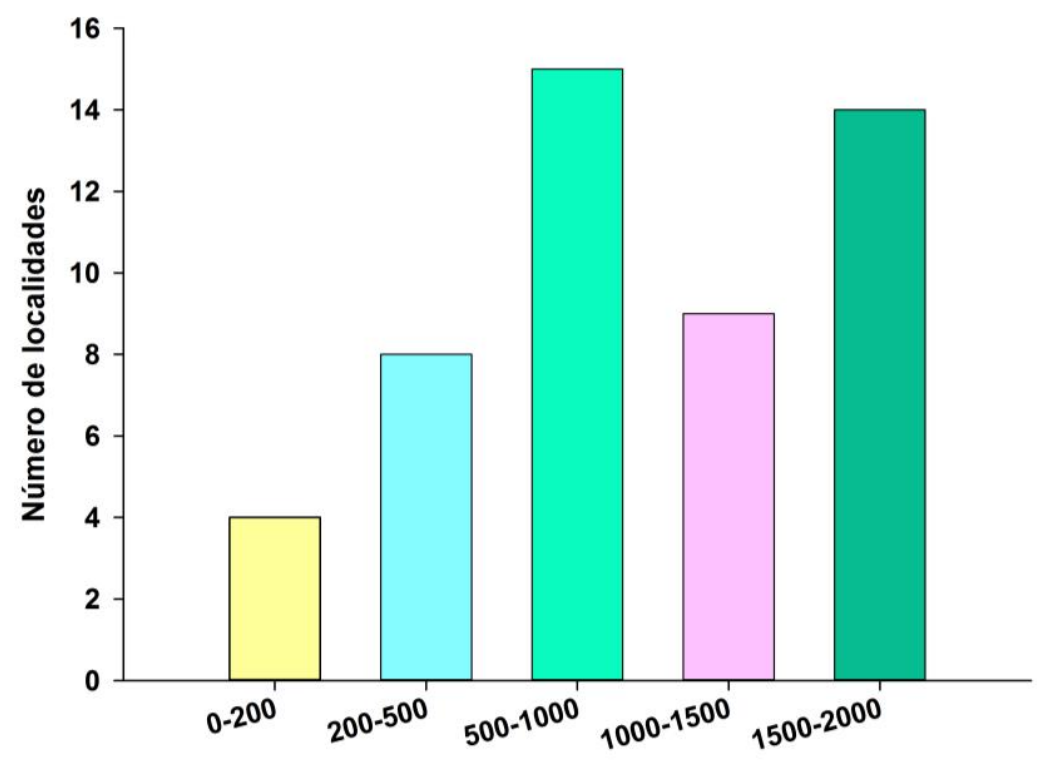

Rango altitudinal (msnm)

Figura 11. Número de localidades de Mimosa luisana por rango altitudinal.

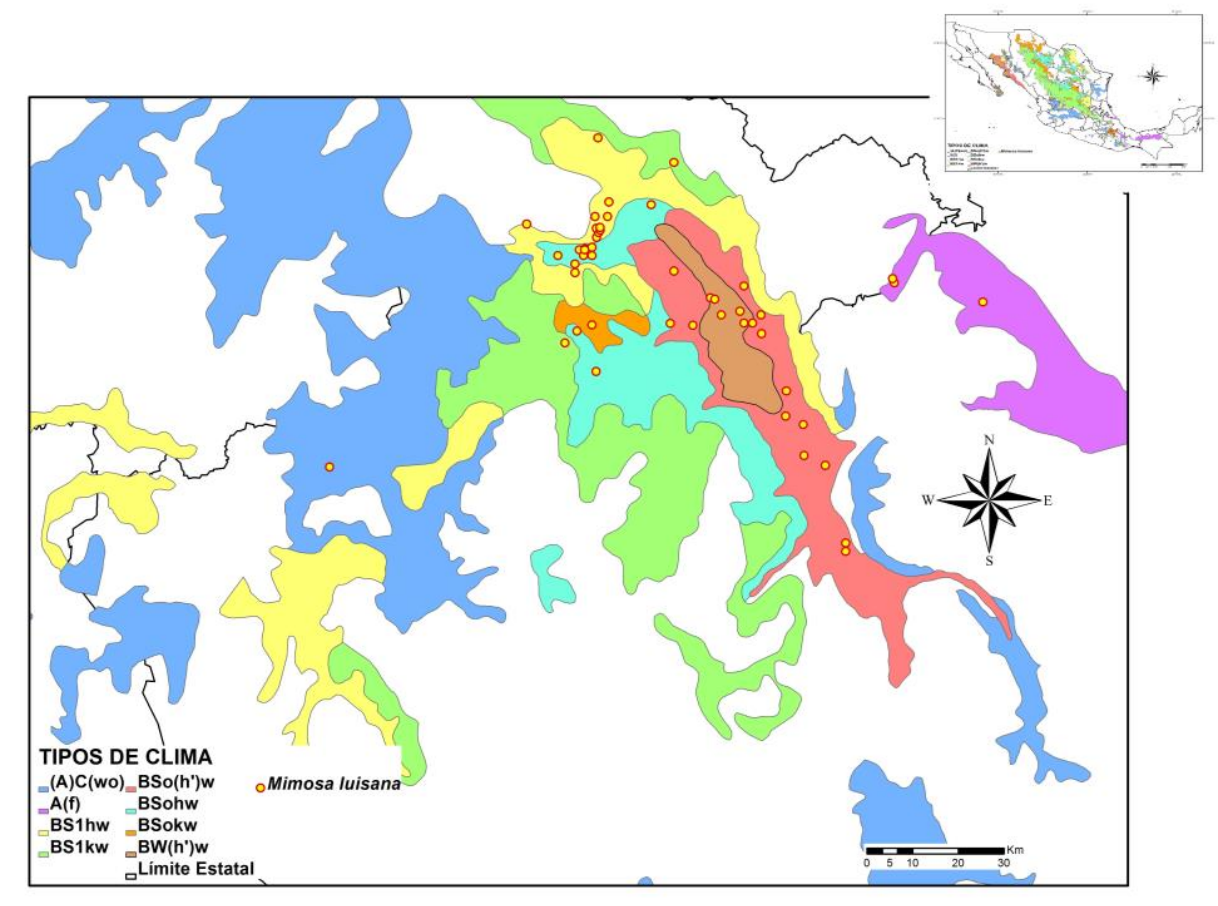

Figura 12. México, climas en los que se localizan los registros de Mimosa luisana. 


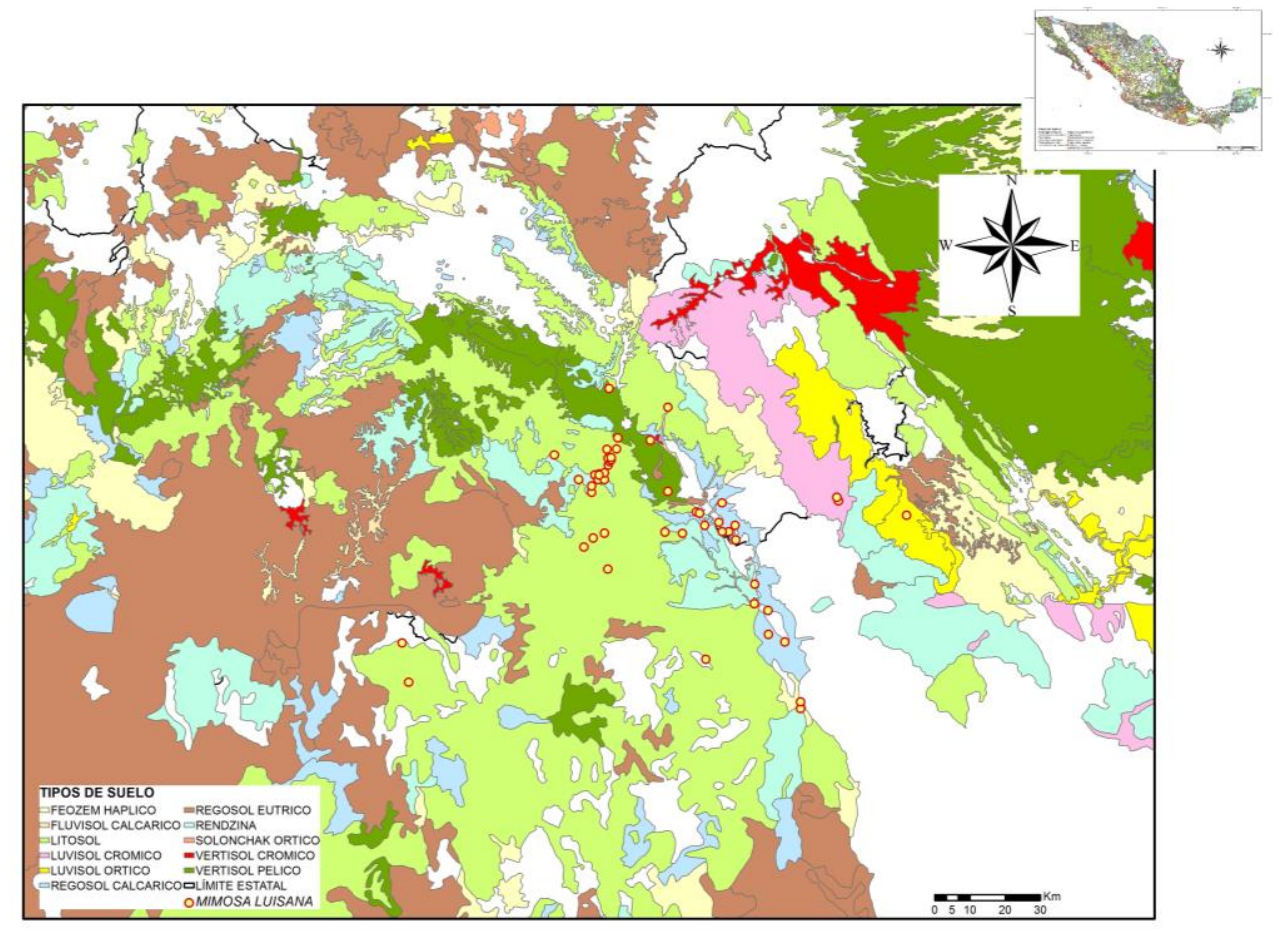

Figura 13. México, suelos en los que se localizan los registros de Mimosa luisana.

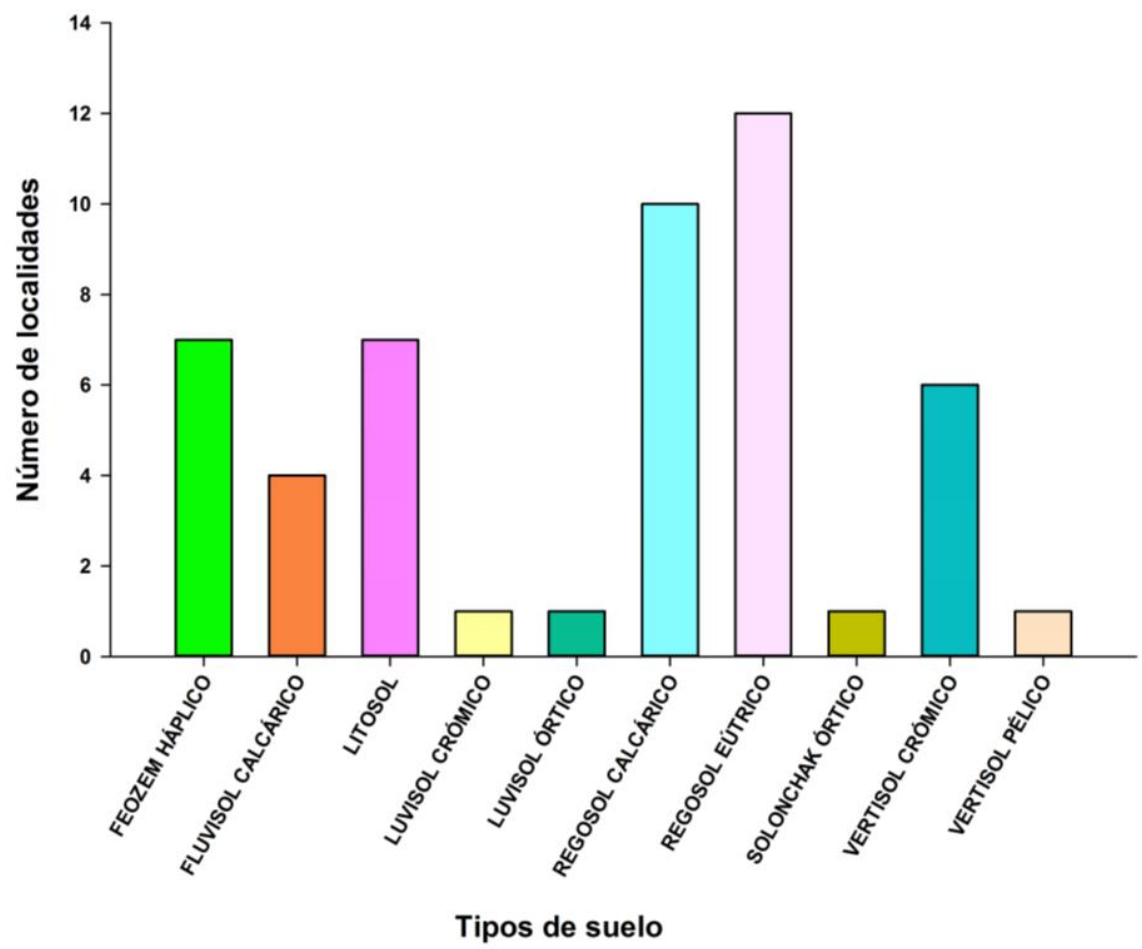

Figura 14. Número de localidades de Mimosa luisana por tipo de suelo. 


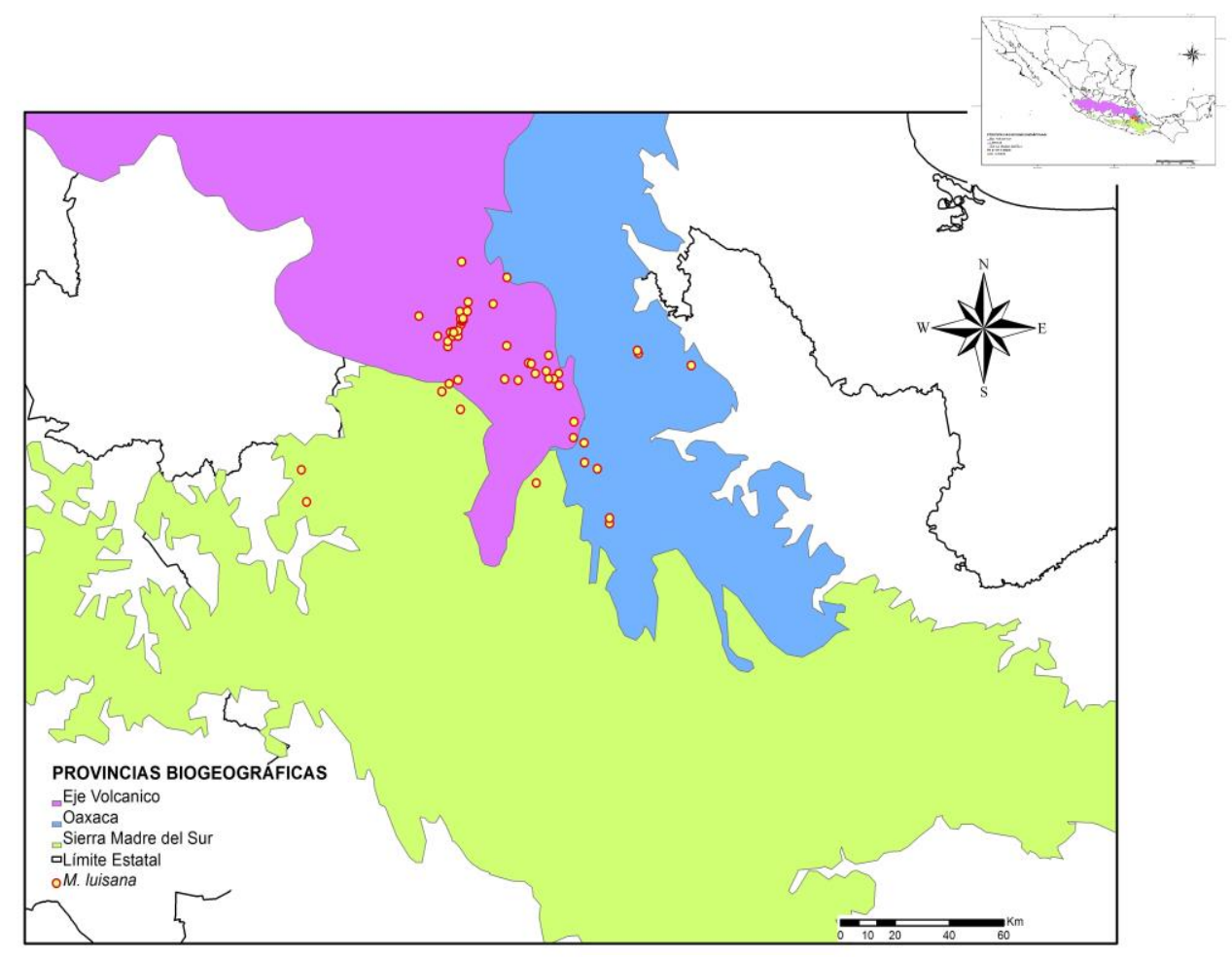

Figura 15. Provincias biogeográficas en las que se localizan los registros de Mimosa luisana.

Además, las localidades se encuentran asociadas a la Cuenca del Río Papaloapan y la del Río Atoyac; aunque, en la primera es en donde está la mayor parte de los datos de presencia (44- Figura 16). 


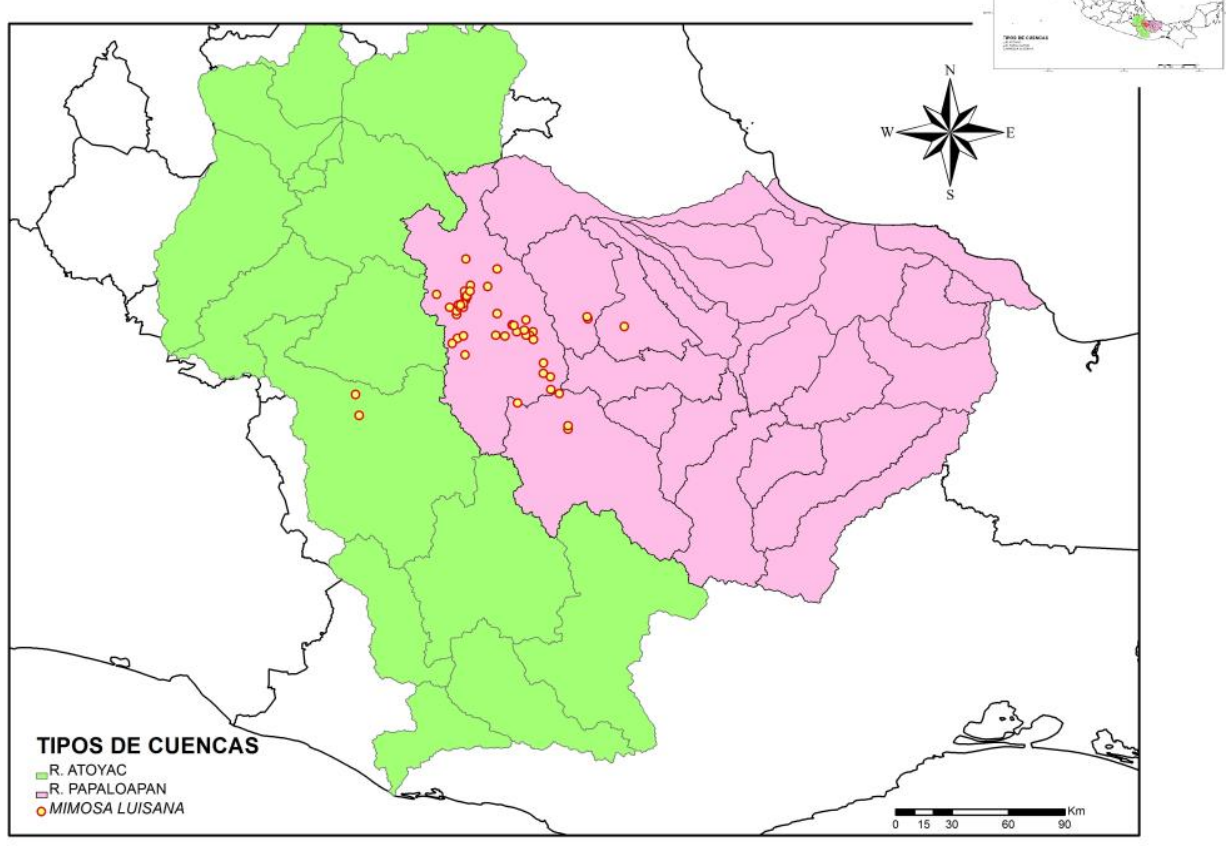

Figura 16. México, cuencas hidrológicas en las que se localizan los registros de Mimosa luisana.

\section{Distribución potencial de los taxa}

\subsection{Mimosa aculeaticarpa var. aculeaticarpa}

El perfil bioclimático generado muestra que este taxon puede habitar lugares donde la temperatura promedio anual sea de $17.9^{\circ} \mathrm{C}$, con una precipitación promedio anual de $959 \mathrm{~mm}$ (Anexo 3).

El Jacknife, generado con las 19 variables climáticas en MAXENT, mostró que las variables EDT (Estacionalidad de la temperatura, 18.5\%) y TCC (Temperatura promedio del cuatrimestre más cálido, 54.4\%) son las que aportan mayor información al modelo. Igualmente, el Jacknife mostró que el modelo se sesgaría si no se 
consideraban las variables EDT y PCF (Precipitación promedio del cuatrimestre más frío). Por lo anterior, el modelo final se generó utilizando las variables EDT y PCF, y se complementó con el análisis de correlación de Pearson, ya que este último indicó que éstas son las únicas variables independientes (Anexo 4). De modo que, aunque el Jacknife indicó que la variable TCC contribuía con un alto porcentaje al modelo, ésta presentó correlación con otras 12 variables, por lo que fue descartada.

El modelo de distribución potencial mostró un valor de AUC (área bajo la curva) de 0.91 , por lo que se considera un modelo excelente, ya que representa una predicción con alta exactitud.

Asimismo, el modelo de distribución potencial de $M$. aculeaticarpa var. aculeaticarpa sugiere que existen sitios (P. ej. Penínsulas de Baja California y de Yucatán) con las condiciones adecuadas para que este taxon amplíe su distribución, desde el centro del país hacia la región del Altiplano Sur (Zacatecano-Potosino); también este taxon podría extender su distribución hacia el noroeste del Eje Volcánico y hacia la parte sur de la Sierra Madre del Sur (Figura 17).

De manera adicional, el modelo muestra que la distribución de $M$. aculeaticarpa var. aculeaticarpa se extiende hacia áreas geográficas que no han sido muestreadas, principalmente, la parte norte del Altiplano Sur (Zacatecano-Potosino), la parte oeste del Eje Volcánico y el suroeste del Altiplano Norte (Chihuahuense). 


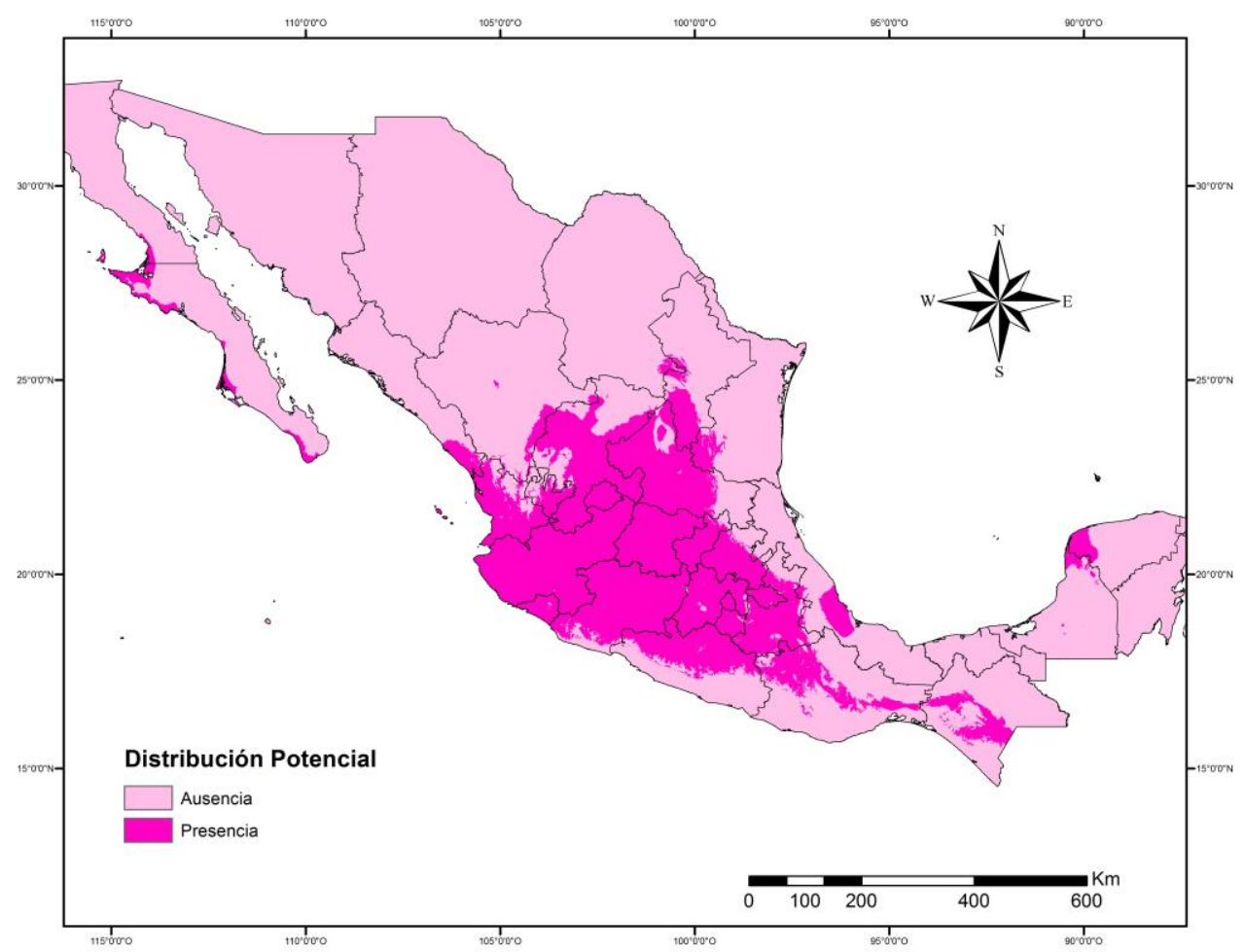

Figura 17. Distribución potencial de M. aculeaticarpa var. aculeaticarpa en México.

Es relevante señalar que el modelo predice la distribución del taxon considerando sitios con las condiciones de precipitación y temperatura necesarias para que éste se establezca, sin considerar los límites geográficos del taxon.

Por lo que, al generar la región de movilidad del taxon (M), se observa que no es posible localizar el taxon ni en la Península de Baja California, ni en la de Yucatán, ni en el estado de Chiapas (Figura 18). 


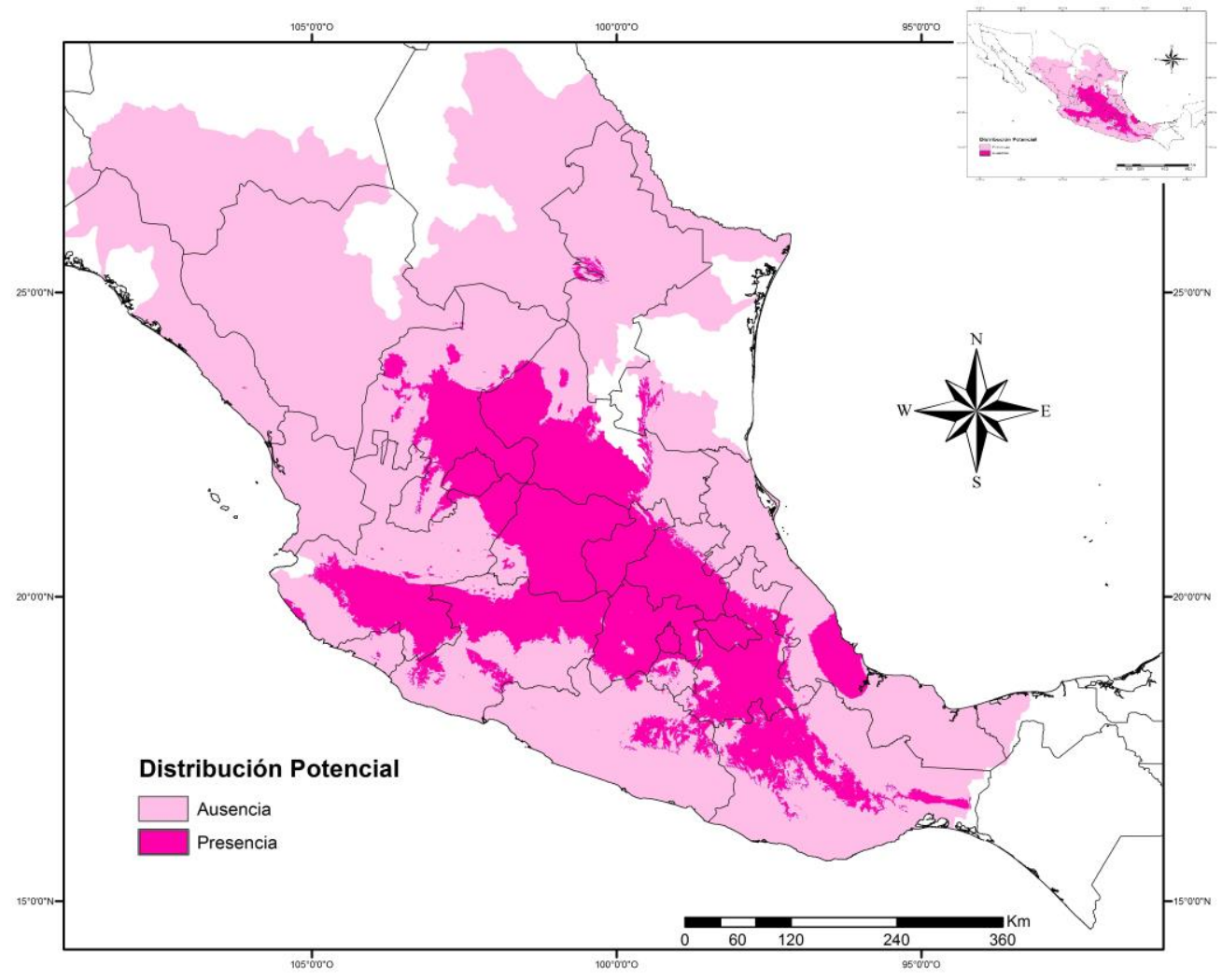

Figura 18. Modelo de la movilidad de M. aculeaticarpa var. aculeaticarpa en México.

\subsection{Mimosa luisana}

El perfil bioclimático muestra que este taxon puede establecerse en lugares con una temperatura promedio anual de $21.1^{\circ} \mathrm{C}$, y con una precipitación promedio anual de $563.2 \mathrm{~mm}$ (Anexo 5).

El análisis Jacknife, generado con las 19 variables climáticas, mostró que las variables EDT (Estacionalidad de la temperatura, 31.5\%) y PCF (Precipitación promedio del cuatrimestre más frío, $45.7 \%$ ) son las variables que aportan mayor información al modelo. Además de mostrar que la variable EDT debería ser considerada para que el modelo no se sesgara. Por lo anterior, y considerando el 
análisis Jacknife y la correlación de Pearson, el modelo final se generó utilizando las variables EDT y PCF (Anexo 6).

El modelo de distribución potencial mostró un valor de AUC (área bajo la curva) de 0.97 , por lo que se considera un modelo excelente, que representa una predicción con una exactitud alta.

Asimismo, el modelo de distribución potencial de M. luisana sugiere que existen las condiciones para que este taxon puede ampliar su distribución hacia la región noreste del Eje Volcánico, las regiones suroeste y sureste de la Sierra Madre del Sur, y abarcar, en su totalidad, la provincia biogeográfica de Oaxaca y extenderse hacia una pequeña porción del oeste de la provincia del Golfo de México (Figura 19). El modelo de predicción indica que este taxon puede encontrarse en áreas que aún no han sido muestreadas, principalmente, en la región oeste del Golfo de México.

Pese a lo anterior, cuando se genera el modelo reconociendo la movilidad del taxon, se detecta que éste no llega ni al centro del estado de Oaxaca y, mucho menos, al estado de Chiapas. Además, existen otros puntos donde, aunque están presentes las condiciones climáticas para el establecimiento del taxon, existen límites geográficos que impiden su ocurrencia en esos sitios (Figura 20). 


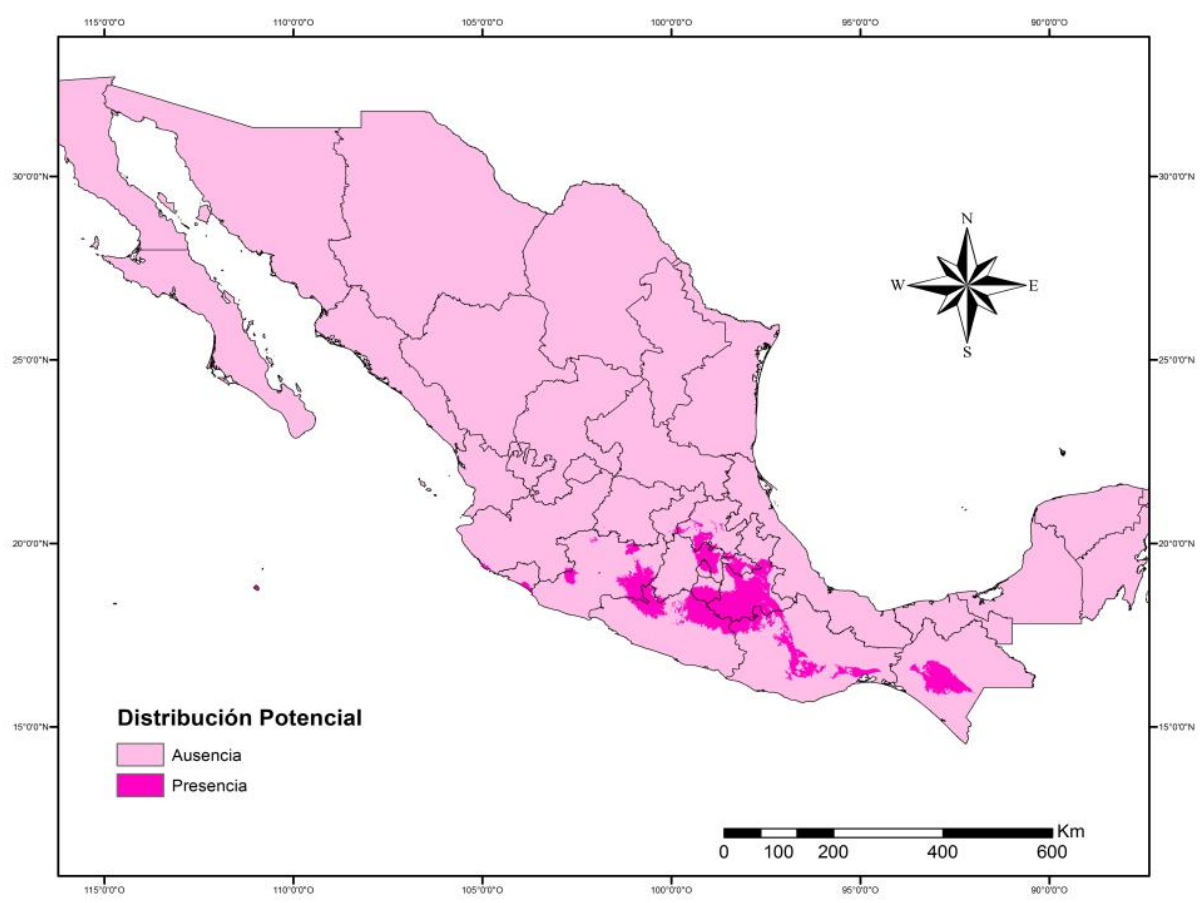

Figura 19. Distribución potencial de M. luisana en México.

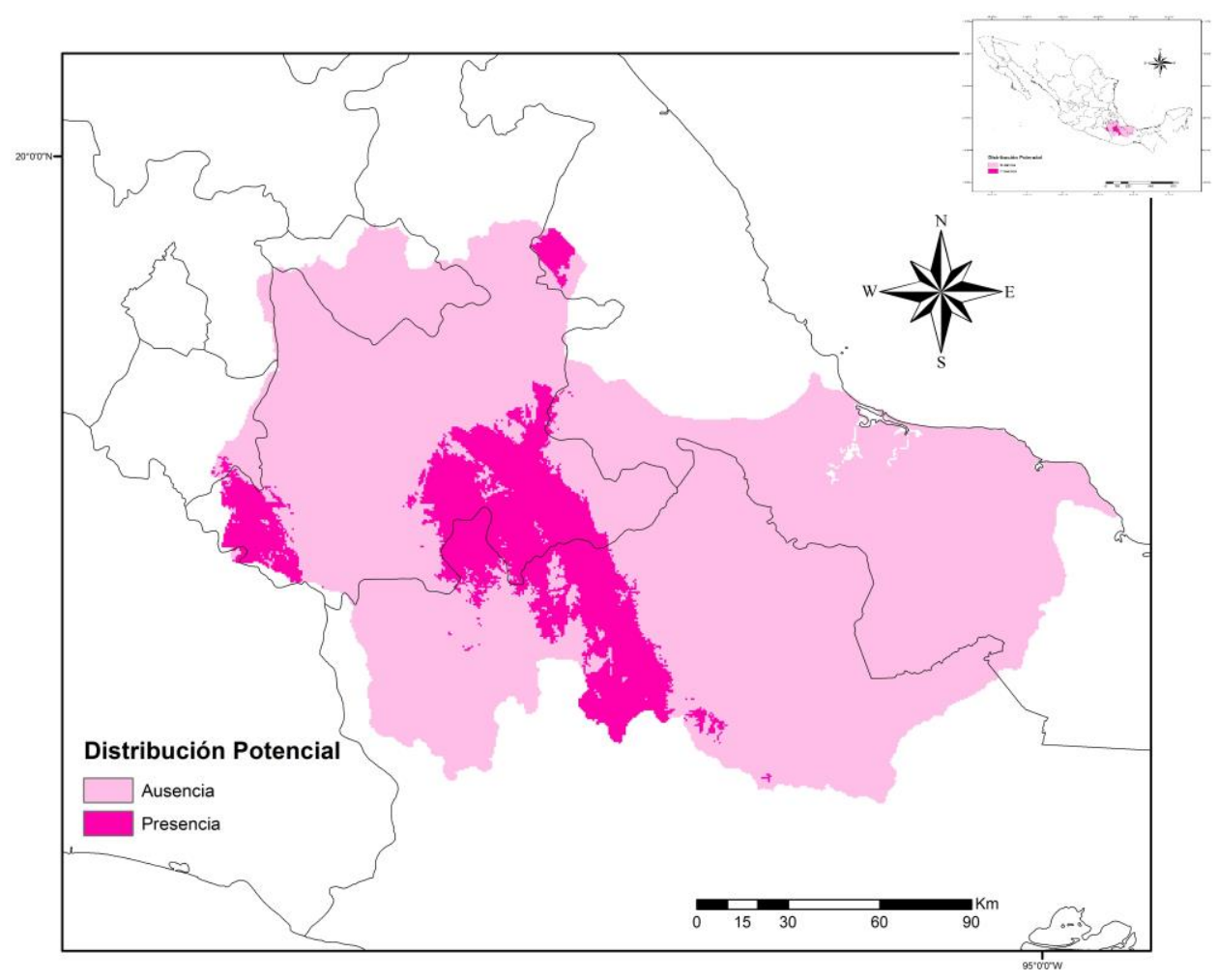

Figura 20. Modelado de la movilidad de M. luisana en México. 


\section{DISCUSIÓN}

\section{Distribución conocida}

Los resultados muestran una variación en cuanto al número de registros obtenidos por taxon. Además indican que M. aculeaticarpa var. aculeaticarpa está presente en 16 estados de la República, lo que concuerda con lo reportado por Camargo-Ricalde et al. (2001) y Grether et al. (2007).

En el caso de la distribución de M. luisana, ésta coincide en que sólo se establece en los estados de Puebla y Oaxaca, como lo reportan Martínez-Bernal y Grether (2006). De manera adicional, los mapas de distribución conocida, en ambos taxa, muestran las localidades más estudiadas y aquéllas donde falta realizar colectas.

Asimismo, los mapas de la distribución conocida indican, con precisión, los sitios más estudiados para cada taxon ( $M$. aculeaticarpa var. aculeaticarpa, Michoacán y M. luisana, Puebla), lo que puede interpretarse como un sesgo en la metodología al momento de generar los modelos predictivos (Phillips et al., 2009); sin embargo, los modelos generan una distribución hipotética que, de acuerdo con Trotta-Moreu et al. (2008), puede ser utilizada tanto en la conservación como en la biogeografía de los taxa; además de ser una herramienta útil para la planeación de nuevas colectas.

La modelación de este tipo de distribución muestra que la mayoría de los registros, en ambos taxa, se localizan, principalmente, en altitudes entre 1,500-2,000 
msnm; este rango altitudinal entra en el propuesto por Grether et al. (2015) para la distribución del género Mimosa.

Respecto a los climas, ambos taxa se encuentran en sitios con climas áridos y semiáridos, lo que coincide con los antecedentes de los taxa reportados por Martínez-Bernal y Grether (2006) y Grether et al. (2007).

\section{Distribución potencial}

Algunos autores como Lindenmayer et al. (1996) y Peterson et al. (2000), consideran que para generar los modelos de distribución potencial es necesario contar con, al menos, 50 registros para poder predecir la distribución de los taxa; sin embargo, existen estudios que han estimado la distribución con un número inferior a 50 registros y los modelos han sido considerados con un alto nivel de predicción (Palacios, 2010; Villaseñor y Téllez, 2004). Cabe mencionar que, en este estudio, sólo $M$. aculeaticarpa var. aculeaticarpa contó con más de 50 registros; aunque, es importante mencionar que los modelos obtenidos para ambos taxa, tuvieron una excelente predicción (Burgueño,1995; Mezaour, 2005).

Además, los modelos de distribución potencial de ambos taxa, coinciden con su distribución conocida, lo que muestra un bajo error de omisión (Contreras-Medina et al., 2010). Igualmente, dichos modelos presentan un valor AUC alto, por lo que se pueden considerar robustos (Marmion et al., 2009; Marini et al., 2010). Sin embargo, 
los resultados señalan, asimismo, que el modelo de distribución potencial de $M$. aculeaticarpa var. aculeaticarpa fue inferior (0.91) al de M. luisana (0.97), lo que sugiere que el modelado de un taxon con amplia distribución, es menos preciso que uno correspondiente a un taxon con distribución restringida, aspecto ya comentado por Guevara-Escobar et al. (2008), Hernandez et al. (2006) y Naoki et al. (2006).

Además, algunos autores como Engler et al. (2004), y Chefaoui y Lobo (2008) Zaniewski et al. (2002), consideran que los modelos basados en datos sólo de presencias, pueden sobreestimar la distribución de los taxa. En este sentido, aunque el modelo de distribución potencial de $M$. aculeaticarpa var. aculeaticarpa es considerado un modelo excelente, podría indicar una sobreestimación de su distribución (Península de Yucatán y algunas partes de la Península de Baja California). De igual manera, sucede con el modelo de $M$. Iuisana, ya que predice que este taxon puede ampliar su distribución hacia las regiones centro y suroeste de Oaxaca, y centro de Chiapas, debido a que existen las condiciones de temperatura y precipitación adecuadas para que se desarrolle. Al respecto, existen estudios que sugieren que para robustecer los modelos predictivos es necesario incorporar otros factores como la topografía (Aalto y Luoto, 2014; Naoki et al., 2006); así como considerar los datos históricos de los taxa (Escalante, 2003).

Aunque la delimitación de la región $\mathrm{M}$ de los taxa es un tema poco tratado en la literatura, es probablemente una forma más para robustecer los modelos. De acuerdo con Brown (1995), la distribución de un taxa está determinada por la interacción de su ecología con su historia evolutiva, por lo que para realizar 
predicciones de su distribución, se deben considerar sus límites geográficos, ya que ello permite reconocer sus límites de dispersión (Soberón y Peterson, 2005).

Dado lo anterior, la validación de los modelos es un tema controversial; si bien el AUC es un método aceptado (Benito de Pando y Peñas de Giles, 2007), se requiere de la validación del modelo por métodos de muestreo en campo (ContrerasMedina, 2010), ya que los algoritmos no consideran las interacciones bióticas que pueden afectar la distribución de los taxa (Naoki et al., 2006; Palacios, 2010; Soberón y Peterson, 2005). Aunque, en este caso particular (P. ej. experiencia taxonómica y florística del género Mimosa en México), los modelos generados en este trabajo pueden considerarse como una aproximación al conocimiento de la distribución potencial de los taxa estudiados.

Por otra parte, desde una perspectiva de cambio climático, los modelos de distribución potencial, en ambos taxa, sugieren una reducción y una ampliación de su área de distribución, respectivamente, ya que de acuerdo con Gómez-Díaz et al. (2007), los ecosistemas templados podrían reducirse y los secos ampliarse (Palacios, 2010). Bajo esta premisa, M. aculeaticarpa var. aculeaticarpa podría reducir su distribución; mientras que $M$. luisana la podría ampliar. No obstante, en este trabajo no se contemplaron los posibles cambios en los ecosistemas (Parmensan y Yohe, 2003), por lo que se sugiere ampliar este estudio bajo escenarios de cambio climático y de uso de suelo. 


\section{CONCLUSIONES}

Considerando que México es el segundo centro de distribución del género Mimosa, los mapas de distribución conocida y potencial de sus taxa, deben considerarse como una aproximación al conocimiento de las mimosas mexicanas.

Asimismo, aunque este trabajo aporta datos e información sobre zonas del territorio nacional que no han podido ser estudiadas por diversas causas ( $P$. ej. dificultad de acceso y seguridad, entre otras), posteriormente, podrían ser corroborados en campo; aunque, es importante considerar que los modelos son estáticos, ya que no consideran las interacciones bióticas, por lo que su relación con la realidad puede variar.

Finalmente, aunque los modelos aquí presentados son una aproximación a la distribución conocida y potencial de los taxa estudiados, es importante incorporar otros aspectos (además de los climáticos) como los históricos y topográficos; así como edáficos y el cambio de uso del suelo, para una mayor precisión de los modelos de predicción.

\section{LITERATURA CITADA}

Aalto, J., y Luoto M. 2014. Integrating climate and local factors for geomorphological distribution models. Earth Surface Processes and Landforms 39: 1729-1740. 
Almazán, N.R.C. 2007. Modelaje ecológico de la distribución geográfica de la avifauna del estado de Querétaro. Tesis de Maestría, Facultad de Ciencias Naturales, Universidad Autónoma de Querétaro, Querétaro, México. 103 p.

Alsos, I.G., Alm T., Normand S. y Brochmann C. 2009. Past and future range shifts and loss of diversity in dwarf willow (Salix herbacea L.) inferred from genetics, fossils and modeling. Global Ecology and Biogeography 18: 223-239.

Anderson, R.P., Lew D. y Peterson A.T. 2003. Evaluating predictive models of species' distributions: criteria for selecting optimal models. Ecological Modelling 162: $211-232$.

Arundel, C.J. 2004. Using spatial models to establish climatic limits of plant species distributions. Ecological Modeling 30: 1-23.

Ávila-Bello, C.H. y López-Mata L. 2001. Distribución y análisis estructural de Abies hickelii (Flous \& Gaussen) en México. Interciencia 26: 244-251.

Benito de Pando, B. y Peñas de Giles J. 2007. Aplicación de modelos de distribución de especies a la conservación de la biodiversidad en el sureste de la Península Ibérica. GeoFocus 7: 100-119.

Bessega, C., Vilardi J.C. y Saidman B.O. 2006. Genetic relationships among American species of the genus Prosopis (Mimosoideae, Leguminosae) inferred from ITS sequences: evidence for long-distance dispersal. Journal of Biogeography 33: 1905-1915.

Bravo, E.A.V. 2011. Análisis biogeográfico de las especies arbóreas de Chile. Tesis de Licenciatura. Facultad de Ciencias Forestales y Recursos Naturales, Universidad Austral de Chile. 52 p. 
Brown, J.H. 1995. Macroecology. University of Chicago Press, Illinois. 269 p.

Burgueño, M. J., García-Bastos L. y Gonzáles-Buitrago J.M. 1995. Las curvas ROC en la evaluación de pruebas diagnósticas. Medicina Clínica 104: 661-670.

Camargo-Ricalde, S.L., Grether R., Martínez-Bernal A., García-García V. y Barriosdel-Rosal S. 2001. Especies útiles del género Mimosa (Fabaceae-Mimosoideae) en México. Boletín de la Sociedad Botánica de México 68: 33-44.

Cawsey, E.M., Austin M.P. y Baker B.L. 2002. Regional vegetation mapping in Australia: a case study in the practical use of statistical modelling. Biodiversity \& Conservation 11: 2239-2274.

Chefaoui, R.M. y Lobo J.M. 2008. Assessing the effects of pseudo-absences on predictive distribution model performance. Ecological modelling 210: 478-486.

Comisión Nacional para el Conocimiento y Uso de la Biodiversidad (CONABIO). 2011. México. http:/www.conabio.gob.mx.

Contreras-Medina, R., Luna-Vega I., y Ríos-Muñoz C.A. 2010. Distribución de Taxus globosa (Taxaceae) en México: Modelos ecológicos de nicho, efectos del cambio del uso de suelo y conservación. Revista Chilena de Historia Natural 83: 421-433.

Corsi, F., De Leeuw J. y Skidmore A. 2000. Modelling Species Distribution with GIS In: Boitani, L. y Fuller, K. (eds.) Research techniques in animal ecology: controversies and consequences. New York, Columbia University Press. 389$425 \mathrm{p}$.

Cruz-Cárdenas, G., Villaseñor J.L., López-Mata L. y Ortiz E. 2012. Potential distribution of humid mountain forest in Mexico. Botanical Sciences 90: 331-340. 
Cushman, S.A. 2006. Effects of habitat loss and fragmentation on amphibians: a review and prospectus. Biological Conservation 128: 231-240.

De la Estrella, M., Mateo R.G., Wieringa J.J., Mackinder B. y Muñoz J. 2012. Legume diversity patterns in West Central Africa: influence of species biology on distribution models. PloS one 7: 41526.

Dhillion, S.S., Aguilar-Støen M. y Camargo-Ricalde S.L. 2004. Integrative ecological restoration and local involvement in the Tehuacán-Cuicatlán Valley, Mexico. Environmental Conservation 13: 1-3.

Duno-de Stefano, R., Can-Itza L.L., Rivera-Ruiz A. y Calvo-Irabién L.M. 2012. Regionalización y relaciones biogeográficas de la Península de Yucatán con base en los patrones de distribución de la familia Leguminosae. Revista Mexicana de Biodiversidad 83: 1053-1072.

Elith, J., Kearney M., y Phillips S. 2010. The art of modelling range-shifting species. Methods in ecology and evolution 1: 330-342.

Elith, J.C.H, Anderson R.P., Dudik M., Ferrier S. y Guisan A., Hijmans R.J., Huettmann M., Leathwick J.R., Lehmann A., Lohmann L.G., Lois B.A., Manion G., Moritz C., Nakamura M., Overton J.M., Peterson T., Phillips S.J., Richardson K., Scachetti-Pereira P., Schapire R.E., Soberón J., Williams S., Wisz M.S. y Zimmermann N. 2006. Novel methods improve prediction of species' distributions from occurrence data. Ecography 29: 129-151.

Engler, R., Guisan A. y Rechsteiner L. 2004. An improved approach for predicting the distribution of rare and endangered species from occurrence and pseudo-absence data. Journal of Applied Ecology 41: 263-274. 
Escalante, E.T. 2003. Determinación de prioridades en las áreas de conservación para los mamíferos terrestres de México, empleando criterios biogeográficos. Anales del Instituto de Biología, Serie Zoología 74: 211-238.

Fischer, J., Lindenmayer D.B., Nix H.A., Stein J.L. y Stein J.A. 2001. Climate and animal distribution: a climatic analysis of the Australian marsupial Trichosurus caninus. Journal of Biogeography 28: 293-304.

Franklin, J. 2009. Mapping Species Distributions: Spatial inference and prediction. Cambridge, Reino Unido: Cambridge University Press. 318 p.

Gelviz, G.S.M. 2013. Especies arbustivas tolerantes al cambio climático, para ser propuestas en proyectos de restauración del matorral xerófilo en el estado de Hidalgo. Tesis de Doctorado en Biodiversidad y Conservación. Universidad Autónoma del Estado de Hidalgo, Hidalgo, México. 97 p.

Gómez-Díaz, J.D., Monterroso-Rivas A.I. y Tinoco-Rueda J.A. 2007. Comportamiento de la vegetación bajo escenarios de cambio climático en la reserva de la Biosfera Barranca de Metztitlán, Hidalgo, México. Zonas Áridas 11: 61-69.

Gómez-Mendoza, L., Galicia L. y Aguilar-Santelises R. 2008. Sensibilidad de grupos funcionales al cambio climático en la Sierra Norte de Oaxaca, México. Investigaciones geográficas 67: 76-100.

González-Espinosa, M., Rey-Benayas J.M., Ramírez-Marcial N., Huston M.A. y Golicher D. 2004. Tree diversity in the northern Neotropics: regional patterns in highly diverse Chiapas, México. Ecography 27: 741-756. 
Graham, C.H., Elith J., Hijmans R.J., Guisan A., Townsend-Peterson A. y Loiselle B. A. 2008. The influence of spatial errors in species occurrence data used in distribution models. Journal of Applied Ecology 45: 239-247.

Graham, C.H., Ferrier S., Huettman F., Moritz C. y Peterson A.T. 2004. New developments in museum-based informatics and applications in biodiversity analysis. Trends in Ecology and Evolution 19: 497-503.

Grand, J., Cummings M.P., Rebelo T.G., Ricketts T.H. y Neel M.C. 2007. Biased data reduce efficiency and effectiveness of conservation reserve networks. Ecology Letters 10: 364-374.

Grether, R., Camargo-Ricalde S.L. y Martínez-Bernal A. 1996. Especies del género Mimosa (Leguminosae) presentes en México. Boletín de la Sociedad Botánica de México 58: 149-152.

Grether, R. Camargo-Ricalde S.L., Martínez-Bernal A., Montaño-Arias S. y. Fraile Ma.E. 2015. Diversity and geographical distribution patterns of the genus Mimosa (Mimosoideae) in the United States, Mexico, and Central America. En: V Conferencia Internacional de Leguminosas (VILC). R. Fortunato (ed.). Fundación CICCUS. 224 p.

Grether, R., Martínez-Bernal A., Camargo-Ricalde S.L. 2007. Mimosa. En: Rzedowski J. y G. Calderón de Rzedowski (eds.). Flora del Bajío y de regiones adyacentes. Instituto. Ecología, Centro Regional del Bajío, México. Fascículo 150: 1-229. Grinnell, J. 1917. The niche-relationships of the California Thrasher. Auk 34: 427434. 
Guevara-Escobar, A., Gonzáles-Sosa E., Susán-Azpiri H., Malda-Barrera G., Martínez y Díaz M., Gómez-Sánchez M., Hernández-Sandoval L., PantojaHernández Y. y Olvera-Valerio D. 2008. Distribución potencial de algunas leguminosas arbustivas en el Altiplano Central de México. Agrociencia 42: 703716.

Harbert, R.S., Brown A.H. y Doyle J.J. 2014. Climate niche modeling in the perennial Glycine (Leguminosae) allopolyploid complex. American Journal of Botany 101: 710-721.

Hernandez, P.A., Graham C.H., Master L.L. y Albert D.L. 2006. The effect of sample size and species characteristics on performance of different species distribution modeling methods. Ecography 29: 773-785.

Hernández-Pérez, E., González-Espinosa M., Trejo I. y Bonfil C. 2011. Distribución del género Bursera en el estado de Morelos, México y su relación con el clima. Revista Mexicana de Biodiversidad 82: 964-976.

Herrera, C.A. 2012. Aplicación de tecnologías de información para modelar la distribución de plagas. Tesis de Maestría. Ciudad Universitaria Rodrigo Facio, Costa Rica. 61 p.

Hijmans, R.J., Cameron S.E., Parra J.L., Jones P.G. y Jarvis A. 2005. Very high resolution interpolated climate surfaces for global land areas. International Journal of Climatology 25: 1965-1978.

Hole, D.G., Willis S.G., Pain D.J., Fishpool L.D., Butchart S.H.M., Collingham Y.C., Rahbek C. y Huntley B. 2009. Projected impacts of climate change on a continent wide protected area network. Ecology Letters 12: 420-431. 
Hurtado, A.C. 2007. Uso de modelos de predicción como herramienta para estimar el área de distribución potencial de la especie Aniba perutilis Hemsley (comino crespo) en el Departamento del Valle del Cauca. Tesis de Licenciatura Facultad de Ciencias Naturales. Fundación Universitaria de Popayán. 72 p.

Hutchinson, G. E. 1957. A Treatise on Limnology. Volume I Geography, Physics, and Chemistry. Chapman and Hall. New York. 1015 p.

Hutchinson, G.E. 1944. Limnological studies in Connecticut. VII. A critical examination of the supposed relationship between phytoplakton periodicity and chemical changes in lake waters. Ecology 25: 3-26.

INEGI. 2005. Instituto Nacional de Geografía e Historia. Catálogo de claves de entidades federativas, municipios y localidades. http://geoweb.inegi.org.mx/mgn2k/catalogo.jsp

Jarvis, A., Yeamam S., Guarino L. y Tohme J. 2005. The role of geographic analysis in locating, understanding and using plant genetic diversity. Methods in enzymology 395: 279-298.

Jeschke, J.M. y Strayer D.L. 2008. Usefulness of bioclimatic models for studying climate change and invasive species. Annals of the New York Academy of Sciences 1134: 1-24.

Kumar, S. y Stohlgren T.J. 2009. Maxent modelling for predicting suitable habitat for threatened and endangered tree Canacomyrica monticola in New Caledonia. Journal of Ecology and Natural Environment 1: 94-98. 
Leathwick, J.R. 2001. New Zealand's potential forest pattern as predicted from current species-environment relationships. New Zealand Journal of Botany 39: 447-464.

Lindenmayer, D.B., Mackey B.G. y Nix H.A. 1996. The bioclimatic domains of four species of commercially important eucalypts from south-eastern Australia. Australian forestry 59: 74-89.

Lindenmayer, D.B., Nix H.A., Mcmahon J.P., Hutchinson M.F. y Tanton M.T. 1991. The conservation of Leadbeater's possum, Gymnobelideus leadbeateri (McCoy): a case study of the use of bioclimatic modeling. Journal of Biogeography 18: 371-383.

Lobo, J.M., Jiménez-Valverde A. y Real R. 2007. AUC: a misleading measure of the performance of predictive distribution models. Global Ecology and Biogeography 17: $145-151$.

Loiselle, B.A., Howell C.A., Graham C.H., Goerck J.M., Brooks T., Smith K.G. y Williams P.H. 2003. Avoiding pitfalls of using species distribution models in conservation planning. Conservation Biology 17: 1591-1600.

Lomolino, M.V., B.R. Riddle y J. H. Brown. 2005. Biogeography, 3a. edición. Sinauer. Sunderland, Massachusetts. 868 p.

Manel, S., Williams H.C. y Ormerod S.J. 2001. Evaluating presence-absence models in ecology: The need to account prevalence. Journal of Applied Ecology 38: $921-931$. 
Marini, M.Â., Barbet-Massin M., Martinez J., Prestes N.P. y Jiguet F. 2010. Applying ecological niche modelling to plan conservation actions for the Red-spectacled Amazon (Amazona pretrei). Biological Conservation 143: 102-112.

Marmion, M., Parviainen M., Luoto M., Heikkinen R.K. y Thuiller W. 2009. Evaluation of consensus methods in predictive species distribution modelling. Diversity and Distributions 15: 56-69.

Martínez-Bernal, A. y Grether R. 2006. Mimosa. En: Novelo A. y Medina-Lemus R. (eds.). Flora del Valle de Tehuacán-Cuicatlán. Fascículo 44. Instituto de Biología, Universidad Nacional Autónoma de México, México. 1-108 p.

Martínez-Pérez, G., Orozco-Segovia A. y Mantorell C. 2006. Efectividad de algunos tratamientos pre-germinativos para ocho especies leñosas de la Mixteca Alta Oaxaqueña con características relevantes para la restauración. Boletín de la Sociedad Botánica de México 79: 9-20.

Mateo, R.G. 2008. Modelos predictivos de riqueza de diversidad vegetal. Comparación y Optimización de Métodos de Modelado Ecológico. Tesis de Doctorado, Universidad Complutense de Madrid, España. 187 p.

Mateo, R.G., Croat T.B., Felicísimo A.M. y Muñoz J. 2010. Profile or group discriminative techniques? Generating reliable species distribution models using pseudo-absences and target-group absences from natural history collections. Diversity and Distributions 16: 84-94.

Mateo, R.G., Felicísimo M.A. y Muñoz J. 2011. Modelos de distribución de especies: Una revisión sintética. Revista Chilena de Historia Natural 84: 217-240. 
Maxted, N. y Kell S.P. 2009. Establishment of a Global Network for the In Situ Conservation of Crop Wild Relatives: Status and Needs. FAO Commission on Genetic Resources for Food and Agriculture, Rome, Italy. 266 p.

McPherson, J. M., Jetz W. y Rogers D.J. 2004. The effects of species' range sizes on the accuracy of distribution models: ecological phenomenon or statistical artifact? Journal of Applied Ecology 41: 811823.

Mezaour, A. 2005. Filtering Web Documents for a Thematic Warehouse Case Study: eDot a Food Risk Data Warehouse (extended) In: Intelligent information processing and web mining. Laboratoire de Recherche en Informatique (LRI), Université Paris Sud, France. 269-278 p.

Morales, S.N. 2012. Modelos de distribución de especies: Software Maxent y sus aplicaciones en conservación. Revista Conservación Ambiental 2: 1-5.

Naoki, K., Gómez M.I., López R.P., Meneses R.I. y Vargas J. 2006. Comparación de modelos de distribución de especies para predecir la distribución potencial de vida silvestre en Bolivia. Ecología en Bolivia 41: 65-78.

Ndayishimiye, J., Greve M., Stoffelen P., Bigendako M.J., De Cannière C., Svenning J.C. y Bogaert J. 2012. Modelling the spatial distribution of endemic Caesalpinioideae in Central Africa, a contribution to the evaluation of actual protected areas in the region. International Journal of Biodiversity and Conservation 4: 118-129.

Nix, H.A. 1986. A biogeographic analysis of Australian elapid snakes. In Atlas of elapid snakes of Australia. R. Longmore (ed.) Australia Government Publishing Service 4-16 $p$. 
Núñez-Colín, C.A. 2010. Distribución y caracterización eco-climática del membrillo cimarrón (Amelanchier denticulata (Kunth) Koch) en México. Revista Chapingo, Serie horticultura 16: 195-206.

Pacheco, S., Malizia L.R. y Cayuela L. 2010. Effects of climate change on subtropical forests of South America. Tropical Conservation Science 3: 423-437.

Palacios, R. 2010. Efectos del cambio climático sobre la distribución de nopales (género Opuntia y Nopalea: Cactaceae) en la región central de México. Tesis de Maestría. Instituto de Biología. Universidad Nacional Autónoma de México. 105 p.

Papeş, M. y Gaubert P. 2007. Modelling ecological niches from low numbers of occurrences: assessment of the conservation status of poorly known viverrids (Mammalia, Carnivora) across two continents. Diversity and Distributions 13: 890-902.

Parmesan, C. y Yohe G. 2003. A globally coherent fingerprint of climate change impacts across natural systems. Nature 421: 37-42.

Pavón, N.P., Ballato-Santos J. y Pérez-Pérez C. 2011. Germinación y establecimiento de Mimosa aculeaticarpa var. biuncifera (FabaceaeMimosoideae). Revista Mexicana de Biodiversidad 82: 653-661.

Pearce, J. y Ferrier S. 2001. The practical value of modelling relative abundance of species for regional conservation planning: a case study. Biological Conservation 98: 33-43.

Pearson, R.G., Raxworthy C.J., Nakamura M. y Townsend-Peterson A. 2006. Predicting species distributions from small numbers of occurrence records: a 
test case using cryptic geckos in Madagascar. Journal of Biogeography 34: 102117.

Peterson, A. T., Navarro-Sigüenza A.G. y Benítez-Díaz H. 1998. The need for continued scientific collecting; a geographic analysis of Mexican bird specimens. Ibis 140: 288-294.

Peterson, A.T. y Cohoon K.P. 1999. Sensitivity of distributional prediction algorithms to geographic data completeness. Ecological modelling 117: 159-164.

Peterson, A.T., Egbert S.L., Sánchez-Cordero V. y Price K.P. 2000. Geographic analysis of conservation priority: endemic birds and mammals in Veracruz, Mexico. Biological Conservation 93: 85-94.

Peterson, A.T., Soberón J., Pearson R.G., Anderson R.P., Martínez-Meyer E., Nakamura M., y Araújo M.B. 2011. Ecological Niches and Geographic Distributions. Princenton University Press. New Jersey. 314 p.

Peterson, A.T., Stockwell D.R.B. y Kluza D.A. 2002. Distributional prediction based on ecological niche modeling of primary occurrence data. In J.M. Scott, P.J. Heglund y M.L. Morrison (eds.), Predicting species occurrences: Issues of scale and accuracy. Island Press, Washington, D.C. 617-623 p.

Phillips, S.J. y Dudík M. 2008. Modeling of species distributions with MaxEnt: new extensions and a comprehensive evaluation. Ecography 31: 161-175.

Phillips, S.J., Anderson R.P., Schapire R.E. 2006. Maximum entropy modelling of species geographic distributions. Ecological Modelling 190: 231-259. 
Phillips, S.J., Dudík M. y Schapire R.E. 2004. A maximum entropy approach to species distribution modeling. In Proceedings of the twenty-first international conference on Machine learning. 83 p.

Phillips, S.J., Dudík M., Elith J., Graham C.H., Lehmann A., Leathwick J. y Ferrier S. 2009. Sample selection bias and presence-only distribution models: implications for background and pseudo-absence data. Ecological Applications 19: 181-197.

Ramírez-Villegas, J., Khoury C., Jarvis A., Debouck D.G. y Guarino L. 2010. A gap analysis methodology for collecting crop genepools: a case study with Phaseolus beans. PloS one 5: e13497.

Reguerín, L.J.M.I. 2012. Distribución potencial de especies de la familia Araliaceae de la región Madidi. Tesis de Licenciatura. Universidad Mayor de San Andrés, La Paz, Bolivia 131 p.

Riquelme, J.D. 2013. Técnicas para el análisis de patrones de uso del espacio en felinos americanos (Mammalia: Carnivora). Gestión Ambiental 25: 53-84.

Rodríguez-Ochoa, R., Alberdi J.R.O., Chocarro C., Martínez V. y Bilbao I. 2014. Autoecología y distribución potencial de la encina (Quercus ilex subsp. ballota (Desf.) Samp.) en la zona norte de Monegros. Revista Ecosistemas 23: 108115.

Rushton S.P., Ormerod S.J. y Kerby G. 2004. New paradigms for modelling species distributions? Journal of Applied Ecology 41: 193-200.

Rzedowski, J. 1991. Diversidad y orígenes de la flora fanerogámica de México. Acta Botánica Mexicana 14: 3-21. 
Schoener, T.W. 1989. Ecological Concepts: The Contribution of Ecology to an Understanding of the Natural World, ed Cherrett JM (Blackwell Scientific, Oxford). $79-113 \mathrm{p}$.

Soberón, J. y Peterson A.T. 2005. Interpretation of models of fundamental ecological niches and species' distributional areas. Biodiversity Informatics 2: 110.

Sokal, R. y Rohlf F. 1995. Biometry. Freeman and Company, San Francisco, C.A. $887 \mathrm{p}$.

Sosa, V. y Dávila P. 1994. Una evaluación del conocimiento florístico de México. Annals of the Missouri Botanical Garden 81: 749-757.

Sotuyo, S., Delgado-Salinas A., Lewis G.P., Chase M.W., Ferrari L. y Oyama K. 2010. Filogeografía del complejo Caesalpinia hintonii (Leguminosae: Caesalpinioideae: Poincianella). Revista Mexicana de Biodiversidad 81: 883894.

SPSS, 2012. IBM SPSS Statistics. Disponible en www.ibm.com.analytics/spss.

Stein, B.R. y Wieczorek J.R. 2004. Mammals of the world: MaNIS as an example of data integration in a distributed network environment. Biodiversity Informatics 1: $14-22$.

Stockwell, D. y Peters D. 1999. The GARP modeling system: problems and solutions to automated spatial prediction. International Journal of Geographical Information Science 13: 143-158.

Stockwell, D.R.B. y Peterson A.T. 2002. Effects of sample size on accuracy of species distribution models. Ecological Modelling 148: 1-13. 
Sunil, N., Sivaraj N., Anitha K., Abraham B., Kumar V., Sudhir E. y Varaprasad K.S. 2009. Analysis of diversity and distribution of Jatropha curcas L. germplasm using Geographic Information System (DIVA-GIS). Genetic resources and crop evolution 56: 115-119.

Téllez-Valdés, O. y Dávila-Aranda P. 2003 Protected areas and climate change: a case study of the cacti in the Tehuacán-Cuicatlán Biosphere Reserve, México. Conservation Biology 17: 846-853.

Thomas, C.D., Cameron A., Green R.E., Bakkenes M., Beaumont L.J., Collingham Y.C., Erasmus B.F.N., de Siqueira M.F., Grainger A., Hannah L., Hughes L., Huntley B., van Jaarsveld A.S., Midgley G.F., Miles L., Ortega-Huerta M.A., Peterson A.T., Phillips O.L. y Williams S.E. 2004. Extinction risk from climate change. Nature 427: 145-148.

Thuiller, W., Albert C., Araujo M.B., Berry P.M., Cabeza M., Guisan A., Hickler T., Midgely G.F., Paterson J., Schurr F.M., Sykes M.T. y Zimmermann N.E. 2008. Predicting global change impacts on plant species' distributions: future challenges. Perspectives in Plant Ecology, Evolution and Systematics 9: 137152.

Trejo, I., Martínez-Meyer E., Calixto-Pérez E., Colón-Sánchez S., Vázquez de la Torre R. y Villers-Ruiz L. 2011. Analysis of the effects of climate change on plant communities and mammals in Mexico. Atmósfera 24: 1-14.

Trotta-Moreu, M.N., Lobo J.M. y Cabrero-Sañudo F.J. 2008. Distribución conocida y potencial de las especies de Geotrupinae (Coleoptera: Scarabaeoidea) en México. Acta Zoológica Mexicana 24: 39-65. 
Tsoar, A., Allouche O., Steinitz O., Rotem D. y Kadmon R. 2007. A comparative evaluation of presence-only methods for modelling species distribution. Diversity and Distributions 13: 397-405.

Villaseñor, J.L. y Téllez-Valdez O. 2004. Distribución potencial de las especies del género Jefea (Asteraceae) en México. Anales del Instituto de Biología, Serie Botánica 75: 205-220.

Wisz, M.S., Hijmans R.J., Li J., Peterson A.T., Graham C.H. y Guisan A. 2008. Effects of sample size on the performance of species distribution models. Diversity and Distributions 14: 763-773.

WorldClim. Data for current conditions ( 1950-2000). Disponible en http://www.worldclim.org/current.

Yberri, F.G. 2009. Distribución geográfica de Nopalxochia phyllanthoides (DC) Britton et Rose (Cactaceae): Modelos predictivos y conservación. Tesis de Licenciatura., Facultad de Ciencias, Universidad Nacional Autónoma de México, México DF. 64 p.

Zaniewski, A.E., Lehmann A. y Overton J.M. 2002. Predicting species spatial distributions using presence-only data: a case study of native New Zealand ferns. Ecological modelling 157: 261-280. 
Respuestas ecoanatómicas y ecofisiológicas de dos especies del género Mimosa (Leguminosae) ante el cambio climático

\section{ANEXOS}


Respuestas ecoanatómicas y ecofisiológicas de dos especies del género Mimosa (Leguminosae) ante el cambio climático

Anexo 1. Tipos de climas en los que se distribuye Mimosa aculeaticarpa var. aculeaticarpa en el territorio mexicano (continúa).

\begin{tabular}{|c|c|c|c|c|}
\hline Clima & Características & Precipitación & Abreviatura & No. de registros \\
\hline Mésico & $\begin{array}{c}\text { Semicálido-subhúmedo, temperatura media anual mayor de } \\
18^{\circ} \mathrm{C} \text {, temperatura del mes más frío menor de } 18^{\circ} \mathrm{C} \text {, } \\
\text { temperatura del mes más caliente mayor de } 22^{\circ} \mathrm{C} \text {. }\end{array}$ & $\begin{array}{l}\text { En el mes más seco es menor a } 40 \mathrm{~mm} \text {; } \\
\text { Iluvias de verano, porcentaje de lluvia invernal } \\
\text { mayor al } 10.2 \% \text { del total anual. }\end{array}$ & $(A) C(w o) x^{\prime}$ & 1 \\
\hline \multirow{4}{*}{ Semiárido } & $\begin{array}{l}\text { Semiárido, semicálido, temperatura media anual mayor de } \\
18^{\circ} \mathrm{C} \text {, temperatura del mes más frio menor de } 18^{\circ} \mathrm{C} \text {, } \\
\text { temperatura del mes más caliente mayor de } 22^{\circ} \mathrm{C} \text {. }\end{array}$ & $\begin{array}{l}\text { Lluvias repartidas todo el año y porcentaje de } \\
\text { Iluvia invernal mayor al } 18 \% \text { del total anual. }\end{array}$ & $\operatorname{BS} 1 \mathrm{~h}\left(\mathrm{x}^{\prime}\right)$ & 2 \\
\hline & $\begin{array}{l}\text { Semiárido, semifrío, temperatura del mes más frio entre }-3^{\circ} \mathrm{C} \\
\text { y } 18^{\circ} \mathrm{C} \text {, temperatura del mes más caliente menor de } 22^{\circ} \mathrm{C} \text {. }\end{array}$ & $\begin{array}{l}\text { Lluvias de verano y porcentaje de lluvia } \\
\text { invernal mayor al } 18 \% \text { del total anual. }\end{array}$ & BS1k"w & 3 \\
\hline & $\begin{array}{c}\text { Semiárido, templado, temperatura media anual entre } 12^{\circ} \mathrm{Cy} \\
18^{\circ} \mathrm{C} \text {, temperatura del mes más frio entre } 3 \text { y } 18^{\circ} \mathrm{C} \\
\text { temperatura del mes más caliente menor de } 22^{\circ} \mathrm{C} \text {. }\end{array}$ & $\begin{array}{l}\text { Lluvias de verano y porcentaje de lluvia } \\
\text { invernal mayor al } 18 \% \text { del total anual. }\end{array}$ & $B S 1 k\left(x^{\prime}\right)$ & 24 \\
\hline & $\begin{array}{l}\text { Semiárido, templado, temperatura media anual entre } 12^{\circ} \mathrm{C} \text { y } \\
18^{\circ} \mathrm{C} \text {, temperatura del mes más frio entre }-3^{\circ} \mathrm{C} \text { y } 18^{\circ} \mathrm{C} \text {, } \\
\text { temperatura del mes más caliente menor de } 22^{\circ} \mathrm{C} \text {. }\end{array}$ & $\begin{array}{l}\text { Lluvias de verano y porcentaje de lluvia } \\
\text { invernal del } 5 \% \text { a } 10.2 \% \text { del total anual. }\end{array}$ & BS1kw & 2 \\
\hline \multirow{7}{*}{ Árido } & $\begin{array}{l}\text { Árido, semicálido, temperatura media anual mayor de } 18^{\circ} \mathrm{C} \text {, } \\
\text { temperatura del mes más frio menor de } 18^{\circ} \mathrm{C} \text {, temperatura } \\
\text { del mes más caliente mayor de } 22^{\circ} \mathrm{C} \text {. }\end{array}$ & $\begin{array}{l}\text { Lluvias de invierno, el porcentaje de lluvia } \\
\text { invernal es mayor del } 36 \% \text { del total anual. }\end{array}$ & BShs & 1 \\
\hline & $\begin{array}{l}\text { Árido, templado, temperatura media anual entre } 12^{\circ} \mathrm{C} \text { y } \\
18^{\circ} \mathrm{C} \text {, temperatura del mes más frio entre }-3^{\circ} \text { y } 18^{\circ} \mathrm{C} \text {, } \\
\text { temperatura del mes más caliente menor de } 22^{\circ} \mathrm{C} \text {. }\end{array}$ & $\begin{array}{l}\text { Lluvias de invierno, el porcentaje de lluvia } \\
\text { invernal es mayor del } 36 \% \text { del total anual. }\end{array}$ & BSks & 4 \\
\hline & $\begin{array}{l}\text { Árido, cálido, temperatura media anual mayor de } 22^{\circ} \mathrm{C} \text {, } \\
\text { temperatura del mes más frio mayor de } 18^{\circ} \mathrm{C} \text {. }\end{array}$ & $\begin{array}{l}\text { Lluvias repartidas todo el año, y porcentaje de } \\
\text { lluvia invernal mayor al } 18 \% \text { del total anual. }\end{array}$ & $\mathrm{BSo}\left(\mathrm{h}^{\prime}\right)\left(\mathrm{x}^{\prime}\right)$ & 2 \\
\hline & $\begin{array}{c}\text { Árido, semicálido, temperatura entre } 18^{\circ} \mathrm{C} \text { y } 22^{\circ} \mathrm{C} \text {, } \\
\text { temperatura del mes más frio menor de } 18^{\circ} \mathrm{C} \text {, temperatura } \\
\text { del mes más caliente mayor de } 22^{\circ} \mathrm{C} \text {. }\end{array}$ & $\begin{array}{l}\text { Lluvias repartidas todo el año y porcentaje de } \\
\text { lluvia invernal del } 5 \text { al } 10.2 \% \text { del total anual. }\end{array}$ & $\operatorname{BSoh}\left(x^{\prime}\right)$ & 5 \\
\hline & $\begin{array}{c}\text { Árido, semicálido, temperatura entre } 18^{\circ} \mathrm{C} \text { y } 22^{\circ} \mathrm{C} \text {, } \\
\text { temperatura del mes más frio menor de } 18^{\circ} \mathrm{C} \text {, temperatura } \\
\text { del mes más caliente mayor de } 22^{\circ} \mathrm{C} \text {. }\end{array}$ & $\begin{array}{l}\text { Lluvias de verano y porcentaje de lluvia } \\
\text { invernal del } 5 \% \text { al } 10.2 \% \text { del total anual. }\end{array}$ & BSohw & 2 \\
\hline & $\begin{array}{l}\text { Árido, semifrío, temperatura media anual entre } 5^{\circ} \mathrm{C} \text { y } 12^{\circ} \mathrm{C} \text { y } \\
\text { temperatura del mes más frio entre }-13^{\circ} \mathrm{C} \text { y } 18^{\circ} \mathrm{C} \text {. }\end{array}$ & $\begin{array}{l}\text { Lluvias de verano y porcentaje de lluvia } \\
\text { invernal del } 5 \% \text { al } 10.2 \% \text { del total anual. }\end{array}$ & BSok"w & 2 \\
\hline & $\begin{array}{l}\text { Árido, templado, temperatura entre } 12^{\circ} \mathrm{C} \text { y } 18^{\circ} \mathrm{C} \text {, } \\
\text { temperatura del mes más frio entre }-^{\circ} \mathrm{C} \text { y } 18^{\circ} \mathrm{C} \text {, }\end{array}$ & Lluvias repartidas todo el año y porcentaje de & BSok $\left(x^{\prime}\right)$ & 6 \\
\hline
\end{tabular}


Respuestas ecoanatómicas y ecofisiológicas de dos especies del género Mimosa (Leguminosae) ante el cambio climático

Anexo 1. Continuación...

\begin{tabular}{|c|c|c|c|c|}
\hline Clima & Características & Precipitación & Abreviatura & No. de registros \\
\hline \multirow{8}{*}{ Árido } & $\begin{array}{l}\text { Árido, templado, temperatura media anual entre } 12^{\circ} \mathrm{C} \text { y } \\
18^{\circ} \mathrm{C} \text {, temperatura del mes más frio entre }-3^{\circ} \mathrm{C} \text { y } 18^{\circ} \mathrm{C} \text {. }\end{array}$ & $\begin{array}{l}\text { Lluvias de verano, porcentaje de lluvia invernal } \\
\text { entre } 5 \% \text { y } 10.2 \% \text { del total anual. }\end{array}$ & BSokw & 8 \\
\hline & $\begin{array}{l}\text { Muy árido, cálido, temperatura media anual mayor de } 22^{\circ} \mathrm{C} \text {, } \\
\text { temperatura del mes más frio mayor de } 18^{\circ} \mathrm{C} \text {. }\end{array}$ & $\begin{array}{l}\text { Lluvias repartidas todo el año y porcentaje de } \\
\text { lluvia invernal mayor al } 18 \% \text { del total anual. }\end{array}$ & $\mathrm{BW}\left(\mathrm{h}^{\prime}\right)\left(\mathrm{x}^{\prime}\right)$ & 5 \\
\hline & $\begin{array}{l}\text { Muy árido, semicálido, temperatura media anual entre } 18^{\circ} \text { y } \\
22^{\circ} \mathrm{C} \text {, temperatura del mes más frio menor de } 18^{\circ} \mathrm{C} \text {, } \\
\text { temperatura del mes más caliente mayor de } 22^{\circ} \mathrm{C} \text {. }\end{array}$ & $\begin{array}{l}\text { Lluvias repartidas todo el año y porcentaje de } \\
\text { lluvia invernal mayor al } 18 \% \text { del total anual. }\end{array}$ & $\mathrm{BWh}\left(\mathrm{x}^{\prime}\right)$ & 6 \\
\hline & $\begin{array}{l}\text { Muy árido, semicálido, temperatura media anual entre } 18^{\circ} \mathrm{C} \\
\text { y } 22^{\circ} \mathrm{C} \text {, temperatura del mes más frío menor de } 18^{\circ} \mathrm{C} \text {, } \\
\text { temperatura del mes más caliente mayor de } 22^{\circ} \mathrm{C} \text {. }\end{array}$ & $\begin{array}{l}\text { Lluvias de invierno y precipitación invernal } \\
\text { mayor al } 36 \% \text { del total anual. }\end{array}$ & BWhs & 3 \\
\hline & $\begin{array}{l}\text { Muy árido, semicálido, temperatura media anual entre } 18^{\circ} \mathrm{C} \\
\text { y } 22^{\circ} \mathrm{C} \text {, temperatura del mes más frío menor de } 18^{\circ} \mathrm{C} \text {, } \\
\text { temperatura del mes más caliente mayor de } 22^{\circ} \mathrm{C} \text {. }\end{array}$ & $\begin{array}{l}\text { Lluvias de verano y porcentaje de lluvia } \\
\text { invernal del } 5 \% \text { al } 10.2 \% \text { del total anual. }\end{array}$ & BWhw & 2 \\
\hline & $\begin{array}{l}\text { Muy árido, templado, temperatura media anual entre } 12^{\circ} \mathrm{C} \text { y } \\
18^{\circ} \mathrm{C} \text {, temperatura del mes más frío entre }-3^{\circ} \mathrm{C} \text { y } 18^{\circ} \mathrm{C} \text {, } \\
\text { temperatura del mes más caliente menor de } 22^{\circ} \mathrm{C} \text {. }\end{array}$ & $\begin{array}{l}\text { Lluvias repartidas todo el año y precipitación } \\
\text { invernal mayor al } 18 \% \text { del total anual. }\end{array}$ & $B W k\left(x^{\prime}\right)$ & 2 \\
\hline & $\begin{array}{l}\text { Muy árido, templado, temperatura media anual entre } 12^{\circ} \mathrm{C} \text { y } \\
18^{\circ} \mathrm{C} \text {, temperatura del mes más frío entre }-3^{\circ} \mathrm{C} \text { y } 18^{\circ} \mathrm{C} \text {, } \\
\text { temperatura del mes más caliente menor de } 22^{\circ} \mathrm{C} \text {. }\end{array}$ & $\begin{array}{l}\text { Lluvias de invierno y porcentaje de lluvia } \\
\text { invernal mayor al } 36 \% \text { del total anual. }\end{array}$ & BWks & 3 \\
\hline & $\begin{array}{l}\text { Muy árido, templado, temperatura media anual entre } 12^{\circ} \mathrm{C} \text { y } \\
18^{\circ} \mathrm{C} \text {, temperatura del mes más frío entre }-3^{\circ} \mathrm{C} \text { y } 18^{\circ} \mathrm{C} \text {, } \\
\text { temperatura del mes más caliente menor de } 22^{\circ} \mathrm{C} \text {. }\end{array}$ & $\begin{array}{l}\text { Lluvias de verano y porcentaje de lluvia } \\
\text { invernal del } 5 \% \text { al } 10.2 \% \text { del total anual. }\end{array}$ & BWkw & 1 \\
\hline \multirow{3}{*}{ Templado } & $\begin{array}{l}\text { Templado, subhúmedo, temperatura media anual entre } 12^{\circ} \mathrm{C} \\
\text { y } 18^{\circ} \mathrm{C} \text {, temperatura del mes más frío entre }-3^{\circ} \mathrm{C} \text { y } 18^{\circ} \mathrm{C} \text { y } \\
\text { temperatura del mes más caliente bajo } 22^{\circ} \mathrm{C} \text {. }\end{array}$ & $\begin{array}{l}\text { Precipitación en el mes más seco menor de } 40 \\
\text { mm; lluvias de verano y porcentaje de lluvia } \\
\text { invernal mayor al } 10.2 \% \text { del total anual. }\end{array}$ & $C(w 1) x^{\prime}$ & 2 \\
\hline & $\begin{array}{l}\text { Templado, subhúmedo, temperatura media anual entre } 12^{\circ} \mathrm{C} \\
\text { y } 18^{\circ} \mathrm{C} \text {, temperatura del mes más frío entre }-3^{\circ} \mathrm{C} \text { y } 18^{\circ} \mathrm{C} \text { y } \\
\text { temperatura del mes más caliente bajo } 22^{\circ} \mathrm{C} \text {. }\end{array}$ & $\begin{array}{l}\text { Precipitación en el mes más seco menor de } 40 \\
\text { mm; lluvias en verano y porcentaje de lluvia } \\
\text { invernal mayor al } 10.2 \% \text { del total anual. }\end{array}$ & $C($ wo $) x^{\prime}$ & 5 \\
\hline & $\begin{array}{l}\text { Semifrío, subhúmedo con verano fresco largo, temperatura } \\
\text { media anual entre } 5^{\circ} \mathrm{C} \text { y } 12^{\circ} \mathrm{C} \text {, temperatura del mes más frío } \\
\text { entre }-^{\circ} \mathrm{C} \text { y } 18^{\circ} \mathrm{C} \text {, temperatura del mes más caliente bajo } \\
22^{\circ} \mathrm{C} \text {. }\end{array}$ & $\begin{array}{l}\text { Precipitación en el mes más seco menor de } 40 \\
\text { mm; lluvias de verano y porcentaje de lluvia } \\
\text { invernal mayor al } 10.2 \% \text { del total anual. }\end{array}$ & $\mathrm{Cb}^{\prime}(\mathrm{w} 1) \mathrm{x}^{\prime}$ & 1 \\
\hline
\end{tabular}


Respuestas ecoanatómicas y ecofisiológicas de dos especies del género Mimosa (Leguminosae) ante el cambio climático

Anexo 1. Continuación...

\begin{tabular}{|c|c|c|c|c|}
\hline Clima & Características & Precipitación & Abreviatura & No. de registros \\
\hline \multirow[b]{2}{*}{ Templado } & $\begin{array}{l}\text { Semifrío, subhúmedo con verano fresco largo, temperatura } \\
\text { media anual entre } 5^{\circ} \mathrm{C} \text { y } 12^{\circ} \mathrm{C} \text {, temperatura del mes más frío } \\
\text { entre }-^{\circ} \mathrm{C} \text { y } 18^{\circ} \mathrm{C} \text {, temperatura del mes más caliente bajo } \\
22^{\circ} \mathrm{C} \text {. }\end{array}$ & $\begin{array}{l}\text { Precipitación en el mes más seco menor de } 40 \\
\text { mm; lluvias de verano y porcentaje de lluvia } \\
\text { invernal mayor al } 10.2 \% \text { del total anual. }\end{array}$ & $\mathrm{Cb}^{\prime}(\mathrm{w} 2) \mathrm{x}^{\prime}$ & 2 \\
\hline & $\begin{array}{c}\text { Semifrío, subhúmedo con verano fresco largo, temperatura } \\
\text { media anual entre } 5^{\circ} \mathrm{C} \text { y } 12^{\circ} \mathrm{C} \text {, temperatura del mes más frío } \\
\text { entre }-^{\circ} \mathrm{C} \text { y } 18^{\circ} \mathrm{C} \text {, temperatura del mes más caliente bajo } \\
22^{\circ} \mathrm{C} \text {. }\end{array}$ & $\begin{array}{l}\text { Lluvias de invierno, con porcentaje de lluvia } \\
\text { invernal mayor del } 36 \% \text { del total anual. }\end{array}$ & Cb's & 4 \\
\hline
\end{tabular}


Anexo 2. Tipos de climas en los que se distribuye Mimosa luisana en el territorio mexicano (continúa).

\begin{tabular}{|c|c|c|c|c|}
\hline Clima & Características & Precipitación & Abreviatura & No. de registros \\
\hline \multirow{5}{*}{ Semiárido } & $\begin{array}{l}\text { Semiárido, semicálido, temperatura media anual mayor de } \\
18^{\circ} \mathrm{C} \text {, temperatura del mes más frío menor de } 18^{\circ} \mathrm{C} \text {, } \\
\text { temperatura del mes más caliente mayor de } 22^{\circ} \mathrm{C} \text {. }\end{array}$ & $\begin{array}{l}\text { Lluvias repartidas todo el año y porcentaje de } \\
\text { lluvia invernal mayor al } 18 \% \text { del total anual. }\end{array}$ & $\operatorname{BS} 1 \mathrm{~h}\left(\mathrm{x}^{\prime}\right)$ & 2 \\
\hline & $\begin{array}{l}\text { Semiárido, templado, temperatura media anual entre } 12^{\circ} \mathrm{Cy} \\
18^{\circ} \mathrm{C} \text {, temperatura del mes más frío entre } 3 \text { y } 18^{\circ} \mathrm{C} \text {, } \\
\text { temperatura del mes más caliente menor de } 22^{\circ} \mathrm{C} \text {. }\end{array}$ & $\begin{array}{l}\text { Lluvias de verano y porcentaje de lluvia } \\
\text { invernal mayor al } 18 \% \text { del total anual. }\end{array}$ & BS1k $\left(x^{\prime}\right)$ & 3 \\
\hline & $\begin{array}{l}\text { Semiárido, templado, temperatura media anual entre } 12^{\circ} \mathrm{C} \text { y } \\
18^{\circ} \mathrm{C} \text {, temperatura del mes más frío entre }-3^{\circ} \mathrm{C} \text { y } 18^{\circ} \mathrm{C} \text {, } \\
\text { temperatura del mes más caliente menor de } 22^{\circ} \mathrm{C} \text {. }\end{array}$ & $\begin{array}{l}\text { Lluvias de verano y porcentaje de lluvia } \\
\text { invernal del } 5 \% \text { a } 10.2 \% \text { del total anual. }\end{array}$ & BS1kw & 6 \\
\hline & $\begin{array}{l}\text { Árido, semicálido, temperatura media anual mayor de } 18^{\circ} \mathrm{C} \text {, } \\
\text { temperatura del mes más frío menor de } 18^{\circ} \mathrm{C} \text {, temperatura } \\
\text { del mes más caliente mayor de } 22^{\circ} \mathrm{C} \text {. }\end{array}$ & $\begin{array}{l}\text { Lluvias de invierno, el porcentaje de lluvia } \\
\text { invernal es mayor del } 36 \% \text { del total anual. }\end{array}$ & BShs & 2 \\
\hline & $\begin{array}{l}\text { Árido, templado, temperatura media anual entre } 12^{\circ} \mathrm{C} \text { y } \\
18^{\circ} \mathrm{C} \text {, temperatura del mes más frío entre }-3^{\circ} \text { y } 18^{\circ} \mathrm{C} \text {, } \\
\text { temperatura del mes más caliente menor de } 22^{\circ} \mathrm{C} \text {. }\end{array}$ & $\begin{array}{l}\text { Lluvias de invierno, el porcentaje de lluvia } \\
\text { invernal es mayor del } 36 \% \text { del total anual. }\end{array}$ & BSks & 4 \\
\hline \multirow{7}{*}{ Árido } & $\begin{array}{l}\text { Árido, semicálido, temperatura entre } 18^{\circ} \mathrm{C} \text { y } 22^{\circ} \mathrm{C} \text {, } \\
\text { temperatura del mes más frío menor de } 18^{\circ} \mathrm{C} \text {, temperatura } \\
\text { del mes más caliente mayor de } 22^{\circ} \mathrm{C} \text {. }\end{array}$ & $\begin{array}{l}\text { Lluvias repartidas todo el año y porcentaje de } \\
\text { lluvia invernal del } 5 \text { al } 10.2 \% \text { del total anual. }\end{array}$ & BSoh $\left(x^{\prime}\right)$ & 3 \\
\hline & $\begin{array}{l}\text { Árido, semifrío, temperatura media anual entre } 5^{\circ} \mathrm{C} \text { y } 12^{\circ} \text { C y } \\
\text { temperatura del mes más frío entre }-13^{\circ} \mathrm{C} \text { y } 18^{\circ} \mathrm{C} \text {. }\end{array}$ & $\begin{array}{l}\text { Lluvias de verano y porcentaje de Iluvia } \\
\text { invernal del } 5 \% \text { al } 10.2 \% \text { del total anual. }\end{array}$ & BSok"w & 2 \\
\hline & 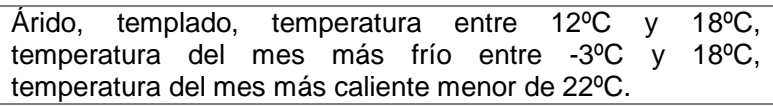 & $\begin{array}{l}\text { Lluvias repartidas todo el año y porcentaje de } \\
\text { lluvia invernal mayor al } 18 \% \text { del total anual. }\end{array}$ & BSok(x') & 5 \\
\hline & $\begin{array}{l}\text { Árido, templado, temperatura media anual entre } 12^{\circ} \mathrm{C} \text { y } \\
18^{\circ} \mathrm{C} \text {, temperatura del mes más frío entre }-3^{\circ} \mathrm{C} \text { y } 18^{\circ} \mathrm{C} .\end{array}$ & $\begin{array}{l}\text { Lluvias de verano, porcentaje de lluvia invernal } \\
\text { entre } 5 \% \text { y } 10.2 \% \text { del total anual. }\end{array}$ & BSokw & 7 \\
\hline & $\begin{array}{l}\text { Muy árido, cálido, temperatura media anual mayor de } 22^{\circ} \mathrm{C} \text {, } \\
\text { temperatura del mes más frío mayor de } 18^{\circ} \mathrm{C} \text {. }\end{array}$ & $\begin{array}{l}\text { Lluvias repartidas todo el año y porcentaje de } \\
\text { lluvia invernal mayor al } 18 \% \text { del total anual. }\end{array}$ & $B W\left(h^{\prime}\right)\left(x^{\prime}\right)$ & 2 \\
\hline & $\begin{array}{l}\text { Muy árido, semicálido, temperatura media anual entre } 18^{\circ} \text { y } \\
22^{\circ} \mathrm{C} \text {, temperatura del mes más frío menor de } 18^{\circ} \mathrm{C} \text {, } \\
\text { temperatura del mes más caliente mayor de } 22^{\circ} \mathrm{C} \text {. }\end{array}$ & $\begin{array}{l}\text { Lluvias repartidas todo el año y porcentaje de } \\
\text { lluvia invernal mayor al } 18 \% \text { del total anual. }\end{array}$ & $\mathrm{BWh}\left(\mathrm{x}^{\prime}\right)$ & 4 \\
\hline & $\begin{array}{l}\text { Muy árido, semicálido, temperatura media anual entre } 18^{\circ} \mathrm{C} \\
\text { y } 22^{\circ} \mathrm{C} \text {, temperatura del mes más frío menor de } 18^{\circ} \mathrm{C} \text {, } \\
\text { temperatura del mes más caliente mayor de } 22^{\circ} \mathrm{C} \text {. }\end{array}$ & $\begin{array}{l}\text { Lluvias de invierno y precipitación invernal } \\
\text { mayor al } 36 \% \text { del total anual. }\end{array}$ & BWhs & 2 \\
\hline
\end{tabular}


Respuestas ecoanatómicas y ecofisiológicas de dos especies del género Mimosa (Leguminosae) ante el cambio climático

Anexo 2. Continuación...

\begin{tabular}{|c|c|c|c|c|}
\hline Clima & Características & Precipitación & Abreviatura & No. de registros \\
\hline \multirow{4}{*}{ Árido } & $\begin{array}{l}\text { Muy árido, semicálido, temperatura media anual entre } 18^{\circ} \mathrm{C} \\
\text { y } 22^{\circ} \mathrm{C} \text {, temperatura del mes más frío menor de } 18^{\circ} \mathrm{C} \text {, } \\
\text { temperatura del mes más caliente mayor de } 22^{\circ} \mathrm{C} \text {. }\end{array}$ & $\begin{array}{l}\text { Lluvias de verano y porcentaje de lluvia } \\
\text { invernal del } 5 \% \text { al } 10.2 \% \text { del total anual. }\end{array}$ & BWhw & 2 \\
\hline & $\begin{array}{l}\text { Muy árido, templado, temperatura media anual entre } 12^{\circ} \mathrm{C} \text { y } \\
18^{\circ} \mathrm{C} \text {, temperatura del mes más frío entre }-3^{\circ} \mathrm{C} \text { y } 18^{\circ} \mathrm{C} \text {, } \\
\text { temperatura del mes más caliente menor de } 22^{\circ} \mathrm{C} \text {. }\end{array}$ & $\begin{array}{l}\text { Lluvias repartidas todo el año y precipitación } \\
\text { invernal mayor al } 18 \% \text { del total anual. }\end{array}$ & BWk(x') & 2 \\
\hline & $\begin{array}{l}\text { Muy árido, templado, temperatura media anual entre } 12^{\circ} \mathrm{C} \text { y } \\
18^{\circ} \mathrm{C} \text {, temperatura del mes más frío entre }-3^{\circ} \mathrm{C} \text { y } 18^{\circ} \mathrm{C} \text {, } \\
\text { temperatura del mes más caliente menor de } 22^{\circ} \mathrm{C} \text {. }\end{array}$ & $\begin{array}{l}\text { Lluvias de invierno y porcentaje de lluvia } \\
\text { invernal mayor al } 36 \% \text { del total anual. }\end{array}$ & BWks & 2 \\
\hline & $\begin{array}{l}\text { Muy árido, templado, temperatura media anual entre } 12^{\circ} \mathrm{C} \text { y } \\
18^{\circ} \mathrm{C} \text {, temperatura del mes más frío entre }-3^{\circ} \mathrm{C} \text { y } 18^{\circ} \mathrm{C} \text {, } \\
\text { temperatura del mes más caliente menor de } 22^{\circ} \mathrm{C} \text {. }\end{array}$ & $\begin{array}{l}\text { Lluvias de verano y porcentaje de lluvia } \\
\text { invernal del } 5 \% \text { al } 10.2 \% \text { del total anual. }\end{array}$ & BWkw & 2 \\
\hline
\end{tabular}


Anexo 3. Perfil bioclimático de Mimosa aculeaticarpa var. aculeaticarpa.

\begin{tabular}{|c|c|c|c|c|c|c|}
\hline Abreviatura & Variables ambientales & $\begin{array}{c}\text { Número } \\
\text { de } \\
\text { localidades } \\
\text { únicas }\end{array}$ & Media & Mínimo & Máximo & $\begin{array}{l}\text { Desviación } \\
\text { Estándar }\end{array}$ \\
\hline EDT & Estacionalidad de la temperatura & 94 & 0.7 & 0.4 & 1.3 & 0.3 \\
\hline EP & Estacionalidad de la precipitación & 94 & 89.3 & 73.0 & 107 & 10.0 \\
\hline ISO & Isotermalidad & 94 & 0.7 & 0.6 & 0.7 & 0.1 \\
\hline OAT & Oscilación anual de la temperatura & 94 & 22.5 & 17.7 & 29.3 & 3.0 \\
\hline ODT & Oscilación diurna de la temperatura & 94 & 14.7 & 10.2 & 17.8 & 1.9 \\
\hline PA & Precipitación anual & 94 & 959.0 & 479.0 & 3204 & 705.5 \\
\hline PCC & Precipitación del cuatrimestre más cálido & 94 & 289.5 & 166.0 & 873 & 168.4 \\
\hline PCF & Precipitación del cuatrimestre más frío & 94 & 54.8 & 19.0 & 251 & 62.4 \\
\hline PCLL & Precipitación del cuatrimestre más lluvioso & 94 & 525.0 & 276.0 & 1739 & 392.6 \\
\hline PCS & Precipitación del cuatrimestre más seco & 94 & 38.2 & 0.0 & 194 & 49.6 \\
\hline PPLL & Precipitación del período más lluvioso & 94 & 50.9 & 26.0 & 172 & 37.7 \\
\hline PPS & Precipitación del período más seco & 94 & 0.7 & 0.0 & 13 & 3.0 \\
\hline TCC & $\begin{array}{l}\text { Temperatura promedio del cuatrimestre más } \\
\text { cálido }\end{array}$ & 94 & 20.2 & 16.1 & 27.2 & 2.8 \\
\hline TMPPC & $\begin{array}{l}\text { Temperatura promedio del cuatrimestre más } \\
\text { cálido }\end{array}$ & 94 & 28.9 & 24.9 & 34.6 & 2.4 \\
\hline TPA & Temperatura promedio anual & 94 & 17.9 & 14.0 & 24.6 & 2.6 \\
\hline TPCF & Temperatura promedio del cuatrimestre más frío & 94 & 15.0 & 11.6 & 21.3 & 2.7 \\
\hline TPCLL & $\begin{array}{l}\text { Temperatura promedio del cuatrimestre más } \\
\text { lluvioso }\end{array}$ & 94 & 19.2 & 14.9 & 26.2 & 2.7 \\
\hline TPCS & $\begin{array}{l}\text { Temperatura promedio del cuatrimestre más } \\
\text { seco }\end{array}$ & 94 & 16.2 & 11.7 & 23.6 & 3.1 \\
\hline TPPF & $\begin{array}{c}\text { Temperatura mínima promedio del período más } \\
\text { frío }\end{array}$ & 94 & 6.4 & 1.7 & 15.4 & 3.8 \\
\hline
\end{tabular}


Respuestas ecoanatómicas y ecofisiológicas de dos especies del género Mimosa (Leguminosae) ante el cambio climático

Anexo 4. Correlación de Pearson entre las 19 variables climáticas en las que se desarrolla M. aculeaticarpa var. aculeaticarpa (continúa).

\begin{tabular}{|c|c|c|c|c|c|c|c|c|c|c|c|c|c|c|c|c|c|c|c|c|}
\hline & & EDT & EP & ISO & OAT & ODT & PA & PCC & PCF & PCLL & PCS & PPLL & PPS & TCC & TMPPC & TPA & TPCF & TPCLL & TPCS & TPPF \\
\hline \multirow[t]{2}{*}{ EDT } & Pearson & 1 & & & & & & & & & & & & & & & & & & \\
\hline & $\mathrm{P}$ & & & & & & & & & & & & & & & & & & & \\
\hline \multirow[t]{2}{*}{ EP } & Pearson & -.156 & 1 & & & & & & & & & & & & & & & & & \\
\hline & $P$ & .134 & & & & & & & & & & & & & & & & & & \\
\hline \multirow[t]{2}{*}{ ISO } & Pearson & $-.682^{* *}$ & .199 & 1 & & & & & & & & & & & & & & & & \\
\hline & $\mathrm{P}$ & .000 & .054 & & & & & & & & & & & & & & & & & \\
\hline \multirow[t]{2}{*}{ OAT } & Pearson & $.771^{* *}$ & .128 & -.178 & 1 & & & & & & & & & & & & & & & \\
\hline & $P$ & .000 & .219 & .087 & & & & & & & & & & & & & & & & \\
\hline \multirow[t]{2}{*}{ ODT } & Pearson & $.410^{* *}$ & $.205^{*}$ & $.301^{* *}$ & $.881^{* *}$ & 1 & & & & & & & & & & & & & & \\
\hline & $\mathrm{P}$ & .000 & .047 & .003 & .000 & & & & & & & & & & & & & & & \\
\hline \multirow[t]{2}{*}{ PA } & Pearson & $-.354^{* *}$ & .177 & -.007 & $-.490^{* *}$ & $-.464^{* *}$ & 1 & & & & & & & & & & & & & \\
\hline & $\mathrm{P}$ & .000 & .087 & .945 & .000 & .000 & & & & & & & & & & & & & & \\
\hline \multirow[t]{2}{*}{ PCC } & Pearson & $-.255^{*}$ & .126 & .063 & $-.334^{* *}$ & $-.280^{* *}$ & $.934^{* *}$ & 1 & & & & & & & & & & & & \\
\hline & $\mathrm{P}$ & .013 & .228 & .546 & .001 & .006 & .000 & & & & & & & & & & & & & \\
\hline \multirow[t]{2}{*}{ PCF } & Pearson & .018 & -.176 & $-.368^{* *}$ & $-.342^{* *}$ & $-.488^{* *}$ & $.845^{* *}$ & $.787^{* *}$ & 1 & & & & & & & & & & & \\
\hline & $\mathrm{P}$ & .862 & .089 & .000 & .001 & .000 & .000 & .000 & & & & & & & & & & & & \\
\hline \multirow[t]{3}{*}{ PCLL } & Pearson & $-.354^{* *}$ & $.358^{* *}$ & .016 & $-.426^{* *}$ & $-.393^{* *}$ & $.978^{* *}$ & $.903^{* *}$ & $.768^{* *}$ & 1 & & & & & & & & & & \\
\hline & $\mathrm{P}$ & .000 & .000 & .879 & .000 & .000 & .000 & .000 & .000 & & & & & & & & & & & \\
\hline & $\mathrm{N}$ & 94 & 94 & 94 & 94 & 94 & 94 & 94 & 94 & 94 & & & & & & & & & & \\
\hline \multirow[t]{2}{*}{ PCS } & Pearson & -.008 & $-.365^{* *}$ & $-.354^{* *}$ & $-.397^{* *}$ & $-.538^{* *}$ & $.732^{* *}$ & $.692^{* *}$ & $.901^{* *}$ & $.633^{* *}$ & 1 & & & & & & & & & \\
\hline & $\mathrm{P}$ & .936 & .000 & .000 & .000 & .000 & .000 & .000 & .000 & .000 & & & & & & & & & & \\
\hline \multirow[t]{2}{*}{ PPLL } & Pearson & $-.329^{* *}$ & $.328^{* *}$ & -.011 & $-.419^{* *}$ & $-.397^{* *}$ & $.981^{* *}$ & $.914^{* *}$ & $.793^{* *}$ & $.990^{* *}$ & $.645^{* *}$ & 1 & & & & & & & & \\
\hline & $P$ & .001 & .001 & .917 & .000 & .000 & .000 & .000 & .000 & .000 & .000 & & & & & & & & & \\
\hline
\end{tabular}


Anexo 4. Continuación...

\begin{tabular}{|c|c|c|c|c|c|c|c|c|c|c|c|c|c|c|c|c|c|c|c|c|}
\hline & & EDT & EP & ISO & OAT & ODT & PA & PCC & PCF & PCLL & PCS & PPLL & PPS & TCC & TMPPC & TPA & TPCF & TPCLL & TPCS & TPPF \\
\hline \multirow[t]{2}{*}{ PPS } & Pearson & .014 & -.112 & $-.213^{*}$ & -.192 & $-.273^{* *}$ & $.657^{* *}$ & $.669^{* *}$ & $.737^{* *}$ & $.579^{* *}$ & $.663^{* *}$ & $.621^{* *}$ & 1 & & & & & & & \\
\hline & $\mathrm{P}$ & .890 & .281 & .039 & .064 & .008 & .000 & .000 & .000 & .000 & .000 & .000 & & & & & & & & \\
\hline \multirow[t]{2}{*}{ TCC } & Pearson & $.558^{* *}$ & -.107 & $-.471^{* \star}$ & $.330^{* *}$ & .080 & .107 & .045 & $.333^{* *}$ & .066 & $.207^{*}$ & .109 & $.346^{* *}$ & 1 & & & & & & \\
\hline & $P$ & .000 & .307 & .000 & .001 & .445 & .305 & .669 & .001 & .530 & .045 & .294 & .001 & & & & & & & \\
\hline \multirow[t]{2}{*}{ TMPPC } & Pearson & $.638^{* *}$ & .004 & $-.396^{* *}$ & $.569^{* *}$ & $.351^{* *}$ & -.028 & -.050 & .169 & -.036 & .032 & .001 & $.251^{*}$ & $.953^{* *}$ & 1 & & & & & \\
\hline & $\mathrm{P}$ & .000 & .970 & .000 & .000 & .001 & .788 & .631 & .104 & .732 & .758 & .992 & .015 & .000 & & & & & & \\
\hline \multirow[t]{2}{*}{ TPA } & Pearson & $.351^{* *}$ & -.093 & $-.328^{* *}$ & .164 & -.011 & $.230^{*}$ & .143 & $.382^{* *}$ & .181 & $.253^{*}$ & $.225^{*}$ & $.392^{* *}$ & $.971^{\star \star}$ & $.897^{* *}$ & 1 & & & & \\
\hline & $\mathrm{P}$ & .001 & .373 & .001 & .114 & .920 & .026 & .168 & .000 & .080 & .014 & .029 & .000 & .000 & .000 & & & & & \\
\hline \multirow[t]{2}{*}{ TPCF } & Pearson & -.030 & -.029 & -.083 & -.145 & -.190 & $.384^{* *}$ & $.243^{*}$ & $.397^{* *}$ & $.333^{* *}$ & $.266^{* *}$ & $.368^{* *}$ & $.411^{* *}$ & $.812^{* *}$ & $.698^{* *}$ & $.925^{* *}$ & 1 & & & \\
\hline & $\mathrm{P}$ & .777 & .782 & .424 & .165 & .067 & .000 & .018 & .000 & .001 & .010 & .000 & .000 & .000 & .000 & .000 & & & & \\
\hline \multirow[t]{2}{*}{ TPCLL } & Pearson & $.566^{* *}$ & -.114 & $-.425^{* *}$ & $.366^{* *}$ & .138 & .123 & .090 & $.349^{* *}$ & .080 & $.221^{*}$ & .126 & $.359^{* *}$ & $.992^{* *}$ & $.955^{* *}$ & $.966^{* *}$ & $.800^{* *}$ & 1 & & \\
\hline & $\mathrm{P}$ & .000 & .274 & .000 & .000 & .186 & .237 & .387 & .001 & .441 & .032 & .225 & .000 & .000 & .000 & .000 & .000 & & & \\
\hline \multirow[t]{2}{*}{ TPCS } & Pearson & .167 & $.291^{* *}$ & $-.212^{*}$ & .059 & -.055 & $.429^{* *}$ & $.299^{* *}$ & $.457^{* *}$ & $.452^{* \star}$ & $.221^{*}$ & $.472^{* *}$ & $.392^{* *}$ & $.801^{\star *}$ & $.741^{* *}$ & $.855^{* *}$ & $.848^{* *}$ & $.797^{\star *}$ & 1 & \\
\hline & $\mathrm{P}$ & .109 & .004 & .040 & .573 & .598 & .000 & .003 & .000 & .000 & .033 & .000 & .000 & .000 & .000 & .000 & .000 & .000 & & \\
\hline \multirow[t]{2}{*}{ TPPF } & Pearson & -.169 & -.133 & $-.224^{*}$ & $-.492^{* *}$ & $-.593^{* *}$ & $.507^{* *}$ & $.313^{* *}$ & $.551^{* *}$ & $.429^{* *}$ & $.466^{* *}$ & $.459^{*+}$ & $.476^{* *}$ & $.648^{* *}$ & $.436^{* *}$ & $.770^{* *}$ & $.898^{* *}$ & $.611^{* *}$ & $.721^{* *}$ & 1 \\
\hline & $P$ & .104 & .200 & .030 & .000 & .000 & .000 & .002 & .000 & .000 & .000 & .000 & .000 & .000 & .000 & .000 & .000 & .000 & .000 & \\
\hline
\end{tabular}


Anexo 5. Perfil bioclimático de Mimosa luisana.

\begin{tabular}{|c|c|c|c|c|c|c|}
\hline Abreviatura & Variables ambientales & $\begin{array}{c}\text { Número } \\
\text { de } \\
\text { localidades } \\
\text { únicas }\end{array}$ & Media & Mínimo & Máximo & $\begin{array}{l}\text { Desviación } \\
\text { Estándar }\end{array}$ \\
\hline EDT & Estacionalidad de la temperatura & 45 & 0.7 & 0.6 & 0.9 & 0.1 \\
\hline EP & Estacionalidad de la precipitación & 45 & 98.0 & 87.0 & 106.0 & 4.2 \\
\hline ISO & Isotermalidad & 45 & 0.6 & 0.6 & 0.7 & 0.0 \\
\hline OAT & Oscilación anual de la temperatura & 45 & 22.8 & 20.2 & 25.5 & 1.4 \\
\hline ODT & Oscilación diurna de la temperatura & 45 & 14.8 & 13.0 & 16.8 & 0.9 \\
\hline PA & Precipitación anual & 45 & 563.2 & 338.0 & 1647.0 & 199.4 \\
\hline PCC & Precipitación del cuatrimestre más cálido & 45 & 183.7 & 111.0 & 409.0 & 46.9 \\
\hline PCF & Precipitación del cuatrimestre más frío & 45 & 18.5 & 6.0 & 103.0 & 14.9 \\
\hline PCLL & Precipitación del cuatrimestre más lluvioso & 45 & 301.8 & 190.0 & 917.0 & 115.0 \\
\hline PCS & Precipitación del cuatrimestre más seco & 45 & 3.5 & 0.0 & 84.0 & 14.5 \\
\hline PPLL & Precipitación del período más lluvioso & 45 & 31.8 & 21.0 & 84.0 & 9.7 \\
\hline PPS & Precipitación del período más seco & 45 & 0.0 & 0.0 & 0.0 & 0.0 \\
\hline TCC & $\begin{array}{l}\text { Temperatura promedio del cuatrimestre más } \\
\text { cálido }\end{array}$ & 45 & 23.6 & 17.5 & 28.4 & 3.1 \\
\hline TMPPC & $\begin{array}{c}\text { Temperatura promedio del cuatrimestre más } \\
\text { cálido }\end{array}$ & 45 & 32.4 & 25.8 & 37.1 & 3.4 \\
\hline TPA & Temperatura promedio anual & 45 & 21.1 & 15.3 & 25.3 & 2.8 \\
\hline TPCF & Temperatura promedio del cuatrimestre más frío & 45 & & & & \\
\hline & & & 18.3 & 13.2 & 22.0 & 2.5 \\
\hline TPCLL & $\begin{array}{c}\text { Temperatura promedio del cuatrimestre más } \\
\text { Iluvioso }\end{array}$ & 45 & 22.3 & 15.7 & 26.5 & 2.8 \\
\hline TPCS & $\begin{array}{l}\text { Temperatura promedio del cuatrimestre más } \\
\text { seco }\end{array}$ & 45 & 18.7 & 13.9 & 22.7 & 2.7 \\
\hline TPPF & $\begin{array}{c}\text { Temperatura mínima promedio del período más } \\
\text { frío }\end{array}$ & 45 & 9.6 & 5.6 & 13.7 & 2.3 \\
\hline
\end{tabular}


Respuestas ecoanatómicas y ecofisiológicas de dos especies del género Mimosa (Leguminosae) ante el cambio climático

Anexo 6. Correlación de Pearson entre las 19 variables climáticas en las que se desarrolla M. luisana (continúa).

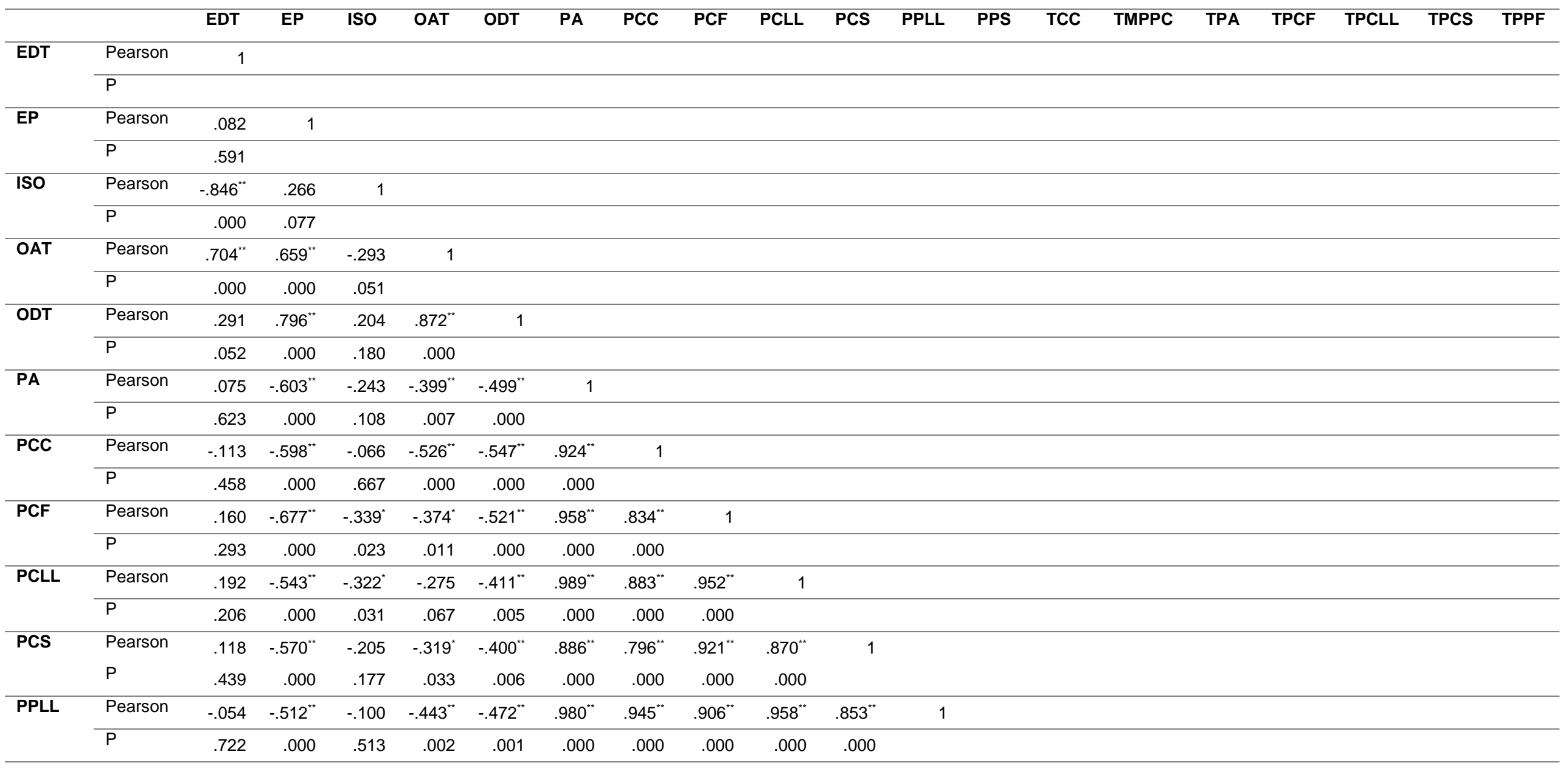


Respuestas ecoanatómicas y ecofisiológicas de dos especies del género Mimosa (Leguminosae) ante el cambio climático

Anexo 6. Continuación...

\begin{tabular}{|c|c|c|c|c|c|c|c|c|c|c|c|c|c|c|c|c|c|c|c|c|}
\hline & & EDT & EP & ISO & OAT & ODT & PA & PCC & PCF & PCLL & PCS & PPLL & PPS & TCC & TMPPC & TPA & TPCF & TPCLL & TPCS & TPPF \\
\hline \multirow[t]{2}{*}{ PPS } & Pearson & & & & & & & & & & & & & & & & & & & \\
\hline & $P$ & & & & & & & & & & & & & & & & & & & \\
\hline \multirow[t]{2}{*}{ TCC } & Pearson & $.947^{* *}$ & $.321^{*}$ & $-.715^{* *}$ & $.804^{* *}$ & $.463^{* *}$ & .060 & -.133 & .100 & .190 & .080 & -.029 & $\mathrm{~b}$ & 1 & & & & & & \\
\hline & $P$ & .000 & .032 & .000 & .000 & .001 & .695 & .382 & .514 & .210 & .603 & .852 & & & & & & & & \\
\hline \multirow[t]{2}{*}{ TMPPC } & Pearson & $.923^{* *}$ & $.398^{* *}$ & $-.645^{* *}$ & $.867^{* *}$ & $.563^{* *}$ & -.014 & -.205 & .024 & .120 & .018 & -.096 & $\mathrm{~b}$ & $.993^{* *}$ & 1 & & & & & \\
\hline & $\mathrm{P}$ & .000 & .007 & .000 & .000 & .000 & .927 & .178 & .876 & .433 & .908 & .532 & & .000 & & & & & & \\
\hline \multirow[t]{2}{*}{ TPA } & Pearson & $.939^{* *}$ & $.339^{*}$ & $-.696^{* *}$ & $.807^{* *}$ & $.476^{* *}$ & .061 & -.129 & .097 & .191 & .084 & -.023 & $\mathrm{~b}$ & $.999^{* *}$ & $.993^{* *}$ & 1 & & & & \\
\hline & $P$ & .000 & .023 & .000 & .000 & .001 & .690 & .399 & .526 & .209 & .583 & .882 & & .000 & .000 & & & & & \\
\hline \multirow[t]{2}{*}{ TPCF } & Pearson & $.922^{* *}$ & $.368^{*}$ & $-.673^{* *}$ & $.813^{* *}$ & $.494^{* *}$ & .059 & -.131 & .088 & .190 & .074 & -.019 & $\mathrm{~b}$ & $.997^{\star *}$ & $.993^{* *}$ & $.999^{* *}$ & 1 & & & \\
\hline & $\mathrm{P}$ & .000 & .013 & .000 & .000 & .001 & .698 & .392 & .565 & .210 & .629 & .902 & & .000 & .000 & .000 & & & & \\
\hline \multirow[t]{2}{*}{ TPCLL } & Pearson & $.944^{* *}$ & $.328^{*}$ & $-.696^{* *}$ & $.805^{* *}$ & $.469^{* *}$ & .057 & -.114 & .095 & .182 & .090 & -.026 & $\mathrm{~b}$ & $.995^{* *}$ & $.987^{* *}$ & $.995^{* *}$ & $.992^{* *}$ & 1 & & \\
\hline & $\mathrm{P}$ & .000 & .028 & .000 & .000 & .001 & .712 & .455 & .536 & .230 & .558 & .863 & & .000 & .000 & .000 & .000 & & & \\
\hline \multirow[t]{2}{*}{ TPCS } & Pearson & $.927^{* *}$ & $.320^{*}$ & $-.693^{* *}$ & $.793^{* *}$ & $.467^{* *}$ & .104 & -.108 & .146 & .235 & .120 & .018 & $\mathrm{~b}$ & $.994^{* *}$ & $.988^{* *}$ & $.995^{\star *}$ & $.995^{* *}$ & $.987^{* *}$ & 1 & \\
\hline & $P$ & .000 & .032 & .000 & .000 & .001 & .496 & .479 & .338 & .121 & .434 & .906 & & .000 & .000 & .000 & .000 & .000 & & \\
\hline \multirow[t]{2}{*}{ TPPF } & Pearson & $.941^{* *}$ & .182 & $-.783^{* *}$ & $.674^{* *}$ & $.298^{*}$ & .222 & .017 & .265 & $.345^{*}$ & .220 & .127 & $\mathrm{~b}$ & $.980^{* *}$ & $.952^{* *}$ & $.978^{* *}$ & $.975^{* *}$ & $.972^{* *}$ & $.980^{* *}$ & 1 \\
\hline & $\mathrm{P}$ & .000 & .232 & .000 & .000 & .047 & .142 & .911 & .078 & .020 & .146 & .407 & & .000 & .000 & .000 & .000 & .000 & .000 & \\
\hline
\end{tabular}




\section{CAPÍTULO II}

\section{Morfología de la semilla y anatomía de la testa de dos taxa del género Mimosa (Leguminosae-Mimosoideae) \\ Seed morphology and anatomy of the seed coat of two taxa of Mimosa \\ (Leguminosae-Mimosoideae)}

\section{INTRODUCCIÓN}

La familia Leguminosae se caracteriza por presentar semillas duras (Morrison et al., 1998; Villiers, 1972) y una cubierta seminal que las hace impermeables al agua, provocándoles una latencia de tipo física (Baskin y Baskin, 1998; Venier et al., 2012); si bien, a nivel general, se reconoce que existen cinco tipos de latencia: la fisiológica, la morfológica, la morfo-fisiológica, la física, y la combinatoria entre la fisiológica y la física (Baskin y Baskin, 2004).

A nivel morfológico, estas semillas se caracterizan por presentar: l) Hilo, ii) Lente, iii) Línea fisural o pleurograma, irregular, con brazos de igual o diferente longitud, con extensiones que van del 50 al 100\% (Arambarri, 2002; Gunn, 1984; Melo et al., 2004), iv) Pleurograma, y v) Micrópilo (Corner, 1951; Gunn, 1984, 1991; Kopooshian, 1963). Con relación al embrión, la información anatómica es escasa; aunque, de acuerdo con Gunn (1984) se sabe que presenta: I) Eje del embrión, recto o curvo, ii) Radícula, expuesta u oculta, iii) Cotiledones, enteros, divididos o 
auriculados, y iv) Plúmula, muy o moderadamente desarrollada o rudimentaria (no desarrollada).

Desde el punto de vista anatómico, la testa de la semilla, presenta cuatro capas: i) Cutícula, ii) Macroesclereidas, iii) Osteoesclereidas y iv) Parénquima (Corner, 1951; Kopooshian, 1963).

Asimismo, es relevante mencionar que en las leguminosas, la presencia o ausencia, la posición y los tamaños de los caracteres morfológicos y anatómicos de la semilla son de relevancia taxonómica a nivel supra e infra-específico (Corner, 1976; Gunn, 1984, 1991). Igualmente, estos caracteres son importantes para realizar interpretaciones ecológicas (Castillo y Guenni, 2001; Irving, 1984; Jayasuriya et al., 2013; Venier et al., 2012;). Por ejemplo, Qutob et al. (2008) y Venier et al. (2012) sugieren que la latencia física de las semillas está asociada con la estructura anatómica de la testa; mientras que otros como, Castillo y Guenni (2001), SerratoValenti et al. (1994) y Turner et al. (2005), relacionan este tipo de latencia con las propiedades histoquímicas de la semilla.

Del mismo modo, el rompimiento de la latencia de la semilla se ha investigado en varios taxa de leguminosas como Albizia lebbeck (L.) Benth. (Navarro et al., 2010), Cassia leptophylla Vogel (De Paula et al., 2012), Leucaena leucocephala Lam. (Serrato-Valenti et al., 1995), Parkia multijuga Benth., P. panurensis Benth. ex H. C. Hopkins y P. velutina Benoist (Melo, 2011), Senna macranthera (DC. ex Collad.) H.S. Irwin \& Barneby (De Paula et al., 2012), Stylosanthes hamata (L.) Taub. (Castillo y 
Guenni, 2001) y Sophora tomentosa L. (Delgado, 2015), entre otras, y ha permitido reconocer cuáles son las estructuras morfológicas y anatómicas de la semilla que le confieren la permeabilidad al agua. Por ejemplo, Baskin et al. (2000), Baskin (2003), Burns (1959), Delgado (2015), Hanna (1984), Hu et al. (2009), Karaki et al. (2012), Morrison et al. (1992), y Serrato-Valenti et al. (1995), señalan a la lente como el sitio primario por el cual entra el agua a la semilla; mientras que otros como Hu et al. (2008) y Taylor (2005), consideran que la entrada del agua también es posible a través del hilo o por el micrópilo como lo demostraron Baskin y Baskin (1998).

Asimismo, las estructuras de las semillas permeables al agua varían entre los géneros de leguminosas (Baskin y Baskin, 1998; Burns, 1959; Hu et al., 2008, Morrison et al., 1992; Serrato-Valenti et al., 1994). Más aún y de acuerdo con Delgado et al. (2015), De Paula et al. (2012), Hu et al. (2009) y Souza et al. (2012), cuando se utiliza un método de escarificación determinado o se realizan ensayos bloqueando algunas estructuras de la semilla como pueden ser el micrópilo y el hilo, el micrópilo, el hilo y la lente, o solamente la lente, es posible que se modifique el sitio de entrada del agua.

En el caso de las semillas de esta familia, la escarificación es un método común debido a que producen semillas con una capa resistente al agua que las hace físicamente inactivas (Auld, 1996; van Klinken y Flack, 2005), lo que restringe su germinación en condiciones naturales (D'Aubeterre et al., 2002). Por consiguiente, se han realizado diversos estudios que exploran su germinación sometiéndolas a diferentes métodos de escarificación como el ácido (González-Castañeda et al., 
2004), el mecánico (Camargo-Ricalde et al., 2004; Martínez-Pérez et al., 2006) y el térmico (Torres y Barbosa-Dos Santos, 1994), entre otras, con el fin de romper la latencia física. Aunque, se admite que todavía se desconoce que causa la impermeabilidad en la mayoría de las semillas y que, por lo mismo, la selección del método de escarificación utilizado es indistinto, autores como Navarro (2003) y Sanabria et al. (2004), señalan, por ejemplo, que el uso de ácido puede dañar al embrión y alterar el proceso de germinación, lo que, a su vez, repercute en el desarrollo de la plántula. Así, Navarro (2003) sugiere que para romper la latencia física de la semilla a través de la selección de un método de escarificación adecuado, es preciso conocer su estructura para determinar las causas de su impermeabilidad y discernir sobre sus implicaciones ecológicas.

\section{ANTECEDENTES}

Las semillas de las leguminosas provienen de óvulos anátropos o campilótropos. Según Corner $(1951,1976)$ y Van Staden et al. (1989), las semillas de las subfamilias Mimosoideae y Caesalpinoideae provienen de óvulos anátropos; mientras que en Papilionoideae, provienen de óvulos campilótropos (Bravato, 1974; De-Paula y Oliveira 2007 -Figura 1-).

De acuerdo con Schmidt y Jøker (2001), en un óvulo anátropo, el funículo se curva $180^{\circ}$, quedando el micrópilo situado en la parte inferior y la calaza en la superior; mientras que en un óvulo campilótropo, el micrópilo está orientado en ángulo hacia la placenta, de manera que, el micrópilo y la calaza quedan casi a la 
misma altura (Schmidt y Jøker, 2001 - Figura 1). Es importante señalar que el funículo se considera una estructura fundamental en la formación de la semilla, ya que de ella surgen otras estructuras como el hilo. El funículo es la estructura que une al óvulo con el ovario y, cuando éste degenera, deja una cicatriz conocida como hilo (Boelcke, 1946; Bravato, 1974).

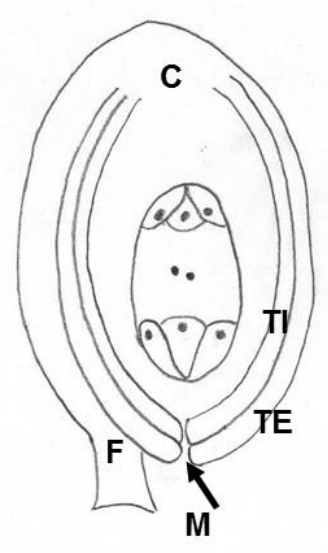

Anátropo

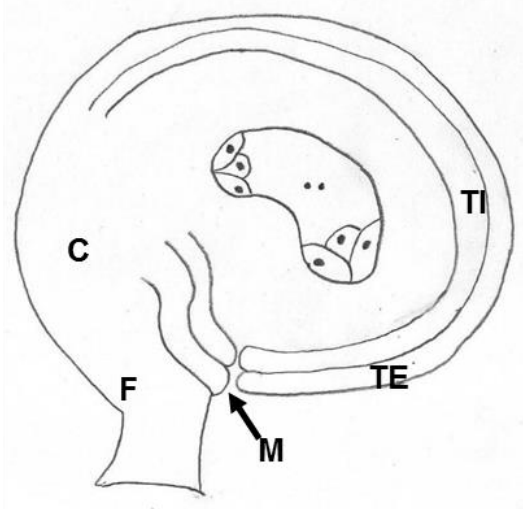

Campilótropo

Figura 1. Esquema de los tipos de óvulos presentes en la familia Leguminosae. $\mathrm{C}=$ Calaza, $\mathrm{F}=$ Funículo, M=Micrópilo, TE=Tegumento Externo; Tl=Tegumento Interno (Modificado de Diego-Pérez, 2013).

Otra estructura importante en la morfología de la semilla es el micrópilo, el cual es el espacio ubicado entre los tegumentos y se localiza en la parte apical de los óvulos (Boelcke, 1946; Schmidt y Jøker, 2001). Particularmente, las semillas de las leguminosas provienen de óvulos bi-tégmicos; es decir, son semillas que constan de un tegumento externo y uno interno (Eames y MacDaniels, 1953). Además, Dnysagar (1958) señaló que durante el proceso de maduración de la semilla, el tegumento 
interno puede reducirse e, incluso, reabsorberse, como lo determinaron Boesewinkel y Bouman (1984) y Eames y MacDaniels (1953).

Asimismo, la zona de los tegumentos, ubicada entre el hilo y el micrópilo, se eleva en forma de cúpula y recibe el nombre de lente (Gunn, 1984); sin embargo, a la lente también se le puede referir como estrofíolo (Egley, 1979; Robles, 2011; Smýkal et al., 2014) o rafe (Boelcke, 1946).

Por otra parte, Boelcke (1946) define otra característica morfológica de la semilla, la línea fisural, la cual es una fractura que atraviesa toda la testa; no obstante, Gunn (1984) nombra a esta fractura como pleurograma. En las leguminosas, la línea fisural es una estructura en forma de herradura (Schmidt y Jøker, 2001); particularmente en la subfamilia Mimosoideae, la línea fisural se ubica en ambas caras de la semilla (Gunn, 1984; Forero y Romero, 2005).

No obstante, sigue sin haber consenso en cuanto a los sitios permeables al agua, ya que Schmidt (2000) señala al hilo y a la línea fisural como los sitios frágiles de las semillas y, por tanto, los sitios permeables al agua; aunque, como ya se comprobó, además de esas dos estructuras, la lente y el micrópilo también son permeables (P. ej. Baskin y Baskin, 1998; Geisler, 2013; Hu et al., 2009; Morrison et al., 1992; Serrato-Valenti et al., 1995; Taylor, 2005).

Anatómicamente, la testa de las semillas de las leguminosas se caracteriza por presentar una cutícula (Alsina, 1988) y una capa de macroesclereidas (Corner, 1951) o células en empalizada que conforman a la epidermis (Vaughan, 1968). A su 
vez, la capa de macroesclereidas presenta una línea lúcida que atraviesa a toda la capa, la cual también es una característica distintiva de esta familia (Alsina, 1988). La capa subyacente a las macroesclereidas son las osteoesclereidas o también llamada capa subepidérmica (Vaughan, 1968; Smýkal et al., 2014) y, por último, se sitúa una capa de parénquima (Gunn, 1981).

Diversos autores (P. ej. Barretto y Ferreira, 2011; Egley, 1979; Endo, 2012; Hamly, 1932; Molizane, 2012; Meireles y Tozzi, 2008; Pammel, 1886; Pitot, 1935; De Souza, 1982; Ubiergo y Lapp, 2007; Vaughan, 1968; Varela y Albornoz, 2013) han llevado a cabo estudios relacionados con el reconocimiento de la estructura morfoanatómica de las semillas. Asimismo, otros investigadores (P. ej. Delgado et al., 2015; De Paula et al., 2012; Mariño et al., 2007; Molizane, 2012; Schmidt, 2000; Souza et al., 2012), además de analizar dicha estructura, también han tratado de descifrar las implicaciones fisiológicas que puede haber entre dicha estructura y la fisiología de la semilla. Inclusive, existen estudios que analizan la composición química de la testa (Castillo y Guenni, 2001; Delgado et al., 2015; Venier et al., 2012) o de la semilla completa (Geisler, 2013; Irving, 1984).

Dada la importancia económica y cultural de las leguminosas, son numerosos los trabajos que abordan el estudio morfo-anatómico de sus semillas; aunque, la información relacionada con la anatomía del embrión es escasa. Entre estos estudios, destacan los de las subfamilias Caesalpinoideae (Cassia leptophylla, Senna macranthera [De Paula et al., 2012] y Schizolobium parahyba (Vell.) S.F. Blake [Souza et al., 2012] y Papilionoideae (P. ej. Sophora tomentosa, Erythrina 
speciosa Andr., Canavalia maritima (Aubl.) Thouars, Canavalia plagiosperma Piper), los cuales están enfocados en localizar y describir el punto de entrada de agua y el efecto que tiene la alternancia de temperaturas en el rompimiento de la latencia física; aunque, en el caso de esta última subfamilia, se han incorporado análisis histoquímicos de la testa (Castillo y Guenni, 2001; Delgado et al., 2015; Koizumi y Kano, 2014).

En el caso de la subfamilia Mimosoideae, Boelcke (1946) estudió la morfología de la semilla en 11 géneros, de los cuales, Bravato (1974) retoma nueve y agrega nueve más; asimismo, Lima (1985) retoma ocho géneros ya estudiados por los dos autores antes mencionados, e incorpora nueve más. Los tres autores coinciden en la morfología de las semillas de los géneros compartidos (P. ej. Acacia, Albizia, Calliandra, Inga, Leucaena y Mimosa, entre otros) y, a su vez, sus descripciones concuerdan con lo reportado por autores como Braz et al. (2012), Gunn (1984), Leython (2010) y Leython y Jaúregui (2008).

Por consiguiente, el análisis de sus resultados permite caracterizar a esta subfamilia, ya que presentan: i) Hilo, posición apical o sub-apical, ii) Lente, conspicua, pequeña, larga y lateral, iii) Cubierta seminal, color variable, lisa y brillante, delgada y a veces gruesa (P. ej. Adenanthera, Albizia y Enterolobium, entre otros), iv) Línea fisural, forma de herradura; los brazos pueden estar unidos o casi unidos, ser o no paralelos, éstos pueden ser cortos o prolongarse hasta el extremo hilar, v) Tegmen, puede o no estar presente y cuando está, puede estar reducido en los cantos, vi) Endospermo, cuando presente vítreo o córneo, en cantidad variable, o 
ausente, vii) Eje embrionario, puede o no estar desarrollado y cuando está, es corto y grueso, y viii) Cotiledones, enteros, divididos o auriculados.

Respecto a los estudios anatómicos de la semilla de Mimosoideae, éstos son escasos. Se han descrito las semillas de algunos taxa pertenecientes a los géneros Acacia (Hanna, 1984; Pammel, 1989; Venier, 2012), Adenanthera (Varela y Albornoz, 2013), Calliandra (Leython y Jaúregui, 2008), Mimosa (Geisler, 2013; Iwazaki, 2008) y Prosopis (Irving, 1984). En todos ellos se analiza la estructura de la semilla y sus implicaciones en el proceso de germinación; y, aunque son pocos los géneros examinados, el análisis conjunto de lo reportado permite dar una aproximación sobre la estructura interna de la semilla y establecer que la anatomía de la cubierta seminal es constante (Van Staden et al., 1989). Anatómicamente, la semilla presenta: i) Cutícula, ii) Estrato de macroesclereidas, iii) Estrato de osteoesclereidas, iv) Línea lúcida, posición variable, puede estar presente en la parte apical (P. ej. Calliandra riparia Pittier) o media (P. ej. Calliandra falcata Benth.) de las macroesclereidas y $v$ ) De 5 a 8 estratos de parénquima de grosor variable.

Por lo que este capítulo está enfocado en describir la morfología de la semilla y la anatomía de la testa de dos taxa del género Mimosa presentes en México. A nivel mundial, este género consta de ca. 530 taxa (Särkinen et al., 2011; Simon et al., 2011). En México, Mimosa es el género más numeroso de mimosoideas, consta de ca. 110 taxa, de las cuales el 60\% es endémico del país (Grether et al., 1996), de ahí que México es considerado el segundo centro de diversificación del género, después de Brasil (Barneby, 1991; Grether, 1978; Simon et al., 2011). 
Dada la importancia biológica y ecológica de sus taxa (Camargo-Ricalde et al., 2002; Camargo-Ricalde y Dhillion, 2003; Camargo-Ricalde et al., 2010a, b), éstas han sido objeto de múltiples estudios taxonómicos y sistemáticos (Chehaibar, 1988; Grether, 2000), palinológicos (Caccavari, 1985, 1986, 1987; Flores-Cruz et al., 2006), ecológicos (Camargo-Ricalde et al., 2010a, b; Moreno-Calles y Casas, 2010; Pavón et al., 2011) y, recientemente, ecoanatómicos (Montaño-Arias et al., 2013). Además, dadas sus características biológicas, ecológicas y de uso, algunos de sus taxa son consideradas plantas multipropósito (Camargo-Ricalde, 2001); entre ellas destacan M. aculeaticarpa Ortega var. aculeaticarpa, la cual se distribuye en regiones templadas y mésicas, y es endémica de México, y $M$. luisana Brandegee que es endémica del Valle semiárido de Tehuacán-Cuicatlán, Puebla y Oaxaca, México. Ambos taxa han sido sugeridos para ser utilizados en procesos de restauración ambiental en sus respectivos ambientes (Camargo-Ricalde et al., 2004; MontañoArias et al., 2015; Pavón et al., 2011).

Con relación al estudio de la anatomía de la semilla del género Mimosa, es relevante mencionar que se trata de un aspecto poco explorado y, en el caso de estos dos taxa en particular, no existe ningún estudio, por lo que éste es el primero.

Para Argentina, Boelcke (1946) estudió cuatro taxa de Mimosa, de las cuales, Bravato (1974) retomó dos y añadió 20 taxa distribuidas en Venezuela; sin embargo, ambos autores se enfocaron solamente en la morfología de la semilla y realizaron una descripción general, y no una descripción específica de cada uno de los taxa estudiados. Por su parte, Barneby (1991) y Grether (1997) describieron, también de 
manera general, la morfología de la semilla de varios taxa de Mimosa (P. ej. M. orthocarpa Spruce ex Benth., M. pigra L.); ambos autores coinciden con Boelcke (1946), Bravato (1974) y Lima (1985), al reportar que todas las semillas examinadas presentan una línea fisural bien definida, que la textura es lisa o porosa, opaca 0 brillante y de color pardo-rojizo o negro, entre otras características.

Respecto a la anatomía de la semilla de Mimosa, Iwazaki (2008) describió la anatomía de la semilla de M. daleoides Benth., M. dolens Vell. var. anisitsii (Lindm.) Barneby y $M$. orthacantha Benth. Los tres taxa presentan una capa de macroesclereidas, línea lúcida en la parte media de las macroesclereidas, una capa de osteoesclereidas, una capa de parénquima y endospermo de aspecto vítreo. Asimismo, Geisler (2013) caracterizó la anatomía de la semilla de M. bimucronata (DC) O. Kuntze, la cual presenta una cutícula, una capa de macroesclereidas con una línea lúcida, una capa de osteoesclereidas y una capa de parénquima. Es importante mencionar que todos los taxa examinados fueron recolectados en Brasil.

Asimismo, existen otras investigaciones que abordan la latencia física de las semillas de Mimosa con el objetivo de entender los procesos involucrados en su germinación. Por ejemplo, Jayasuriya et al. (2013) experimentaron con M. invisa Colla, M. pigra y M. pudica L., taxa tropicales e introducidas a Sri Lanka, y van Klinken y Goulier (2013), quienes estudiaron a M. pigra, ya que en Australia, este taxon, también introducido, se comporta como una gran invasor que habita, principalmente, en sitios inundables. Sin embargo, en ningún caso, se analizó la anatomía de la semilla. Dado lo anterior, se requiere de estudios que permitan 
integrar a la anatomía con la fisiología de la semilla, con el fin de contextualizar y comprender mejor sus implicaciones ecológicas.

\section{PREGUNTAS DE INVESTIGACIÓN}

- ¿Cómo es la morfología de la semilla de dos taxa de Mimosa (LeguminosaeMimosoideae) presentes en México?

- ¿Cómo es la anatomía de la testa de la semilla de dos taxa de Mimosa (Leguminosae-Mimosoideae) presentes en México?

- ¿Existe una correlación entre las características morfológicas de la semilla y anatómicas de la testa de dos taxa de Mimosa (Leguminosae-Mimosoideae), presentes en México, con el clima preponderante?

\section{HIPÓTESIS}

Aunque se reconoce un patrón morfológico y anatómico que caracteriza a las semillas de la subfamilia Mimosoideae, se plantea la siguiente hipótesis:

Si los taxa están adaptados a los ambientes en los que se desarrollan, entonces la morfología de la semilla y la anatomía de la testa (número de capas) será diferente al comparar entre los dos taxa de Mimosa en estudio: l) $M$. aculeaticarpa var. aculeaticarpa, habita en sitios mésicos, y ii) M. luisana, habita en sitios semiáridos. 


\section{OBJETIVO}

Describir la morfología de la semilla y la anatomía de la testa de dos taxa de Mimosa (Leguminosae-Mimosoideae), presentes en México, que habitan en ambientes contrastantes (ambiente mésico vs. ambiente semiárido).

\section{MÉTODOS}

\section{Recolección de frutos y semillas}

De $M$. aculeaticarpa var. aculeaticarpa y de $M$. luisana, se recolectaron frutos maduros de ocho individuos de altura y cobertura similar $(2.0 \mathrm{~m}$ y $2.5 \mathrm{~m}$, respectivamente), que no presentaran daño aparente, se consideró que tuvieran el mayor número de frutos y que las semillas estuvieran maduras, por taxon. Los frutos, en su mayoría, estaban dehiscentes y sin daño evidente. La recolección de los frutos se realizó al azar, abarcando el área total de la copa. Se extrajeron las semillas separándolas en dos lotes, uno para el estudio morfológico y otro para la caracterización anatómica de la semilla.

Las semillas se extrajeron de los frutos inmediatamente después de la recolección. Se obtuvieron aproximadamente 10,000 semillas, por taxon, que fueron almacenadas en contenedores de plástico bajo condiciones ambientales de temperatura y humedad de la Ciudad de México.

Los ejemplares botánicos de referencia están depositados en el Herbario Metropolitano (UAMIZ), de la Universidad Autónoma Metropolitana-Iztapalapa. 


\section{Análisis morfológico}

Para la caracterización morfológica, se eligieron 100 semillas por individuo, por taxon, con la finalidad de considerar todo el ámbito de variación morfológica del taxon. En semillas secas, se determinó el tamaño, midiendo el largo, ancho y grosor, con un calibrador Vernier Digital (Absolute Digimatic, CD-6" CS). El largo de la semilla fue medido desde el extremo hilar hasta el calazal; el ancho fue medido en la porción media y más ancha de la semilla, al igual que el grosor. Para definir la forma de las semillas, se siguió lo indicado por Murley (1951; tomado de Bravato, 1974; Gunn, 1984). El color fue estimado en semillas maduras mediante las tablas de Munsell Color Company (1990). Se adoptó el término de línea fisural, y ésta fue descrita siguiendo la terminología propuesta Gunn (1984). El hilo y la forma de la lente, se definieron según Boelcke (1946), Bravato (1974), Gunn (1984) y Escala (1999).

En forma adicional, 50 semillas sanas se hidrataron durante una semana para ablandar la cubierta y observar la morfología del embrión (cotiledones, radícula), así como el endospermo). Las descripciones se realizaron con base en Boelcke (1946) y Gunn (1984). Todas las observaciones se efectuaron en un microscopio estereoscópico marca Leica, modelo Zoom 2000. 


\section{Análisis anatómico}

Debido a que las semillas son duras, se realizó un tratamiento de ablandamiento de la testa; en este caso, fue por hidratación, ya que, de acuerdo con Sandoval-Zapotitla (2005), existen varias técnicas de ablandamiento como la de hidratación, la solución glicerina, alcohol etílico y agua, la solución etilendiamina, y el hidróxido de sodio y ácido acético glacial; sin embargo, se considera que la técnica menos dañina es la de hidratación, ya que no altera los pigmentos y no es tóxica.

Por lo tanto, para el análisis anatómico, se eligieron 100 semillas por taxon, las cuales fueron hidratadas hirviéndolas en agua destilada para ablandar la testa y realizar cortes. Las semillas de $M$. aculeaticarpa var. aculeaticarpa se mantuvieron hirviendo durante tres horas; mientras que las de $M$. luisana, permanecieron hirviendo únicamente dos horas debido a que, en ese tiempo, empieza a desprenderse una capa fina que, probablemente, sea la cutícula.

Después de hervir las semillas, se procedió a separar, de forma manual, la testa y los cotiledones de 50 semillas por taxon. Una vez separadas, se fijaron en FAA (formaldehído, alcohol 96\%, agua destilada y ácido acético glacial) al 50\%, durante 24 hrs. Posteriormente, se realizó la infiltración e inclusión de la testa y de los cotiledones, por separado, en paraplast (marca Sigma); para ello, se siguió la metodología propuesta por Johansen (1940) y Sandoval-Zapotitla (2005).

Una vez realizados los bloques de parafina, se hicieron cortes de $8 \mu \mathrm{m}$ de grosor en un micrótomo rotatorio (American Optical, Spencer Microtome, modelo 
820). Los cortes fueron montados en grenetina al $10 \%$. Una vez montados los cortes, se les retiró el paraplast y éstos fueron teñidos con Azul de Toluidina al $1 \%$ y se montaron de forma permanente con resina sintética (Stern, 1992).

De forma adicional, algunos cortes fueron seleccionados para realizarles pruebas histoquímicas. Para la dar contraste a los cortes se tiñó con Azul de Toluidina y Safranina, para la identificación de lignina se utilizó Floroglucina Clorhídrica. Asimismo, para comprobar la presencia de cutícula, se tiñó con Rojo O de aceite y SUDÁN III que también detectan lípidos y suberinas. Para almidones, se utilizó Lugol (Johansen, 1940; Sandoval-Zapotitla, 2005). Todas las fotografías se generaron en un microscopio óptico, marca Zeiss, modelo Axiostar-Plus.

\section{RESULTADOS}

\section{Morfología y anatomía de la semilla de Mimosa aculeaticarpa var. aculeaticarpa}

Las semillas se caracterizan por presentar una longitud que va desde 3.0 a $4.4 \mathrm{~mm}$, ancho de 2.0 a $3.0 \mathrm{~mm}$ y el grosor de 0.01 a $0.02 \mathrm{~mm}$, lo que sugiere que son delgadas. Son aplanadas dorsiventralmente y ligeramente convexas. La forma de las semillas es ovoide. La testa es lisa, punteada, color marrón rojizo oscuro o rojo amarillento, glabra, opaca o brillante. La línea fisural está presente en ambas caras, forma una herradura alejada de los bordes, con brazos de igual longitud, abiertos y de $50 \%$ de extensión (Figura 2A-B). 
La región hilar es puntiforme aguda; en ella, el micrópilo es circular, de color claro y está en posición apical (Figura 2B-C). El hilo es ovalado, de color claro, se ubica en posición sub-apical y está cubierto por remanentes del funículo (Figura 2D). La lente es ovalada, de color oscuro y rara vez claro, y se encuentra ubicada en la porción opuesta al micrópilo (Figura 2C-E).

Cabe mencionar que en semillas hidratadas, se observó la ruptura de la línea fisural, lo que indica que, probablemente, éste sea el sitio permeable.

Respecto al endospermo, las semillas se caracterizan por presentar un endospermo vítreo, el cual está adherido a la cubierta seminal y se encuentra reducido hacia los cantos, formando un disco arriba de los cotiledones (Figura 3B). El eje del embrión es recto (Figura 3C). Se observaron cotiledones planos, sagitados y auriculados (Figura 3A, C, D). La radícula es corta $(3 \mathrm{~mm})$, gruesa $(0.5 \mathrm{~mm})$, recta y expuesta. Se observa el epicótilo (Figura 3C-D) y no hay desarrollo de primordios foliares (plúmula).

Anatómicamente, los cotiledones presentan una epidermis que está formada por células alargadas paralelas a la superficie, de forma rectangular y tamaño variable (Figura 4A-B, D). Asimismo, la epidermis es monoestratificada compuesta por células isodiamétricas, ésta mostró estomas de tipo paracítico en la región del envés (Figura 4C).

Continuo a la epidermis, se observó una capa de parénquima en empalizada (Figura 4A-B); le sigue el parénquima, éste se presenta en varias capas de células 
más o menos poliédricas (Figura 4C-E). Entre las capas de este tejido, se observan nítidamente haces vasculares que recorren el cotiledón (Figura 4A-B).

Cabe mencionar que las células que conforman el parénquima, muestran abundantes contenidos. La prueba histoquímica realizada indicó que no hay presencia de lípidos (figura no mostrada). Asimismo, la prueba de Lugol indicó la presencia de almidones en los cotiledones (Figura 4D y E).

En la cara externa de la testa se encuentra una estructura que recubre a las capas internas de las células (Figura $5 \mathrm{~A}-\mathrm{C}$ ), la cual se tiñe en rojo con Rojo $\mathrm{O}$ de aceite, indicando la presencia de lípidos (Figura 5D), por lo que esta capa puede estar constituida cutina y suberina, y por ello conformar una estructura impermeable como es la cutícula. Asimismo, se observó una capa de macroesclereidas con paredes engrosadas y radialmente alargadas, los lúmenes son anchos en su base y presentan abundantes contenidos intracelulares. Además, en las macroesclereidas se distingue la línea lúcida, la cual se ubica en la parte superior de esta capa (Figura $5 A-B)$.

La capa subyacente a las macroesclereidas es el parénquima, el cual está compuesto por 8-10 estratos de células poliédricas e isodiamétricas (Figura 5A-D). 


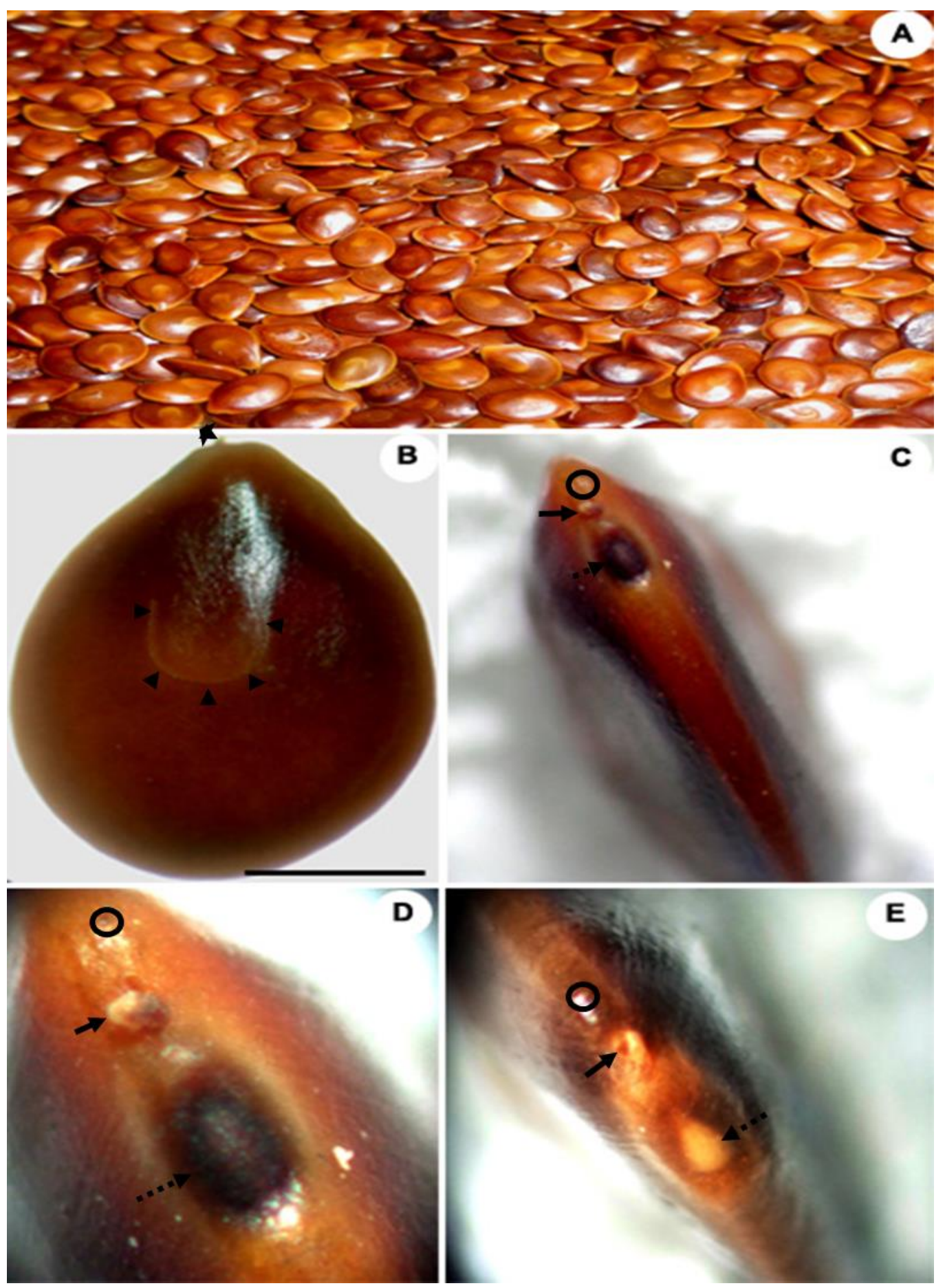

Figura 2. Morfología de la semilla de Mimosa aculeaticarpa var. aculeaticarpa. A. Vista general de semillas; B. Forma ovoide de la semilla; C. Vista de canto de la semilla; DE. Acercamientos de la lente, el hilo, restos del funículo y el micrópilo. Barra, equivalente a 1 $\mathrm{mm}$. Simbología: $\rightarrow=$ hilo, $\cdots$ - =lente, $\boldsymbol{\nabla}$ =línea fisural, $\mathrm{O}=$ micrópilo, $\boldsymbol{\kappa}=$ restos del funículo. 


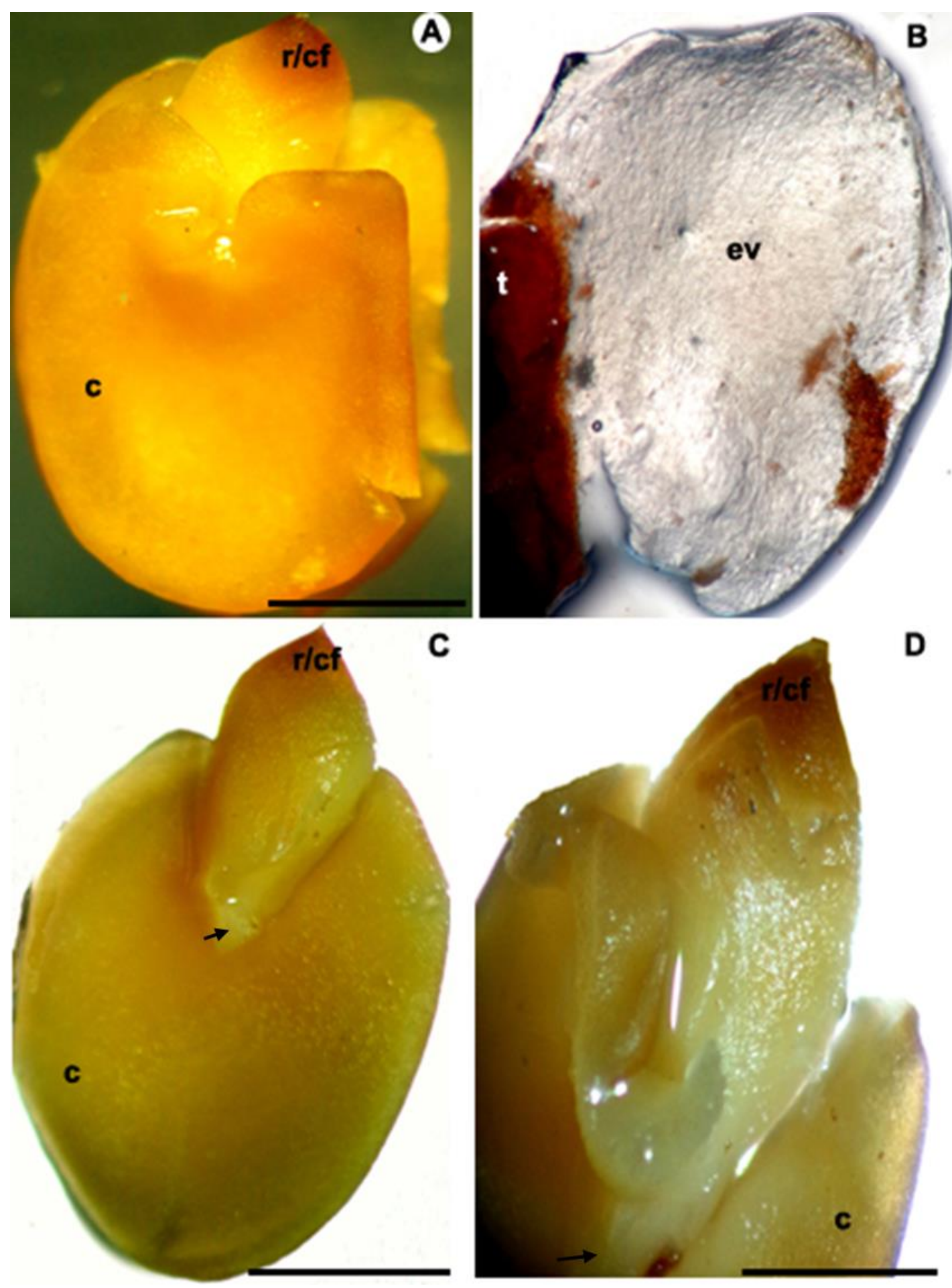

Figura 3. Morfología de los cotiledones de Mimosa aculeaticarpa var. aculeaticarpa. A. Vista general; B. Endospermo; C. Cotiledón, epicótilo y radícula; D. Acercamientos del cotiledón. $=$ cotiledones, $\mathrm{cf}=\mathrm{cofia}$, ev=endospermo vítreo, $\mathrm{r}=$ radícula, $\mathrm{t}=\mathrm{testa}$. Barras equivalentes $\mathrm{a}$ : $A=1.6 \mathrm{~mm}, C=1 \mathrm{~mm}, \mathrm{D}=0.7 \mathrm{~mm}$. Simbología: $\rightarrow=$ epicótilo. 

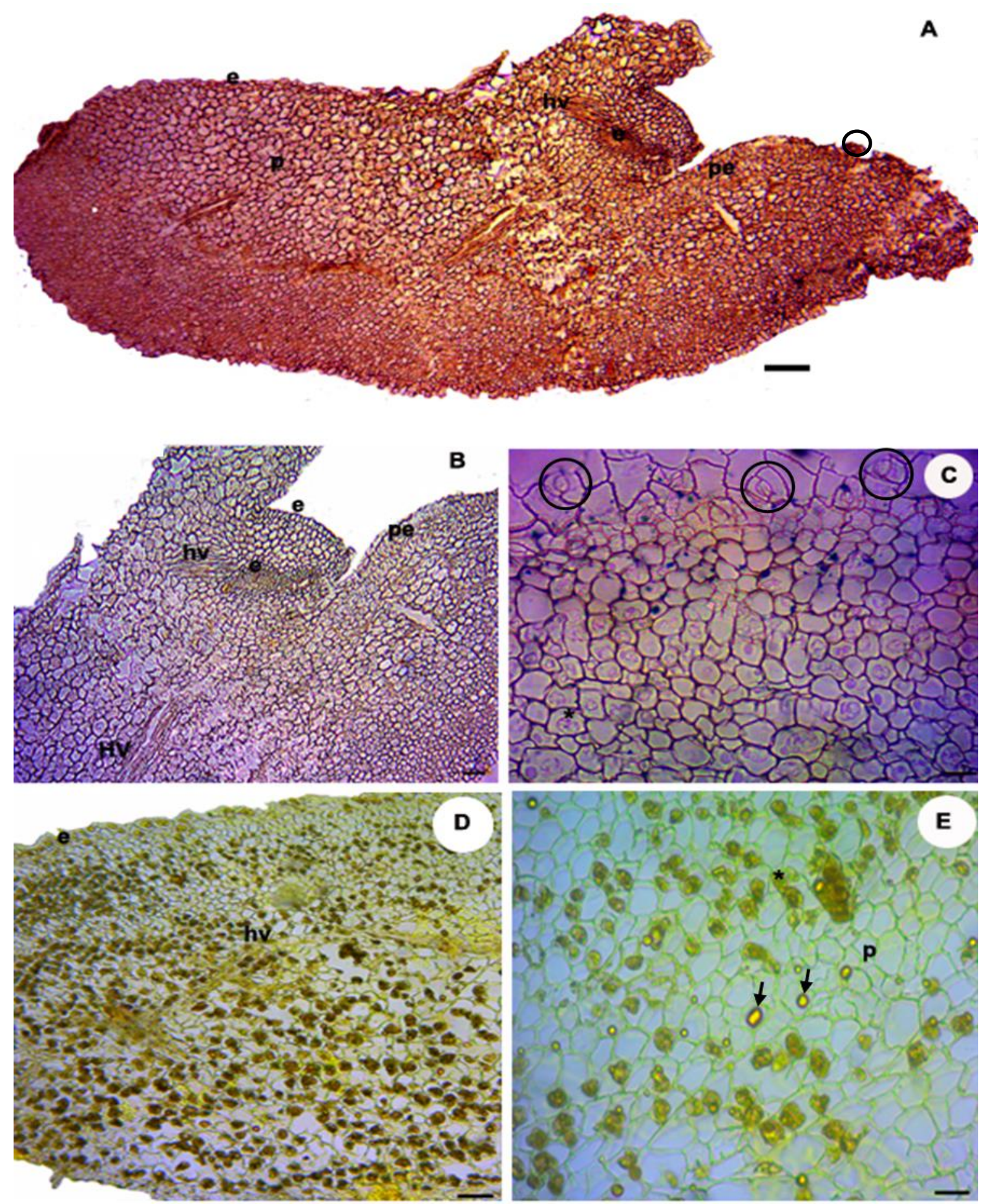

Figura 4. Corte longitudinal del cotiledón de Mimosa aculeaticarpa var. aculeaticarpa. A. Vista general; B. Acercamiento del epicótilo; C. Acercamiento de la epidermis del cotiledón; D. Almidones, E. Acercamiento del parénquima con almidones. e=epidermis, $h v=h a z$ vascular, pe=parénquima en empalizada, $p=$ parénquima. $A, B$ y $C$, cortes teñidos con Azul de Toluidina; $D$ y $E$, teñidos con Lugol. Barras equivalentes a: $A=100 \mu \mathrm{m}, B$ y $D=50 \mu \mathrm{m}$, C y $E=20 \mu \mathrm{m}$. Simbología: ${ }^{*}=$ amiloplastos, $\rightarrow$ =grano de almidón, $\mathrm{O}=$ estomas. 


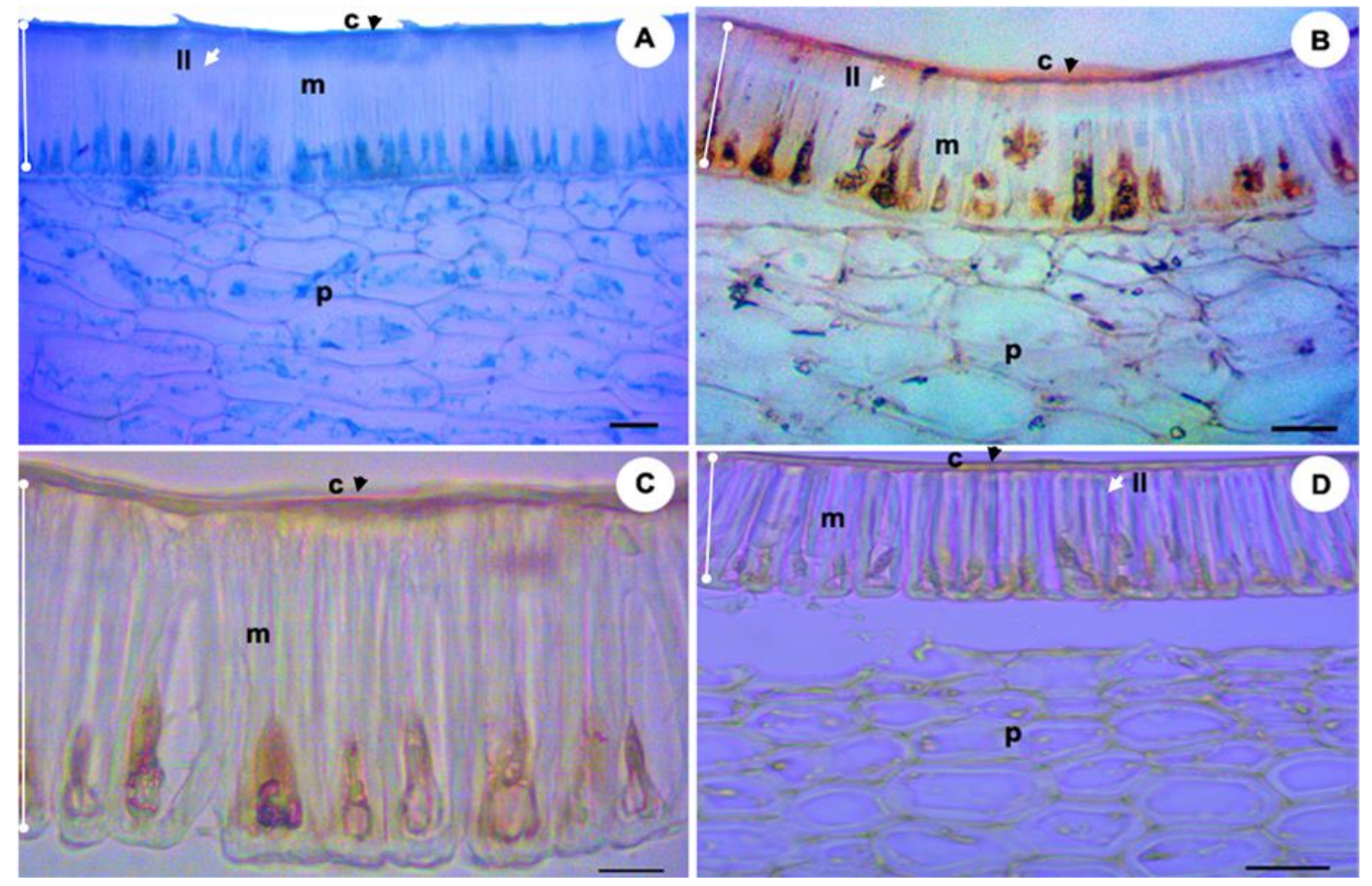

Figura 5. Anatomía de la testa de Mimosa aculeaticarpa var. aculeaticarpa. A. Tinción con Azul de Toluidina; B. Tinción con Safranina, C. Tinción con Floroglucina Clorhídrica, D. Tinción con Rojo $\mathrm{O}$ de aceite. c=cutícula (flecha negra), II=línea lúcida (flecha blanca), $\mathrm{m}=$ macroesclereidas (línea blanca), $\mathrm{p}=$ parénquima. Barras equivalentes $a: A, B$ y $\mathrm{D}=20 \mu \mathrm{m}$, $\mathrm{C}=10 \mu \mathrm{m}$. 


\section{Morfología y anatomía de la semilla de Mimosa luisana}

Las semillas se caracterizan por presentar una longitud que va desde 2.6 a $3.5 \mathrm{~mm}$, ancho de 1.8 a $2.4 \mathrm{~mm}$ y el grosor de 2.0 a $2.7 \mathrm{~mm}$, lo que sugiere que son ligeramente gruesas y umbonadas en el centro (Figura 6A-C). La forma de las semillas es de circular a elíptica (Figura 6B). La testa es glabra, lisa, punteada, color negro o marrón rojizo, brillante u opaca. La línea fisural está presente en ambas caras, forma una herradura alejada de los bordes, con brazos de igual longitud, abiertos y de 75\% de extensión (Figura 6A-B).

La región hilar es de obtusa a aguda; en ella, el micrópilo es circular, de color claro y está en posición apical (Figura 6C-E). El hilo es ovalado, de color claro, se ubica en posición sub-apical. La lente es circular, de color oscuro y se encuentra ubicada en la porción opuesta al micrópilo (Figura 6C-E).

Cabe mencionar que en semillas hidratadas, se observó la ruptura de la línea fisural y del micrópilo, lo que indica que estas estructuras, probablemente, sean los sitios permeables.

Por otro lado, las semillas se caracterizan por presentar un endospermo vítreo, adherido a toda la cubierta seminal (Figura 7B). El eje del embrión es recto. Se observaron cotiledones planos, sagitados y auriculados (Figura 7A-C). La radícula es corta $(2 \mathrm{~mm})$, gruesa $(0.5 \mathrm{~mm})$, recta y expuesta. Se observa el epicótilo (Figura 7CD) y no hay desarrollo de primordios foliares (plúmula). 

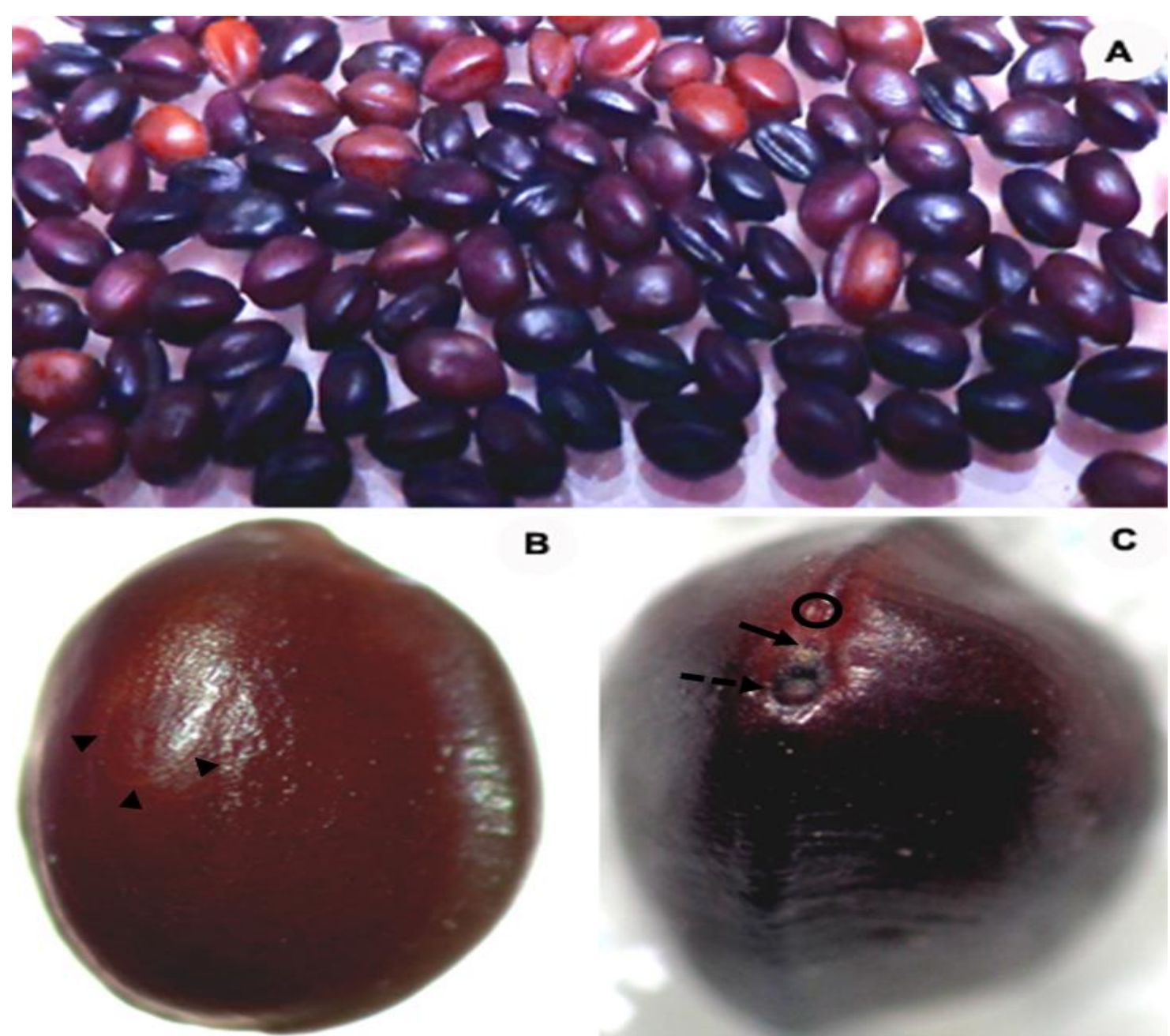

C
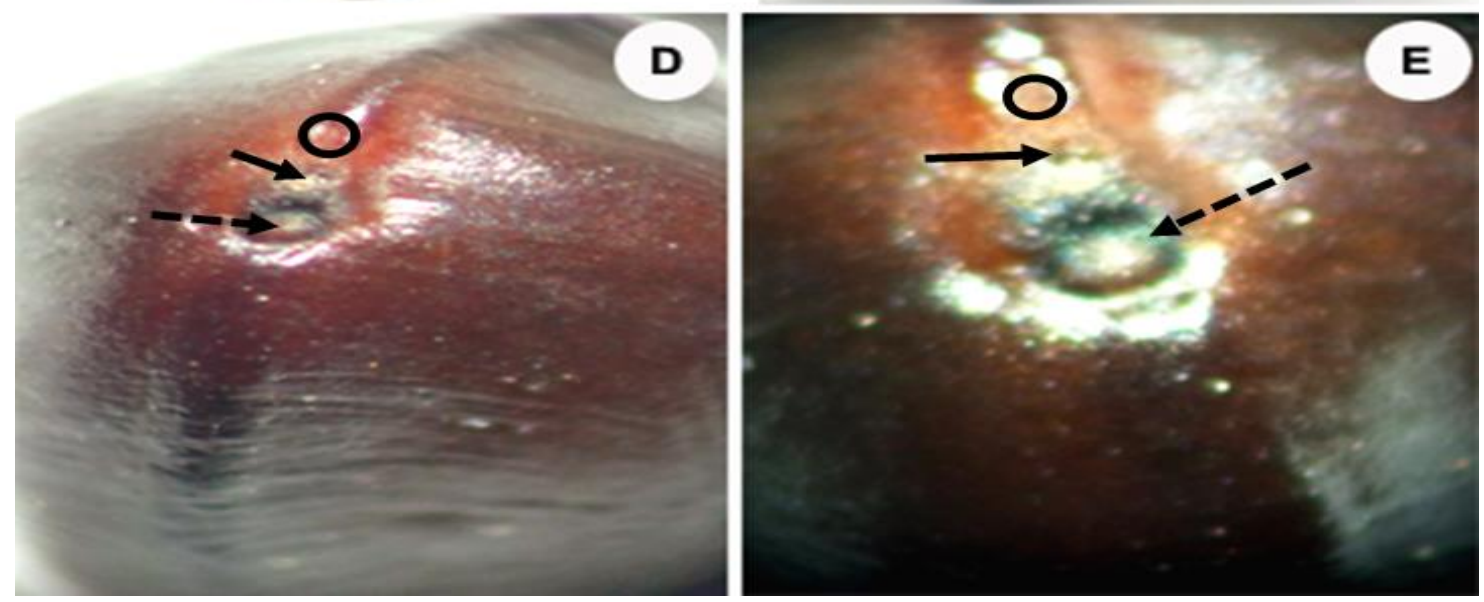

Figura 6. Morfología de la semilla de Mimosa luisana. A. Vista general de semillas; B. Forma circular a elíptica de la semilla; C. Vista de canto de la semilla; D-E. Acercamientos de la lente, el hilo y el micrópilo. Barra equivalente a $0.9 \mathrm{~mm}$.

Simbología: $\rightarrow=$ Hilo, $\cdots$ =lente, $\boldsymbol{\nabla}$ =línea fisural, $\mathrm{O}=$ micrópilo. 
Anatómicamente, los cotiledones presentan una epidermis que está formada por células alargadas paralelas a la superficie, de forma rectangular y tamaño variable (Figura 8A-B, D). Asimismo, la epidermis es monoestratificada compuesta por células isodiamétricas, ésta mostró estomas de tipo paracítico en la región del envés (Figura 8C).

Continuo a la epidermis, se observó una o dos capas de parénquima en empalizada (Figura 8A-B); le sigue el parénquima, éste se presenta en varias capas de células más o menos esféricas y poco compactadas (Figura 8C-E). Entre las capas de este tejido, se observan nítidamente haces vasculares que recorren el cotiledón (Figura 8A-B).

Cabe mencionar que las células que conforman el parénquima, muestran abundantes contenidos. La prueba histoquímica realizada indicó que no hay presencia de lípidos (figura no mostrada). Asimismo, la prueba de Lugol indicó la presencia de almidones en los cotiledones (Figura 8D y E).

Por otro lado, en la cara externa de la testa de esta semilla se encuentra una estructura que recubre a las capas internas de las células (Figura 9A-C), la cual se tiñe en rojo con Rojo O de aceite, indicando la presencia de lípidos (Figura 9D), por lo que esta capa puede estar constituida cutina y suberina, y por ello conformar una estructura impermeable como es la cutícula. Asimismo, se observó una capa de macroesclereidas con paredes engrosadas y radialmente alargadas, los lúmenes son anchos en su base y presentan abundantes contenidos intracelulares. 


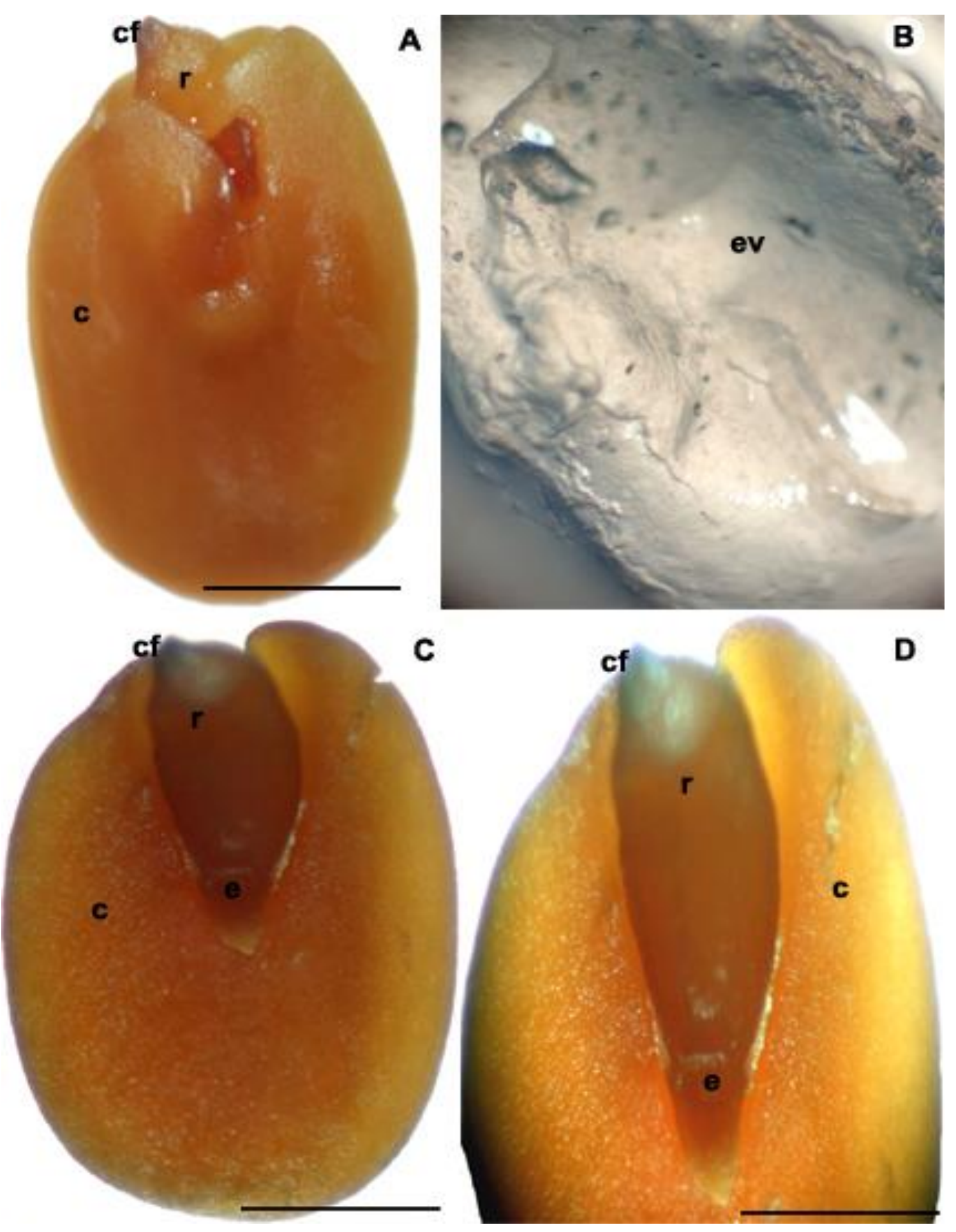

Figura 7. Morfología de los cotiledones de Mimosa luisana. A. Vista general; B. Endospermo; C. Cotiledón, epicótilo y radícula; D. Acercamientos del cotiledón, el epicótilo y la radícula. $\mathrm{C}=$ cotiledones, $\mathrm{cf}=\mathrm{cofia} \mathrm{ev}=\mathrm{endospermo}$ vítreo, $\mathrm{e}=$ =epicótilo, $\mathrm{r}=$ radícula. Barras equivalentes $\mathrm{a}$ : $\mathrm{A}=0.9 \mathrm{~mm}, \mathrm{C}=0.64 \mathrm{~mm}, \mathrm{D}=0.3 \mathrm{~mm}$. 

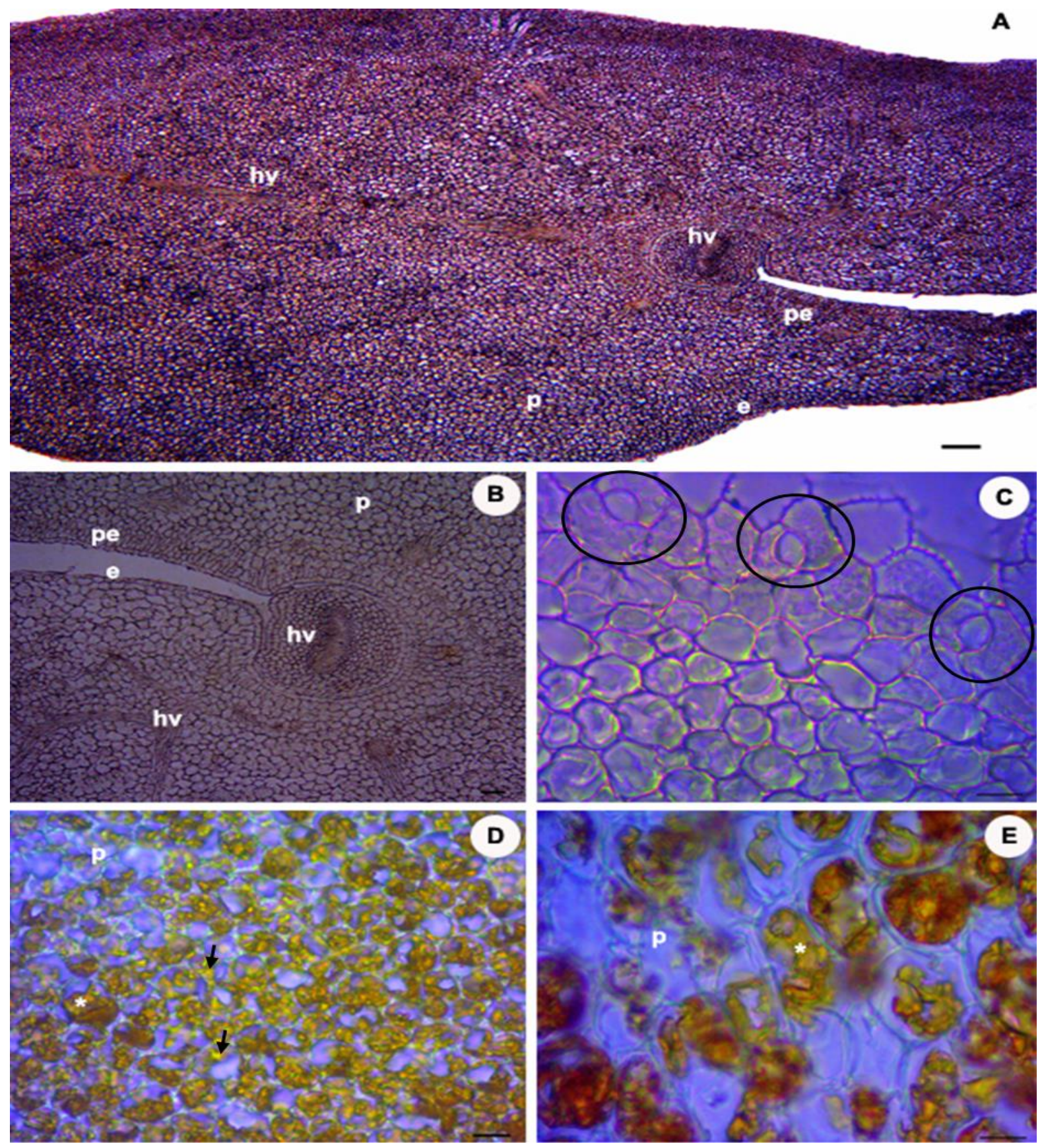

Figura 8. Cortes longitudinales del cotiledón de Mimosa luisana. A. Vista general; B. Acercamiento del eje del embrión; C. Acercamiento de la epidermis del cotiledón; D. Contenidos; E. Acercamiento del parénquima esponjoso con contenidos. e=epidermis, es=estomas, hv=haz vascular, pe=parénquima en empalizada, $p=$ parénquima, ${ }^{*}=$ contenidos. Barras equivalentes a: $A=100 \mu \mathrm{m}, B=50 \mu \mathrm{m}, C$ y $E=10 \mu \mathrm{m}$.

Simbología:*=amiloplastos, $\rightarrow$ =grano de almidón, $\mathrm{O}=$ estomas. 
Además, en las macroesclereidas se distingue la línea lúcida, la cual se ubica en la parte media de esta capa (Figura 9A-B, D).

La capa subyacente a las macroesclereidas son las osteoesclereidas. Las células de esta capa tienen paredes engrosadas. Debajo de las osteoesclereidas, se encuentra el parénquima que consta de 8-9 estratos de células tangencialmente alargadas (Figura 9A-D).
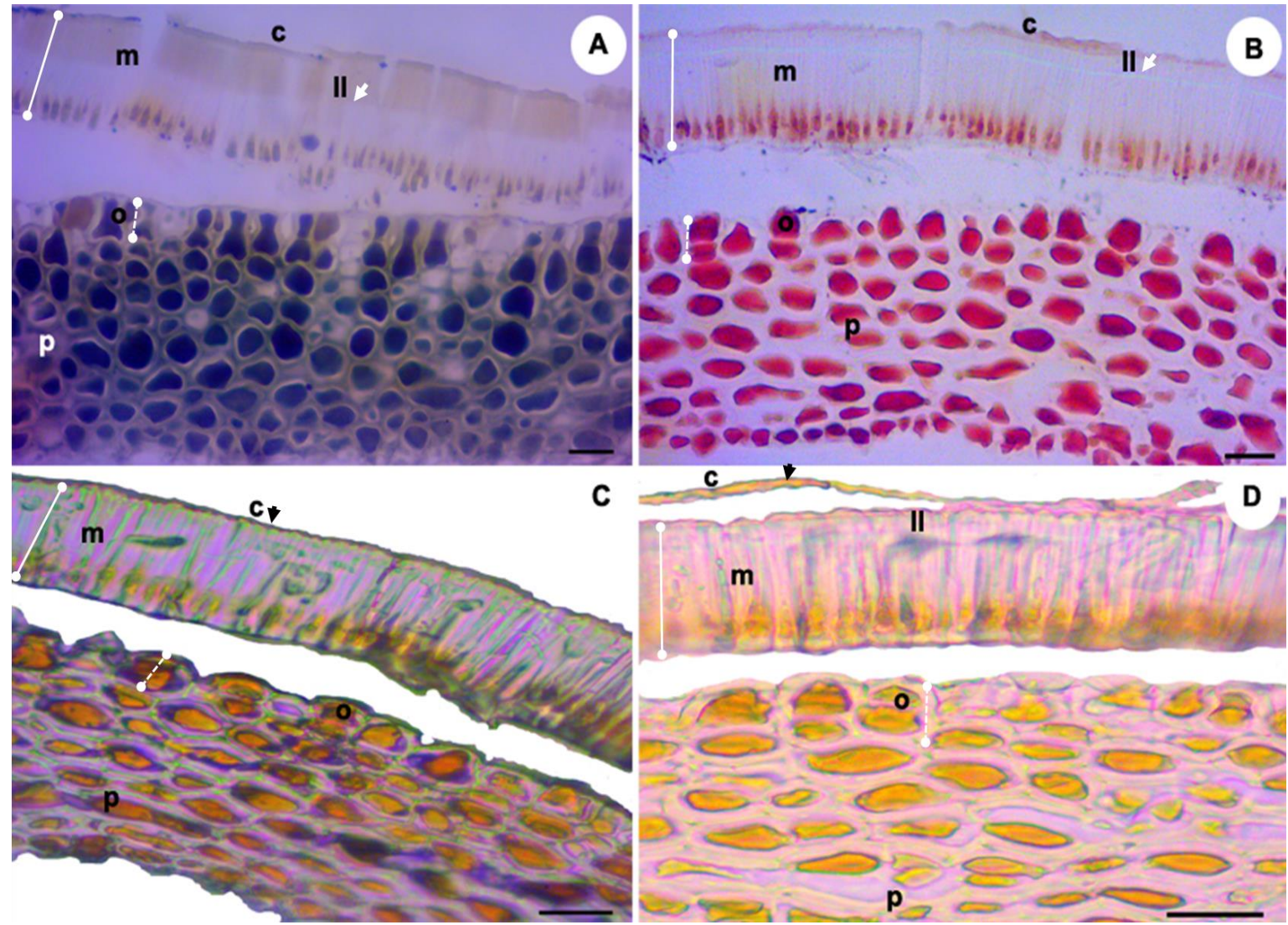

Figura 9. Anatomía de la testa de Mimosa luisana. A. Tinción con Azul de Toluidina; B. Tinción con Safranina, C. Tinción con Floroglucina Clorhídrica, D. Tinción con Rojo O de aceite. $\mathrm{c}=$ cutícula (flecha negra), Il=línea lúcida (flecha blanca), $\mathrm{m}=$ macroesclereidas (línea blanca), o=osteoesclereidas (línea blanca punteada), p=parénquima. Barras equivalentes a $20 \mu \mathrm{m}$. 


\section{DISCUSIÓN}

\section{Morfología de la semilla}

Las semillas de los taxa estudiados mostraron características morfológicas (hilo, micrópilo, lente y línea fisural) similares a las ya reportadas para la familia Leguminosae (P. ej. Boelcke, 1946; Corner, 1951; De Paula et al., 2012; Gunn, 1984, 1991; Lima, 1985).

Los resultados obtenidos, en conjunto con lo reportado en otros trabajos (P. ej. Gunn, 1984; Iwazaki, 2008; Leython y Jaúregui, 2008; Lima, 1985; Pammel, 1989), sugieren un patrón morfológico y anatómico que caracteriza a las semillas de la subfamilia Mimosoideae, el cual podría no mostrar relación con los ambientes en los que se establecen y desarrollan estos taxa vegetales; ya que la forma, la superficie lisa, la posición del hilo, la lente, la línea fisural y el micrópilo, son similares en varios géneros de mimosoideas como Albizia, Calliandra, Desmanthus, Entada, Mimosa, Neptunia, Parkia, Piptadenia y Prosopis, entre otros, y que habitan en ambientes diferentes, desde templados hasta cálido húmedos y secos (Boelcke, 1946; Bravato, 1974; Lima, 1985; Melo, 2011).

A nivel mundial, sólo se conoce la morfología de la semilla de ca. $12 \%$ de los taxa de Mimosa; sin embargo, es posible señalar que las semillas de este género presentan endospermo y una línea fisural bien definida. No obstante, al incorporar otros caracteres, existe un patrón específico para cada taxon, lo que permite identificarlas entre sí; por ejemplo, los dos taxa estudiados poseen endospermo, pero la forma de las semillas es diferente, ya que en $M$. aculeticarpa var. aculeaticarpa, la 
semilla es ovoide; mientras que las semillas de M. luisana son de circulares a elípticas.

Con relación a otros caracteres morfológicos como la extensión de los brazos que forma la línea fisural o la presencia de un endospermo vítreo, estos son compartidos con $M$. bimucronata, M. bonplandii (Gill.) Benth. y $M$. braacatinga Hoehne L. (Boelcke, 1946). Cabe señalar que estos caracteres y la forma de las semillas de los dos taxa estudiados, ya han sido reportados por Bravato (1974) y Lima (1985) en otros taxa de Mimosa (P. ej. M. arenosa (Willd.) Poir., M. camporum Benth. y M. tenuiflora (Willd.) Poir.); aunque, estos autores sólo realizaron una descripción general sobre la morfología de las semillas, sin dar detalles a nivel específico, lo que dificulta la comparación entre los taxa.

Asimismo, al analizar y comparar la morfología de las semillas de $M$. aculeaticarpa var. aculeaticarpa y M. luisana, con las descripciones de las semillas de los 61 taxa de Mimosa reportadas por Boelcke (1946), Bravato (1974), Lima (1985) y Melo (2011), es posible sugerir que la morfología de la semilla puede considerarse como un caracter constante; aunque, todavía falta por conocer la morfología de las semillas de ca. $88 \%$ de los taxa de este género.

Aunque este estudio no estuvo enfocado en reconocer los sitios permeables de las semillas, se observó que cuando se hidratan las semillas de ambos taxa, la línea fisural se fractura lo que podría indicar que se trata de un sitio frágil como lo reportó Schmidt (2000) y, por tanto, el probable sitio permeable. Sin embargo, no se 
descarta la posibilidad de que esta ruptura sea posterior a la entrada de agua y, refleje una liberación de presión para no generar daño al embrión. Cabe señalar que en M. luisana, además de la línea fisural, el micrópilo también sufrió una fractura, el cual también ha sido considerado uno de los sitios permeables de la semilla (Baskin y Baskin, 1998). Sin embargo, para ambos taxa, deben realizarse otras investigaciones encaminadas al bloqueo de los diferentes sitios de la semilla que, efectivamente, corroboren que la línea fisural y el micrópilo son los sitios permeables.

\section{Anatomía de las semillas}

Mimosa aculeaticarpa var. aculeaticarpa presenta semillas conformadas por sólo una capa de macroesclereidas; mientras que M. luisana presenta, además de la capa de macroesclereidas, una de osteoesclereidas. Asimismo, ambos taxa presentan línea lúcida, la cual se ubica en la capa de macroesclereidas. Estos dos últimos caracteres pueden considerarse como conservados, tanto a nivel de género como de familia (Corner, 1951; Geisler, 2013; De Paula et al., 2012), lo que concuerda con Van Staden et al. (1989), quienes señalan que las semillas de las leguminosas muestran un patrón estructural constante.

La presencia y organización de los caracteres anatómicos de la semilla de los taxa estudiados, coincide con lo reportado para otras leguminosas; por ejemplo, en Peltophorum dubium (Spreng.) Taub. (Geisler, 2013), Stylosanthes hamata (Castillo y Guenni, 2001) y Schizolobium parahyba (Souza et al., 2012). En la subfamilia Mimosoideae, esta misma organización ha sido observada en los géneros Acacia 
(Araújo-Neto et al., 2002), Adenanthera (Varela y Albornoz, 2013), Calliandra (Leython y Jaúregui, 2008), Desmanthus (Wood et al., 2010), Pithecellobium (Parra et al., 2011) y Prosopis (Irving, 1984), entre otros.

Asimismo, se considera que lo que le confiere rigidez a la testa y dureza a la semilla, es la capa de macroesclereidas lignificada (Martín-Gómez y Saco-Sierra, 2012). En los taxa estudiados, la capa de macroesclereidas presenta lignina, es continua y compacta, lo que, le proporciona rigidez y, de acuerdo con Parra (2011), funcionan como una barrera impermeable y, por tanto, le da protección al embrión (Smith et al., 2002).

Como ya se señaló, la presencia de una capa de macroesclereidas en la testa de la semilla se considera un caracter constante en las leguminosas y, por lo mismo, no está relacionado con el clima, sino con el genoma de esta familia de plantas (Martín-Gómez, 2013); probablemente, sea el resultado de respuestas adaptativas, ya que ambos taxa, aunque se desarrollan en ambientes contrastantes ( $M$. aculeaticarpa var. aculeaticarpa, ambiente mésico, y $M$. luisana, ambiente semiárido), mostraron una capa de macroesclereidas lignificadas. Además, la presencia de macroesclereidas también ha sido reportada en otras leguminosas de amplia distribución y que, actualmente, presentan un uso ornamental en muchas partes del mundo como Acacia kempeana F. Muell. (Hanna, 1984), originaria de Australia, que habita en climas cálido secos; Anadenanthera colubrina var. cebil (Vell.) Brenan (Varela y Albornoz, 2013), taxon de amplia distribución en Sudamérica $y$, por lo mismo, se desarrolla en diferentes ambientes como pueden ser las sabanas 
y los bosques tropicales húmedos, con climas que van desde los cálido secos hasta los húmedos; Cassia leptophylla, originaria del SE del Brasil, habita en climas cálido húmedos hasta cálido secos; y Senna macranthera, originaria del norte sudamericano, habita principalmente en climas cálido húmedos (De Paula et al., 2012). De acuerdo con Smith et al. (2002) y Radchuk y Borisjuk (2014), la función de las macroesclereidas es fungir como una barrera en la entrada de agua y gases, pero no es la única, porque la primera línea de impermeabilidad es la cutícula. En este estudio, las semillas de ambos taxa mostraron una cutícula (para su determinación se utilizó el reactivo Rojo O de aceite y SUDÁN III); sin embargo, en el tratamiento de hidratación de la semilla, ésta se desprende; la ruptura de la cutícula también se ha observado en las semillas de Mimosa bimucronata cuando son sometidas a tratamientos de escarificación térmica (Geisler, 2013).

En el caso de la capa de osteoesclereidas, ésta está ausente en las semillas de M. aculeaticarpa var. aculeaticarpa, lo que permitió diferenciarla de las semillas de M. luisana. La presencia de osteosesclereidas también ha sido observada en otras Mimosoideae como Leucaena leucocephala (Serrato-Valenti, 1994) y Prosopis velutina Woot. (Irving, 1984). Estas plantas, al igual que M. Iuisana, habitan zonas secas, lo que sugiere que sus semillas están más protegidas para sobrevivir a períodos desfavorables (Debeaujon et al., 2010; Smith et al., 2002). Asimismo, Radchuk y Borisjuk (2014) sugieren que la presencia de esclereidas en la testa de las semillas indica una protección contra la desecación; así como una mayor resistencia mecánica y es, además, una forma de controlar el desarrollo de las 
semillas, ya que los nutrientes deben atravesar las capas de la testa para favorecer el desarrollo del embrión.

Las pruebas histoquímicas realizadas en este estudio mostraron que las macroesclereidas y las osteoesclereidas presentan lignina, lo que indica la resistencia (López et al., 2011) e impermeabilidad de las semillas (Jayasuriya et al., 2007). De acuerdo con Melo (2011), la presencia de macroesclereidas y de osteoesclereidas es la causa probable de la latencia de las semillas, ya que impiden la entrada de agua y de oxígeno, recursos requeridos en la germinación. Aunado a esto, las semillas de ambos taxa presentaron la línea lúcida en la parte superior o media de las macroesclereidas. Según Geisler (2013), la línea lúcida puede contener calosa, lo que implica una impermeabilización más eficaz contra la entrada de agua y gases. Sin embargo, en este estudio, no se abordó a detalle la parte histoquímica, por lo que se requiere de este tipo de estudios para poder asociar la impermeabilidad de las semillas con su anatomía y contenidos.

Desde una perspectiva integral, es importante señalar que la testa de la semilla presenta una función moduladora entre las estructuras internas de la semilla y el ambiente. En este sentido y en concordancia con lo señalado por Arambarri (2002) y De Souza y Marcos-Filho (2001), la morfología de la semilla y la anatomía de la testa de los dos taxa estudiados, estarían indicando no sólo la impermeabilidad de las semillas, sino también su longevidad y el tipo de dispersión de las mismas. 


\section{CONCLUSIONES}

En el caso del estudio de las semillas de las leguminosas, la morfología es el aspecto más explorado, en comparación con la anatomía. Particularmente, en el género Mimosa se ha estudiado la morfología de las semillas de ca. 12\% (61 taxa) de los taxa a nivel mundial; mientras que el conocimiento de su anatomía es muy limitado. Al respecto, solamente se tienen tres registros; sin embargo, estos no consideran la parte de la testa de la semilla.

Este estudio demuestra que las semillas de $M$. aculeaticarpa var. aculeaticarpa se caracterizan por presentar: I) Cutícula, ii) Macroesclereidas, y iii) Línea lúcida y, M. luisana por poseer: i) Cutícula, ii) Macroesclereidas, iii) Línea lúcida, y iv) Osteoesclereidas. Estos caracteres, además de prevenir la germinación inicial, elevan la longevidad de la semilla y son la causa probable de la impermeabilidad. Además, indican que las semillas de M. luisana tienen una testa con mayor número de capas, posiblemente, esto esté asociado con el ambiente en el que se desarrolla o a que deben estar protegidas, ya que son infestadas por brúquidos (Camargo-Ricalde et al., 2004; Montaño-Arias et al., 2015) y consumidas por caprinos (Giordani, 2008).

Por otro lado, analizando de manera conjunta los resultados obtenidos con la literatura, se sugiere que la presencia de macroesclereidas es un caracter no relacionado con el clima, sino con el genoma de la familia que puede ser el resultado de procesos adaptativos; mientras que, en el caso de las osteoesclereidas, todavía no es posible definir si pudiesen estar relacionadas con el clima o con el genoma de 
la familia; sin embargo, el hecho de que formen parte de la testa, sugiere que las semillas de $M$. luisana son más longevas que las semillas de $M$. aculeaticarpa var. aculeaticarpa.

Por lo anterior, se confirma la hipótesis planteada; sin embargo, es importante señalar que el conocimiento sobre la morfología y la anatomía de las semillas y la explicación del funcionamiento de las estructuras presentes en éstas, son elementos a considerar para decidir, de manera objetiva, sobre cuál método de escarificación sería el adecuado para evitar cualquier tipo de daño al embrión y promover la germinación de las semillas; así como para elaborar hipótesis relacionadas con los procesos adaptativos de la familia Leguminosae.

Aunque el conocimiento anatómico de la semilla solamente se ha abordado en cinco taxa de Mimosa, sumando los aquí estudiados, es factible llevar a cabo inferencias relacionadas con la germinación de sus semillas. Desde una perspectiva ecológica, esto permite entender parte de la relación planta-ambiente, considerando, principalmente, las fluctuaciones de temperatura y precipitación. Por lo mismo, falta complementar estas investigaciones con otras relacionadas con la longevidad de las semillas, los sitios de entrada de agua y la dispersión de éstas, entre muchas otras.

\section{LITERATURA CITADA}

Alsina, M. 1988. Estudio morfológico y anatómico de las semillas del género Ornithopus L. (Fabaceae). Acta Botánica Malacitana 13: 171-178. 
Arambarri, A.M. 2002. Morfología, Anatomía y formaciones cristalinas en especies del género Senna, sección Chamaefistula de la Argentina (LeguminosaeCaesalpinioideae-Cassieae-Cassinae). Doctoral dissertation, Facultad de Ciencias Exactas. Universidad Nacional de La Plata, Argentina. 205 p.

Araújo-Neto, J.C., Aguiar I.B. Ferreira V.M. y Paula R.C. 2002. Caracterização morfológica de frutos e sementes e desenvolvimento pós-seminal de monjoleiro (Acacia polyphylla DC.). Revista Brasileira de Sementes 24: 203-211.

Auld, T.D. 1996. Ecology of the Fabaceae in the Sydney region: fire, ants and the soil seedbank. Cunninghamia 4: 531-551.

Barneby, R.C. 1991. Sensitivae Censitae. A description of the genus Mimosa L. (Mimosaceae) in the New World. Memoirs of the New York Botanical Garden 65: 1-835.

Barretto, S.S.B. y Ferreira R.A. 2011. Aspectos morfológicos de frutos, sementes, plântulas e mudas de Leguminosae Mimosoideae: Anadenanthera colubrina (Vellozo) Brenan e Enterolobium contortisiliquum (Vellozo) Morong. Revista Brasileira de Sementes 33: 223-232.

Baskin, C.C. 2003. Breaking physical dormancy in seeds focusing on the lens. New Phytologist 158: 229-232.

Baskin, C.C. y Baskin J.M. 1998. Seeds: ecology, biogeography, and evolution of dormancy and germination. San Diego, California, USA, Academic Press. 666 p. Baskin, J.M. y Baskin C.C. 2004. A classification system for seed dormancy. Seed Science Research 14: 1-16. 
Baskin, J.M., Baskin C.C. y Li X. 2000. Taxonomy, anatomy and evolution of physical dormancy. Plant Species Biology 15: 139-152.

Boelcke, O. 1946. Estudio morfológico de las semillas de Leguminosas, Mimosoideas y Caesalpinoideas de interés agronómico en la Argentina. Darwiniana 7: 240321.

Bravato, M. 1974. Estudio morfológico de frutos y semillas de las Mimosoideae (Leguminosae) de Venezuela. Acta Botanica Venezuelica 9: 317-361.

Braz, M.D.S.S., Freitas S.D.L.S., Campos M.A.L., de Miranda D.D.O.A. y Cosme M.C. 2012. Caracterização morfológica do fruto, semente, plântula e planta jovem e germinação de Inga ingoides (Rich) Willd. Cerne, Lavras 18: 353-360.

Burns, R.E. 1959. Effect of acid scarification on lupine seed impermeability. Plant Physiology 34: 107-108.

Caccavari, M.A. 1985. Granos de polen de las Leguminosas de la Argentina IV. Género Mimosa. Boletín de la Sociedad Argentina de Botánica 24: 151-167.

Caccavari, M.A. 1986. Estudio de los caracteres del polen de las Mimosa-Lepidotae. Pollen et Spores 28: 29-42.

Caccavari, M.A. 1987. Estudio de los caracteres del polen de Mimosa-Glanduliferae, VII, Simposio Argentino de paleobotánica y Palinología. Actas 141-144.

Camargo-Ricalde, S.L. y Dhillion S.S. 2003. Endemic Mimosa species can serve as mycorrhizal "resource islands" within semiarid communities of the TehuacánCuicatlán Valley, Mexico. Mycorrhiza 13: 129-136. 
Camargo-Ricalde, S.L., Dhillion S.S. y Grether R. 2002. Community structure of endemic Mimosa species and environmental heterogeneity in a semi-arid Mexican valley. Journal of Vegetation Science 13: 697-704.

Camargo-Ricalde, S.L., Grether R., Martínez-Bernal A., García-García V. y Barriosdel-Rosal S. 2001. Especies útiles del género Mimosa (Fabaceae-Mimosoideae) en México. Boletín de la Sociedad Botánica de México 68: 33-44.

Camargo-Ricalde, S.L., Dhillion S.S. y García-García V. 2004. Phenology, and seed production and germination of seven endemic Mimosa species (FabaceaeMimosoideae) of the Tehuacán-Cuicatlán Valley, Mexico. Journal of Arid Environments 58: 423-437.

Camargo-Ricalde, S.L., Montaño N.M., Reyes-Jaramillo I., Jiménez-González C. y Dhillion S.S. 2010a. Effect of mycorrhizae on seedlings of six endemic Mimosa L. species (Leguminosae-Mimosoideae) from the semi-arid Tehuacán-Cuicatlán Valley, Mexico. Trees-Structure and Function 24: 67-78.

Camargo-Ricalde, S.L., Reyes-Jaramillo I. y Montaño N.M. 2010b. Forestry insularity effect of four Mimosa L. species (Leguminosae-Mimosoideae) on soil nutrients of a Mexican semiarid ecosystem. Agroforestry Systems 80: 385-397.

Castillo, R. y Guenni O. 2001. Latencia en semillas de Stylosanthes hamata (Leguminosae) y su relación con la morfología de la cubierta seminal. Revista de Biologia Tropical 49: 287-299.

Corner, E. 1951.The Leguminous seed. Phytomorphology 1: 117-150. 
Corner, E. 1976. The seeds of Dicotyledons. Vol. I. Cambridge University. Madingley Road, Cambridge, England. 309 p.

Chehaibar, M.T. 1988. Estudio Taxonómico de la Serie Xantiae y especies afines del Género Mimosa (Leguminosae), Tesis de Maestría en Ciencias, Facultad de Ciencias, UNAM, México. 107 p.

D’Aubeterre, R., Principal J. y García J. 2002. Efecto de diferentes métodos de escarificación sobre la germinación de tres especies del género Prosopis. Revista Científica 12: 575-577.

Debeaujon, I., Léon-Kloosterziel K.M. y Koornneef M. 2000.Influenceof the testa on seed dormancy, germination, and longevity in Arabidopsis. Plant Physiology 122: $403-413$.

De Paula, A.S., Delgado C.M.L., Paulilo M.T.S. y Santos M. 2012. Breaking physical dormancy of Cassia leptophylla and Senna macranthera (Fabaceae: Caesalpinioideae) seeds: water absorption and alternating temperatures. Seed Science Research 22: 1-9.

De Souza, F.H.D y Marcos-Filho J. 2001. The seed coat as a modulator of seedenvironment relationships in Fabaceae. Revista Brasileira de Botânica 24: 365375.

De Souza, L.A. 1982. Estrutura do tegumento das sementes de Cassia cathartica Mart. (Leguminosae). Ciência e Cultura 34: 71-74. 
Delgado, C.M. L., De Paula A.S., Santos M. y Paulilo M.T.S. 2015. Dormancybreaking requirements of Sophora tomentosa and Erythrina speciosa (Fabaceae) seeds. International Journal of Tropical Biology and Conservation 63: $285-294$.

De-Paula, O.C. y Oliveira D.M.T. 2007. Variação da estrutura carpelar em seis espécies de Cassiinae (Leguminosae: Caesalpinioideae). Acta Botanica Brasilica 21: 915-925.

Diego-Pérez N. 2013. El gineceo. 68-72 p. En: Márquez-Guzmán J., Collazo-Ortega M., Orozco-Segovia A., Vázquez-Santana S. (eds.). Biología de angiospermas. Universidad Nacional Autónoma de México.

Egley, G.H. 1979. Seed coat impermeability and germination of showy crotolaria (Crotolaria spectabilis) seeds. Weed Science 27: 355-361.

Endo, Y. 2012. Anatomical diversity of funicles in Leguminosae. Journal of Plant Research 125: 41-53.

Escala, M. 1999. Estudio morfoanatómico de frutos y semillas de Leguminosas de los Altos Llanos Centrales de Venezuela (Estación Biológica de los Llanos de La Sociedad Venezolana de Ciencias Naturales). Boletín de la Sociedad Venezolana de Ciencias Naturales 148: 259-316.

Forero, E. y Romero C. 2005. Estudios en leguminosas colombianas. Academia Colombiana de Ciencias Exactas, Físicas y Naturales. Colección Jorge Álvarez Lleras (25: 11-18). Santa Fé de Bogotá, Colombia: Editora Guadalupe Ltda. 
Flores-Cruz, M.F., Lira H.D.S., Martínez-Bernal A. y Fraile M.E. 2006. Morfología del polen de Mimosa serie quadrivalves (Leguminosae, Mimosoideae). Acta Botánica Mexicana 77: 1-13.

Geisler, G.E. 2013. Quebra de dormência física e identificação do local de entrada de água em sementes de duas espécies de Fabaceae Peltophorum dubium (Caesalpinioideae) e Mimosa bimucronata (DC) O. Kuntze (Mimosoideae). Tesis de Maestría. Centro de Ciências Biológicas da Universidade Federal de Santa Catarina, Florianópolis, S.C., Brasil. 79 p.

Giordani L. 2008. The role of goats in germination and dispersal of Mimosa luisana Brandegee (Leguminosae-Mimosoideae) seeds in the Tehuacán-Cuicatlán valley, Puebla State, Mexico. Master Thesis, Norwegian University of life Sciences, Norway, $32 \mathrm{p}$.

González-Castañeda, J., Angoa-Pérez M.V., Frías-Hernández J.T., Olalde-Portugal V., Flores-Ancira E., Terrones-Rincón T.R., Van Cleemput O. y Dendooven L. 2004. Germination of seeds of huisache (Acacia schaffneri) and catclaw (Mimosa monancistra) as affected by sulphuric acid and mechanical scarification and subsequent growth and survival in a greenhouse and field experiment. Seed Science and Technology 32: 727-738.

Grether, R. 1978. A general review of the genus Mimosa L. (Leguminosae) in Mexico. Bulletin of the International Group for the Study of Mimosoideae 6: 45-50.

Grether, R., Camargo-Ricalde S.L. y Martínez-Bernal A. 1996. Especies del género Mimosa (Leguminosae) presentes en México. Boletín de la Sociedad Botánica de México 58: 149-152. 
Grether, R. 2000. Nomenclatural changes in the genus Mimosa (Fabaceae, Mimosoideae) in Southern Mexico and Central America. Novon 10: 29-37.

Gunn, C.R. 1984. Fruits and seeds of genera in the subfamily Mimosoideae (Fabaceae). Technical Bulletin no. 1681. Agricultural Research Service. United States Departament of Agriculture, Washington DC. 194 p.

Gunn, C.R. 1981. Seeds of Leguminosae. In R.M. Polhill y P.H. Raven (eds.). Advances in legume systematics, Crow Copyright, Kew. 2: 913-925.

Gunn, C.R. 1991. Fruits and seeds of genera in the subfamily Caesalpinoideae (Fabaceae). Technical Bulletin no. 1755. Agricultural Research Service. United States Departament of Agriculture, Washington DC. 408 p.

Hamly, D.H. 1932. Softening of the seeds of Melilotus alba. Botanical Gazette 93: 345-375.

Hanna, P.J. 1984. Anatomical features of the seed coat of Acacia kempeana (Mueller) which relate to increased germination rate induced by heat treatment. New Phytologist 96: 23-29.

Hu, X.W., Wang Y.R., Wu Y.P. y Baskin C.C. 2008. Role of the lens in physical dormancy in seeds of Sophora alopecuroides L. (Fabaceae) from northwest China. Australian Journal of Agricultural Research 59: 491-497.

Hu, X.W., Wang Y.R., Wu Y.P., y Baskin C.C. 2009. Role of the lens in controlling water uptake in seeds of two Fabaceae (Papilionoideae) species treated with sulphuric acid and hot water. Seed Science Research 19: 73-80.

Irving, D.W. 1984. Seed structure and histochemistry of Prosopis velutina (Leguminosae). Botanical Gazette 145: 340-345. 
Iwazaki, M.C. 2008. Frutos, sementes e plântulas de três espécies de Mimosa Linnaeus (Fabaceae: Mimosoideae): aspectos morfoanatômicos e considerações ecológico-filogenéticas. Dissertação de Mestrado. Universidade Estadual Paulista (UNESP), Botucatu, São Paulo, Brasil. 108 p.

Jayasuriya, K.M.G., Wijetunga A.S., Baskin J.M. y Baskin C.C. 2013. Seed dormancy and storage behaviour in tropical Fabaceae: a study of 100 species from Sri Lanka. Seed Science Research 23: 257-269.

Jayasuriya, K.M.G.G., Baskin J.M., Geneve R.L. y Baskin C.C. 2007. Morphology and anatomy of physical dormancy in Ipomoea lacunosa: identification of the water gap in seeds of Convolvulaceae (Solanales). Annals of Botany 100: 13-21.

Johansen, D.A. 1940. Plant Microtechnique. McGraw-Hill, New York.

Karaki, T., Watanabe Y., Kondo T. y Koike T. 2012. Strophiole of seeds of the black locust acts as a water gap. Plant Species Biology 27: 226-232.

Koizumi, M. y Kano H. 2014. Lens: Water channel for dry broad bean seeds at germination observed by micro-magnetic resonance imaging. American Journal of Biology and Life Sciences 2: 37-40.

Kopooshian, H. 1963. Seed character relationships in the Leguminosae. 166 p.

Leython, L. y Jaúregui D. 2008. Morfología de la semilla y anatomía de la cubierta seminal de cinco especies de Calliandra (Leguminosae-Mimosoideae) de Venezuela. Revista Biología Tropical 56: 1075-1086.

Leython, S. 2010. Estudio morfológico de semillas del género Calliandra Benth. (Leguminosae-Mimosoideae) de Venezuela. Acta Botánica Venezuelica 33: 4165. 
Lima, M.P.M. 1985. Morfologia dos frutos e sementes dos gêneros da tribo Mimoseae (Leguminosae-Mimosoideae) aplicada à Sistemática. Rodriguésia 37: 53-78.

López, F., Zamudio M.A.M., de Alva H.E., Pérez A., García J.C., García-Morales M. y Martín-Alfonso J.E. 2011. Caracterización y aplicación de lignina de Paulownia obtenida mediante un proceso de autohidrólisis y deslignificación $\mathrm{NaOH} /$ antraquinona. Afinidad 68: 189-194.

Mariño, N., Escala M., de Miranda M.C. y Ramis C. 2007. Características morfológicas cualitativas y cuantitativas en semillas de algunas especies del género Canavalia. Revista de la Facultad de Agronomía 33: 55-76.

Martínez-Pérez, G., Orozco-Segovia A. y Martorell C. 2006. Efectividad de algunos tratamientos pre-germinativos para ocho especies leñosas de la Mixteca Alta Oaxaqueña con características relevantes para la restauración. Boletín de la Sociedad Botánica de México 79: 9-20.

Martín-Gómez, J.J. 2013. Análisis morfológico de las semillas mediante modelos basados en las curva cardioide. Tesis de Doctorado, Centro de Investigaciones Científicas. Universidad de Salamanca, España. 175 p.

Martín-Gómez, S. y Saco-Sierra D. 2012. Estudio de los tejidos para la caracterización de las plantas. REDUCA 4: 1-26.

Meireles, J.E. y Tozzi A.M.G.A. 2008. Seed and embryo morphology of Poecilanthe (Fabaceae, Papilionoideae, Brongniartieae). Botanical Journal of the Linnean Society 158: 249-256. 
Melo, M.G.G. 2011. Frutos, sementes e desenvolvimento plantular de três espécies de Parkia R. Br. (Fabaceae-Mimosoideae): uma abordagem Morfoanatómica, hitoquímica e tecnológica. Doctoral dissertation, Faculdade de Ciências Agrárias, Universidade Federal do Amazonas. Manaus, Brasil. 180 p.

Melo, M.G.G., Mensonça M.S. y Mendes A.M.S. 2004. Análise morfológica de sementes, germinação e plântulas de jatobá (Hymenaea intermedia Ducke var. adenotricha (Ducke) Lu \& Lang.) (Leguminosae-Caesalpinioideae). Acta Amazônica 34: 9-14.

Molizane, D.M. 2012. Estabelecimento e superação de dormência em sementes de Erythrina speciosa Andrews. Doctoral dissertation, Instituto de Biociências. Botucatu, São Paulo, Brasil. 77 p.

Montaño-Arias, S., Camargo-Ricalde S.L. y De la Paz-Pérez-Olvera C. 2013. Ecoanatomía de los elementos vasculares de la madera de cinco especies del género Mimosa (Leguminosae-Mimosoideae). Botanical Sciences 91: 1-10.

Montaño-Arias, S.A., Camargo-Ricalde S.L., Grether R. y Díaz-Pontones D. 2015. Effect of scarification and temperature on seed germination of two Mexican species of Mimosa (Leguminosae-Mimosoideae). Botanical Sciences 93: 649659.

Moreno-Calles, A.I. y Casas A. 2010. Agroforestry systems: restoration of semiarid zones in the Tehuacán Valley, Central Mexico. Ecological Restoration 28: 361368. 
Morrison, D.A., Auld T.D., Rish S., Porter C. y McClay K. 1992. Patterns of testaimposed seed dormancy in native Australian legumes. Annals of Botany 70: 157-163.

Morrison, D.A., McClay K., Porter C. y Rish S. 1998. The role of the lens in controlling heat-induced breakdown of testa-imposed dormancy in native Australian legumes. Annals of Botany 82: 5-40.

Munsell Color Company. 1990. Munsell soil color charts. Baltimore, MD, USA. 17 p.

Navarro, M. 2003. Desempeño fisiológico de las semillas de árboles leguminosos de uso múltiple en el trópico. Pastos y Forrajes 26: 97-114.

Navarro, M., Febles G., Torre V. y Noda A. 2010. Effect of moist and dry scarification on the germination capacity of seeds from Albizia lebbeck (L.) Benth. Pastos y Forrajes 33: 1-7.

Pammel, L.H. 1886. On the structure of the testa of several Leguminous seeds. Bulletin of the Torrey Botanical Club 13: 17-24.

Parra, S., Sanabria M. y Maciel N. 2011. Aspectos descriptivos de la semilla, emergencia y crecimiento de plántulas de Yacure (Pithecellobium dulce) y Roble (Platymiscium diadelphum). Revista de la Facultad de Agronomía 28: 576-585.

Pavón, N.P., Ballato-Santos J. y Pérez-Pérez C. 2011. Germinación y establecimiento de Mimosa aculeaticarpa var. biuncifera (FabaceaeMimosoideae). Revista Mexicana de Biodiversidad 82: 653-661.

Pitot, A. 1935. Le développement du tégument des graines de Légumineuses. Bulletin de la Société Botanique de France 82: 311-314. 
Qutob, D., Ma F., Peterson C.A., Bernards M.A. y Gijzen M. 2008. Structural and permeability properties of the soybean seed coat. Botany 86: 219-227.

Radchuck, V. y Borisjuk L. 2014. Physical, metabolic and developmental functions of the seed coat. Frontiers in Plant Science 5: 1-17.

Robles, D.E. 2011. Identificación del" hueco de agua" y su relación con la latencia física en semillas del género Lupinus spp. de Jalisco, México. Tesis de Maestría. Instituto Potosino de Investigación Científica y Tecnológica, A.C. San Luis Potosí, México. 75 p.

Sanabria, D., Silva-Acuña R., Oliveros M. y Manrique U. 2004. Nota técnica germinación de semillas de las leguminosas arbustivas forrajeras Cratylia argentea y Cassia moschata sometidas a inmersión en ácido sulfúrico. Bioagro 16: $225-230$.

Sandoval-Zapotitla, E. 2005. Técnicas Aplicadas al Estudio de la Anatomía Vegetal. Cuadernos del Instituto de Biología, No. 38. Universidad Nacional Autónoma de México, D.F. México, México. 278 p.

Särkinen, T.E., Marcelo-Peña J.L., Yomona A.D., Simon M.F., Pennington R.T. y Hughes C.E. 2011. Underestimated endemic species diversity in the dry interAndean valley of the Río Marañón, northern Peru: An example from Mimosa (Leguminosae, Mimosoideae). Taxon 60: 139-150.

Schmidt, L. y Jøker D. 2001. Glossary of Seed Biology and Technology. DFSC Series of Technical Notes, TN59, Danida Forest Seed Centre, Humlebaek, Denmark. $35 \mathrm{p}$. 
Schmith, L. 2000. Guide to handling of tropical and subtropical forest seeds. Danida forest seed center, Krogerupvej-21, Denmark. 511 p.

Serrato-Valenti, G., Cornara L., Ghisellini P. y Ferrando M. 1994.Testa structure and histochemistry related to water uptake in Leucaena leucocephala Lam. (De Wit). Annals of Botany 73: 531-537.

Serrato-Valenti, G., Vries M.D. y Cornara L. 1995. The hilar region in Leucaena leucocephala Lam. (De Wit) seed: structure, histochemistry and the role of the lens in germination. Annals of Botany 75: 569-574.

Simon, M.F., Grether R., de Queiroz L.P., Särkinen T.E., Dutra V.F. y Hughes C.E. 2011. The evolutionary history of Mimosa (Leguminosae) toward a philogeny of the sensitive plants. American Journal of Botany 98: 1201-1221.

Smith, M.T., Wang B.S.P. y Msanga H.P. 2002. Dormancy and germination. 149-176 p. In Vozzo, J.A. (ed.) Tropical tree seed manual. Agriculture Handbook 721. Washington DC, USDA Forest Service.

Smýkal, P., Vernoud V., Blair M.W. Soukup A. y Thompson R.D. 2014. The role of the testa during development and in establishment of dormancy of the legume seed. Frontiers in Plant Science 5: 1-19.

Souza, T.V., Voltolini C.H., Santos M. y Paulilo M.T.S. 2012. Water absorption and dormancy-breaking requirements of physically dormant seeds of Schizolobium parahyba (Fabaceae-Caesalpinioideae). Seed Science Research 22: 169-176.

Stern, W.T. 1992. Botanical latin. History, grammar, syntax, termimology and vocabulary. Ed. Hafner Publishing Company, New York, 566 p. 
Taylor, G.B. 2005. Hardseededness in Mediterranean annual pasture legumes in Australia: a review. Australian Journal of Agricultural Research 56: 645-661.

Torres, S.B., y Barbosa-Santos D.S. 1994. Superação de dormência em sementes de Acacia senegal (L.) Willd. e Parkinsonia aculeata L. Revista Brasileira de Sementes 16: 54-57.

Turner, S.R., Merritt D.J., Baskin C.C., Dixon K.W. y Baskin J.M. 2005. Physical dormancy in seeds of six genera of Australian Rhamnaceae. Seed Science Research 15: 51-58.

Ubiergo, P. y Lapp M. 2007. Caracterización morfológica de semillas de algunas especies de los géneros Cassia L. y Senna Mill. (Leguminosae Juss.). Revista de la Facultad de Agronomía 24: 426-441.

van Klinken, K.D. y Goulier J.B. 2013. Habitat-specific seed dormancy-release mechanisms in four legume species. Seed Science Research 23: 181-188.

van Klinken, R.D. y Flack L. 2005. Wet heat as a mechanism for dormancy release and germination of seeds with physical dormancy. Weed Science 53: 663-669.

Van Staden, J., Manning J.C. y Kelly K.M. 1989. Legumes seeds the structure: function equation. 417-450 p. In Stirton, C.H.; Zarucchi, J.L. (eds.). Advances in legume biology, monographs on systematic botany. St. Louis, Missouri Botanical Garden.

Varela, R.O. y Albornoz P.L. 2013. Morpho-anatomy, imbibition, viability and germination of the seed of Anadenanthera colubrina var. cebil (Fabaceae). International Journal of Tropical Biology and Conservation 61:1109-1118. 
Vaughan, J.G. 1968. Seed anatomy and Taxonomy. Proceedings of the Linnean Society of London 179: 251-255.

Venier, P., Carrizo-García C., Cabido M. y Funes G. 2012. Survival and germination of three hard-seeded Acacia species after simulated cattle ingestion: The importance of the seed coat structure. South African Journal of Botany 79: 1924.

Villers, T.A. 1972. Seed dormancy. 220-282 p. In Kozlowsky, T.T. (ed.) Seed biology. New York, Academic Press.

Wood, D.F., Orts W.J. y Glenn G.M. 2010. Microstructure of Desmanthus illinoensis. In Scanning Microscopy. International Society for Optics and Photonics 7729$77291 \mathrm{~V}-2$. 


\title{
CAPÍTULO III
}

\section{Efecto de la escarificación y la temperatura en la germinación de dos especies de Mimosa (Leguminosae-Mimosoideae)}

\author{
Effect of scarification and temperature on the germination of two species of Mimosa \\ (Leguminosae-Mimosoideae)
}

\section{INTRODUCCIÓN}

De acuerdo con Parmesan y Yohe (2003), es importante determinar la respuesta de germinación de las semillas a la escarificación y a las fluctuaciones de temperatura, ya que los ecosistemas podrían expandirse o contraerse en respuesta a el grado de tolerancia de los taxa a un aumento o disminución de la temperatura, por lo tanto, se necesitan estudios que determinen la capacidad y resistencia de la semilla a la germinación en respuesta a diferentes factores ambientales.

En México, los taxa de Mimosa L. (Leguminosae-Mimosoideae) han atraído la atención debido a sus múltiples usos, su capacidad de sobrevivir en ambientes hostiles, el rebrote después de haber sido cortadas o quemadas, y a que el género tiene muchos valores ecológicos, económicos y culturales (Camargo-Ricalde et al., 2001). Mimosa comprende ca. 530 taxa en el mundo, y es uno de los tres géneros más grandes de Mimosoideae, junto con Acacia e Inga (Simon et al., 2011). Después de Brasil, México es el segundo centro de diversificación de Mimosa, siendo el género más diverso de la subfamilia con ca. 110 taxa, el $60 \%$ son endémicas del 
país, muchos de ellos son elementos dominantes o co-dominantes en los ecosistemas áridos, presentan amplia distribución en la vegetación tropical, y solo algunos taxa crecen en bosques templados (Camargo-Ricalde et al., 2002; Grether et al., 1996).

Dentro de los ambientes áridos y semiáridos, algunos taxa de Mimosa son formadoras de islas de recursos, enriqueciendo el suelo con materia orgánica y nutrientes (Camargo-Ricalde et al., 2002, 2010a), y como reservorios de esporas de hongos micorrizógenos arbusculares (Camargo-Ricalde y Dhillion, 2003), y de bacterias fijadoras de nitrógeno (Camargo-Ricalde et al., 2010a, b). Además, el efecto de nodrizaje es muy claro entre M. luisana Brandegee y Neobuxbaumia tetetzo (Weber) Backeberg, una cactácea columnar endémica de México (ValienteBanuet et al., 1991; Valiente-Banuet y Ezcurra, 1991). Por lo anterior, algunos taxa de Mimosa se consideran potencialmente útiles para proyectos de restauración ambiental (Dhillion et al., 2004; Moreno-Calles y Casas, 2010; Pavón et al., 2011).

Como una aproximación, se sabe que las semillas de algunos taxa de Mimosa son capaces de germinar en una amplia gama de temperaturas (Camargo-Ricalde et al., 2004; De Souza y De Castro, 1983; Pavón et al., 2011), y que la escarificación aumenta el porcentaje de germinación (Camargo-Ricalde y Grether, 1998; CamargoRicalde et al., 2004; Chahuan y Johnson, 2008; Ferreira et al., 1992; GonzálezCastañeda et al., 2004; Jayasuriya et al., 2013; Leal y Biondi, 2007; Pavón et al., 2011; Silveira y Fernandes, 2006). Sin embargo, aún no es posible generalizar acerca de cómo responden las semillas tanto a la escarificación como a las 
fluctuaciones de temperatura, debido a que sólo se ha estudiado el $5 \%$ de los taxa de Mimosa a nivel mundial. En México, únicamente se ha estudiado la germinación de semillas en 13 taxa que crecen en ecosistemas áridos (Camargo-Ricalde et al., 2004, Pavón et al., 2011) y sólo un taxa que crece en bosques templados (Martínez-Pérez et al., 2006).

\section{ANTECEDENTES}

Las leguminosas son plantas dominantes en regiones tropicales, áridas y semiáridas de América y África (De la Barrera y Andrade, 2005); sin embargo, se desconocen los factores que influyen en los procesos de germinación de sus semillas y en el establecimiento de sus plántulas.

La semilla es considerada el medio de reproducción de las angiospermas, de ella depende la supervivencia de la planta e incluso del taxon; su estructura consiste de un embrión, un endospermo y una cubierta protectora llamada testa; el tamaño del embrión y la cantidad de endospermo es variable entre taxa (Esau, 1985; Niembro, 1979). Según Cronquist (1987), cualquier semilla madura para iniciar el proceso de germinación requiere de ciertos factores ambientales como: humedad, oxígeno, temperatura e incluso en ocasiones luz; cuando estos factores son adecuados las semillas alcanzarán un mayor porcentaje de germinación. Se considera que dicho proceso ha concluido cuando emerge la radícula, aunque varios autores manejan que ésta debe alcanzar de 1 a $3 \mathrm{~mm}$ de longitud (Bewley y Black, 1978; Camargo-Ricalde et al., 2004; Kestring et al., 2009; Leal y Biondi, 2007). 
La temperatura óptima de germinación es variable entre taxa y está asociada con su hábitat y su distribución del taxa; por lo que en ocasiones las temperaturas fluctuantes producen porcentajes más altos de germinación comparados con temperaturas constantes (Fearn, 1981). La luz es otro factor que influye en la germinación, existen semillas que sin la existencia de luz no pueden germinar (sensibles a la luz), otras en que este factor no afecta el proceso de germinación (fotoblásticas indistintas) y, las que son resistentes a la luz, por lo que deben mantenerse en oscuridad durante el proceso (Fearn, 1981).

La influencia de la temperatura en la germinación ha sido estudiada en varios géneros de leguminosas; Soto-Gonzales et al. (2010) determinaron que la temperatura óptima de germinación de Albizia hassleri (Chodat) Burr. es a los $25^{\circ} \mathrm{C}$. En el caso de A. lebbeck (L.) Benth., Gliricidia sepium Jacq. y Bauhinia purpurea L. se ha registrado que la temperatura óptima de germinación se alcanza a una temperatura alterna de $25 / 30^{\circ} \mathrm{C}$; sin embargo, el porcentaje difiere entre taxa; ya que en $A$. lebbeck es de $26 \%$, en B. purpurea es de $16 \%$ y en $G$. sepium es del $100 \%$ (Reino et al., 2008).

En el caso particular de la subfamilia Mimosoideae, existen trabajos sobre la germinación de distintos taxa de Mimosa; no obstante, considerando el número de taxa a nivel mundial (ca. 520), se considera que los estudios son escasos. Dentro de estos trabajos destacan: Compton (1912), quien reporta que el tipo de germinación epígea es común en Mimosoideas y que la de tipo hipógea se presenta en raras ocasiones. Las mimosoideas pueden presentar una germinación fanerocotilar; es decir, que los cotiledones emergen de la semilla o criptocotilar en la que los 
cotiledones no emergen de la semilla (Duke, 1969); por ejemplo, Mimosa albida Humb. et Bonpl. ex Willd., M. arenosa (Willd.) Poir., M. camporum Benth. y $M$. tenuiflora (Willd) Poir. presentan este tipo de germinación (Parra, 1984).

Camargo-Ricalde y Grether (1998), estudiaron la germinación en M. tenuiflora y concuerdan con Parra (1984), en el tipo de germinación fanerocotilar, y establecieron que $25^{\circ} \mathrm{C}$ es la temperatura óptima con un $95 \%$ de germinación. Asimismo, Camargo-Ricalde et al. (2004) estudiaron la germinación de Mimosa adenantheroides (M. Martens y Galeotti) Benth., M. calcicola B. L. Rob., M. lacerata Rose, M. luisana Brandegee, M. polyantha Benth., M. purpusii Brandegee y $M$. texana (A Gray) Small var. filipes (Britton y Rose) Barneby y observaron que las semillas de $M$. adenantheroides, $M$. luisana y $M$. texana var. filipes germinan entre los 23 y $24^{\circ} \mathrm{C}$. Mientras que, en $\mathrm{M}$. calcicola germina el $100 \%$ de las semillas entre los 25 y $30^{\circ} \mathrm{C}$; asimismo, M. polyantha alcanzó el $100 \%$ de germinación a una temperatura de $35^{\circ} \mathrm{C}$ pero, la temperatura óptima de germinación está entre 27 y 24.5드. Mimosa lacerata es la única que alcanza el 100\% de germinación entre los 15 y $25^{\circ} \mathrm{C}$.

Por otra parte, González-Castañeda et al. (2004), reportaron que la escarificación mecánica promueve la germinación de las semillas de Mimosa monancistra Benth. De igual manera sucede con las semillas de $M$. foliolosa Benth. subsp. pachycarpa (Benth.) Barneby var. pachycarpa (Silveira y Fernandes, 2006).

Pavón et al. (2011) determinaron las condiciones óptimas de germinación, evaluando el efecto de luz sobre la germinación de $M$. aculeaticarpa var. biuncifera (Benth.) Barneby obteniendo que las semillas no son fotoblásticas, y que la 
temperatura es un factor importante en la germinación, obteniéndose los valores más bajos a $15^{\circ} \mathrm{C}$; mientras que a los $30^{\circ} \mathrm{C}$ se obtuvieron los valores más altos.

Otro factor determinante en la germinación es el tamaño de las semillas; al respecto Carvalho y Nakagawa (2000) mencionan que las semillas de mayor tamaño son las más vigorosas durante su desarrollo; además, el tamaño de la semilla es indicativo de sus cualidad fisiológica, siendo las semillas pequeñas las que presentan un menor porcentaje de germinación comparadas con las de mayor tamaño (Popinigis, 1985).

Los trabajos sobre germinación de semillas de leguminosas que abordan la importancia de la procedencia y del tamaño de las semillas, son escasos; entre ellos destaca el de Sturion (1984), quien estudió la influencia del tamaño de las semillas en $M$. scabrella Benth. en la sobrevivencia y en el crecimiento de las plántulas; compara tres sitios de procedencia de las semillas, observando diferencias significativas entre sitios y observó que el porcentaje de germinación no sólo varia según la procedencia de la semillas; sino que, es mayor en las semillas de menor tamaño $(3.0 \mathrm{~mm})$. En contraste, Alves et al. (2005) menciona que en $M$. caesalpinifolia Benth. no existe variación en el tamaño de la semilla respecto al lugar procedencia, pero sí en cuanto a la velocidad de germinación, siendo las semillas pequeñas las que germinan primero.

Los factores ambientales como temperatura y luz han sido evaluados de forma independiente y conjunta en la germinación de las semillas del género Mimosa; sin embargo, debido a la predominancia del género en diversos ecosistemas húmedos y secos (Orozco-Almanza et al., 2003) es importante conocer las respuestas 
ecofisiológicas de sus taxa ante una variación en la temperatura y en la precipitación, tanto a nivel de semilla como de plántula, ya que son las etapas más vulnerables para el establecimiento de la planta (Duke y Polhill, 1981).

Al respecto, sólo existen dos estudios ecofisiológicos de Mimosa, y corresponden a $M$. pudica y $M$. pigra taxa considerados como malezas de las regiones tropicales (Lonsdale y Abrecht, 1989).

\section{PREGUNTAS DE INVESTIGACIÓN}

¿Cómo afecta la escarificación y la temperatura la germinación de dos taxa de Mimosa?

¿Cuál es la temperatura óptima de germinación de las semillas de dos taxa de Mimosa?

\section{HIPÓTESIS}

Si los taxa están adaptados a sus ambientes; entonces, la germinación de sus semillas, responderá a las temperaturas promedio de su hábitat.

\section{OBJETIVO}

Determinar el efecto de la escarificación y la temperatura sobre la germinación de dos taxa del género Mimosa y definir la temperatura óptima de geminación. 


\section{MÉTODOS}

\section{Diseño experimental}

Los frutos maduros de Mimosa aculeaticarpa var. aculeaticarpa y M. luisana fueron colectados durante la temporada de máxima productividad de cada taxon (noviembre y octubre, respectivamente), de cada taxon se seleccionaron ocho individuos, con la misma altura y cobertura. La colecta de los frutos fue al azar, que abarcó toda la zona de la copa por individuo.

Mimosa aculeaticarpa var. aculeaticarpa se colectó en un bosque templado, ubicado en el estado de Michoacán, 1958.218 'N, 101³1.664' W, a 1950 msnm, y M. luisana en un matorral semiárido en el Valle de Tehuacán, estado de Puebla, $18^{\circ} 15^{\prime} 23.7^{\prime \prime} \mathrm{N}, 97^{\circ} 09^{\prime} 03.3^{\prime \prime} \mathrm{W}$, a $2232 \mathrm{msnm}$. Los ejemplares de respaldo fueron depositados en el Herbario Metropolitano (UAMIZ), Universidad Autónoma Metropolitana-Iztapalapa.

\section{Caracterización de semillas y tratamientos previos a la siembra}

Después de la colecta, se retiraron las semillas de los frutos. Aproximadamente, se obtuvieron 10,000 semillas, por taxon, y se almacenaron en recipientes de plástico, a temperatura ambiente $\left(20^{\circ} \mathrm{C}\right)$ en la Ciudad de México. Durante dos semanas, se recogieron y se fijaron en FAA los brúquidos (Insecta, Coleoptera) que emergieron de las semillas para su posterior identificación. 
Dado que el tamaño de la semilla y el peso pueden influir en la tasa de germinación (Mantilla, 2004; Skogen et al., 2010); se caracterizaron 3,600 semillas maduras y sanas, por taxa. Las variables evaluadas fueron: longitud, anchura y espesor, así como el peso de la semilla. El tamaño de la semilla se midió con un calibrador digital vernier (Absoluto Digimatic, CD- 6 "CS) y el peso se determinó individualmente utilizando una balanza analítica con $4.10 \mathrm{~g}$ de resolución (Adventurer, Ohaus, Melrose, EE.UU.). Las semillas sanas, de ambos taxa, con tamaño y peso similar, se mezclaron para obtener una muestra compuesta. Es importante mencionar que para asegurar el desarrollo adecuado de todo el experimento, se escogió el rango de tamaño de la semilla y peso en términos de la cantidad mínima de semillas necesarias para ello.

Antes de los experimentos, todas las semillas se lavaron con detergente comercial (3 g/100 ml de agua; Camargo - Ricalde y Grether, 1998).

\section{Los ensayos de germinación en condiciones de laboratorio}

Se sabe que las semillas de las leguminosas tienen latencia física (Baskin, 2003; Jayasuriya et al., 2013; Van Assche et al., 2003; Venier et al., 2012), y en particular los taxa de Mimosa (Jayasuriya et al., 2013; Martínez-Pérez et al., 2006). Las semillas Mimosa fueron escarificadas mecánicamente: la cubierta de la semilla se cortó en el lado opuesto al eje del embrión con el fin de evitar daños. Los ensayos de germinación se realizaron en una incubadora (Conviron T 38/Lb/AP), utilizando bandejas $(30 \times 15 \times 20 \mathrm{~cm})$, con agar $(3 \%)$ como sustrato. Se fijó un gradiente de 
temperatura con nueve intervalos de $5^{\circ} \mathrm{C}$ cada uno (de 5 a $\left.45^{\circ} \mathrm{C}\right)$, y un fotoperíodo de $12 \mathrm{~h}$ luz y $12 \mathrm{~h}$ oscuridad.

Para cada tratamiento térmico, se establecieron cinco repeticiones de 20 semillas escarificadas (100 semillas por taxon; 1,800 semillas en total), así como cinco repeticiones de 20 semillas no escarificadas como tratamiento control (100 semillas por taxon, 1,800 semillas en total). Se consideraron semillas germinadas cuando la radícula alcanzó $1 \mathrm{~mm}$ de longitud (Bewley y Black, 1994). Todos los ensayos tuvieron una duración de 30 días.

Los resultados de la germinación se analizaron mediante el cálculo del porcentaje total de la germinación (PG), la tasa media de germinación (G50), y la tasa de germinación (GR) (Enríquez-Peña et al., 2004; Piedrahita 1997, 1998; Weng y Hsu, 2006). Para analizar el efecto de las fluctuaciones de temperatura en relación con el comportamiento de la germinación de semillas de plantas, diversos autores ( $P$. ej. Enríquez-Peña et al., 2004; Piedrahita 1997, 1998; Pavón et al., 2011; Weng y Hsu, 2006) consideran los siguientes parámetros los cuáles también se utilizarán para los taxones Mimosa estudiados aquí: el porcentaje de germinación (PG) como el porcentaje de germinación total al final del ensayo; la tasa media de Germinación (G50) es el número de días, después de la siembra, que se necesitan para alcanzar el 50\% de germinación, y se estimó mediante la interpolación de un día antes y el día después en que se obtuvo el $50 \%$ de la germinación total. La tasa de germinación (GR) se define como la correlación entre el número de semillas germinadas y el tiempo de germinación: $\mathrm{GR}=\Sigma(\mathrm{NI}) / \mathrm{t}$, donde $\mathrm{Ni}=$ número de semillas germinadas en un 
día (i), t= el tiempo desde la siembra hasta que germina la última semilla y, la tasa de saturación (SR) se define como el tiempo de germinación en relación con el porcentaje de germinación: $\mathrm{SR}=\Sigma(\mathrm{niti}) / \mathrm{N}$, donde ni=número de semillas germinadas en un día (i); ti= número de días después de la siembra, $\mathrm{N}=$ número total de semillas sembradas.

La temperatura óptima se calcula como el promedio de todas las temperaturas ponderadas con el porcentaje total de germinación en cada temperatura (Olff et al., 1994).

\section{Análisis estadísticos}

El peso de la semilla se comparó entre los taxa por medio de la prueba $t$-Student $(P<0.05)$. La normalidad (Kolmogorov $P<0.05)$ y la homogeneidad de varianzas (Levene's $P<0.05$ ) fueron examinadas para todas las temperaturas. Cuando los datos cumplieron con ambos supuestos, se realizó un ANOVA $(P<0.05)$ de una vía para analizar la variación intraespecífica en los porcentajes de germinación y entre el control y las semillas escarificadas, y un ANOVA de dos vías para examinar la variación interespecífica entre los porcentajes de germinación, donde el taxon y las temperaturas fueron las variables (ANOVA, $P<0.05$ ). Una prueba de comparación de medias fue empleada (HSD de Tukey, $P<0.05$ ) para formar grupos (Sokal y Rohlf, 1995). En Mimosa aculeaticarpa var. aculeaticarpa, SR no cumplió con homogeneidad de varianza, por lo tanto, se utilizó la prueba de Kruskal-Wallis $(P<0.05)$, y las medias se compararon mediante la prueba de Mann-Whitney $(P<0.05$, 
Sokal y Rohlf, 1995). Todos los análisis se realizaron con el software NCSS (Hintze, 2001).

\section{RESULTADOS}

\section{Tamaño de la semilla, el peso y la producción}

Los dos taxa de Mimosa estudiados producen numerosas semillas de peso y tamaño variable y, aunque el peso no mostró diferencias significativas entre taxa $(\mathrm{t}=0.7442$, $P>0.05$ ), el tamaño de $M$. aculeaticarpa var. aculeaticarpa fue el más grande (Cuadro 1).

No todas las semillas colectadas estaban sanas; muchas de ellas estaban infestadas por brúquidos (Insecta, Coleoptera). El promedio del porcentaje de infestación fue de $11.9 \%$ para Mimosa aculeaticarpa var. aculeaticarpa y $48.7 \%$ para M. Iuisana (Cuadro 1). En el caso de Mimosa aculeaticarpa var. aculeaticarpa, se identificaron dos taxa de brúquidos, Acanthoscelides chiricahuae (Fall) y $A$. mexicanus (Sharp). Las semillas de Mimosa luisana estaban infestadas por tres taxa, dos pertenecientes al género Acanthoscelides ( $A$. mexicanus y $A$. chiricahuae) y uno al género Stator (S. pruininus (Horn)). 


\section{Efecto de la escarificación sobre el porcentaje total de germinación (PG)}

Los dos taxa de Mimosa mostraron germinación epígea y fanerocotilar, que comenzó el primer día después de la siembra. En ambos taxa, la germinación fue estimulada por escarificación (Figuras 1-3, Cuadro 2). El porcentaje total de germinación (PG) de las semillas no escarificadas fue bajo y lento. Las semillas escarificadas registraron un $\mathrm{PG}$ significativamente mayor $(F=143.88, P<0.001$, Cuadro 2$)$. Las semillas escarificadas de Mimosa aculeaticarpa var. aculeaticarpa germinaron 57 veces más rápido que las de $M$. luisana. En el caso de $M$. luisana, las semillas no escarificadas germinaron cinco veces más rápido que las de $M$. aculeaticarpa var. aculeaticarpa (Figuras 1-3). Aunque estos datos no fueron estadísticamente significativos, las semillas de $M$. luisana tienden a germinar en mayor número que las de $M$. aculeaticarpa var. aculeaticarpa (Cuadro 2).

El análisis de ANOVA de dos vías mostró un efecto significativo de los dos factores, el taxon y la temperatura, sobre el porcentaje total de germinación de las semillas (PG) (Cuadros 3, 4). El porcentaje de germinación más bajo en ambos taxa se registró a $5^{\circ} \mathrm{C}$ (Figuras 1-3), que difieren significativamente de los otras temperaturas $(F=33.03$ y $F=18.63$; con $P<0.005$, respectivamente). El $P G$ más alto (88\%) se registró a $25^{\circ} \mathrm{C}$ en $M$. aculeaticarpa var. aculeaticarpa $(F=33.03 ; P<0,005)$, aunque también se alcanzó el $88 \%$ de germinación a los $15^{\circ} \mathrm{C}$, pero las semillas requieren más días $(S R=5)$ para llegar a este porcentaje (Cuadro 4). En Mimosa luisana, se alcanzó el mayor porcentaje de germinación $(100 \%)$ a $30^{\circ} \mathrm{C}$, mientras que, a temperaturas más altas o más bajas, el PG disminuyó (Figura 2, Cuadro 4). 
Cuadro 1. Tamaño de la semilla madura, peso, producción y porcentaje de semillas infestadas y no infestadas por brúquidos (Insecta, Coleoptera) de dos taxa de Mimosa.

\begin{tabular}{|c|c|c|c|}
\hline \multicolumn{2}{|c|}{ Variables / Taxa } & $\begin{array}{c}\text { Mimosa aculeaticarpa var. } \\
\text { aculeaticarpa }\end{array}$ & Mimosa luisana \\
\hline \multirow{3}{*}{$\begin{array}{c}\text { Tamaño } \\
(\mathrm{mm})\end{array}$} & Longitud & $3.0-4.4$ & $2.6-3.5$ \\
\hline & Ancho & $2.0-3.0$ & $1.8-2.4$ \\
\hline & Grosor & $0.01-0.02$ & $2.0-2.7$ \\
\hline \multicolumn{2}{|c|}{$\begin{array}{l}\text { Peso de la semilla madura (gr) } \\
\text { (promedio } \pm \mathrm{EE} \text { ) }\end{array}$} & $0.008 \pm 0.0004^{\mathrm{a}}$ & $0.00864 \pm 0.0006^{a}$ \\
\hline \multicolumn{2}{|c|}{ Producción (número) } & 9,891 & 12,276 \\
\hline \multicolumn{2}{|c|}{ Semillas parasitadas (\%) } & 11.9 & 48.7 \\
\hline \multicolumn{2}{|c|}{$\begin{array}{l}\text { Producción de semillas no } \\
\text { parasitadas (\%) }\end{array}$} & 88.1 & 51.3 \\
\hline
\end{tabular}

Cuadro 2. Efecto de la escarificación sobre el porcentaje de germinación de las semillas de dos taxa de Mimosa.

\begin{tabular}{|c|c|c|}
\hline Taxa & $\begin{array}{c}\text { Sin escarificar } \\
\% \text { germinación } \pm \text { EE }\end{array}$ & $\begin{array}{c}\text { Escarificadas } \\
\% \text { germinación } \pm \mathrm{EE}\end{array}$ \\
\hline $\begin{array}{c}\text { Mimosa aculeaticarpa var. } \\
\text { aculeaticarpa }\end{array}$ & $1.22 \pm 0.22^{\mathrm{a}}$ & $70.0 \pm 8.35^{b}$ \\
\hline Mimosa luisana & $6.33 \pm 1.46^{a}$ & $79.6 \pm 8.31^{b}$ \\
\hline
\end{tabular}

\section{Efecto de la temperatura en el porcentaje total germinación (PG)}

El efecto de la interacción entre los dos factores, el taxon y la temperatura, en el $P G$ fue significativa $(P<0.001)$, lo que indica que la respuesta germinativa a la 
temperatura depende del taxon. Hubo una disminución en el PG a temperaturas extremas, 5 y $45^{\circ} \mathrm{C}$ (Figuras 1-3).

Cuadro 3. Efecto de la temperatura sobre la germinación de las semillas de dos taxa del género Mimosa.

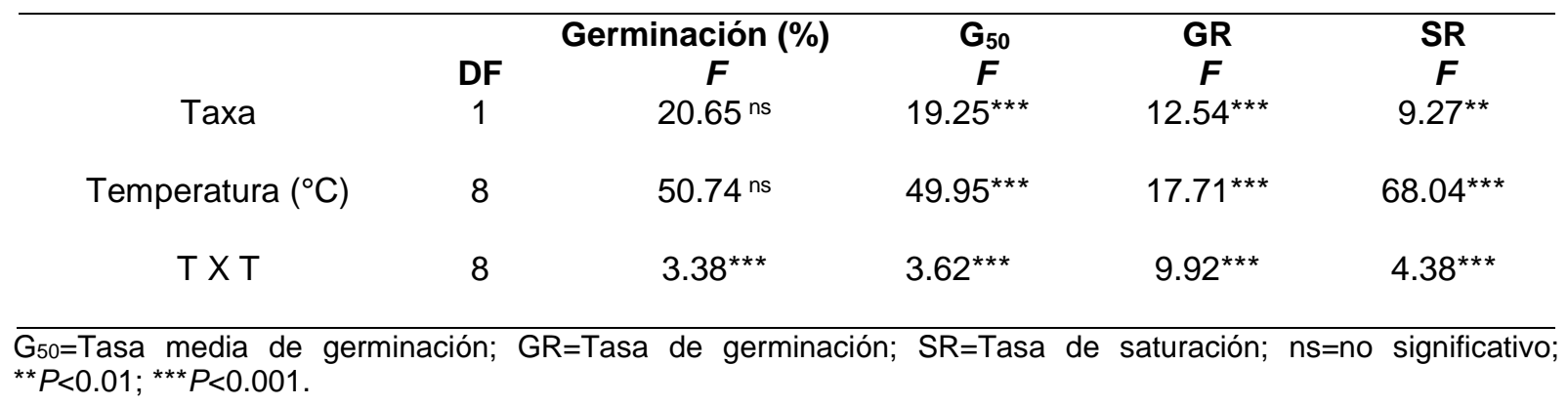

Con relación a la tasa media de germinación de las semillas (G50), el factor taxa presentó una interacción con el factor de temperatura $(P<0.001$, Cuadro 3$)$, lo que indica que la respuesta de la germinación de la semilla (G50) a la temperatura dependía del taxa. Aunque a $20^{\circ} \mathrm{C}, M$. aculeaticarpa var. aculeaticarpa alcanzó el $50 \%$ de germinación al segundo día después de la siembra y, a los 25 y $30^{\circ} \mathrm{C}$, el $50 \%$ de germinación se supera en el segundo día después de la siembra. Sin embargo, se necesitan más días para alcanzar $50 \%$ de germinación a temperaturas inferiores a $20^{\circ} \mathrm{C}$ y superiores a $35^{\circ} \mathrm{C}$. Por otra parte, se llegó a sólo el $35 \%$ de germinación a $45^{\circ} \mathrm{C}$. En el caso de M. luisana, el $50 \%$ de germinación se alcanzó a $30^{\circ} \mathrm{C}$, el primer día después de la siembra, y este porcentaje se supera a temperaturas de 25,35 y $40^{\circ} \mathrm{C}$; sin embargo, el porcentaje total de germinación disminuyó a menos de 27\% a 45드 (Figuras 1-3). 

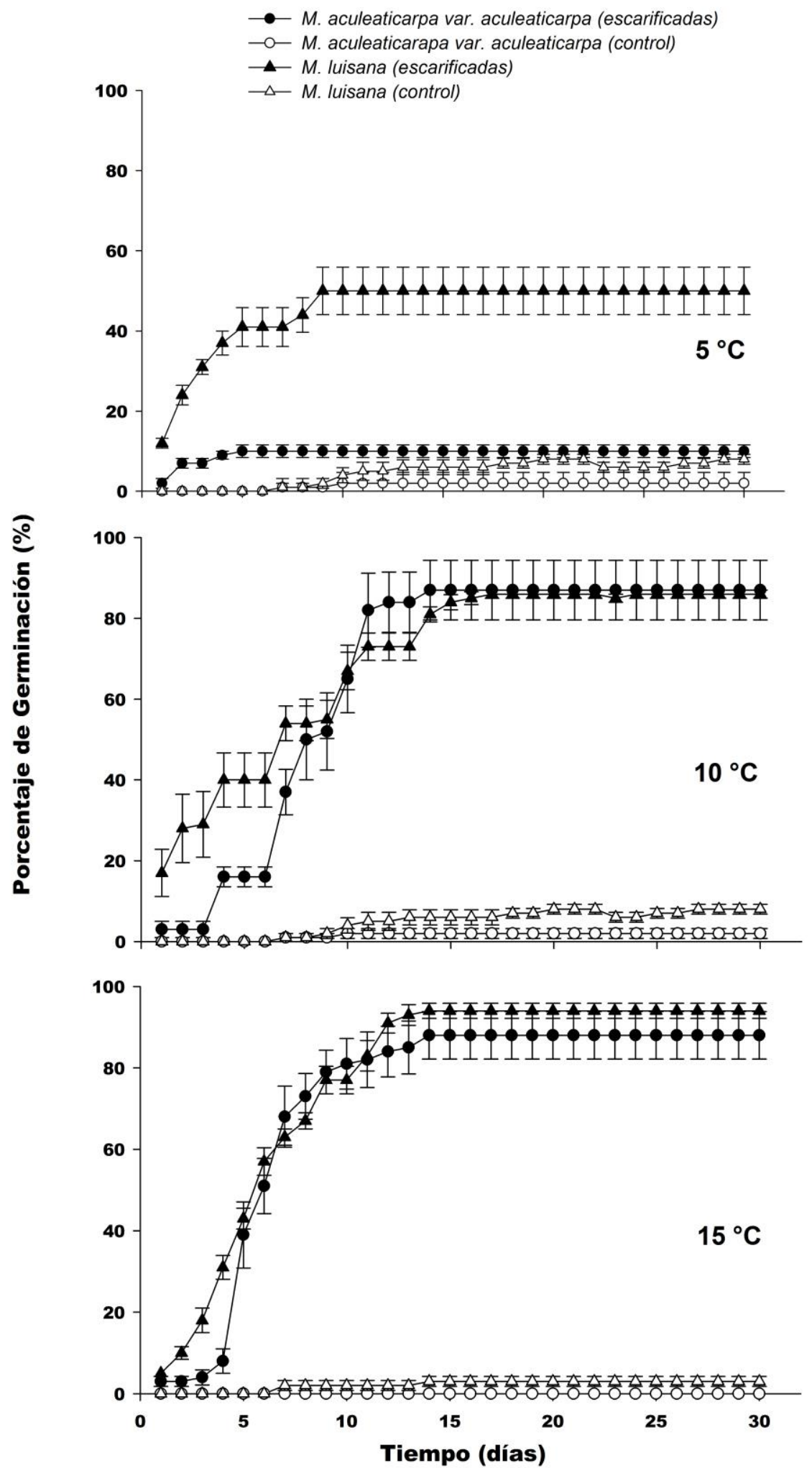

Figura 1. Porcentaje de germinación ( $P G \pm E E)$ de dos taxa de Mimosa lo largo de un gradiente de temperatura de 5 a $15^{\circ} \mathrm{C}$. 


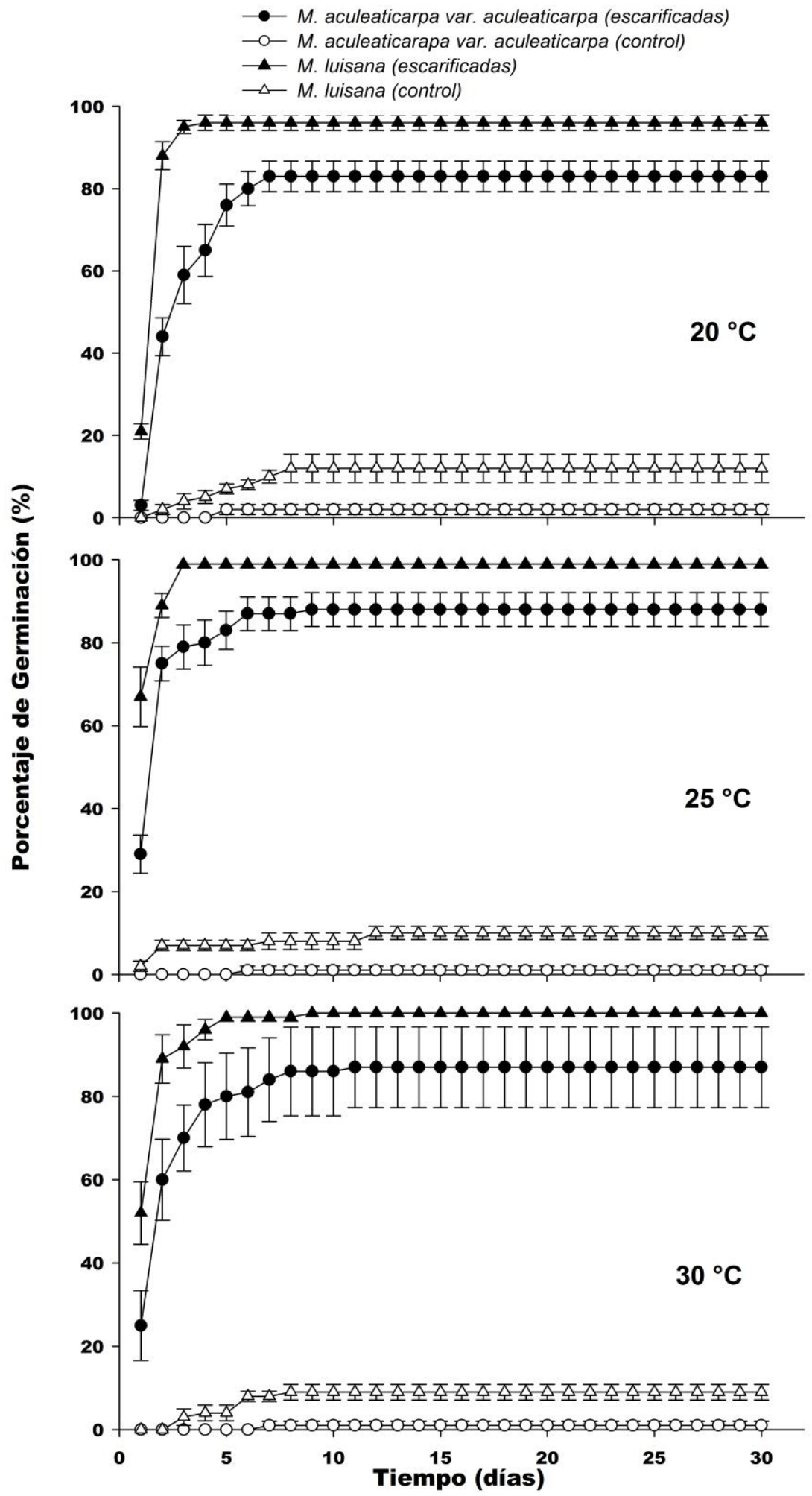

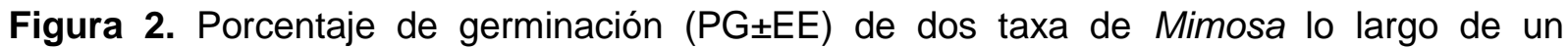
gradiente de temperatura de 20 a $30^{\circ} \mathrm{C}$. 


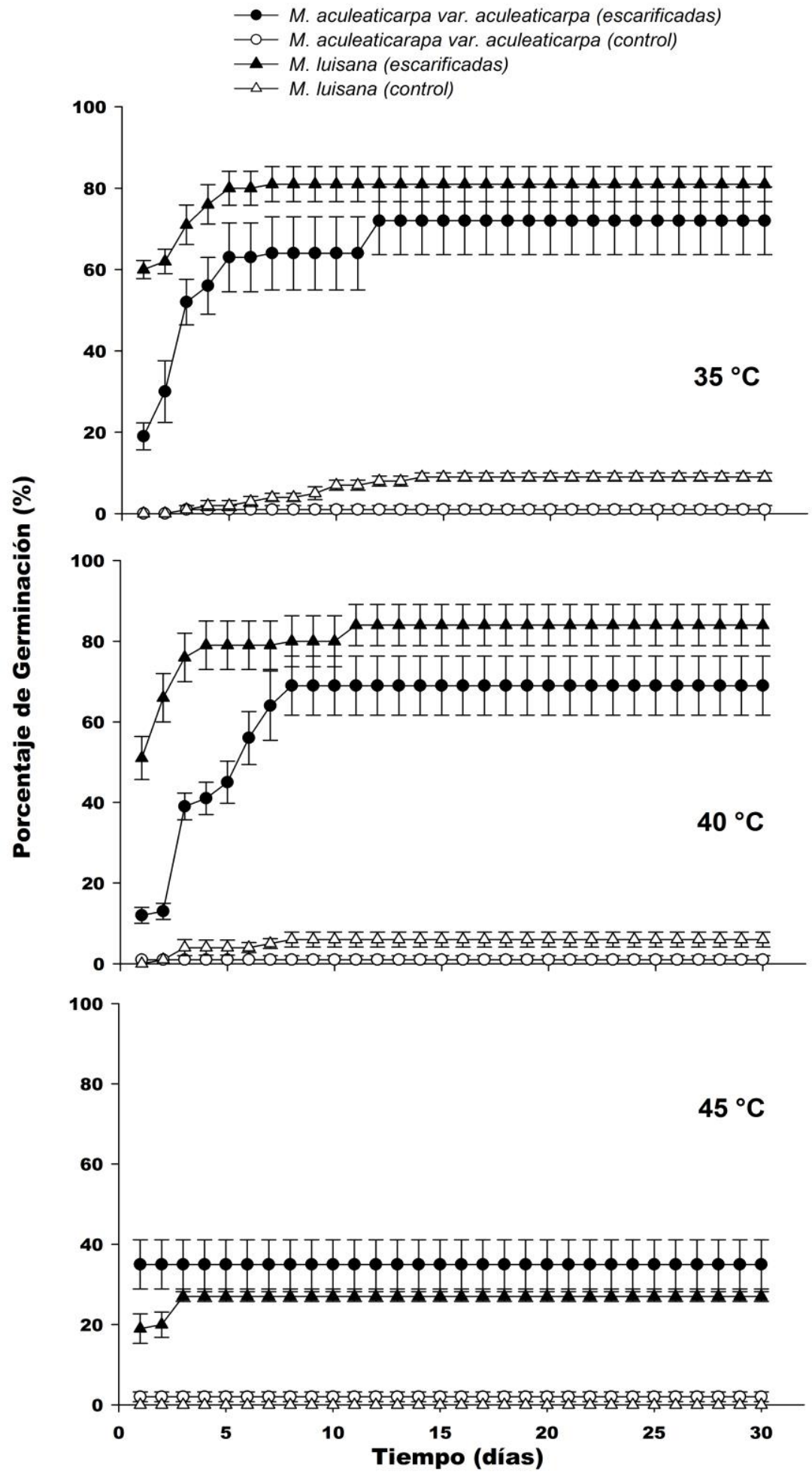

Figura 3. Porcentaje de germinación ( $P G \pm E E$ ) de dos taxa de Mimosa lo largo de un gradiente de temperatura de 35 a $45^{\circ} \mathrm{C}$. 
Cuadro 4. Porcentaje total de germinación (PG), tasa de saturación (SR) de dos taxa del género Mimosa bajo diferentes temperaturas.

\begin{tabular}{|c|c|c|c|}
\hline Temperatura $\left({ }^{\circ} \mathrm{C}\right)$ & Parámetros/Taxa & $\begin{array}{c}\text { M. aculeaticarpa var. } \\
\text { aculeaticarpa (Promedio } \pm \\
\text { EE) }\end{array}$ & $\begin{array}{c}\text { M. Iuisana } \\
\text { (Promedio } \pm \text { EE) }\end{array}$ \\
\hline 5 & $\begin{array}{l}\mathrm{PG}(\%) \\
\mathrm{SR}\end{array}$ & $10 \pm 1.58^{\mathrm{Ab}}$ & $50 \pm 5.92^{\mathrm{Bb}}$ \\
\hline 10 & $\begin{array}{l}\text { PG (\%) } \\
\text { SR }\end{array}$ & $\begin{array}{c}87 \pm 7.34^{\mathrm{Aa}} \\
7\end{array}$ & $86 \pm 1^{\mathrm{Aa}}$ \\
\hline 15 & $\begin{array}{c}\text { PG (\%) } \\
\text { SR }\end{array}$ & $\begin{array}{c}88 \pm 5.83^{\mathrm{Aa}} \\
5\end{array}$ & $\begin{array}{c}94 \pm 1.87^{\mathrm{Aa}} \\
6\end{array}$ \\
\hline 20 & $\begin{array}{c}\text { PG (\%) } \\
\text { SR }\end{array}$ & $\begin{array}{c}83 \pm 3.74^{\mathrm{Aa}} \\
3\end{array}$ & $\begin{array}{c}96 \pm 1.87^{\mathrm{Aa}} \\
2\end{array}$ \\
\hline 25 & $\begin{array}{l}\text { PG }(\%) \\
\text { SR }\end{array}$ & $\begin{array}{c}88 \pm 4.06^{\mathrm{Aa}} \\
2\end{array}$ & $99 \pm 1^{\mathrm{Aa}}$ \\
\hline 30 & $\begin{array}{l}P G(\%) \\
\text { SR }\end{array}$ & $\begin{array}{c}87 \pm 9.69^{\mathrm{Aa}} \\
2\end{array}$ & $100 \pm 0^{\mathrm{Aa}}$ \\
\hline 35 & $\begin{array}{l}\text { PG (\%) } \\
\text { SR }\end{array}$ & $\begin{array}{c}72 \pm 8.30^{\mathrm{Aa}} \\
2\end{array}$ & $\begin{array}{c}81 \pm 4.30^{\mathrm{Aa}} \\
1\end{array}$ \\
\hline 40 & $\begin{array}{l}P G(\%) \\
\text { SR }\end{array}$ & $\begin{array}{c}69 \pm 7.31^{\mathrm{Aa}} \\
3\end{array}$ & $84 \pm 5_{1}^{5.09^{\mathrm{Aa}}}$ \\
\hline 45 & $\begin{array}{l}P G(\%) \\
\text { SR }\end{array}$ & $\begin{array}{c}35 \pm 6.12^{\mathrm{Ab}} \\
1\end{array}$ & $27 \pm 1.22^{\mathrm{Ab}}$ \\
\hline Temperatura Óptima $\left({ }^{\circ} \mathrm{C}\right)$ & & 25 & 25 \\
\hline
\end{tabular}

Además, los resultados mostraron que las semillas de $M$. aculeaticarpa var. aculeaticarpa y M. luisana germinaron a lo largo del gradiente de temperatura (5 $\left.45^{\circ} \mathrm{C}\right)$. Sin embargo, la temperatura óptima para la germinación de semillas para ambos taxa se determinó a $25^{\circ} \mathrm{C}$ (Cuadro 4).

\section{Efecto de la temperatura sobre la tasa de germinación (GR)}

La tasa de germinación (GR) fue significativamente afectada por los taxa y los factores de temperatura ( $F=9.9 ; P<0.001$, Figura $4 \mathrm{~A}$ y Cuadro 3$)$. GR aumentó significativamente cuando la temperatura alcanzó $30^{\circ} \mathrm{C}$. En promedio, tres semillas 
de $M$. aculeaticarpa var. aculeaticarpa germinaron/día a $25^{\circ} \mathrm{C}$; seis semillas de $M$. luisana germinaron/día a la misma temperatura. Sin embargo, la GR de semillas de M. aculeaticarpa var. aculeaticarpa y de $M$. luisana disminuyeron a temperaturas superiores a 30 y $35{ }^{\circ} \mathrm{C}$, respectivamente. En el caso de $M$. aculeaticarpa var. aculeaticarpa, la GR se incrementó a $45{ }^{\circ} \mathrm{C}$, aunque sólo se registró el $35 \%$ de germinación de las semillas (Figura 4A).

En cuanto a la tasa de saturación (SR), también se observó una interacción significativa entre los dos factores, el taxon y la temperatura $(F=4,38, P<0.001$, Cuadro 3), lo que indica que la SR depende del taxon. M. aculeaticarpa var. aculeaticarpa requiere más días para llegar a la PG; mientras que M. luisana requiere aún más días para llegar al PG a $15^{\circ} \mathrm{C}$ (Figura 4B). 
- - M. aculeaticarapa var. aculeaticarpa (control)

$\_$M. luisana (escarificadas)

$\triangle-$ M. luisana (control)
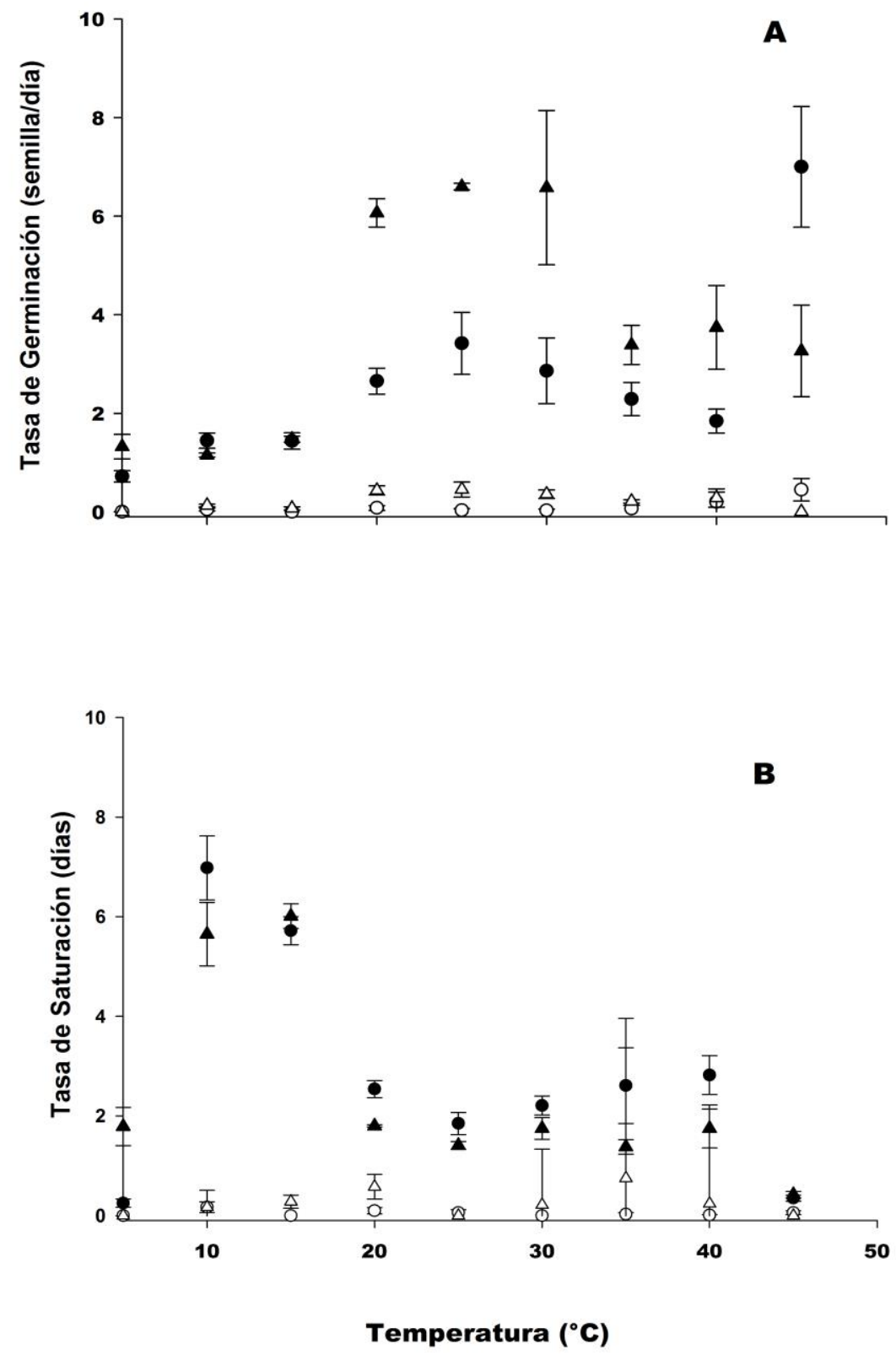

Figura 4. A. Tasa de germinación (GR $\pm \mathrm{EE}$ ) de dos taxa de Mimosa lo largo de un gradiente de temperatura; $\mathrm{B}$. Tasa de saturación (SR土EE) de dos taxa de Mimosa lo largo de un gradiente de temperatura. 


\section{DISCUSIÓN}

Los resultados globales obtenidos en este estudio son relevantes en términos de la comprensión de la distribución real y potencial de los taxa Mimosa en el contexto de la expansión o contracción de los ecosistemas bajo diferentes escenarios térmicos. En este caso, este estudio intenta dilucidar el efecto tanto de la escarificación y la temperatura en la germinación de semillas de Mimosa.

\section{Tamaño de la semilla, el peso y la producción}

Las semillas Mimosa maduras mostraron un tamaño significativo y la variación de peso, incluso procedentes de la misma planta madre. Tanto el tamaño pequeño de las semillas y su alta producción son características intrínsecas que conducen a las plantas a ser potencialmente más competitivas, tales como M. tenuiflora (Willd.) Poir. (Camargo-Ricalde y Grether, 1998) y M. pigra L., consideradas como taxa pioneros o invasores (Creager, 1992; Lonsdale, 1999).

Por otro lado, la depredación de semillas Mimosa por gorgojos (Insecta, Coleoptera), independientemente del tamaño, podría reducir su potencial de germinación (P. ej. Fontúrbel, 2002; Romero-Nápoles et al., 2005). Nuestros resultados son consistentes con los reportados por Orozco-Almanza et al. (2003) y Camargo-Ricalde et al. (2004), quienes encontraron que los taxa de Mimosa tenían un alto porcentaje de semillas infestadas por brúquidos (30-75\%), la reducción del número de semillas viables y, en consecuencia, el número de plántulas para el posterior reclutamiento. 
En este estudio, las semillas de M. luisana estaban infestadas por tres taxa de brúquidos diferentes; este taxon tenía el mayor porcentaje de semillas parasitadas (48\%), así como la más alta GR; Mientras tanto, M. aculeaticarpa var. aculeaticarpa registró la presencia de dos taxa brúquidos y el $11 \%$ de las semillas estuvo infestado, y muestra un porcentaje de germinación (PG) más bajo de semillas, y lo que sugiere que la presencia de más de un taxon brúquidos por planta puede estar relacionado con una estrategia reproductiva (Westoby et al., 1992) y un alto porcentaje de brúquidos-infestación conduce a una GR alta. Es posible que en la naturaleza, brúquidos actúen como escarificadores mecánicos "naturales" de semillas como ocurre en otros taxa de plantas con testa duro (Takakura, 2002).

\section{Efecto de la escarificación de semillas en germinación}

En general, las leguminosas producen semillas con una capa resistente al agua que la hacen inactiva físicamente (Auld, 1996; López et al., 1999; Van Klinken y Flack, 2005). Este tipo de testa, restringe la germinación de semillas en condiciones naturales (D'Aubeterre et al., 2002). Según Lonsdale (1993), Jayasuriya et al. (2013), y Van Klinken y Goulier (2013), las semillas de los taxa de Mimosa presentan latencia física y, debido a que la cubierta de la semilla tiene una o más capas impermeables de células en empalizada, también es posible una latencia fisiológica (Baskin et al., 2000). Por lo tanto, la escarificación es necesaria para promover la germinación de las semillas (Camargo-Ricalde y Grether, 1998; Jayasuriya et al., 2013). Diferentes métodos de escarificación de semillas han sido documentados para 
los taxa de Mimosa (Camargo-Ricalde y Grether, 1998; De Souza y De Castro, 1983; Martínez-Pérez et al., 2006; Silveira y Fernandes, 2006). Sin embargo, CamargoRicalde y Grether (1998), Chauhan y Johnson (2008), De Souza y De Castro (1983), González-Castañeda et al. (2004), Jayasuriya et al. (2013) y Martínez-Pérez et al. (2006) han demostrado que la escarificación mecánica es la técnica más adecuada para romper la latencia de las semillas de los taxa de Mimosa, ya que las semillas escarificadas mecánicamente son capaces de alcanzar las tasas de germinación (GR) más altas en comparación con otros métodos que dañan al embrión y el desarrollo de plántulas (P. ej. escarificación química, de choque térmico, etc). En este estudio, las semillas escarificadas mecánicamente alcanzaron altos porcentajes de germinación (más del 70\%) en ambos taxa, mientras que las semillas no escarificadas sólo alcanzan 0-12\%. Es importante mencionar que las semillas control (es decir, semillas sin escarificar) no deben ser manipuladas de ninguna manera porque la cubierta de la semilla se puede dañar y, por lo tanto, los resultados pueden sesgarse. Por ejemplo, Martínez-Pérez et al. (2006) remojaron las semillas control de cuatro taxa, incluyendo M. aculeaticarpa, en agua/24h, y mostraron casi el mismo comportamiento que nuestras semillas tratadas pero sus semillas control alcanzaron ca. $60 \%$ de germinación, probablemente debido a la manipulación recibida.

En la naturaleza, aunque la germinación de semillas de Mimosa es baja, el proceso de escarificación se produce por diversos mecanismos, tales como cambios en la temperatura diaria, la depredación incompleta por los insectos como los gorgojos (Camargo-Ricalde et al., 2004, Orozco-Almanza et al., 2003), daños 
causados por los microorganismos del suelo, la abrasión por partículas del suelo y el fuego (Baskin et al., 1998; Taylor, 2005), y la ingestión de los animales (P. ej. cabras, Baraza y Valiente-Banuet, 2008; Giordani, 2008).

Diferentes ensayos ( $\mathrm{P}$ ej. Camargo-Ricalde y Grether, 1998; Leal y Biondi, 2007; Martínez-Pérez et al., 2006) confirman que los taxa de Mimosa tienen germinación rápida y tiene lugar dentro del primer y cuarto día después de la siembra; sin embargo, la tasa de germinación (GR) está relacionada con la temperatura. Esta característica también es intrínseca de los taxa pioneros o invasores (Lonsdale, 1999), y una característica importante para las plantas con potencial de restauración ambiental como M. luisana (Camargo-Ricalde et al., 2004) y M. aculeaticarpa Ortega var. biuncifera (Benth.) Barneby (Pavón et al., 2011).

\section{Efectos de la temperatura sobre la germinación de semillas}

Mimosa es un género neotropical (Barneby, 1991; Simon et al., 2011), que crece en lugares donde la temperatura oscila entre $0{ }^{\circ} \mathrm{C}$ y $35^{\circ} \mathrm{C}$ (Cavalcante y Pérez, 1995); temperaturas que son consistentes con este y muchos estudios a nivel mundial ( $P$ ej. Alves et al., 2002; Camargo-Ricalde, 2000; Camargo-Ricalde et al., 2004; CamargoRicalde y Grether, 1998; Creager, 1992; Cruz-Medina y Orozco-Almanza, 2010; Ferreira et al., 1992; Moreno-Casasola, 1973; Orozco-Almanza et al., 2003; Parra, 1984; Rivera-Aguilar et al., 2005; Silveira y Fernandes, 2006) que han definido los rangos y temperaturas óptimas de germinación de 25 taxa de Mimosa. También hemos demostrado que las semillas de Mimosa son capaces de germinar entre 0 y 
$45^{\circ} \mathrm{C}$, aunque la temperatura óptima registrada para los dos taxa estudiados fue de

$25{ }^{\circ} \mathrm{C}$. En este contexto, es importante señalar que Cavalcante y Pérez (1995) sugirieron que los taxa tropicales pueden tolerar altas temperaturas, por lo general $\geq 35^{\circ} \mathrm{C}$. Por otro lado, cuando las semillas fueron expuestas a temperaturas frías $(\leq 5$ $\left.{ }^{\circ} \mathrm{C}\right)$, aún hubo germinación en ambos taxa, lo que significa que a esa temperatura aún no se inhiben sus tasas metabólicas (Hendricks y Taylorson, 1976).

Por lo tanto, la temperatura no es un factor limitante para la germinación de las semillas de los taxa de Mimosa, lo que sugiere que los dos taxa estudiados podrían ampliar sus áreas de distribución, ya sea expandiendo o contrayendo los ecosistemas. Ambos taxa de Mimosa son tolerantes a una amplia gama de temperaturas y mostraron una GR rápida y un PG alto; así como un crecimiento rápido (Camargo-Ricalde y Grether, 1998).

Efecto de la temperatura sobre la tasa de germinación (GR) y la tasa de saturación (SR)

Ambos taxa han registrado una GR alta: 3.4 semillas/día para $M$. aculeaticarpa var. aculeaticarpa $\left(25^{\circ} \mathrm{C}\right)$, y 6.6 semillas/día para M. luisana $\left(25-30{ }^{\circ} \mathrm{C}\right)$. Aunque, Carvalho y Nakagawa (2000) sugirieron que las temperaturas más altas hacen semillas germinen más rápido debido a un aumento en la velocidad de absorción de agua y de las reacciones metabólicas. En el caso de $M$. aculeaticarpa var. aculeaticarpa, cuando la temperatura estaba por encima de $25^{\circ} \mathrm{C}$, el número de semillas germinadas por día disminuyó; sin embargo, la GR se incrementó a $45^{\circ} \mathrm{C}$. 
Según Baskin et al. (2000), este comportamiento puede ser el resultado de un pulso de temperatura que rompe la latencia fisiológica.

Por otra parte, al estudiar Mimosa hostilis (C. Mart.) Benth. (=M. tenuiflora), De Souza y De Castro (1983) informaron que la GR de semillas escarificadas mostró una relación directa con el PG, y estos resultados son consistentes con los resultados presentados aquí.

Las semillas escarificadas de ambos taxa de Mimosa tenían una GR de 0-0.45 semillas/día. El valor más alto se alcanzó a $45{ }^{\circ} \mathrm{C}$ en $M$. aculeaticarpa var. aculeaticarpa, y a $20-25^{\circ} \mathrm{C}$ en M. luisana.

En cuanto a la SR, en ambos taxa estudiados requieren uno o dos días para germinar a $25{ }^{\circ} \mathrm{C}$, después de la siembra, alcanzando altos porcentajes de germinación, mientras que se requiere de una mayor número de días para aumentar el porcentaje de germinación a temperaturas menores de $25{ }^{\circ} \mathrm{C}$, debido a una disminución en el metabolismo de la semilla (Amaral y Paulilo, 1992). El estudio realizado por Pavón et al. (2011) sobre la germinación de semillas escarificadas de M. aculeaticarpa var. biuncifera, confirmó la relación inversa entre el GR y SR: mientras GR aumentó, SR disminuye. Sin embargo, esta relación inversa no se encontró, al comparar las semillas escarificadas, no se encontraron diferencias significativas entre las temperaturas ni entre los taxa.

Por último, si el éxito de un taxon se centra sólo en su resistencia y/o tolerancia al factor de temperatura, los resultados globales sugieren que ambos taxa 
de Mimosa pueden ser capaces de tener éxito en diferentes escenarios térmicos. Sin embargo, se necesitan más estudios para comprender cómo otros factores climáticos, como son los diferentes niveles de las concentraciones de $\mathrm{CO}_{2}$ y de la precipitación pueden afectar los ciclos de las plantas.

\section{CONCLUSIONES}

Las semillas de Mimosa, al igual que los de otras legumbres, tienen una capa dura e impermeable. Para germinar estas semillas requieren escarificación y la escarificación mecánica es el mejor método, ya que ni el eje del embrión ni la plántula son dañados.

Los resultados globales sugieren que ambos taxa de Mimosa pueden ser capaces de sobrevivir y ampliar su área geográfica de distribución debido a que sus semillas son capaces de germinar en una amplia gama de temperaturas. Una comparación entre las semillas sanas y las depredadas por brúquidos también es relevante, ya que estos insectos son considerados como "controles naturales" de las poblaciones de los taxa de Mimosa.

Nuestra hipótesis se confirmó: las semillas de ambos taxa germinaron de acuerdo a las temperaturas promedio de sus hábitats y mostraron tolerancia a un amplio escenario térmico. Además, en este estudio, ya que las semillas de ambos taxa son capaces de germinar en un amplio rango de temperaturas, sus poblaciones 
podrían eventualmente ser capaces de expandirse 0 contraerse en el acompañamiento con los ecosistemas en los que se desarrollan.

Actualmente, ambos taxa de Mimosa se pueden utilizar en programas de restauración ecológica. Como ambos taxa son nativos de México y favorecen los procesos de sucesión que conduce a la restauración de sus ecosistemas originales, respectivamente. Proponemos que: i) En los bosques templados (ecosistemas mésicos mexicanos), M. aculeaticarpa var. aculeaticarpa restauraría ambientes donde la temperatura nunca sea inferior a $5^{\circ} \mathrm{C}$ o superior a $45^{\circ} \mathrm{C}$, y ii) En el matorral tropical árido (ecosistema seco), semillas de M. luisana podría germinar en una gama amplia de temperaturas, lo que sugiere que este taxon endémico es una buena opción para la restauración del ecosistema semiárido en el Valle de TehuacánCuicatlán, México.

\section{LITERATURA CITADA}

Alves, U.E., Cesar P.R., Pereira O.A., AlcÂntara B.R. y Araújo D.E. 2002. GerminaÇÃo de sementes de Mimosa caesalpiniaefolia Benth. em diferentes substratos e temperaturas. Revista Brasileira de Sementes 24: 169-178.

Amaral, L.I. y Paulilo M.T. 1992. Efeito da luz, temperatura, regulador de crescimento e nitrato de potássio na germinação de Miconia cinnamomifolia Naudim. Insula 21: $59-86$.

Auld, T.D. 1996. Ecology of the Fabaceae in the Sydney region: fire, ants and the soil seedbank. Cunninghamia 4: 531-551. 
Baraza, E. y Valiente-Banuet A. 2008. Seed dispersal by domestic goats in a semiarid thornshrub of Mexico. Journal of Arid Environments 72: 1973-1976.

Barneby, R.C. 1991. Sensitivae Censitae. A description of the genus Mimosa L. (Mimosaceae) in the New World. Memoirs of the New York Botanical Garden 65: 1-835.

Baskin, C.C. 2003. Breaking physical dormancy in seeds - focusing on the lens. New Phytologist 158: 229-232.

Baskin, J.M., Baskin C.C. y Li X. 2000. Taxonomy, ecology, and evolution of physical dormancy in seeds. Plant Species Biology 15: 139-152.

Baskin, J.M., Nan X.Y. y Baskin C.C. 1998. A comparative study of seed dormancy and germination in an annual and a perennial species of Senna (Fabaceae). Seed Science Research 8: 501-512.

Bewley, J.D. y Black M. 1994. Seeds: physiology of development and germination. $2^{\text {nd }}$ ed. New York.

Camargo-Ricalde, S.L. y Grether R. 1998. Germinación, dispersión y establecimiento de plántulas de Mimosa tenuiflora (Leguminosae) en México. Revista de Biología Tropical 46: 1-12.

Camargo-Ricalde, S.L. 2000. Descripción, distribución, anatomía, composición química y usos de Mimosa tenuiflora (Fabaceae-Mimosoideae) en México. Revista de Biología Tropical 48: 939-954.

Camargo-Ricalde, S.L., Grether R., Martínez-Bernal A., García-García V. y BarriosDel-Rosal S. 2001. Especies útiles del género Mimosa (FabaceaeMimosoideae) en México. Boletín de la Sociedad Botánica de México 68: 33-44. 
Camargo-Ricalde, S.L., Dhillion S.S. y Grether R. 2002. Community structure of endemic Mimosa species and environmental heterogeneity in a semi-arid Mexican valley. Journal of Vegetation Science 13: 697-704.

Camargo-Ricalde, S.L. y Dhillion S.S. 2003. Endemic Mimosa species can serve as mycorrhizal "resource islands" within semiarid communities of the TehuacánCuicatlán Valley, Mexico. Mycorrhiza 13: 29-136.

Camargo-Ricalde, S.L., Dhillion S.S. y García-García V. 2004. Phenology, and seed production and germination of seven endemic Mimosa species (FabaceaeMimosoideae) of the Tehuacán-Cuicatlán Valley, Mexico. Journal of Arid Environments 58: 423-437.

Camargo-Ricalde, S.L., Reyes-Jaramillo I. y Montaño N.M. 2010a. Forestry insularity effect of four Mimosa L. species (Leguminosae-Mimosoideae) on soil nutrients of a Mexican semiarid ecosystem. Agroforestry Systems 80: 385-397.

Camargo-Ricalde, S.L., Montaño N.M., Reyes-Jaramillo I., Jiménez-González C. y Dhillion S.S. 2010b. Effect of mycorrhizae on seedlings of six endemic Mimosa L. species (Leguminosae-Mimosoideae) from the semi-arid Tehuacán-Cuicatlán Valley, Mexico. Trees-Structure and Function 24: 67-78.

Carvalho, N.M. y Nakagawa J. 2000. Sementes: ciência, tecnologia e produção. 4 ed. Jaboticabal: FUNEP.

Cavalcante, A.M. y Perez S.C.S.G. 1995. Efeitos da temperatura sobre a germinação de sementes de Leucaena leucocephala (LAM) de WIT. Revista Brasileira de Sementes 17: 1-8. 
Chauhan, B.S. y Johnson D.E. 2008. Seed germination and seedling emergence of giant sensitive plant (Mimosa invisa). Weed Science 56: 244-248.

Creager, R.A. 1992. Seed germination, physical and chemical control of catclaw mimosa (Mimosa pigra var. pigra). Weed Technology 6: 884-891.

Cruz-Medina, D. y Orozco-Almanza S. 2010. Germinación de ocho especies de la familia Fabaceae, bajo diferentes regímenes de temperatura. VII Simposio Internacional sobre la flora silvestre en zonas áridas, Universidad de Sonora, Hermosillo, Sonora, México.

D’Aubeterre, R., Principal J. y García J. 2002. Efecto de diferentes métodos de escarificación sobre la germinación de tres especies del género Prosopis. Revista Científica 12: 575-577.

De Souza, A.M. y De Castro G.A. 1983. Métodos para superar a dormÊncia tegumentar em sementes de Jurema- preta (Mimosa hostilis Benth.). Boletim de Pesquisa Florestal, Colombo 6/7: 26-32.

Dhillion, S.S., Aguilar-Støen M. y Camargo-Ricalde S.L. 2004. Integrative ecological restoration and local involvement in the Tehuacán-Cuicatlán Valley, Mexico. Environmental Conservation 13: 1-3.

Enríquez-Peña, E., Suzán-Azpiri H. y Malda-Barrera G. 2004. Viabilidad y germinación de semillas de Taxodium mucronatum (Ten.) en el estado de Querétaro, México. México. Agrociencia 38: 357-381.

Ferreira, A.G., Lipp Joao K.H. y Heuser E.D. 1992. Efeitos de escarificaçao sobre a germinaçao e do pH no crescimento de Acacia bonariensis Gill e Mimosa bimucronata (DC.) Kuntze. Revista Brasileira de Fisiologia Vegetal 4: 63-65. 
Fontúrbel, R.F. 2002. Rol de la coevolución planta-insecto en la evolución de las flores cíclicas en las angiospermas. Ciencia Abierta Internacional 17: 1-11.

Giordani, L. 2008. The role of goats in germination and dispersal of Mimosa luisana Brandegee (Leguminosae-Mimosoideae) seeds in the Tehuacán-Cuicatlán valley, Puebla State, Mexico. Master Thesis, Norwegian University of life Sciences, Norway, $32 \mathrm{p}$.

González-Castañeda, J., Angoa-Pérez M.V., Frías-Hernández J.T., Olalde-Portugal V., Flores-Ancira E., Terrones-Rincón T.R., Van Cleemput O. y Dendooven L. 2004. Germination of seeds of huisache (Acacia schaffneri) and catclaw (Mimosa monancistra) as affected by sulphuric acid and mechanical scarification and subsequent growth and survival in a greenhouse and field experiment. Seed Science and Technology 32: 727-738.

Grether, R., Camargo-Ricalde S.L. y Martínez-Bernal A. 1996. Especies del género Mimosa (Leguminosae) presentes en México. Boletín de la Sociedad Botánica de México 58: 149-152.

Hendricks, S.B. y Taylorson B. 1976. Variation in germination and amino acid leakage of seeds with temperature related to membrane phase change. Plant Physiology 58: 7-11.

Hintze, J. 2001. NCSS. Number Cruncher Statistical System, Kaysville.

Jayasuriya, G.K. Wijetunga A.S., Baskin J.M. y Baskin C.C. 2013. Seed dormancy and storage behavior in tropical Fabaceae: a study of 100 species from Sri Lanka. Seed Science Research 23: 257-269. 
Leal, L. y Biondi D. 2007. Comportamento germinativo de sementes de Mimosa dolens Vell. Publ UEPG Exact Earth Sci Agr Sci Eng Ponta Grossa 13: 37-43.

Lonsdale, W.M. 1993. Losses from the seed bank of Mimosa pigra: soil microorganisms vs. temperature fluctuations. Journal of Applied Ecology 30: 654-660.

Lonsdale, W.M. 1999. Global patterns of plant invasions and the concept of invasibility. Ecology 80: 1522-1536.

Lopez, J., Devesa J.A., Ruiz T. y Ortega-Olivencia A. 1999. Seed germination in Genisteae (Fabaceae) from south-west Spain. Phyton 39: 107-129.

Martínez-Pérez, G., Orozco-Segovia A. y Mantorell C. 2006. Efectividad de algunos tratamientos pre-germinativos para ocho especies leñosas de la Mixteca Alta Oaxaqueña con características relevantes para la restauración. Boletín de la Sociedad Botánica de México 79: 9-20.

Matilla, A. 2004. Ecofisiología de la germinación de semillas. En: Reigosa M.J., Pedrol N. y Sánchez A. La ecofisiología Vegetal: Una ciencia de síntesis. Thomson, España.

Moreno-Calles, A. y Casas A. 2010. Agroforestry systems: restoration of semiarid zones in the Tehuacán Valley, Central Mexico. Ecological Restoration 28: 361 368.

Moreno-Casasola, P. 1973. Estudio sobre viabilidad y latencia de semillas tropicales. Tesis de Licenciatura, Universidad Nacional Autónoma de México, UNAM, México, 78 p.

Olff, H., Pegtel D.M., Van Groenendael J.M. y Bakker J.P. 1994. Germination strategies during grassland succession. Journal of Ecology 82: 69-77. 
Orozco-Almanza, S., Ponce De León-García L., Grether R. y García-Moya E. 2003. Germination of four species of the genus Mimosa (Leguminosae) in a semi-arid zone of Central Mexico. Journal of Arid Environments 55: 75-92.

Parmesan, C. y Yohe G. 2003. A globally coherent fingerprint of climate change impacts across natural systems. Nature 421: 37-42.

Parra, G.P. 1984. Estudio de la morfología externa de plántulas de Calliandra gracilis, Mimosa albida, Mimosa arenosa, Mimosa camporum y Mimosa tenuiflora. Revista de la Facultad de Agronomía (Maracay) 13: 311-350.

Pavón, N.P., Ballato-Santos J. y Pérez-Pérez C. 2011. Germinación y establecimiento de Mimosa aculeaticarpa var. biuncifera (FabaceaeMimosoideae). Revista Mexicana de Biodiversidad 82: 653-661.

Piedrahita, C.E. 1997. Germinación de semillas de Jacaranda copaia bajo condiciones contrastantes de luz. Colombia. Crónica forestal y del medio ambiente 12: 1-4.

Piedrahita, C.E. 1998. Aumento del vigor en semillas de Pinus patula (Schlecht. \& Cham.) por el efecto de osmoacondicionamiento. Crónica forestal y del medio ambiente 13: 1-21.

Rivera-Aguilar, V., Godínez-Álvarez H., Manuell-Cacheux I. y Rodríguez-Zaragoza S. 2005. Physical effects of biological soil crusts on seed germination of two desert plants under laboratory conditions. Journal of Arid Environments 63: 344-352.

Romero-Nápoles, J., Grether R., Camargo-Ricalde S.L. y Jonson C.D. 2005. Método para la evaluación de daño de semillas por brúquidos (Insecta, Coleoptera), en 
el campo con nuevos registros de hospederos y distribución para el grupo. Entomología Mexicana 4: 107-111.

Silveira, F.A. y Fernandes G.W. 2006. Effect of light, temperature and scarification on the germination of Mimosa foliolosa (Leguminosae) seeds. Seed Science and Technology 34: 585-592.

Simon, M.F., Grether R., de Queiroz L.P., Sarkinen T.E., Dutra V.F. y Hughes C.E. 2011. The evolutionary history of Mimosa (Leguminosae): towards a phylogeny of the sensitive plants. American Journal of Botany 78: 1201-1221.

Skogen, K.A., Senack L. y Holsinger K.E. 2010. Dormancy, small seed size and low germination rates contribute to low recruitment in Desmodium cuspidatum (Fabaceae). Journal of the Torrey Botanical Society 137: 355-365.

Sokal, R.R. y Rohlf F.J. 1995. Biometry. Freeman and Company, San Francisco, C.A. $887 \mathrm{pp}$.

Takakura, K. 2002. The specialist seed predator Bruchidius dorsalis (Coleóptera: Bruchidae) plays a crucial role in the seed germination of its host plant, Gleditsia japonica (Leguminosae). Functional Ecology 16: 252-257.

Taylor, G.B. 2005. Hard seededness in Mediterranean annual pasture legumes in Australia. Australian Journal of Agricultural Research 56: 645-661.

Valiente-Banuet, A. y Ezcurra E. 1991. Shade as a cause of the association between the cactus Neobuxbaumia tetetzo and the nurse shrub Mimosa luisana. Journal of Ecology 79: 961-971. 
Valiente-Banuet, A., Vite F. y Zavala-Hurtado J.A. 1991. Interaction between the cactus Neobuxbaumia tetetzo and the nurse shrub Mimosa luisana. Journal of Vegetation Science 2: 11-14.

Van Assche, J.A., Debucquoy K.L. y Rommens W.A. 2003. Seasonal cycles in the germination capacity of buried seeds of some Leguminosae (Fabaceae). New Phytologist 158: 315-323.

Van Klinken, R.D. y Flack L. 2005. Wet heat as a mechanism for dormancy release and germination of seeds with physical dormancy. Weed Science 53: 663-669.

Van Klinken, R.D. y Goulier J-B. 2013. Habitat-specific seed dormancy-release mechanisms in four legume species. Seed Science Research 23: 181-188.

Venier, P., Funes, G. y Carrizo-García C. 2012. Physical dormancy and histological features of seeds of five Acacia species (Fabaceae) from xerophytic forests in central Argentina. Flora 207: 39-46.

Weng, J-H. y Hsu F-H. 2006. Variation of germination response to temperature in Formosan lily (Lilium formosanum Wall.) collected from different latitudes and elevations in Taiwan. Plant Production Science 9: 281-286.

Westoby, M., Jurado E. y Leishman M. 1992. Comparative evolutionary ecology of seed size. Trends in Ecology and Evolution 7: 368-372. 


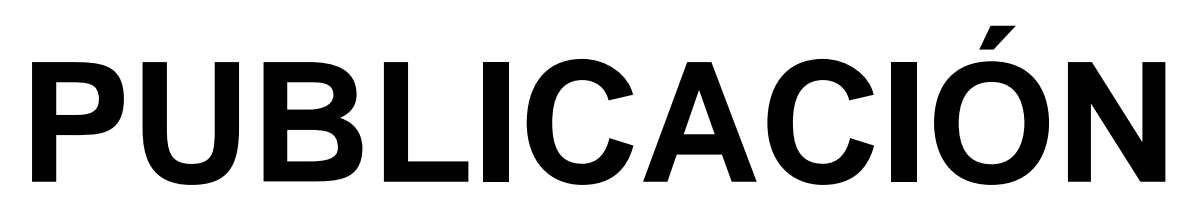




\title{
EFFECT OF SCARIFICATION AND TEMPERATURE ON SEED germination of two Mexican speCies of Mimosa (LEGUMINOSAE-MIMOSOIDEAE)
}

\author{
Susana Adriana Montaño-Arias ${ }^{1,2,4}$, Sara lucía Camargo-Ricalde ${ }^{2,4}$, Rosaura Grether ${ }^{2}$ \\ y DAVID DÍAZ-PontOnes ${ }^{3}$ \\ 'Doctorado en Ciencias Biológicas y de la Salud \\ ${ }^{2}$ Departamento de Biología \\ ${ }^{3}$ Departamento de Ciencias de la Salud, División de Ciencias Biológicas y de la Salud, \\ Universidad Autónoma Metropolitana-Iztapalapa, México, D.F. México \\ ${ }^{4}$ Corresponding authors: slcr@xanum.uam.mx; arias_susan@hotmail.com
}

\begin{abstract}
It has been considered that Mimosa aculeaticarpa var. aculeaticarpa and M. luisana have the potential to restore temperate and semi-arid environments, respectively. Mature seeds were collected from eight mother plants per taxon to determine the effects of scarification and temperature on seed germination of both taxa, and to define the optimum temperature for germination. To obtain a representative sample of each taxon, seeds with the same weight and size were mixed. Five replicates of 20 seeds each (100 seeds per taxon/temperature, plus the control) were established. The seeds were mechanically scarified and incubated under controlled conditions: 5 to $45^{\circ} \mathrm{C}$ with $5{ }^{\circ} \mathrm{C}$ intervals, and a $12 \mathrm{~h} \mathrm{light} / 12 \mathrm{~h}$ darkness photoperiod. Results showed that scarification and temperature were significant factors in seed germination. In both taxa, germination was epigeal and phanerocotylar. The highest seed germination percentages were obtained when seeds were scarified. $88 \%$ of seeds of M. aculeaticarpa var. aculeaticarpa germinated at $25^{\circ} \mathrm{C}$. Hundred percent of seeds of $M$. luisana germinated at $30{ }^{\circ} \mathrm{C}$. The optimum temperature for germination of seeds of both taxa was established at $25^{\circ} \mathrm{C}$. Mimosa taxa differ in the germination rate: M. luisana germinated at 6.6 seeds/day and M. aculeaticarpa var. aculeaticarpa at 3.4 seeds/day. Overall results suggest that, for both taxa, an increase or decrease in temperature will not inhibit seed germination, supporting the recommendation to use these plants for reforestation, as part of environmental restoration projects in temperate and semi-arid Mexican regions.
\end{abstract}

Key words: arid tropical scrub, conservation, restoration, temperate forest.

Resumen: Mimosa aculeaticarpa var. aculeaticarpa y M. luisana son taxa con potencial para la restauración ambiental. Se evaluaron los efectos de la escarificación y la temperatura en la germinación de semillas de ambos taxa y se definió la temperatura óptima de germinación, se colectaron semillas maduras de ocho individuos por especie. Las semillas (igual peso y tamaño) se mezclaron para obtener una muestra compuesta por taxon. Se establecieron cinco repeticiones de 20 semillas por taxon (100 semillas por taxon, por temperatura, más el control). Las semillas fueron escarificadas mecánicamente, realizando un corte en el extremo opuesto al eje del embrión e incubadas en un gradiente de 5 a $45^{\circ} \mathrm{C}$, con intervalos de $5{ }^{\circ} \mathrm{C}$ y un fotoperíodo de $12 \mathrm{~h}$ luz/12h oscuridad. Los resultados indican que la escarificación y la temperatura son factores significativos para la germinación de las semillas. En ambos taxa, la germinación fue epígea y fanerocotilar. Los mayores porcentajes de germinación se obtuvieron cuando las semillas fueron escarificadas. Mimosa aculeaticarpa var. aculeaticarpa logró el $88 \%$ de germinación a $25^{\circ} \mathrm{C}$; mientras que $M$. luisana alcanzó $100 \%$ a $30^{\circ} \mathrm{C}$; sin embargo, para ambos taxa la temperatura óptima de germinación fue de $25^{\circ} \mathrm{C}$. La tasa de germinación difiere, en $M$. luisana se registraron 6.6 semillas/día; mientras que en M. aculeaticarpa var. aculeaticarpa sólo 3.4 semillas/día. Los resultados sugieren que ante un incremento o decremento en la temperatura, la germinación de las dos especies estudiadas no será inhibida; por lo tanto, se apoya la recomendación del uso de ambas especies en reforestación como parte de proyectos de restauración ambiental en regiones templadas y semiáridas de México.

Palabras clave: bosque templado, conservación, matorral xerófilo; restauración.

n Mexico, species of Mimosa L. (Leguminosae-Mimosoideae) have attracted attention due to their multiple uses, their ability to survive in harsh environments, to resprout after having been cut or burnt, because the genus has many ecological, economic, and cultural values (Camargo-Ricalde et al., 2001). Mimosa comprises ca. 530 species in the world, and it is one of the three largest genera of Mimosoideae, along with Acacia and Inga (Simon et al., 2011). 
After Brazil, Mexico is the second diversification center of Mimosa, being the most diverse genus of the subfamily with ca. 110 species, $60 \%$ endemic to the country, many of them occurring as dominant or co-dominant elements in arid ecosystems, widely distributed in tropical vegetation, and few species growing in temperate forests (Grether et al., 1996; Camargo-Ricalde et al., 2002). Within arid and semi-arid environments, some Mimosa species are resource-island formers, enriching the soil with organic matter and nutrients (Camargo-Ricalde et al., 2002, 2010a), and as reservoirs of arbuscular mycorrhizal fungal spores (Camargo-Ricalde and Dhillion, 2003), and nitrogen-fixing bacteria (CamargoRicalde et al., 2010a, b). In addition, the nurse effect is very clear between Mimosa luisana Brandegee and Neobuxbaumia tetetzo (F.A. C.Weber ex K.Schum) Backeberg, a columnar cactus endemic to Mexico (Valiente-Banuet et al., 1991; Valiente-Banuet and Ezcurra, 1991). Hence, some Mimosa species are considered potentially useful for ecological restoration projects (Dhillion et al., 2004; MorenoCalles and Casas, 2010; Pavón et al., 2011).

As a first step, it is known that seeds of some Mimosa species are able to germinate in a wide range of temperatures (De Souza-Araújo and De Castro-Andrade, 1983; CamargoRicalde et al., 2004; Pavón et al., 2011), and that scarification increases the percentage of germination (Ferreira et al., 1992; Camargo-Ricalde and Grether, 1998; Camargo-Ricalde et al., 2004; González-Castañeda et al., 2004; Silveira and Fernandes, 2006; Leal and Biondi, 2007; Chahuan and Johnson, 2008; Pavón et al., 2011; Gehan-Jayasuriya et al., 2013). However, it is not yet possible to generalize about how seeds will respond to both seed scarification and temperature fluctuation because only $5 \%$ of the species of $\mathrm{Mi}$ mosa have been studied around the world. For the Mexican Mimosa, seed germination has merely been studied in 13 species occurring in arid ecosystems (i.e. Camargo-Ricalde et al., 2004, Pavón et al., 2011) and only one from temperate forests (Martínez-Pérez et al., 2006).

Hence, and under the assumption that species are adapted to the environments where they have evolved, arid and semiarid ecosystem species will be able to germinate at higher and more extreme temperatures than temperate ecosystem species. Therefore, the aims of this study were: (i) To determine the effects of scarification and temperature on seed germination percentage, germination rate and saturation rate; and (ii) To define the optimum temperature for seed germination, of two Mimosa taxa occurring in two contrasting ecosystems: Mimosa aculeaticarpa var. aculeaticarpa Ortega (temperate forest, endemic to Mexico) and M. luisana (arid tropical scrub, narrow endemic to Mexico).

\section{Materials and Methods}

Experimental design. Mature fruits of M. aculeaticarpa var. aculeaticarpa and M. luisana were collected during the maximum productivity season of each taxon (November and October, respectively), from eight different mother plants with similar height and foliage cover. Fruit harvesting was random, spanning the entire area of the canopy per plant.

Mimosa aculeaticarpa var. aculeaticarpa was collected from a temperate forest, in the Municipality of Tiripetío, State of Michoacán, $19^{\circ} 58.218^{\prime} \mathrm{N}, 101^{\circ} 31.664^{\prime} \mathrm{W}$, at $1,950 \mathrm{~m}$ a.s.l., and M. luisana from an arid tropical scrub, in the Valley of Tehuacán, State of Puebla, $18^{\circ} 15^{\prime} 23.7^{\prime \prime} \mathrm{N}$, $97^{\circ} 09^{\prime} 03.3^{\prime \prime} \mathrm{W}$, at 2,232 $\mathrm{m}$ a.s.l. Voucher specimens were deposited at the Herbario Metropolitano (UAMIZ), Universidad Autónoma Metropolitana-Iztapalapa.

Seed characterization and treatments prior to sowing. After collection, seeds were removed from the fruits. Approximately, 10,000 seeds, per species, were obtained and stored in plastic containers, at room temperature $\left(20^{\circ} \mathrm{C}\right)$, in Mexico City. For two weeks, bruchids (Insecta, Coleoptera) emerging from the seeds were collected and fixed in FAA for identification.

Since seed size and weight can influence the rate of germination (Matilla, 2004; Skogen et al., 2010), 3,600 healthy mature seeds per taxon, were characterized. The evaluated variables were: length, width and thickness, as well as seed weight. Seed size was measured with a digital vernier caliper (Absolute Digimatic, CD-6"CS), and seed weight was determined individually using an analytical balance with $10^{-4} \mathrm{~g}$ resolution (Adventurer, Ohaus, Melrose, USA). Healthy seeds, of both taxa, with a similar range of size and weight, were mixed to obtain a combined sample. It is important to mention that for assuring the adequate development of the whole assay, the range of seed size and weight was chosen in terms of the minimum number of seeds needed for it.

Germination assays under laboratory conditions. Legume seeds are known to have physical dormancy (Baskin, 2003; Van Assche et al., 2003; Venier et al., 2012; Gehan-Jayasuriya et al., 2013), as Mimosa species (Martínez-Pérez et al., 2006; Gehan-Jayasuriya et al., 2013). Prior to any assay, all Mimosa seeds were washed with commercial detergent ( $3 \mathrm{~g} / 100 \mathrm{ml}$ water/3 $\mathrm{min}$ ) (Camargo-Ricalde and Grether, 1998). Seeds were mechanically scarified: the seed coat was cut at the side opposite to the embryo's axis in order to avoid damage. Germination assays took place in an incubator (Conviron T 38/Lb/AP), using trays $(30 \times 15 \times 20 \mathrm{~cm})$, with agar $(3 \%)$ as substrate. A temperature gradient with nine intervals of $5{ }^{\circ} \mathrm{C}$ each (from 5 to $45^{\circ} \mathrm{C}$ ), and a photoperiod of $12 \mathrm{~h}$ light $/ 12 \mathrm{~h}$ darkness was set.

For every thermal treatment, five replicates of 20 scarified seeds each (100 seeds per taxon, 1,800 seeds in total), as well as five replicates of 20 unscarified seeds each as control (100 seeds per taxon, 1,800 seeds in total) were established. Seeds were considered as germinated when the radicle reached $1 \mathrm{~mm}$ in length (Bewley and Black, 1994). All the assays continued for 30 days. 
To analyze the effect of temperature fluctuations in relation to the seed germination behavior of plants, diverse authors (i.e. Piedrahita-Cardona 1997, 1998; Enríquez-Peña et al., 2004; Weng and Hsu, 2006; Pavón et al., 2011) consider the parameters listed below, which will be used, as well, for the Mimosa taxa studied here:

Total Percentage of Germination (PG).- it is defined as the percentage of the total germination at the end of the assay.

Half Germination Rate $\left(\mathrm{G}_{50}\right)$.- it is the number of days, after sowing, needed to reach $50 \%$ of germination, and it was estimated by interpolating the day before and the day after in which $50 \%$ of the total seed germination was obtained.

Germination Rate (GR).- it is defined as the correlation between the number of germinated seeds and the germination time: $\mathrm{GR}=\Sigma\left(\mathrm{n}_{\mathrm{i}}\right) / \mathrm{t}$, where $\mathrm{n}_{\mathrm{i}}=$ number of germinated seeds in one day (i), $\mathrm{t}=$ time from sowing until the last seed germinates.

Saturation Rate (SR).- it is defined as the time for germination in relation to the germination percentage: $\mathrm{SR}=\Sigma\left(\mathrm{n}_{\mathrm{i}} \mathrm{t}_{\mathrm{i}}\right) /$ $\mathrm{N}$, where $\mathrm{n}_{\mathrm{i}}=$ number of germinated seeds in one day (i); $\mathrm{t}_{\mathrm{i}}$ = number of days after sowing, $\mathrm{N}=$ total number of seeds sown.

Optimum Temperature (OT).- it was calculated as the average of all temperatures, weighted with the total seed germination percentage, at each temperature (Olff et al., 1994).

Statistical analyses. Seed weight was compared between taxa using a $t$-student test $(P<0.05)$. Homogeneity of variance was examined for all temperature treatments (Levene's test, $P<0.05$ ). When homogeneity of variance was found, a one-way ANOVA was used to analyze the intraspecific variation within the germination percentages and between control and scarified seeds, and a two-way ANOVA to examine the interspecific variation within the germination percentages, where the taxa and the temperatures were the variables (ANOVA, $P<0.05$ ). A multiple comparison test was employed (Tukey's HSD, $P<0.05$ ) to form groups. In $M i$ mosa aculeaticarpa var. aculeaticarpa, the homogeneity of variance of $S R$ was not found; therefore, the non-parametric Kruskal-Wallis test was used $(P<0.05)$, and medians were compared by the Mann-Whitney test $(P<0.05$, Sokal and Rohlf, 1995). All analyses were performed with the NCSS Software (Hintze, 2001).

\section{Results}

Seed size, weight, and production. The two studied Mimosa taxa produce numerous seeds of variable weight and size. When comparing the weight of seeds between both taxa and within each taxon, no significant differences were showed $(t$ $=0.7442, P>0.05)$. In this sense, no significant differences were found, when comparing the size between and within both taxa; though, M. aculeaticarpa var. aculeaticarpa seeds were the biggest (Table 1).
Not all collected seeds were healthy; many of them were infested by bruchids (Insecta, Coleoptera). The mean percentage of infestation was $11.9 \%$ for M. aculeaticarpa var. aculeaticarpa, and $48.7 \%$ for M. luisana (Table 1). In the case of $M$. aculeaticarpa var. aculeaticarpa, two species of seed predator bruchids were identified, Acanthoscelides chiricahuae (Fall) and A. mexicanus (Sharp). Mimosa luisana seeds were infested by three species, two belonging to genus Acanthoscelides (Acanthoscelides mexicanus and A. chiricahuae) and one to genus Stator [Stator pruininus (Horn)].

Scarification effect on the total percentage of seed germination $(P G)$. The two Mimosa taxa showed both epigeal and phanerocotylar germination, which started the first day after sowing. In both taxa, germination was stimulated by scarification (Figures 1-3; Table 2). The PG of unscarified seeds was low and slow. Scarified seeds registered a significantly higher PG $(F=143.88, P<0.001$; Table 2$)$. Scarified seeds of M. aculeaticarpa var. aculeaticarpa germinated 57 times faster than those of M. luisana. In the case of Mimosa luisana, unscarified seeds germinated five times faster than those of M. aculeaticarpa var. aculeaticarpa (Figures 1-3). Although these data were not statistically significant, seeds of Mimosa luisana tended to germinate in greater numbers than those of M. aculeaticarpa var. aculeaticarpa (Table 2).

Temperature effect on total seed germination percentage $(P G)$. The two-way ANOVA analysis showed a significant effect of the two factors, taxon and temperature, on the PG (Tables 3,4). The lowest germination percentage of both taxa was recorded at $5{ }^{\circ} \mathrm{C}$ (Figures 1-3), differing significantly from the other temperature ranges $(F=33.03$ and $F=18.63$; both with $P<0.005$, respectively). The highest PG (88\%) was recorded at $25^{\circ} \mathrm{C}$ in M. aculeaticarpa var. aculeaticarpa $(F=33.03 ; P<0.005)$; although, $88 \%$ of

Table 1. Mimosa taxa mature seed size, weight, production, and percentage of infested and non-infested seeds by bruchids (Insecta, Coleoptera).

\begin{tabular}{cccc}
\hline \multicolumn{2}{c}{$\begin{array}{c}\text { Variables / } \\
\text { Taxon }\end{array}$} & $\begin{array}{c}\text { M. aculeaticarpa } \\
\text { var. aculeaticarpa }\end{array}$ & M. luisana \\
\hline Size $(\mathrm{mm})$ & Length & $3.0-4.4$ & $2.6-3.5$ \\
& Width & $2.0-3.0$ & $1.8-2.4$ \\
& Thickness & $0.01-0.02$ & $2.0-2.7$
\end{tabular}

\begin{tabular}{lcc}
\hline $\begin{array}{l}\text { Mature seed } \\
\text { weight }(\mathrm{gr}) \\
\text { (Mean } \pm \mathrm{SE} \text { ) }\end{array}$ & $0.008 \pm 0.0004^{\mathrm{a}}$ & $0.00864 \pm 0.0006^{\mathrm{a}}$ \\
\hline Production (number) & 9,891 & 12,276 \\
\hline $\begin{array}{l}\text { Infested seeds (\%) } \\
\text { Non-infested seed } \\
\text { production (\%) }\end{array}$ & 11.9 & 48.7 \\
\hline
\end{tabular}

Values followed by the same letter are not significantly different $(P<0.05)$. 

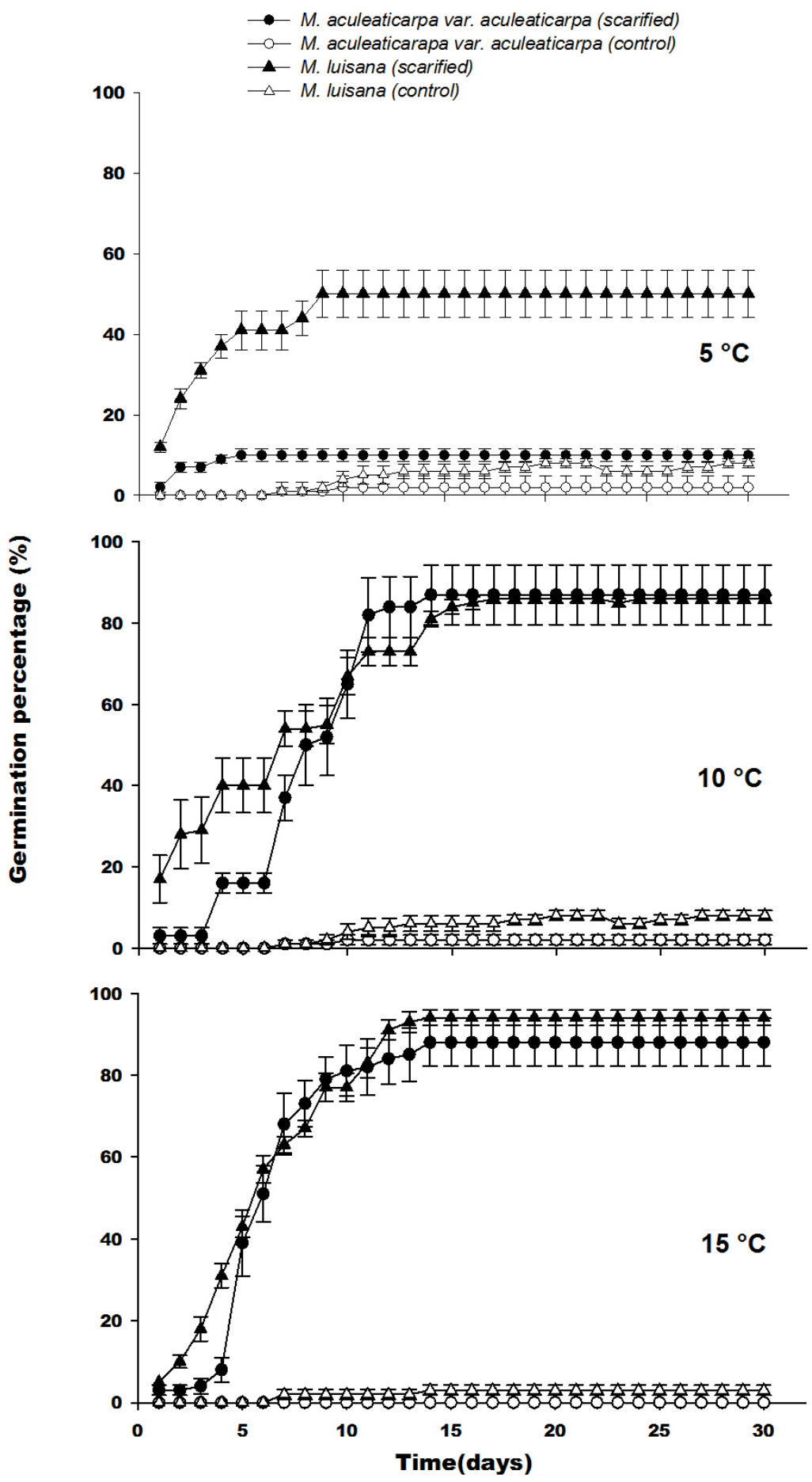

Figure 1. Seed Germination Percentage (PG $- \pm \mathrm{SE}$ ) of two Mimosa taxa along a temperature gradient $5-15^{\circ} \mathrm{C}$.

germination was also achieved at $15^{\circ} \mathrm{C}$, but seeds required more days $(\mathrm{SR}=5)$ to reach this percentage (Table 4). In $M$. luisana, the highest percentage of germination $(100 \%)$ was reached at $30^{\circ} \mathrm{C}$; whereas, at higher or lower temperatures, the PG decreased (Figure 2; Table 4).

The effect of the interaction between the two factors, taxon and temperature, on the PG was significant $(P<0.001)$, indicating that the germinative response to temperature depended on the taxon. There was a decrease in the PG at extreme temperatures, 5 and $45^{\circ} \mathrm{C}$ (Figures 1-3).

In relation to the half of seed germination $\left(\mathrm{G}_{50}\right)$, the taxon factor presented an interaction with the temperature factor $(P<0.001$, Table 3$)$, indicating that seed germination response $\left(\mathrm{G}_{50}\right)$ to temperature depended on the taxon. 


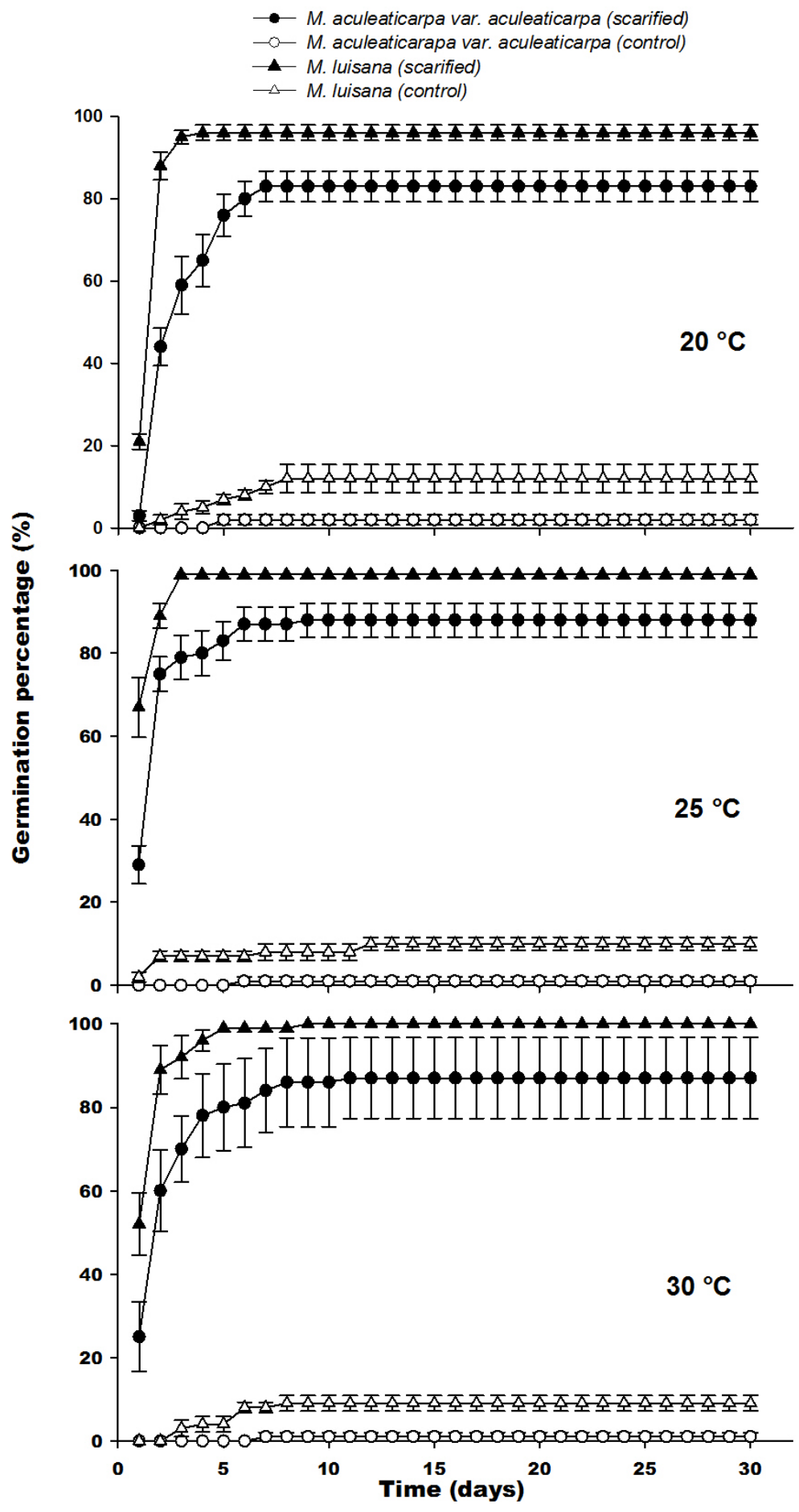

Figure 2. Seed Germination Percentage (PG - \pm SE) of two Mimosa taxa along a temperature gradient $20-30{ }^{\circ} \mathrm{C}$.

Although at $20^{\circ} \mathrm{C}, M$. aculeaticarpa var. aculeaticarpa reached $50 \%$ of seed germination on the second day after sowing, at 25 and $30{ }^{\circ} \mathrm{C}$, the $50 \%$ of seed germination was exceeded on the second day after sowing. However, more days were needed to reach $50 \%$ of germination at temperatures below $20^{\circ} \mathrm{C}$ and above $35^{\circ} \mathrm{C}$. Moreover, only $35 \%$ of seed germination was reached at $45^{\circ} \mathrm{C}$. In the case of $M$. luisana, $50 \%$ of seed germination was attained at $30{ }^{\circ} \mathrm{C}$, the first day after sowing, and this percentage was exceeded at temperatures of 25,35 , and $40{ }^{\circ} \mathrm{C}$; however, the total germination percentage decreased to less than 27 $\%$ at $45^{\circ} \mathrm{C}$ (Figures $1-3$ ).

Furthermore, the results showed that seeds of $M$. aculeaticarpa var. aculeaticarpa and M. luisana germinated 
Table 2. Effect of seed scarification on the percentage of germination of two taxa of genus Mimosa.

\begin{tabular}{lll}
\hline Taxon & \multicolumn{2}{c}{ Germination (\%) } \\
\cline { 2 - 3 } & $\begin{array}{l}\text { Unscarified } \\
\text { (Mean } \pm \text { SE) }\end{array}$ & $\begin{array}{l}\text { Scarified } \\
\text { (Mean } \pm \text { SE) }\end{array}$ \\
\hline $\begin{array}{l}\text { M. aculeaticarpa var. } \\
\text { aculeaticarpa }\end{array}$ & $1.22 \pm 0.22^{\mathrm{Aa}}$ & $70.0 \pm 8.35^{\mathrm{Bb}}$ \\
M. luisana & $6.33 \pm 1.46^{\mathrm{Aa}}$ & $79.6 \pm 8.31^{\mathrm{Bb}}$ \\
\hline
\end{tabular}

Values followed by the same letter are not significantly different in columns (lower case) and rows (upper case), $P<0.05$.

along the gradient of temperature $\left(5-45^{\circ} \mathrm{C}\right)$. However, the optimum temperature (OT) for seed germination for both taxa was determined at $25^{\circ} \mathrm{C}$ (Table 4).

Temperature effect on the germination rate $(G R)$. The Germination Rate (GR) was significantly affected by the taxon and the temperature factors $(F=9.9 ; P<0.001$, Figure 4A, Table $3)$. GR increased significantly when the temperature reached $30{ }^{\circ} \mathrm{C}$. In average, three seeds of M. aculeaticarpa var. aculeaticarpa germinated/day at $25^{\circ} \mathrm{C}$; whereas, six seeds of $\mathrm{M}$. luisana germinated/day at the same temperature. However, the GR of seeds of both, M. aculeaticarpa var. aculeaticarpa and of M. luisana, decreased at temperatures above 30 and $35^{\circ} \mathrm{C}$, respectively. In the case of M. aculeaticarpa var. aculeaticarpa, the $\mathrm{GR}$ increased at $45^{\circ} \mathrm{C}$; although, only $35 \%$ of seed germination was recorded (Figure 4A).

Regarding the saturation rate (SR), a significant interaction between the two factors, taxon and temperature, was also observed $(F=4.38 ; P<0.001$, Table 3$)$, indicating that the SR depended on the taxon. Mimosa aculeaticarpa var. aculeaticarpa required numerous days to reach the PG; whereas, $M$. luisana required even more days to reach it at $15^{\circ} \mathrm{C}$ (Figure 4B).

\section{Discussion}

The overall results obtained in this study are relevant under the context of possible temperature and precipitation fluctuation. In this case, this study tries to elucidate the influence of both temperature change and seed scarification on Mimosa seeds germination:

Table 3. Two-way ANOVA to analyze the effect of the temperature on the percentage of seed germination of two taxa of genus Mimosa.

\begin{tabular}{lccccc}
\hline & & $\begin{array}{c}\text { Germination } \\
(\mathbf{\%})\end{array}$ & $\mathbf{G}_{50}(\mathbf{d})$ & $\begin{array}{c}\mathbf{G R} \\
(\mathbf{s e e d s} / \mathbf{d})\end{array}$ & $\mathbf{S R}(\mathbf{d})$ \\
& $\mathbf{D F}$ & $\boldsymbol{F}$ & $\boldsymbol{F}$ & $\boldsymbol{F}$ & $\boldsymbol{F}$ \\
\hline Taxon $(\mathrm{S})$ & 1 & $20.65^{\text {ns }}$ & $19.25^{* * *}$ & $12.54^{* * *}$ & $9.27^{* *}$ \\
Temperature $(\mathrm{T})$ & 8 & $50.74^{\text {ns }}$ & $49.95^{* * *}$ & $17.71^{* * *}$ & $68.04^{* * *}$ \\
$\mathrm{~S} \times \mathrm{T}$ & 8 & $3.38^{* * *}$ & $3.62^{* * *}$ & $9.92^{* * *}$ & $4.38^{* * *}$ \\
\hline
\end{tabular}

$\mathrm{G}_{50}=$ Half Germination Rate; GR=Germination Rate; $\mathrm{SR}=$ Saturation Rate; ns=not significative; ${ }^{* *} P<0.01 ;{ }^{* * *} P<0.001$
Table 4. Total Percentage of seed Germination (PG) and Saturation Rate (SR) of two taxa of genus Mimosa under different temperatures, in a laboratory assay.

\begin{tabular}{|c|c|c|c|}
\hline $\begin{array}{c}\text { Temperature } \\
{ }^{\circ} \mathrm{C}\end{array}$ & $\begin{array}{l}\text { Parameter/ } \\
\text { Taxon }\end{array}$ & $\begin{array}{l}\text { M. aculeaticarpa } \\
\text { var. aculeaticarpa } \\
\text { (Mean } \pm \text { SE) }\end{array}$ & $\begin{array}{c}\text { M. Iuisana } \\
\text { (Mean } \pm \text { SE) }\end{array}$ \\
\hline \multirow[t]{2}{*}{5} & PG (\%) & $10 \pm 1.58^{\mathrm{Ab}}$ & $50 \pm 5.92^{\mathrm{Bb}}$ \\
\hline & SR & 1 & 1 \\
\hline \multirow[t]{2}{*}{10} & PG (\%) & $87 \pm 7.34^{\mathrm{Aa}}$ & $86 \pm 1^{\mathrm{Aa}}$ \\
\hline & SR & 7 & 5 \\
\hline \multirow[t]{2}{*}{15} & PG (\%) & $88 \pm 5.83^{\mathrm{Aa}}$ & $94 \pm 1.87^{\text {Аа }}$ \\
\hline & SR & 5 & 6 \\
\hline \multirow[t]{2}{*}{20} & PG (\%) & $83 \pm 3.74^{\mathrm{Aa}}$ & $96 \pm 1.87^{\mathrm{Aa}}$ \\
\hline & SR & 3 & 2 \\
\hline \multirow[t]{2}{*}{25} & PG (\%) & $88 \pm 4.06^{\mathrm{Aa}}$ & $99 \pm 1^{\text {Aa }}$ \\
\hline & SR & 2 & 1 \\
\hline \multirow[t]{2}{*}{30} & PG (\%) & $87 \pm 9.69^{\text {Аа }}$ & $100 \pm 0^{\text {Aa }}$ \\
\hline & SR & 2 & 1 \\
\hline \multirow[t]{2}{*}{35} & PG (\%) & $72 \pm 8.30^{\text {Аa }}$ & $81 \pm 4.30^{\text {Аа }}$ \\
\hline & $S R$ & 2 & 1 \\
\hline \multirow[t]{2}{*}{40} & PG (\%) & $69 \pm 7.31^{\mathrm{Aa}}$ & $84 \pm 5.09^{\mathrm{Aa}}$ \\
\hline & SR & 3 & 1 \\
\hline \multirow[t]{2}{*}{45} & PG (\%) & $35 \pm 6.12^{\mathrm{Ab}}$ & $27 \pm 1.22^{\mathrm{Ab}}$ \\
\hline & SR & 1 & 1 \\
\hline $\begin{array}{c}\text { Optimum } \\
\text { Temperature }\left({ }^{\circ} \mathrm{C}\right)\end{array}$ & & 25 & 25 \\
\hline
\end{tabular}

Values followed by the same letter are not significantly different in columns (lower case), and a Tukey HSD to analyze the effect of temperature on the percentage of seed germination (upper case), $\mathrm{P}<0.05$.

Seed size, weight and production. Mature Mimosa seeds showed a significant size and weight variation even coming from the same mother plant. Both the small size of the seeds and their high production are intrinsic characteristics that lead to potentially more competitive plants, such as Mimosa tenuiflora (Willd.) Poir. (Camargo-Ricalde and Grether, 1998) and Mimosa pigra L., which are considered as pioneer or invasive species (Creager, 1992; Lonsdale, 1999).

On the other hand, predation of Mimosa seeds by bruchids (Insecta, Coleoptera), regardless of the size, could reduce their potential germination (Fontúrbel, 2002; Romero-Nápoles et al., 2005). In this study, the percentages of infested seeds were consistent with those reported by OrozcoAlmanza et al. (2003) and Camargo-Ricalde et al. (2004), who found that the species of Mimosa had a high percentage of bruchid-infested seeds (30-75\%), reducing the number of viable seeds and, consequently, the number of seedlings for posterior recruitment.

In this study, seeds of M. luisana were infested by three different bruchid species; this Mimosa species had the highest percentage of parasitized seeds ( $48 \%$ ), as well as the highest GR; meanwhile, M. aculeaticarpa var. aculeaticarpa registered the presence of two bruchid species, which infested $11 \%$ of the seeds, showing a lower percentage of 


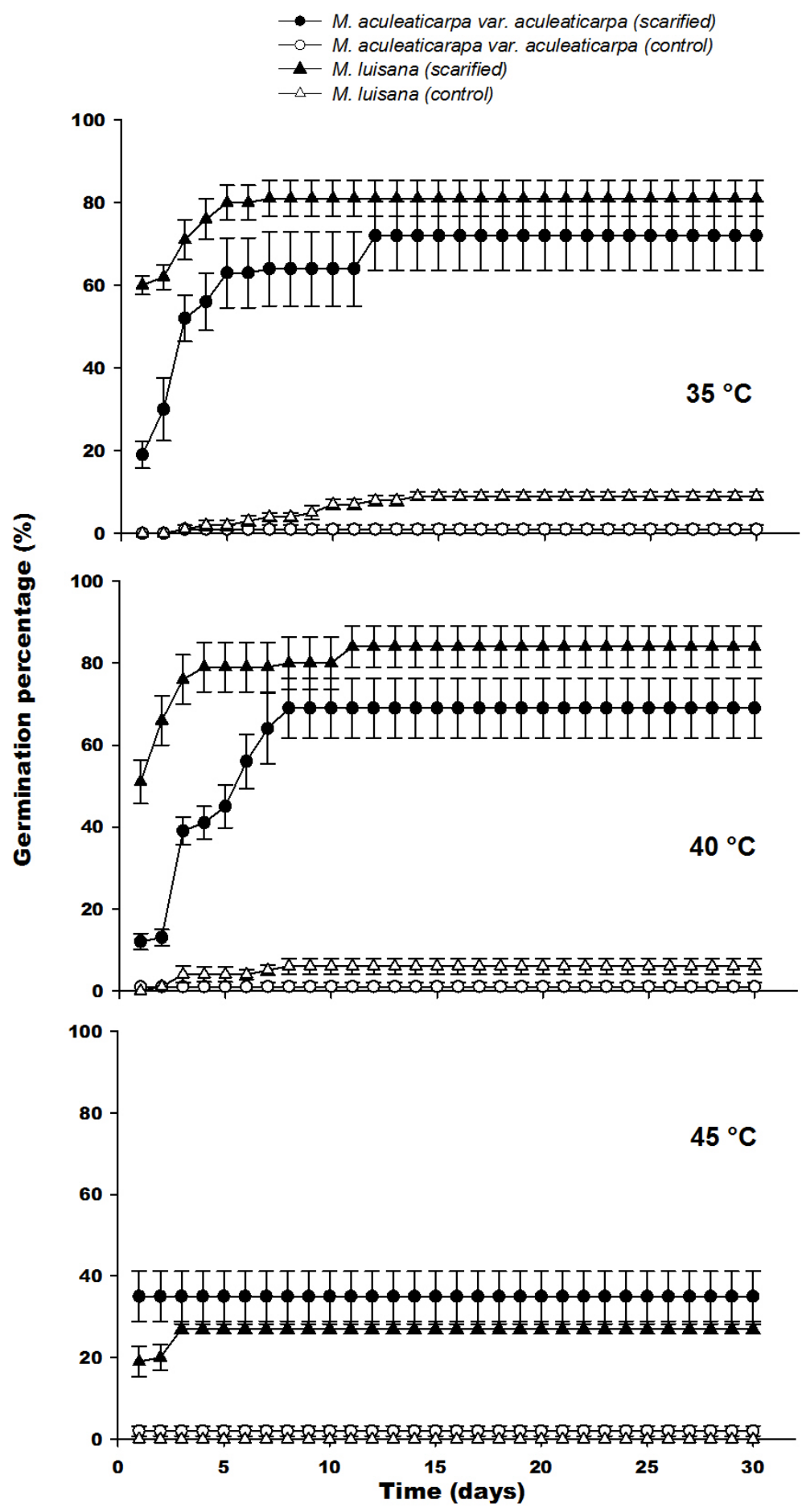

Figure 3. Seed Germination Percentage (PG - \pm SE) of two Mimosa taxa along a temperature gradient $35-45^{\circ} \mathrm{C}$.

seed germination (PG), and suggesting that the presence of more than one bruchid species per plant, may be related to a reproductive strategy (Westoby et al., 1992): a high percentage of bruchid-infestation leads to a high GR. It is possible that in nature, bruchids act as the "natural" seed mechanical scarificators, as it happens in other plant species with a hard seed coat (Takakura, 2002).
Effect of seed scarification on germination. In general, legumes produce seeds with a waterproof coat that causes physical dormancy (Auld, 1996; Lopez et al., 1999; Van Klinken and Flack, 2005), which restricts seed germination under natural conditions (D'Aubeterre et al., 2002). According to Lonsdale (1993), Gehan-Jayasuriya et al. (2013), and Van Klinken and Goulier (2013), seeds of Mi- 
- M. aculeaticarpa var. aculeaticarpa (scarified)

$-\infty$ M. aculeaticarapa var. aculeaticarpa (control)

- M. luisana (scarified)

$\backsim$ M. luisana (control)
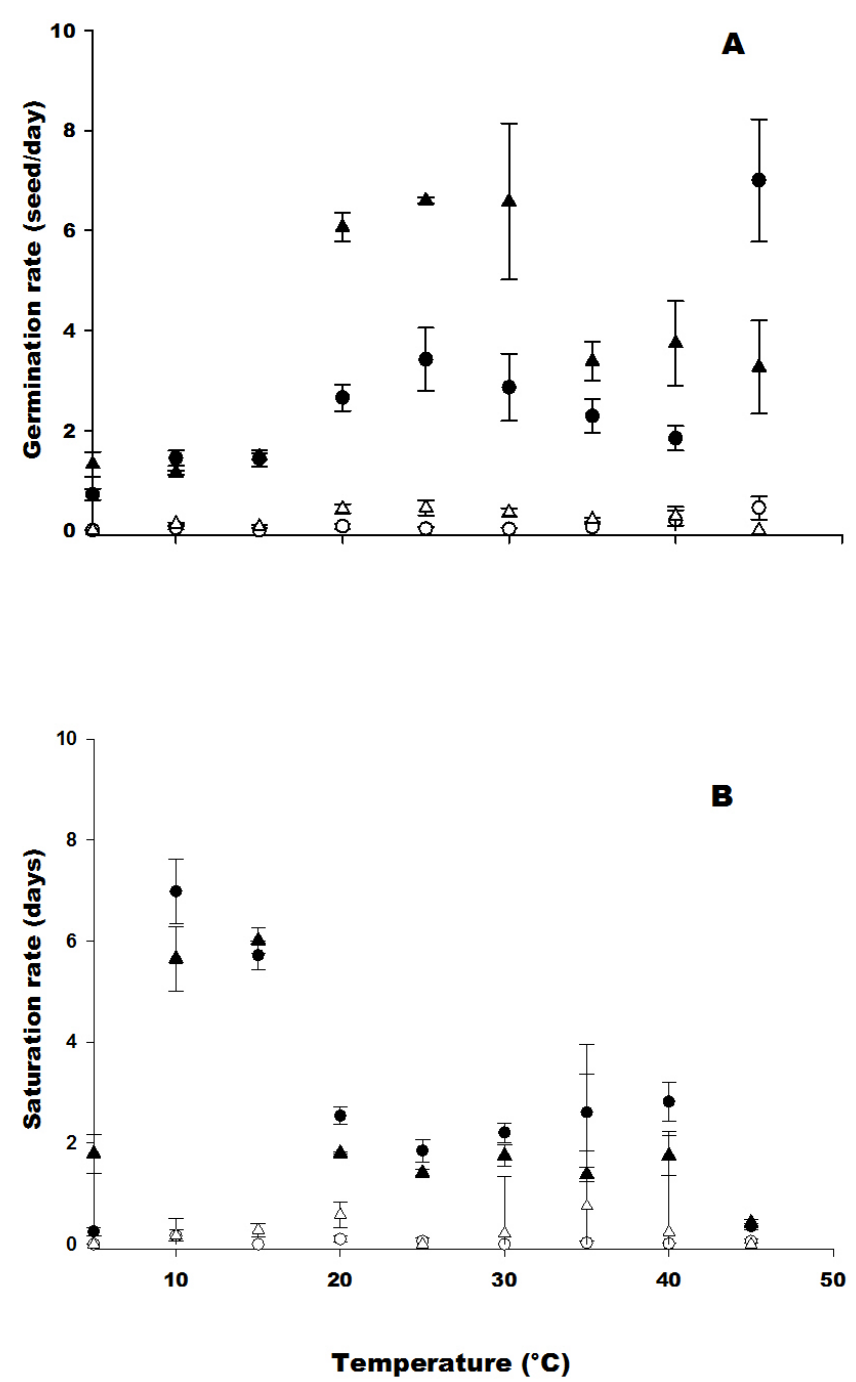

Figure 4. A. Germination Rate (GR - $\pm \mathrm{SE}$ ) of two Mimosa taxa along a temperature gradient; B. Saturation Rate (SR - \pm SE) of two Mimosa taxa along a temperature gradient.

mosa species present physical dormancy and, because the seed coat has one or more impermeable layers of palisade cells, a physiological dormancy is also possible (Baskin $e t$ $a l .$, 2000). Therefore, scarification is necessary to promote seed germination (Camargo-Ricalde and Grether, 1998; Gehan-Jayasuriya et al., 2013). Different seed scarification methods have been documented for Mimosa species (De Souza-Araújo and De Castro-Andrade, 1983; Camargo-Ricalde and Grether, 1998; Martínez-Pérez et al., 2006; Silveira and Fernandes, 2006). However, De Souza-Araújo and De Castro-Andrade (1983), Camargo-Ricalde and Grether (1998), González-Castañeda et al. (2004), Mar-
tínez-Pérez et al. (2006), Chauhan and Johnson (2008), and Gehan-Jayasuriya et al. (2013), have demonstrated that mechanical scarification is the most appropriate technique for breaking seed dormancy of Mimosa species, since mechanically scarified seeds are able to reach the highest germination rates (GR) in comparison to other methods that, positively, damage the embryo and seedling development (i.e. chemical scarification, heat shock, etc.). In this study, mechanically scarified seeds reached high germination percentages (over $70 \%$ ) for both taxa; while, unscarified seeds only achieved 0-12\%. In nature, even if seed germination is low, Mimosa seed scarification occurs by different mechanisms such as changes in daily temperature, incomplete predation by insects as bruchids (Orozco-Almanza et al., 2003; Camargo-Ricalde et al., 2004), damage caused by soil microorganisms, abrasion by soil particles and fire (Baskin et al., 1998; Taylor, 2005), and animal ingestion (i.e. goats, Baraza and Valiente-Banuet, 2008; Giordani, 2008).

However, it is important to mention that control seeds (unscarified seeds) should not be manipulated because the seed coat could be damaged, biasing the results. For instance, Martínez-Pérez et al. (2006) soaked control seeds of four species, including $M$. aculeaticarpa, in water $/ 24 \mathrm{~h}$, reaching $c a$. $60 \%$ germination; almost the same germination behavior as the treated seeds from this study. Thus, control seeds should not be manipulated in any way.

Different assays (i.e. Camargo-Ricalde and Grether, 1998; Martínez-Pérez et al., 2006; Leal and Biondi, 2007) confirm that Mimosa species have fast seed germination, which takes place within the first-fourth day after sowing; however, germination rate (GR) is related to temperature. This characteristic is also intrinsic to pioneer and invasive species (Lonsdale, 1999), and an important feature for plants with ecological restoration potential such as $M$. luisana (Camargo-Ricalde et al., 2004) and Mimosa aculeaticarpa Ortega var. biuncifera (Benth.) Barneby (Pavón et al., 2011).

Temperature effects on seed germination. Mimosa is a neotropical genus (Barneby, 1991; Simon et al., 2011), growing in places where temperature oscillates between 0 and $35^{\circ} \mathrm{C}$ (Cavalcante and Perez, 1995); temperatures that are consistent with this and other studies around the world (i.e. Moreno-Casasola, 1973; Parra, 1984; Creager, 1992; Ferreira et al., 1992; Camargo-Ricalde and Grether, 1998; Camargo-Ricalde, 2000; Ursulino-Alves et al., 2002; Orozco-Almanza et al., 2003; Camargo-Ricalde et al., 2004; Rivera-Aguilar et al., 2005; Silveira and Fernandes, 2006; Cruz-Medina and Orozco-Almanza, 2010), which have defined ranges and optimum seed germination temperatures of 25 Mimosa species. Hence, Mimosa seeds are able to germinate between 0 and $45^{\circ} \mathrm{C}$; though, the optimum temperature (OT) registered for the two taxa studied here is $25^{\circ} \mathrm{C}$.

In this context, it is important to note that Cavalcante 
and Perez (1995) suggested that tropical species can tolerate high temperatures, usually $\geq 35^{\circ} \mathrm{C}$. On the other hand, when seeds were exposed to cold temperatures $\left(\leq 5^{\circ} \mathrm{C}\right)$, germination took place since Mimosa species did not slow their metabolic rate (Hendricks and Taylorson, 1976).

In general, in Mimosa species, temperature is not a limiting factor for seed germination, showing, as well, a fast GR, a high PG, and a fast growth (Camargo-Ricalde and Grether, 1998). These characteristics may explain why Mimosa species may be dominant or co-dominant elements within the plant communities where they occur; for instance, within arid and semi-arid ecosystems (Camargo-Ricalde et al., 2002). Since ecosystems could expand or contract in reaction to plant species tolerance to an increase or decrease in temperature, the response of seed germination to scarification and temperature fluctuation is important to determine (Parmesan and Yohe, 2003). In this case, as both taxa of Mimosa are able to germinate from 5 to $45{ }^{\circ} \mathrm{C}$, their populations may possibly be able to expand or contract in accompaniment with the ecosystems where they occur (i.e. temperate forest and arid tropical scrub).

Effect of temperature on the germination rate (GR) and the saturation rate $(S R)$. Both taxa registered a high GR: 3.4 seeds/day for M. aculeaticarpa var. aculeaticarpa $(25$ $\left.{ }^{\circ} \mathrm{C}\right)$, and 6.6 seeds/day for M. luisana $\left(25-30^{\circ} \mathrm{C}\right)$. Although, Carvalho and Nakagawa (2000) suggested that higher temperatures made seeds germinate faster due to an increase in water absorption speed and metabolic reactions. However, in the case of $M$. aculeaticarpa var. aculeaticarpa, when temperature was above $25^{\circ} \mathrm{C}$, the number of germinated seeds decreased daily; although, the GR increased at $45^{\circ} \mathrm{C}$. According to Baskin et al. (2000), this behavior may be the result of a temperature pulse that breaks the physiological dormancy.

Furthermore, when studying Mimosa hostilis (C.Mart.) Benth. (= Mimosa tenuiflora), De Souza-Araújo and De Castro-Andrade (1983) reported that the GR of scarified seeds showed a direct relationship with the PG, and these results are consistent with the results presented here.

The unscarified seeds of both Mimosa taxa had a GR of 0-0.45 seed/day. The highest value was achieved at $45^{\circ} \mathrm{C}$ for M. aculeaticarpa var. aculeaticarpa, and $20-25{ }^{\circ} \mathrm{C}$ for M. luisana.

Regarding the SR, both Mimosa taxa studied required one to two days to germinate at $25^{\circ} \mathrm{C}$, after sowing, reaching a high germination percentages; whereas, the number of days for seed germination increases at temperatures under $25^{\circ} \mathrm{C}$, due to a decrease in seed metabolism (Amaral and Paulilo, 1992). The study carried out by Pavón et al. (2011) on the germination of scarified seeds of M. aculeaticarpa var. biuncifera, confirmed the inverse relationship between GR and SR: while GR increased, SR decreased. However, this inverse relationship was not found when comparing unscarified seeds, where no significant differences were found neither among temperatures nor species.

Finally, if part of the success of a plant species is focused on its tolerance to the temperature factor, the overall results suggest that both Mimosa taxa may be able to succeed under different thermal scenarios. However, more studies are needed to understand how other climatic factors, such as different levels of precipitation and $\mathrm{CO}_{2}$ concentrations, may affect the seed germination behavior of plant species.

\section{Conclusions}

Seeds of Mimosa, like those of other legumes, have a hard and impermeable coat. To germinate, these seeds require scarification, and mechanical scarification is the best method, as neither the embryo axis nor the seedling is damaged. A comparison between healthy seeds and those prayed by bruchids is also relevant, since these insects are considered natural controls of Mimosa species populations.

Our hypothesis was confirmed: seeds of the two Mimosa taxa studied germinated according to the typical temperatures to their habitats, and both taxa showed tolerance to a wide thermal scenario. Furthermore, in this study, because seeds of both Mimosa taxa are capable to germinate under a wide range of temperatures, their populations may possibly be able to expand or contract in accompaniment with the ecosystems where they occur.

Currently, both Mimosa taxa may be used in ecological restoration programs. As Mexican native taxa, they favor successional processes leading to the restoration of their original ecosystems, respectively. We propose that: $(i)$ In temperate forests (Mexican mesic ecosystems), M. aculeaticarpa var. aculeaticarpa would restore environments where the temperature is never below $5{ }^{\circ} \mathrm{C}$ or above $45^{\circ} \mathrm{C}$, and (ii) In the arid tropical scrub (dry ecosystem), M. luisana seeds would germinate in a wider range of temperatures, suggesting that this narrow endemic species is a good option for the restoration of the semi-arid ecosystem at the Valley of Tehuacán-Cuicatlán, Mexico.

\section{Acknowledgements}

S. A. Montaño-Arias wishes to thank the Consejo Nacional de Ciencia y Tecnología (CONACyT)-México (228993/211528) for the grant to pursue a doctoral degree in the Doctorado en Ciencias Biológicas y de la Salud, Universidad Autónoma Metropolitana. The authors wish to express their appreciation to Jesús Romero-Nápoles, Instituto de Fitosanidad, Colegio de Postgraduados, Campus Montecillo, for determining bruchid specimens (Insecta, Coleoptera), and to Jennifer Bain, Instituto de Biología, UNAM, for the technical revision of the English version. We also thank the anonymous reviewers who improved our manuscript. 


\section{Literature cited}

Ursulino-Alves E., Cesar P.R., Pereira O.A., Alcântara B.R. and Araújo D.E. 2002. Germinação de sementes de Mimosa caesalpiniaefolia Benth. em diferentes substratos e temperaturas. Revista Brasileira de Sementes 24:169-178.

Amaral L.I.V. and Paulilo M.T.S. 1992. Efeito da luz, temperatura, regulador de crescimento e nitrato de potássio na germinação de Miconia cinnamomifolia Naudim. Insula 21:59-86.

Auld T.D. 1996. Ecology of the Fabaceae in the Sydney region: fire, ants and the soil seedbank. Cunninghamia 4:531-551.

Baraza E. and Valiente-Banuet A. 2008. Seed dispersal by domestic goats in a semiarid thornshrub of Mexico. Journal of Arid Environments 72:1973-1976.

Barneby, R.C. 1991. Sensitivae Censitae. A description of the genus Mimosa L. (Mimosaceae) in the New World. Memoirs of the New York Botanical Garden 65:1-835.

Baskin C.C. 2003. Breaking physical dormancy in seeds - focusing on the lens. New Phytologist 158:229-232.

Baskin J.M., Baskin C.C. and Li X. 2000. Taxonomy, ecology, and evolution of physical dormancy in seeds. Plant Species Biology 15:139-152.

Baskin J.M., Nan X. and Baskin C.C. 1998. A comparative study of seed dormancy and germination in an annual and a perennial species of Senna (Fabaceae). Seed Science Research 8:501-512.

Bewley J.D. and Black M. 1994. Seeds: physiology of development and germination. Springer, New York.

Camargo-Ricalde S.L. and Grether R. 1998. Germinación, dispersión y establecimiento de plántulas de Mimosa tenuiflora (Leguminosae) en México. Revista de Biología Tropical 46:1-12.

Camargo-Ricalde S.L. 2000. Descripción, distribución, anatomía, composición química y usos de Mimosa tenuiflora (FabaceaeMimosoideae) en México. Revista de Biología Tropical 48:939954.

Camargo-Ricalde S.L., Grether R., Martínez-Bernal A., GarcíaGarcía V. and Barrios-del-Rosal S. 2001. Especies útiles del género Mimosa (Fabaceae-Mimosoideae) en México. Boletín de la Sociedad Botánica de México 68:33-44.

Camargo-Ricalde S.L., Dhillion S.S. and Grether R. 2002. Community structure of endemic Mimosa species and environmental heterogeneity in a semi-arid Mexican valley. Journal of Vegetation Science 13:697-704.

Camargo-Ricalde S.L. and Dhillion S.S. 2003. Endemic Mimosa species can serve as mycorrhizal "resource islands" within semiarid communities of the Tehuacán-Cuicatlán Valley, Mexico. Mycorrhiza 13:129-136.

Camargo-Ricalde S.L., Dhillion S.S. and García-García V. 2004. Phenology, and seed production and germination of seven endemic Mimosa species (Fabaceae- Mimosoideae) of the Tehuacán-Cuicatlán Valley, Mexico. Journal of Arid Environments 58:423-437.

Camargo-Ricalde S.L., Reyes-Jaramillo I. and Montaño N.M. 2010a. Forestry insularity effect of four Mimosa L. species (Leguminosae-Mimosoideae) on soil nutrients of a Mexican semiarid ecosystem. Agroforestry Systems 80:385-397.

Camargo-Ricalde S.L., Montaño N.M., Reyes-Jaramillo I., Jiménez-González C. and Dhillion S.S. 2010b. Effect of mycorrhizae on seedlings of six endemic Mimosa L. species (Leguminosae-Mimosoideae) from the semi-arid Tehuacán-Cuicatlán Valley, Mexico. Trees 24:67-78.
Carvalho N.M. and Nakagawa J. 2000. Sementes: ciência, tecnologia e produção. 4. ed. Jaboticabal: Funep.

Cavalcante A.M. and Perez S.C.J.A. 1995. Efeitos da temperatura sobre a germinação de sementes de Leucaena leucocephala (Lam.) de Wit. Revista Brasileira de Sementes 17:1-8.

Chauhan B.S. and Johnson D.E. 2008. Seed germination and seedling emergence of giant sensitive plant (Mimosa invisa). Weed Science 56:244-248.

Creager R.A. 1992. Seed germination, physical and chemical control of catclaw mimosa (Mimosa pigra var. pigra). Weed Technology 6:884-891.

Cruz-Medina D. and Orozco-Almanza S. 2010. Germinación de ocho especies de la familia Fabaceae, bajo diferentes regímenes de temperatura. VII Simposio Internacional sobre la flora silvestre en zonas áridas, Universidad de Sonora, Hermosillo, Sonora, México Trabajo en extenso: 197-215 pp.

D’Aubeterre R., Principal J. and García J. 2002. Efecto de diferentes métodos de escarificación sobre la germinación de tres especies del género Prosopis. Revista Científica 12:575-577.

De Souza-Araújo M. and De Castro-Andrade G. 1983. Métodos para superar a dormência tegumentar em sementes de Juremapreta (Mimosa hostilis Benth.). Boletim de Pesquisa Florestal 6/7:26-32.

Dhillion S.S., Aguilar-Støen M. and Camargo-Ricalde S.L. 2004. Integrative ecological restoration and local involvement in the Tehuacán-Cuicatlán Valley, Mexico. Environmental Conservation 13:1-3.

Enríquez-Peña E., Suzán-Azpiri H. and Malda-Barrera G. 2004. Viabilidad y germinación de semillas de Taxodium mucronatum (Ten.) en el estado de Querétaro, México. Agrociencia 38:357-381.

Ferreira A.G., Lipp-Joao K.H. and Heuser E.D. 1992. Efeitos de escarificaçao sobre a germinaçao e do $\mathrm{pH}$ no crescimento de Acacia bonariensis Gill e Mimosa bimucronata (DC.) Kuntze. Revista Brasileira de Fisiologia Vegetal 4:63-65.

Fontúrbel R.F. 2002. Rol de la coevolución planta-insecto en la evolución de las flores cíclicas en las angiospermas. Ciencia Abierta 17:1-11.

Giordani L. 2008. The role of goats in germination and dispersal of Mimosa luisana Brandegee (Leguminosae-Mimosoideae) seeds in the Tehuacán-Cuicatlán valley, Puebla State, Mexico. Master Thesis, Norwegian University of life Sciences, Norway, 24 pp.

González-Castañeda J., Angoa-Pérez M.V., Frías-Hernández J.T., Olalde-Portugal V., Flores-Ancira E., Terrones-Rincón T.R., Van Cleemput O. and Dendooven L. 2004. Germination of seeds of huisache (Acacia schaffneri) and catclaw (Mimosa monancistra) as affected by sulphuric acid and mechanical scarification and subsequent growth and survival in a greenhouse and field experiment. Seed Science and Technology 32:727-738.

Grether R., Camargo-Ricalde S.L. and Martínez-Bernal A. 1996. Especies del género Mimosa (Leguminosae) presentes en México. Boletín de la Sociedad Botánica de México 58:149-152.

Hendricks S.B. and Taylorson B. 1976. Variation in germination and amino acid leakage of seeds with temperature related to membrane phase change. Plant Physiology 58:7-11.

Hintze J. 2001. NCSS 2001. NCSS, LLC. Kaysville, Utah, USA. www.ncss.com.

Gehan-Jayasuriya G.M., Wijetunga A.S.T.B., Baskin J.M. and Baskin C.C. 2013. Seed dormancy and storage behavior in 
tropical Fabaceae: a study of 100 species from Sri Lanka. Seed Science Research 23:257-269.

Leal L. and Biondi D. 2007. Comportamento germinativo de sementes de Mimosa dolens Vell. Publicatio UEPG: Ciências Exatas e da Terra, Agrárias e Engenharias 13:37-43.

Lonsdale W. M. 1993. Losses from the seed bank of Mimosa pigra: soil micro-organisms vs. temperature fluctuations. Journal of Applied Ecology 30:654-660.

Lonsdale W.M. 1999. Global patterns of plant invasions and the concept of invasibility. Ecology 80:1522-1536.

Lopez J., Devesa J.A., Ruiz T. and Ortega-Olivencia A. 1999. Seed germination in Genisteae (Fabaceae) from South-West Spain. Phyton 39:107-129.

Martínez-Pérez G., Orozco-Segovia A. and Martorell C. 2006. Efectividad de algunos tratamientos pre-germinativos para ocho especies leñosas de la Mixteca Alta Oaxaqueña con características relevantes para la restauración. Boletín de la Sociedad Botánica de México 79:9-20.

Matilla A. 2004. Ecofisiología de la germinación de semillas. In: Sánchez A., Reigosa-Roger M.J. y Pedroi-Bonjoch N. La ecofisiología Vegetal: Una ciencia de síntesis. pp. 901-922. Thomson-Paraninfo, España.

Moreno-Calles A.I. and Casas A. 2010. Agroforestry systems: restoration of semiarid zones in the Tehuacán Valley, Central Mexico. Ecological Restoration 28:361-368.

Moreno-Casasola P. 1973. Estudio sobre viabilidad y latencia de semillas de árboles tropicales. Tesis de Licenciatura, Facultad de Ciencias, Universidad Nacional Autónoma de México, México, D.F. 78 pp.

Olff H., Pegtel D.M., Van Groenendael J.M. and Bakker J.P. 1994. Germination strategies during grassland succession. Journal of Ecology 82:69-77.

Orozco-Almanza M. S., Ponce de León-García L., Grether R. and García-Moya E. 2003. Germination of four species of the genus Mimosa (Leguminosae) in a semi-arid zone of Central Mexico. Journal of Arid Environments 55:75-92.

Parmesan C. and Yohe G. 2003. A globally coherent fingerprint of climate change impacts across natural systems. Nature 421:37-42.

Parra G.P. 1984. Estudio de la morfología externa de plántulas de Calliandra gracilis, Mimosa albida, Mimosa arenosa, Mimosa camporum y Mimosa tenuiflora. Revista de la Facultad de Agronomía (Maracay) 13:311-350.

Pavón N.P., Ballato-Santos J. and Pérez-Pérez C. 2011. Germinación y establecimiento de Mimosa aculeaticarpa var. biuncifera (Fabaceae-Mimosoideae). Revista Mexicana de Biodiversidad 82:653-661.

Piedrahita-Cardona E. 1997. Germinación de semillas de Jacaranda copaia bajo condiciones contrastantes de luz. Crónica forestal y del medio ambiente 12:1-4.

Piedrahita-Cardona E. 1998. Aumento del vigor en semillas de Pinus patula (Schlecht. \& Cham.) por el efecto de osmoacondicionamiento. Crónica forestal y del medio ambiente 13:1-21.

Rivera-Aguilar V., Godínez-Álvarez H., Manuell-Cacheux I. and Rodríguez-Zaragoza S. 2005. Physical effects of biological soil crusts on seed germination of two desert plants under laboratory conditions. Journal of Arid Environments 63:344-352.

Romero-Nápoles J., Grether R., Camargo-Ricalde S.L. and Johnson C.D. 2005. Método para la evaluación de daño de semillas por brúquidos (Insecta, Coleoptera), en el campo con nuevos registros de hospederos y distribución para el grupo. Entomología Mexicana 4:107-111.

Silveira F.A.O. and Fernandes G.W. 2006. Effect of light, temperature and scarification on the germination of Mimosa foliolosa (Leguminosae) seeds. Seed Science and Technology 34:585592.

Simon M.F., Grether R., de Queiroz L.P., Särkinen T.E., Dutra V.F. and Hughes C.E. 2011. The evolutionary history of Mimosa (Leguminosae): towards a phylogeny of the sensitive plants. American Journal of Botany 78:1201-1221.

Skogen K.A., Senack L. and Holsinger K.E. 2010. Dormancy, small seed size and low germination rates contribute to low recruitment in Desmodium cuspidatum (Fabaceae). Journal of the Torrey Botanical Society 137:355-365.

Sokal R.R. and Rohlf F.J. 1995. Biometry. W.H. Freeman, Nueva York.

Takakura K. 2002. The specialist seed predator Bruchidius dorsalis (Coleóptera: Bruchidae) plays a crucial role in the seed germination of its host plant, Gleditsia japonica (Leguminosae). Functional Ecology 16:252-257.

Taylor G.B. 2005. Hardseededness in Mediterranean annual pasture legumes in Australia. Australian Journal of Agricultural Research 56: 645-661.

Valiente-Banuet A. and Ezcurra E. 1991. Shade as a cause of the association between the cactus Neobuxbaumia tetetzo and the nurse shrub Mimosa luisana. Journal of Ecology 79:961-971.

Valiente-Banuet A., Vite F. and Zavala-Hurtado J.A. 1991. Interaction between the cactus Neobuxbaumia tetetzo and the nurse shrub Mimosa luisana. Journal of Vegetation Science 2:11-14.

Van Assche J.A., Debucquoy K.L.A. and Rommens W.A.F. 2003. Seasonal cycles in the germination capacity of buried seeds of some Leguminosae (Fabaceae). New Phytologist 158:315-323.

Van Klinken R.D. and Flack L. 2005. Wet heat as a mechanism for dormancy release and germination of seeds with physical dormancy. Weed Science 53:663-669.

Van Klinken R.D. and Goulier J-B. 2013. Habitat-specific seed dormancy-release mechanisms in four legume species. Seed Science Research 23:181-188.

Venier P., Funes, G. and Carrizo-García C. 2012. Physical dormancy and histological features of seeds of five Acacia species (Fabaceae) from xerophytic forests in central Argentina. Flora-Morphology, Distribution, Functional Ecology of Plants 207:39-46.

Weng J-H. and Hsu F-H. 2006. Variation of germination response to temperature in Formosan lily (Lilium formosanum Wall.) collected from different latitudes and elevations in Taiwan. Plant Production Science 9:281-286.

Westoby M., Jurado E. and Leishman M. 1992. Comparative evolutionary ecology of seed size. Trends in Ecology and Evolution 7:368-372.

Received: March 19th, 2014

Accepted: August 6th, 2014 


\section{CAPÍTULO IV}

\section{Análisis ecoanatómico de la madera de Mimosa aculeaticarpa var. aculeaticarpa y M. Iuisana (Leguminosae-Mimosoideae)}

Ecological anatomy of the wood of Mimosa aculeaticarpa var. aculeaticarpa and M. luisana (Leguminosae-Mimosoideae)

\section{INTRODUCCIÓN}

Los estudios ecoanatómicos permiten analizar la estructura interna de las plantas con el fin de conocer su variación frente a los cambios ambientales y encontrar relaciones que pueden ser consideradas estrategias adaptativas (Araque y León, 2006; Polanco y Grande, 2009; Figueroa et al., 2011).

Al respecto, se ha analizado el efecto de algunos parámetros como la disponibilidad de agua, estacionalidad, latitud, longitud, y altitud sobre los caracteres anatómicos de la madera; por ejemplo, el diámetro de los vasos y el número de vasos por superficie $\left(\mathrm{mm}^{2}\right)$ con la altitud (Baas, 1973; Barajas-Morales, 1985; Fisher et al., 2007), y la longitud de los elementos de vaso con la disponibilidad de agua (Giménez et al., 2012; Lindorf, 1994; Parra, 2010).

De acuerdo con Jono (2009), los estudios ecoanatómicos muestran la plasticidad de las plantas en la organización anatómica de la madera que les permite sobrevivir en lugares con condiciones contrastantes, sobre todo, en taxa de amplia 
distribución. Sin embargo, las variaciones ambientales pueden ocurrir a diferentes escalas e influir en el crecimiento y, por consiguiente, en la anatomía de la madera (Luchi, 1998). En los últimos años, los estudios anatómicos de la madera han adquirido relevancia, debido a que aportan información sobre el comportamiento de los taxa y pueden predecir sus respuestas ante cambios ambientales (cambio climático). Este tipo de estudios han sido realizados, principalmente, en taxa arbóreos, muchos de ellos pertenecientes a la familia Leguminosae (de Lima et al., 2009; Silva et al., 2011).

Las leguminosas son una de las cinco familias más diversas que existen en el mundo y en México (Rzedowski, 1991; Sosa y Dávila, 1994). Asimismo, son uno de los elementos dominantes o co-dominantes de las zonas áridas y semiáridas mexicanas (De la Barrera y Andrade, 2005). Por su parte, Mimosa es el género más diverso de Mimosoideae en el país con ca. 110 taxa distribuidos desde las zonas templadas hasta las zonas áridas y semiáridas (Grether et al., 1996).

Por lo anterior y considerando la relevancia biológica y ecológica de algunos taxa de Mimosa (Camargo-Ricalde et al., 2001; Camargo-Ricalde et al., 2002; Camargo-Ricalde et al., 2010 a, b), resulta importante evaluar sus posibles respuestas adaptativas a nivel de la madera, con la finalidad de estimar su resistencia y tolerancia a cambios en la precipitación. 


\section{ANTECEDENTES}

A nivel mundial, se ha estudiado la anatomía de la madera de 41 taxa de Mimosa de ca. 520 (Simon et al., 2011); aunque, en México, existen ca. 68 taxa leñosos, de los cuales sólo 12 han sido estudiados. La mayoría de estos trabajos están enfocados solamente en describir la anatomía de la madera (Cozzo y Cristiani, 1950; Cozzo, 1951; Heringer y De Paula, 1979; 1996; Maccari y Marchiori, 1994; Marchiori, 1982, 1985, 1993; Marchiori y Muñiz, 1997) y, unos cuantos, en determinar los caracteres que pudiesen ayudar a resolver problemas de índole taxonómico dentro de la clasificación del género (Baretta-Kuipers, 1981; Chehaibar y Grether, 1990; MontañoArias, 2010). Más aún, la información que proporcionan dichos estudios también es útil en estudios ecoanatómicos.

La ecoanatomía es la asociación de los caracteres anatómicos de los taxa con relación a su hábitat (Montaño-Arias et al., 2011). Los análisis con un enfoque ecoanatómico permiten estimar la respuesta de los taxa a distintos factores ambientales (P. ej. precipitación). No obstante, estos estudios son escasos, particularmente los del género Mimosa (Montaño-Arias et al., 2013).

Considerando los escenarios climáticos del Panel Intergubernamental sobre Cambio Climático (IPCC), se espera que haya modificaciones en los regímenes de temperatura y precipitación (Christensen et al., 2007), los cuales variarán ampliamente de una región a otra, principalmente, en zonas tropicales con clima semiárido y templado (Cline, 2007). Bajo esta premisa, resulta relevante la realización de estudios ecoanatómicos, ya que proporcionan información básica que 
permitiría relacionar a los taxa con su hábitat y, al mismo tiempo, llevar a cabo inferencias (P. ej. cambios morfofisiológicos) relacionadas con el aumento o disminución de ciertos parámetros climáticos (P. ej. precipitación) con la distribución de dichos taxa vegetales.

Por ejemplo, en las regiones con clima árido y semiárido, donde el agua es uno de los factores limitantes para el establecimiento de las plantas, se ha evaluado la respuesta de los caracteres anatómicos de la madera a variaciones ambientales mediante análisis de tipo ecoanatómico (Arias y Terrazas, 2001; Aguilar-Rodríguez et al., 2006; Bernal-Salazar y Terrazas, 2000; Chávez-Romero et al., 2010; De Lima et al., 2009; Moya y Tomazello, 2008; Sidiyasa y Baas, 1998); sin embargo, todavía falta estudiar gran parte de los taxa vegetales que habitan estas regiones, principalmente, a las leguminosas (De la Barrera y Andrade, 2005).

Al respecto, la anatomía de la madera se ha descrito para varios géneros de leguminosas como: Caesalpinia L., Dalbergia L. Geoffraea L., Indigofera L., Sophora L., Tipuana Benth. (Cozzo y Cristiani, 1950); Acacia Mill., Albizzia Durraz., Calliandra Benth., Enterolobium Benth., Leucaena Benth., Pithecellobium Mart. (Cozzo, 1951); Bossiaea Vent., Templetonia R.Br., Pultenaea Sm. (Carlquist, 1977); Mimosa L. (Marchiori, 1996); Erytrina L., Prosopis L. (Moglia y Giménez, 1998), Campsiandra Benth., y Dimorphandra Schott. (Espinoza de Pernía y Melandri, 2006). Aunque, los estudios ecoanatómicos de leguminosas son escasos. 
Algunos resultados parciales relacionan el hecho de que algunos taxa que viven en climas secos como Acacia burkittii (F. Muell.) Benth., $A$. sowdenii Maiden, $A$. tetragonophylla F. Muell., Hovea elliptica (Sm.) DC., (Carlquist, 1977), Acacia caven (Mol.) Mol., Prosopis vinalillo Stuck. (Moglia y Giménez, 1998), y Geoffroea decorticans Burkart (Giménez, 2004), presentan el mismo tipo de madera, mesomórfica, de acuerdo con Carlquist (1977), este término se refiere aquella madera que presenta características que le confieren un mayor grado de vulnerabilidad al estrés hídrico. Asimismo, la madera mesomórfica también se ha observado en taxa de clima templado como Pseudopiptadenia contorta (DC) G.P. Lewis y M.P. Lima (Ribeiro y Barros, 2006); no obstante, la madera de los taxa en ambos ambientes presenta características xeromórficas, es decir, con adaptaciones a ambientes secos, entre ellas destacan: la presencia de un mayor número de vasos, de diámetro pequeño y longitud corta, vasos agrupados, placas de perforación simple, y punteaduras intervasculares ornamentadas, entre otras, que les proporcionan seguridad en la conducción y la optimización de la escasa agua disponible (Zimmerman, 1983 en: Carlquist, 2001).

En el caso del género Mimosa (Mimosoideae), solamente existe un estudio de tipo ecoanatómico (Montaño-Arias et al., 2013) en el que se analizan los elementos de vaso de cinco taxa: $M$. bahamensis Benth. $M$. hexandra M. Micheli., $M$. leucaenoides Benth., M. tejupilcana R. Grether y A. Martínez-Bernal y M. tenuiflora (Willd.) Poir., concordando con lo determinado para los taxa de leguminosas anteriormente mencionadas, ya que las mimosas también presentan una madera 
mesomórfica con características xeromórficas. Aunque es imposible generalizar, cabe señalar que los taxa de leguminosas de zonas secas, incluyendo los del género Mimosa, se consideran taxa vulnerables a la sequía; aunque, poseen un xilema adaptado para resistir periodos de escasez de agua y sobrevivir en esos ambientes (Montaño-Arias et al., 2013).

El análisis de las características anatómicas como son: la presencia de un mayor número de vasos, de diámetro pequeño y longitud corta, vasos agrupados, placas de perforación simple, y punteaduras intervasculares ornamentadas, entre otras, provee información acerca de la vulnerabilidad de la planta a la sequía; no obstante, Carlquist (1975) estableció dos índices para calcular dicha vulnerabilidad: I) el Índice de Vulnerabilidad (IV), el cual se obtiene dividiendo el promedio del diámetro de los elementos de vaso entre el número de vasos por $\mathrm{mm}^{2}$. El valor de IV inferior a 1 corresponde a un taxon resistente al estrés hídrico y un IV superior a la unidad, indica que es vulnerable y, ii) el Índice de Mesomorfía (IM), este índice se obtiene multiplicando el valor de IV por el promedio de la longitud de los elementos de vaso; dónde un IM>200 indica mesomorfía y uno inferior, xeromorfía.

De acuerdo con Moglia y López (2001), los taxa que habitan en ambientes áridos y semiáridos deben estar preparadas para asegurar la conducción y disminuir el riesgo de embolia (entrada de aire a los vasos) por una pérdida de presión hídrica debida a la escasa cantidad de agua en el sitio; por lo que se esperaría que este tipo de plantas presentara una madera xeromórfica y, por lo tanto, que fuera resistente a la sequía. 
Por lo tanto, para llevar a cabo un estudio ecoanatómico que estime la resistencia y tolerancia de los taxa vegetales a modificaciones en los regímenes de precipitación, es necesario considerar las siguientes características: número de vasos por superficie $\left(\mathrm{mm}^{2}\right)$, diámetro tangencial, presencia de vasos agrupados; así como el grosor de la pared secundaria y longitud de los elementos de vaso, tipo de placa de perforación, tipo de punteadura intervascular, tipo de estructura de la membrana de la punteadura (grosor y porosidad), grosor y longitud de la fibra, entre otros; ya que de acuerdo con Baas (1973), Carlquist, (1975, 2001), de Lima et al. (2009), Chávez-Romero et al. (2010), Choat et al. (2004), León (2001), Yaman (2008) y Zweypfenning (1978) estas características son las que proporcionan información sobre las estrategias de los taxa para conducir de forma segura el agua disponible y optimizarla.

\section{PREGUNTAS DE INVESTIGACIÓN}

¿Cómo es la anatomía de la madera de dos taxa de Mimosa distribuidas en México?

¿Cuáles son las estrategias adaptativas de $M$. aculeaticarpa Ortega var. aculeaticarpa, que habita en un bosque templado, y de M. Iuisana Brandegee, que habita en un matorral xerófilo? 


\section{HIPÓTESIS}

Si los caracteres anatómicos de la madera como: el número de vasos por superficie $\left(\mathrm{mm}^{2}\right)$, diámetro tangencial del vaso, presencia de vasos agrupados; grosor de la pared y longitud de los elementos de vaso, tipo de placa de perforación, tipo de punteadura intervascular, tipo de estructura de la membrana de la punteadura (grosor y porosidad), grosor y longitud de la fibra están influenciados por la disponibilidad de agua; entonces, se espera que los elementos anteriormente mencionados difieran entre la madera de $M$. aculeaticarpa var. aculeaticarpa y la de M. luisana por habitar sitios con diferentes condiciones ambientales.

\section{OBJETIVO}

Describir y comparar la anatomía de la madera de Mimosa aculeaticarpa var. aculeaticarpa y $M$. luisana procedentes de sitios con diferentes condiciones ambientales, con la finalidad de conocer el papel que juega la disponibilidad de agua y sus estrategias adaptativas para resistir los cambios en la precipitación.

\section{MÉTODOS}

\section{Diseño experimental}

Se eligieron dos taxa arbóreos, endémicos de México, que crecen en condiciones ambientales contrastantes. De acuerdo con Grether et al. (2007), Mimosa aculeaticarpa var. acuelaticarpa presenta una amplia distribución en el país, 
estableciéndose tanto en climas secos como templados; mientras que M. luisana es un taxon restringido al Valle de Tehuacán-Cuicatlán, Puebla y Oaxaca, y sólo se establece en climas secos (Martínez-Bernal y Grether, 2006, Cuadro 1).

Para cada sitio de colecta, se registraron las coordenadas geográficas, el tipo de vegetación (Rzedowski, 1978), clima (García, 2004) y datos de los individuos (altura y diámetro del tronco, Cuadro 1). Con la finalidad de tener representada la variabilidad de cada taxa, se recolectaron tres árboles de cada uno con altura y cobertura similar y, se tomaron muestras del tronco a $80 \mathrm{~cm}$ del suelo (Cuadro 1).

\section{Análisis Anatómico}

Con un micrótomo de deslizamiento American Optical, modelo 860, se cortaron secciones transversales, tangenciales y radiales con grosor de $20 \mu \mathrm{m}$; se tiñeron con safranina-verde rápido y se montaron con resina sintética (Johansen, 1940).

Asimismo, se colocaron astillas de la sección radial en un tubo de ensayo con una mezcla, a partes iguales, de ácido acético: ácido láctico: ácido nítrico: glicerina (1:1:1:1), dejándolos incubar por 1-2 semanas en condiciones de luz y temperatura ambiente. Una vez disociado el material, éste se lavó y se hicieron preparaciones temporales para cuantificar la longitud de los elementos de vaso y de fibras, y de las traqueidas vasicéntricas. 
Los ejemplares de referencia y las tablillas correspondientes están depositados en el Herbario Metropolitano (UAMIZ), de la Universidad Autónoma Metropolitana, Unidad Iztapalapa (Cuadro 1).

Cuadro 1. Características de los sitios de recolección y de los individuos de los taxa de Mimosa (Leguminosae-Mimosoideae) estudiados, así como el número de registro de herbario y xiloteca (UAMIZ) de los individuos seleccionados.

\begin{tabular}{|c|c|c|c|c|c|c|}
\hline Taxa & Estado & $\begin{array}{l}\text { Coordenadas } \\
\text { (Altitud msnm) }\end{array}$ & $\begin{array}{c}\text { Tipo de } \\
\text { vegetación }\end{array}$ & $\begin{array}{c}\text { Clima } \\
\text { Temperatura } \\
\text { (Media anual) } \\
\text { Precipitación } \\
\text { (mm anuales) }\end{array}$ & $\begin{array}{c}\text { Hábito } \\
\text { Altura (m) } \\
\text { DAP cm por } \\
\text { individuo }\end{array}$ & $\begin{array}{c}\text { UAMIZ } \\
\text { No. } \\
\text { Registro } \\
\text { Ejemplar / } \\
\text { Tablilla }\end{array}$ \\
\hline $\begin{array}{c}\text { M. } \\
\text { aculeaticarpa } \\
\text { var. } \\
\text { aculeaticarpa }\end{array}$ & Michoacán & $\begin{array}{c}19^{\circ} 58.218^{\prime} \mathrm{N} ; \\
101^{\circ} 31.664^{\prime} \mathrm{W} \\
(1950)\end{array}$ & $\begin{array}{l}\text { Bosque de } \\
\text { Pino-Encino }\end{array}$ & $\begin{array}{c}\text { Templado } \\
\text { Suhúmedo } \\
16.8 \\
955\end{array}$ & $\begin{array}{l}\text { Árbol } \\
2.5,2 \text { y } 2 \\
4,5 \text { y } 4\end{array}$ & $\begin{array}{c}71454 \\
71455 \\
71456 \\
288\end{array}$ \\
\hline M. Iuisana & Puebla & $\begin{array}{c}18^{\circ} 15^{\prime} 23.7^{\prime \prime} \mathrm{N} ; \\
97^{\circ} 09^{\prime} 03.3^{\prime \prime} \mathrm{W} \\
(1,140)\end{array}$ & $\begin{array}{l}\text { Matorral } \\
\text { xerófilo }\end{array}$ & $\begin{array}{c}\text { Seco con lluvias } \\
\text { poco abundantes } \\
23.8^{\circ} \mathrm{C} \\
440.6\end{array}$ & $\begin{array}{l}\text { Árbol } \\
1.5,2 \text { y } 2 \\
4,4.5 \text { y } 4\end{array}$ & $\begin{array}{c}63912 \\
63913 \\
63916 \\
216\end{array}$ \\
\hline
\end{tabular}

\section{Anatomía microscópica}

Para la descripción y el análisis de los caracteres anatómicos de la madera, se siguió la nomenclatura propuesta por la International Association of Wood Anatomists (IAWA, 1989). Asimismo, los cristales fueron descritos conforme a Chattaway (1956) y la descripción de los radios según Kribs (1968). Se realizaron 25 mediciones para cada carácter de la anatomía de la madera, por individuo, por taxon. 
El número de vasos por superficie $\left(\mathrm{mm}^{2}\right)$, se contabilizó tomando en cuenta a los vasos solitarios y agrupados. Debido a que en la literatura (P. ej. Marchiori, 1982, 1985) no se aclara como realizar el conteo de vasos $/ \mathrm{mm}^{2}$ y esto dificulta la comparación entre los taxa, se acordó que en este estudio, cada vaso que conforma a los vasos agrupados, se contabilizara como un vaso solitario. El grosor de la pared del elemento de vaso se midió en corte transversal; el diámetro de la punteadura intervascular y el diámetro del lumen de la punteadura fueron medidos en corte tangencial, siguiendo la clasificación propuesta por Montaño-Arias (2010). Para la longitud del cordón de parénquima, se utilizó la clasificación propuesta para longitud de fibras de la IAWA (1989). Las mediciones se realizaron utilizando un microscopio óptico marca Zeiss, modelo Axiostar-Plus.

El diámetro de los vasos se consideró grande cuanto fue $>200 \mu \mathrm{m}$, mediano entre 100 y $200 \mu \mathrm{m}$ y pequeño <100 $\mu \mathrm{m}$ (IAWA, 1989). Además, el diámetro de los vasos (dv) y el número de vasos $/ \mathrm{mm}^{2}$ (nv) se emplearon para calcular el Índice de Vulnerabilidad (IV), IV=dv/nv; donde un valor inferior a 1 se interpreta como resistente a la sequía (Carlquist, 1977). La longitud del elemento de vaso (Iv) y el IV se emplearon para calcular el Índice de Mesomorfía (IM); donde IM=IV (IV), un IM mayor de 200 indica que el xilema es mesomórfico y un IM menor o igual a 75 indica un xilema xerófito (Carlquist, 1977). 


\section{Análisis estadísticos}

Con el objeto de evaluar la existencia de diferencias estadísticamente significativas entre los caracteres evaluados inter-específicamente, los datos obtenidos se examinaron por medio de una $t$-Student ( $P \leq 0.05$ - Sokal y Rohlf, 1995). Los análisis estadísticos se llevaron a cabo mediante el paquete estadístico NCSS (Hintze, 2001).

\section{RESULTADOS}

La madera de Mimosa aculeaticarpa var. aculeaticarpa presenta porosidad anular (Figura 1A) y la de M. luisana presenta porosidad difusa (Figura 1B). Ambas maderas presentan anillos de crecimiento definidos; en $M$. aculeaticarpa var. aculeaticarpa están delimitados por parénquima paratraqueal y vasos de mayor diámetro (Figura 1A). Mientras que en la madera de $M$. luisana, los anillos son más angostos y están delimitados por ocho hileras de fibras engrosadas y dos hileras de parénquima apotraqueal (Figura 1B).

Además, independientemente del tipo de porosidad, la madera de ambos taxa presenta poros numerosos (>16 vasos/ $\mathrm{mm}^{2}$ ). Cabe señalar que la madera temprana de M. aculeaticarpa var. aculeaticarpa presenta más densidad de vasos por área $\left(\mathrm{mm}^{2}\right)$ que la madera tardía (Cuadro 2). Asimismo, tanto la madera temprana como la tardía de M. aculeaticarpa var. aculeaticarpa, presentan vasos agrupados en dos, rara vez se encuentran tres (Figura $1 \mathrm{~A}$ ). En el caso de $M$ luisana, se presentan principalmente tres vasos agrupados, pero pueden llegar a presentar hasta seis (Figura 1B). 


\section{Descripción de los elementos de vaso}

Ambos taxa presentan paredes de vaso delgadas; aunque, el diámetro tangencial de los vasos difiere. En el caso de $M$. aculeaticarpa var. aculeaticarpa, la madera temprana tiene vasos medianos y en la madera tardía son pequeños, al igual que los de M. luisana (Cuadro 2).

Ambos taxa presentaron elementos de vaso cortos. Cabe señalar que en $M$. aculeaticarpa var. aculeaticarpa, los elementos de vaso de la madera tardía son más largos que los de la madera temprana (Cuadro 2).

Cuadro 2. Características de los elementos de vaso de Mimosa aculeaticarpa var. aculeaticarpa y M. luisana (Leguminosae-Mimosoideae).

\begin{tabular}{|c|c|c|c|c|c|c|}
\hline \multicolumn{7}{|c|}{ Mimosa aculeaticarpa var. aculeaticarpa } \\
\hline \multirow[t]{2}{*}{ Variables } & \multicolumn{2}{|c|}{$\begin{array}{l}\text { Media } \pm \text { desviación } \\
\text { estándar }\end{array}$} & \multicolumn{2}{|c|}{ Valor mínimo } & \multicolumn{2}{|c|}{ Valor máximo } \\
\hline & Temprana & Tardía & Temprana & Tardía & Temprana & Tardía \\
\hline Vasos $/ \mathrm{mm}^{2}$ & $19.44 \pm 2.0$ & $\begin{array}{l}16.77 \pm \\
6.7\end{array}$ & 4 & 6 & 30 & 33 \\
\hline$\varnothing$ tangencial del vaso $(\mu \mathrm{m})$ & $106.26 \pm 5.1$ & $38.3 \pm 5.8$ & 55 & 22.5 & 152.5 & 57.5 \\
\hline Grosor de la pared $(\mu \mathrm{m})$ & $4.53 \pm 1.2$ & $\begin{array}{c}2.83 \pm \\
0.57\end{array}$ & 3.3 & 2.5 & 6.6 & 4.1 \\
\hline $\begin{array}{l}\text { Longitud de los elementos vaso } \\
\qquad(\mu \mathrm{m})\end{array}$ & $167.5 \pm 6.5$ & $\begin{array}{c}193.2 \pm \\
4.0\end{array}$ & 100 & 100 & 237.5 & 250 \\
\hline \multicolumn{7}{|c|}{ Mimosa Iuisana } \\
\hline & \multicolumn{2}{|c|}{$\begin{array}{c}\text { Media } \pm \text { desviación } \\
\text { estándar }\end{array}$} & \multicolumn{2}{|c|}{ Valor mínimo } & \multicolumn{2}{|c|}{ Valor máximo } \\
\hline Vasos $/ \mathrm{mm}^{2}$ & \multicolumn{2}{|c|}{$35.5 \pm 2.63$} & \multicolumn{2}{|c|}{22} & \multicolumn{2}{|c|}{49} \\
\hline$\varnothing$ tangencial del vaso $(\mu \mathrm{m})$ & \multicolumn{2}{|c|}{$50.3 \pm 2.9$} & \multicolumn{2}{|c|}{25} & \multicolumn{2}{|c|}{70} \\
\hline Grosor de la pared $(\mu \mathrm{m})$ & \multicolumn{2}{|c|}{$7.17 \pm 0.61$} & \multicolumn{2}{|c|}{5} & \multicolumn{2}{|c|}{10} \\
\hline $\begin{array}{l}\text { Longitud de los elementos vaso } \\
\qquad(\mu \mathrm{m})\end{array}$ & \multicolumn{2}{|c|}{$159.1 \pm 9.0$} & \multicolumn{2}{|c|}{50} & \multicolumn{2}{|c|}{250} \\
\hline
\end{tabular}


Asimismo, los dos taxa presentan elementos de vaso con placa de perforación simple, punteaduras intervasculares alternas, areoladas (Figura 1C y D), pero en $M$. luisana son ornamentadas. Entre los taxa, existen diferencias estadísticamente significativas con relación al diámetro de la punteadura intervascular y del lumen de la punteadura, siendo M. luisana la que presenta el mayor diámetro (Cuadro 3).

\section{Parénquima axial}

Ambos taxa presentaron parénquima paratraqueal abundante y apotraqueal escaso (Figura $1 \mathrm{~A}$ y $\mathrm{B}$ ). En el caso de $M$. aculeaticarpa var. aculeaticarpa, la madera temprana posee, esencialmente, parénquima aliforme, pero también presenta aliforme confluente que une de dos a cuatro vasos, seguidos de parénquima vasicéntrico y unilateral (Figura 1A). Mientras que en la madera tardía, abunda el parénquima vasicéntrico, aliforme confluente que une de dos a seis vasos, aliforme y unilateral (Figura 1B). 
Cuadro 3. Estadística descriptiva y $t$-Student correspondientes a: punteaduras, parénquima, radios y fibras de Mimosa aculeaticarpa var. aculeaticarpa y M. luisana (LeguminosaeMimosoideae). Continúa

\begin{tabular}{|c|c|c|c|c|c|c|}
\hline \multirow[t]{2}{*}{ Variables } & \multirow[t]{2}{*}{ Taxa } & \multirow[t]{2}{*}{$\begin{array}{c}\text { Media } \pm \text { desviación } \\
\text { estándar }\end{array}$} & \multirow[t]{2}{*}{$\begin{array}{c}\text { Valor } \\
\text { mínimo }\end{array}$} & \multirow[t]{2}{*}{$\begin{array}{c}\text { Valor } \\
\text { máximo }\end{array}$} & \multicolumn{2}{|c|}{$\begin{array}{c}\text { t- Student } \\
(P \leq 0.05)\end{array}$} \\
\hline & & & & & $t$ & $P$ \\
\hline $\begin{array}{c}\varnothing \text { de la } \\
\text { punteadura } \\
\text { intervascular } \\
(\mu \mathrm{m})\end{array}$ & $\begin{array}{c}\text { M. aculeaticarpa } \\
\text { var. aculeaticarpa } \\
\text { M. Iuisana }\end{array}$ & $\begin{array}{l}4.76 \pm 0.10^{b} \\
6.2 \pm 0.50^{a}\end{array}$ & $\begin{array}{c}3.12 \\
5\end{array}$ & $\begin{array}{l}7.05 \\
7.5\end{array}$ & 4.9680 & 0.007662 \\
\hline $\begin{array}{c}\varnothing \text { del lumen de } \\
\text { la punteadura } \\
\text { intervascular } \\
(\mu \mathrm{m})\end{array}$ & $\begin{array}{c}\text { M. aculeaticarpa } \\
\text { var. aculeaticarpa } \\
\text { M. Iuisana }\end{array}$ & $\begin{array}{l}2.76 \pm 0.3^{b} \\
3.73 \pm 0.50^{a}\end{array}$ & $\begin{array}{r}2.02 \\
2.5 \\
\end{array}$ & $\begin{array}{r}3.42 \\
5.0 \\
\end{array}$ & 3.3288 & 0.029139 \\
\hline $\begin{array}{l}\text { Longitud del } \\
\text { cordón del } \\
\text { parénquima } \\
(\mu \mathrm{m})\end{array}$ & $\begin{array}{c}\text { M. aculeaticarpa } \\
\text { var. aculeaticarpa } \\
\text { M. Iuisana }\end{array}$ & $\begin{array}{r}279.08 \pm 20.87^{a} \\
164.93 \pm 8.06^{b}\end{array}$ & $\begin{array}{r}123.4 \\
115 \\
\end{array}$ & $\begin{array}{r}462.74 \\
235 \\
\end{array}$ & 8.8392 & 0.000904 \\
\hline Radios/mm & $\begin{array}{c}\text { M. aculeaticarpa } \\
\text { var. aculeaticarpa } \\
\text { M. Iuisana }\end{array}$ & $\begin{array}{l}6.71 \pm 0.68 a \\
5.20 \pm 0.32 b\end{array}$ & 4 & $\begin{array}{l}10 \\
8\end{array}$ & 2.9675 & 0.041245 \\
\hline $\begin{array}{c}\text { Altura de radios } \\
(\mu \mathrm{m})\end{array}$ & $\begin{array}{c}\text { M. aculeaticarpa } \\
\text { var. aculeaticarpa } \\
\text { M. Iuisana }\end{array}$ & $\begin{array}{l}236.67 \pm 39.73 a \\
107.67 \pm 10.19 b\end{array}$ & $\begin{array}{l}90 \\
55\end{array}$ & $\begin{array}{l}540 \\
230\end{array}$ & 5.4473 & 0.005516 \\
\hline $\begin{array}{l}\text { Anchura de } \\
\text { radios }(\mu \mathrm{m})\end{array}$ & $\begin{array}{c}\text { M. aculeaticarpa } \\
\text { var. aculeaticarpa } \\
\text { M. Iuisana }\end{array}$ & $\begin{array}{l}17.87 \pm 3.15 \\
19.20 \pm 2.96\end{array}$ & $\begin{array}{l}10 \\
10\end{array}$ & $\begin{array}{l}35 \\
25\end{array}$ & 0.5346 & $0.621278 \mathrm{~ns}$ \\
\hline $\begin{array}{l}\text { Longitud de } \\
\text { fibras }(\mu \mathrm{m})\end{array}$ & $\begin{array}{c}\text { M. aculeaticarpa } \\
\text { var. aculeaticarpa } \\
\text { M. Iuisana }\end{array}$ & $\begin{array}{c}674.0 \pm 8.06 \\
661.73 \pm 31.14\end{array}$ & $\begin{array}{r}553.33 \\
480\end{array}$ & $\begin{array}{l}830 \\
890\end{array}$ & 0.7726 & $0.482864 \mathrm{~ns}$ \\
\hline $\begin{array}{l}\varnothing \text { del lumen de } \\
\text { la fibra }(\mu \mathrm{m})\end{array}$ & $\begin{array}{c}\text { M. aculeaticarpa } \\
\text { var. aculeaticarpa } \\
\text { M. Iuisana }\end{array}$ & $\begin{array}{l}7.83 \pm 0.11 \\
6.0 \pm 0.16\end{array}$ & $\begin{array}{l}5 \\
10\end{array}$ & $\begin{array}{c}5 \\
17.5\end{array}$ & 2.0612 & $0.108304^{\mathrm{ns}}$ \\
\hline $\begin{array}{c}\text { Grosor de la } \\
\text { pared de la fibra } \\
(\mu \mathrm{m})\end{array}$ & $\begin{array}{c}\text { M. aculeaticarpa } \\
\text { var. aculeaticarpa } \\
\text { M. Iuisana }\end{array}$ & $\begin{array}{c}5.83 \pm 0.36 \\
5.0 \pm 0\end{array}$ & $\begin{array}{c}3.33 \\
5\end{array}$ & $\begin{array}{l}10 \\
5\end{array}$ & 1.1329 & $0.320575^{\mathrm{ns}}$ \\
\hline $\begin{array}{c}\text { Longitud de } \\
\text { traqueidas } \\
\text { vasicéntricas } \\
(\mu \mathrm{m})\end{array}$ & $\begin{array}{c}\text { M. aculeaticarpa } \\
\text { var. aculeaticarpa } \\
\text { M. Iuisana }\end{array}$ & $\begin{array}{l}668.27 \pm 8.81 \\
659.33 \pm 26.7\end{array}$ & $\begin{array}{l}546.67 \\
486.67\end{array}$ & $\begin{array}{l}800 \\
890\end{array}$ & 0.7990 & $0.469026^{\mathrm{ns}}$ \\
\hline
\end{tabular}

Los valores seguidos por la misma letra indica que no hubo diferencia significativa, con $P<0.05$. $\varnothing=$ Diámetro, ns=no significativo.

El parénquima en la madera de $M$. luisana, primariamente, es aliforme confluente que une de dos a ocho vasos, seguido de aliforme, vasicéntrico y unilateral. En ambos taxa, las células del parénquima axial forman cordones cortos; sin embargo, M. aculeaticarpa var. aculeaticarpa presentó los cordones más largos, 
mostrando diferencias estadísticamente significativas con los de M. luisana (Cuadro 3). En el caso de M. aculeaticarpa var. aculeaticarpa, los cordones están constituidos, por una célula, rara vez se observan dos; mientras que en M. luisana están integrados por dos células y, rara vez, se observan una o tres células. Cabe mencionar que únicamente las células del parénquima de $M$. luisana presentaron de 2 a 14 cristales prismáticos, cada uno de ellos ubicado en su cámara.

\section{Descripción de los radios y las fibras}

Los dos taxa presentan radios numerosos, pero existen diferencias significativas entre ellos, siendo $M$. aculeaticarpa var. aculeaticarpa la que presenta el mayor número de radios/mm y son, esencialmente, uniseriados y, en menor proporción, biseriados (Figura 1C); en M. luisana son, principalmente, biseriados y, en menor proporción, uniseriados (Figura 1D).

En ambos taxa, los radios son homogéneos y están compuestos por células procumbentes; son bajos y finos (Figura 1E y F). Estadísticamente, M. aculeaticarpa var. aculeaticarpa presenta los radios más altos (Cuadro 3).

Respecto a las fibras, ambos taxa tienen fibras libriformes de longitud corta, diámetro fino y pared delgada. Cabe mencionar que ambos taxa presentaron traqueidas vasicéntricas de longitud corta; sin embargo, $M$. aculeaticarpa var. aculeaticarpa sólo las presentó en la madera temprana (Cuadro 3). 

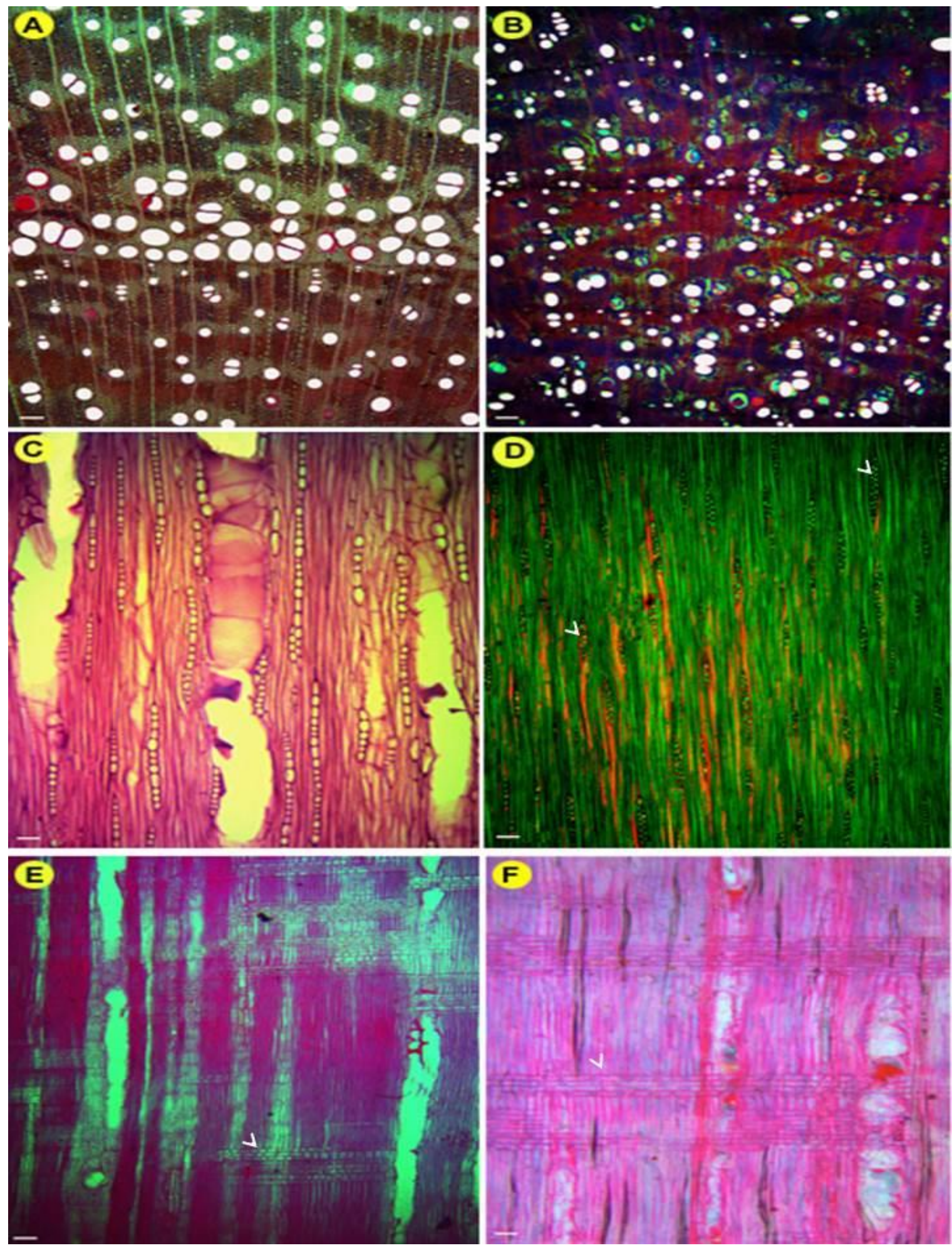

Figura 1. Cortes anatómicos de la madera de Mimosa aculeaticarpa var. aculeaticarpa y Mimosa luisana. A, C, E, M. aculeaticarpa; B, D, F, M. luisana; A, B, cortes transversales; C, D, cortes tangenciales; E, F, cortes radiales. Barra: $100 \mu \mathrm{m}$. 


\section{Índices de Vulnerabilidad y Mesomorfía}

El IV mostró diferencias estadísticamente significativas entre taxa $(t=7.0560$; $P=0.002128$ ). El valor más alto lo presentó $M$. aculeaticarpa var. aculeaticarpa (IV=4.05), lo que indica que es la más vulnerable a la sequía; además, es la que presenta el IM superior (729.05). Mientras que los valores más bajos tanto de IV como de IM, corresponden a M. luisana (1.42 y 226.71, respectivamente), lo que sugiere que este taxon resiste a la sequía. No obstante, debido a que ambos taxa presentaron un IM superior a 200, se considera que ambos presentan un xilema mesomórfico.

\section{DISCUSIÓN}

Las características anatómicas de la madera observadas en ambos taxa de Mimosa, están acorde a las ya reportadas para las mimosoideas (Evans et al., 2006) y para el género (Heringer y De Paula, 1979; Maccari y Marchiori, 1994; Marchiori, 1982; 1985; 1996; Montaño-Arias, 2010). No obstante, el análisis en conjunto de los trabajos con los resultados obtenidos, muestran diferencias a nivel infragenérico en cuanto al tipo de porosidad, diámetro y longitud de los elementos vasculares (P. ej. vasos, fibras), y altura de los radios, entre otros, por lo que es posible considerar que estos caracteres están influenciados por el ambiente (León, 2005; Montaño-Arias et al., 2011; Wodzicki, 2001; Woodcock, 1994) y otros como la predominancia de algún tipo de parénquima y la presencia de placas de perforación, son caracteres que de acuerdo con Polanco y Grande (2009) están relacionados con la evolución de las plantas. 
Al respecto, la porosidad, ya sea anular o difusa, ha sido asociada con la disponibilidad de agua (Bissing, 1982; Gilbert, 1940, en Moglia y Giménez, 1998). La porosidad anular observada en M. aculeaticarpa var. aculeaticarpa, también ha sido observada en otros taxa como M. acantholoba (H. \& B. ex Willd.) Poir. var. eurycarpa (B.L. Rob.), M. benthamii J.F. Macbr. var. benthamii, M. lacerata Rose y M. texana (A. Gray) Small var. filipes (Britton \& Rose) Barneby (Montaño-Arias, 2010). M. aculeaticarpa var. aculeaticarpa proviene de un clima cálido-húmedo, con estacionalidad marcada; mientras que $M$. acantholoba var. eurycarpa, $M$. benthamii var. benthamii, M. lacerata y $M$. texana var. filipes provienen de climas semisecos, también con estacionalidad marcada (Montaño-Arias, 2010).

De acuerdo con Merino (2009), el hecho de que haya una estacionalidad marcada, favorece el desarrollo de una porosidad anular y, por lo tanto, la diferenciación de madera temprana y madera tardía. Según Woodcock (1994), el significado funcional de la porosidad anular deriva en una conducción rápida en la madera temprana, a través de los vasos de mayor diámetro, y la madera tardía garantiza la seguridad de la columna de agua, mediante sus vasos pequeños. No obstante, en taxa de zonas templadas, es más común observar maderas con porosidad anular que en taxa de regiones áridas o semiáridas (Moglia y Giménez, 1998). Lo anterior, concuerda con los resultados obtenidos, ya que M. aculeaticarpa var. aculeaticarpa fue colectada en una zona húmeda, bosque de pino-encino; mientras que $M$. luisana, fue colectada en una zona semiárida, en un matorral xerófilo, presentando porosidad difusa. 
A nivel mundial, se ha estudiado la anatomía de la madera de 41 taxa de Mimosa, de los ca. 520 existentes (Simon et al., 2011); de estos 40, el 76\% presenta porosidad difusa y, únicamente, el 23\% porosidad anular. Al respecto, Gilbert (1940, en Moglia y Giménez, 1998) considera la porosidad difusa como una ventaja para transportar la escasa cantidad de agua existente en el hábitat. Con base en lo anterior, el que predominen los taxa con porosidad difusa en ecosistemas secos, también explica, entre otros factores, el por qué las mimosas llegan a ser uno de los elementos dominantes en estos ambientes.

Por otro lado, ambos taxa presentan vasos numerosos, característica común no sólo de las leguminosas que habitan en sitios secos (Moglia y Giménez, 1998; Silva et al., 1989), sino del género Mimosa (Montaño-Arias et al., 2013). Aunque los vasos numerosos son considerados como característicos de los taxa xerófitos (Carlquist y Hoekman, 1985), también se han reportado en taxa de climas fríos (Miller, 1975). De acuerdo con León (2001), un mayor número de vasos está relacionado con el clima, al darse un incremento de la sequía o una disminución de la temperatura del sitio donde se desarrolla la planta; este dato es consistente con los resultados obtenidos, ya que $M$. luisana presentó el mayor número de vasos $/ \mathrm{mm}^{2}$, siendo un taxon que habita en un sitio cálido seco. Esta tendencia también ha sido observada en otros taxa como $M$. cruenta Benth., $M$. daleoides Benth., $M$. leucaenoides Benth. e incluso en otras mimosoideas como Acacia macracatha Benth., Calliandra gracillis Klotzsch, Leucaena trichodes Benth. y Pithecellobium saman (Jacq.) Benth. que habitan zonas secas (Silva et al., 1989). 
De forma adicional, los vasos de la madera temprana de $M$. aculeaticarpa var. aculeaticarpa presentan diámetros medianos al igual que la madera de $M$. tenuiflora (Montaño-Arias, 2010) y, de acuerdo con Carlquist (2001), estos diámetros, favorecen el manejo de grandes cantidades de agua por unidad de tiempo por vaso; por lo que se sugiere que este taxon está adaptado para manejar mayores volúmenes de agua (estación de lluvias), en comparación con la madera tardía (estación de secas). En el caso de la madera de M. luisana, los vasos son más pequeños, indicando una mayor resistencia a la cavitación y, por consiguiente, éstos contribuyen a reducir los embolismos (Polanco y Grande, 2009; Giménez et al., 2012), mostrando resistencia al estrés hídrico (Montaño-Arias et al., 2013).

Asimismo, la presencia de vasos agrupados es una ventaja, ya que confieren una mayor seguridad en la conducción de agua (Baas y Carlquist, 1985; Carlquist y Hoekman, 1985; Barajas-Morales, 1985), disminuyendo el riesgo por embolia (Moglia y Giménez, 1998). En este estudio, los resultados muestran que ambos taxa presentan vasos agrupados; sin embargo, M. luisana los presenta en mayor número, sugiriendo que su madera es la que provee mayor seguridad a la columna de agua.

Las paredes delgadas de los elementos de vaso han sido asociadas a lugares húmedos (Montaño-Arias et al., 2013), y M. aculeaticarpa var. aculeaticarpa pertenece a un clima húmedo. Aunque en M. luisana los elementos de vaso también tienen paredes delgadas, el grosor es aproximadamente del doble de un vaso de la madera temprana y tres veces el grosor de un vaso de la madera tardía de $M$. aculeaticarpa var. aculeaticarpa. 


\section{Longitud de elementos de vaso, placas de perforación y punteaduras} intervasculares

La longitud de los elementos de vaso es un rasgo de adaptación evolutiva, ya que a medida que éstos sean más cortos (Zimmermann, 1978) y anchos habrá mayor seguridad en la conducción del agua. Los resultados muestran que ambos taxa tienen elementos de vaso cortos, por lo que ambos proveen seguridad en el proceso conductivo. Además, los resultados son consistentes con lo reportado por Carlquist y Hoekman (1985), en cuanto a que la longitud de los elementos de vaso disminuye con la aridez, ya que $M$. luisana tuvo los vasos más cortos y se ubica en un hábitat con menor humedad que el ambiente de $M$. aculeaticarpa var. aculeaticarpa. Esta tendencia, también ha sido observada en M. leucaenoides y M. tenuiflora (MontañoArias et al., 2013).

De acuerdo con Carlquist $(1975,2001)$ y Montaño-Arias et al. (2013), los elementos de vaso de longitud corta son considerados los más fuertes, a causa del estrechamiento formado por la pared del elemento de vaso, aún en aquéllos que presentan placa de perforación simple, ya que esto permite resistir grandes presiones y deformaciones relacionadas con las tensiones de la columna de agua.

La presencia de placas de perforación simple implica una óptima conducción (Moglia y López, 2001), pero genera un aumento en la conductividad hidráulica y, por lo tanto, una mayor vulnerabilidad a los embolismos (Polanco y Grande, 2009). Sin embargo, esta vulnerabilidad es reducida cuando están acompañadas de punteaduras intervasculares alternas y, aún más, cuando éstas son ornamentadas 
(Jansen et al., 2003; Jansen et al., 2004). Por un lado, las punteaduras intervasculares permiten el flujo de agua a los vasos adyacentes (Zweypfenning, 1978) y, por otro, la ornamentación retiene las burbujas de aire provocadas por una pérdida en la presión del agua (Carlquist 1982, Choat et al., 2004) y, de esta forma, evitan la cavitación (Silva et al., 2011). Cabe mencionar que, en este estudio, únicamente $M$. luisana presentó punteaduras intervasculares ornamentadas, pero este tipo de punteaduras han sido reportadas en 17 taxa de Mimosa (P. ej. M. bimucronata (DC) OK., Cozzo, 1951; M. eriocarpa Benth., Carnieletto y Marchiori, 1993; M. incana (Spreng.) Benth, Marchiori, 1996; M. micropteris Beth., da SilvaPereira et al., 2013; M. pilulifera Benth., Marchiori y Muñiz, 1997; M. sparsa Benth., Maccari y Marchiori, 1994).

\section{Parénquima axial, radios y fibras}

De acuerdo con Aguilar-Rodríguez y Barajas-Morales (2005), el parénquima axial es un carácter relacionado con aspectos anatómico-evolutivos de las angiospermas, considerando que el parénquima aliforme y el aliforme confluente son los más evolucionados (Polanco y Grande, 2009). Con base en lo anterior, se sugiere que $M$. luisana es un taxon más reciente, ya que en su madera predominan ambos tipos de parénquima. Al respecto, se ha documentado que los taxa estudiados surgieron hace ca. de 12 millones de años, y aunque, no hubo una definición de la edad de cada taxon, se sugiere que M. luisana es más reciente (Simon et al., 2011). 
Por otra parte, Barajas-Morales (1985) reporta que la presencia de radios altos está asociada a taxa que habitan sitios mésicos, lo que coincide con los resultados obtenidos, ya que $M$. aculeaticarpa var. aculeaticarpa pertenece a este tipo de sitios y presentó los radios más altos.

Asimismo, la altura de los radios ha sido reportada con una baja influencia ambiental (Carlquist, 2001; León, 2001); no obstante, Novaes et al. (2010) reportan que existe una relación directa entre la altura de los radios y la disponibilidad de agua en el sitio, de modo que los radios bajos implican que en el sitio existe poca disponibilidad de agua. Alves y Angyalossy-Alfonso (2002) y Amano (2007) mencionan que, además de la altura de los radios, el grosor de la pared de las fibras también está relacionado con la disponibilidad de agua. Estos autores señalan que las fibras con pared gruesa son frecuentes en taxa de zonas áridas. Sin embargo, los taxa estudiados y otros como $M$. detinens Benth., M. adpressa H. et A., M. ostenii Speg. ex Burk., M. uliginosa Chod. et Hassl.; M. scabrella Benth. (Cozzo, 1951), entre otras, presentaron fibras delgadas, independientemente del sitio en el que se desarrollan, lo que no coincide con lo reportado por estos autores.

De acuerdo con Polanco y Grande (2009), los resultados sugieren que ambos taxa tienen, en términos anatómico-evolutivos, una madera avanzada por presentar elementos de vaso con placa de perforación simple asociados a fibras libriformes. Asimismo, la presencia de fibras libriformes asociadas a un alto número de vasos solitarios, sugiere que los taxa están establecidas en un hábitat con un alto grado de aridez (Polanco y Grande, 2009). Lo anterior, explica por qué sólo M. luisana 
presentó traqueidas vasicéntricas como un elemento conductor adicional necesario para transportar la escasa cantidad de agua existente en su hábitat. Del mismo modo, M. aculeaticarpa var. aculeaticarpa sólo presentó traqueidas vasicéntricas en la madera temprana, lo que indica que durante la estación de lluvias, requiere de elementos conductores adicionales que le permitan transportar el agua. Además, el presentar este carácter les confiere, a ambos taxa, una mayor seguridad en la conducción de agua (Montaño-Arias et al. 2013), volviéndolas más competitivas, ya que las traqueidas vasicéntricas funcionan como un sistema de conducción subsidiario o alternativo que cumple la misma función que los vasos agrupados (Moglia y Giménez, 1998).

\section{Índices de Vulnerabilidad (IV) y Mesomorfía (IM)}

Ambos taxa presentan un alto número de vasos reflejado en un IV superior a la unidad, por lo que se considera que ambos taxa son vulnerables a la sequía. Sin embargo, el IV que mostró la madera de $M$. aculeaticarpa var. aculeaticarpa supera casi tres veces el IV de M. luisana, lo que indica que esta última es la más resistente.

Los IV son similares a los reportados en $M$. tenuiflora (6.26), M. tejupilcana (4.09), M. hexandra (3.56), M. bahamensis (3.36) y M. leucaenoides (1.81), y coinciden en que son taxa vulnerables pero con un xilema adaptado para resistir la sequía (Montaño-Arias et al., 2013). 
Respecto al IM, los taxa estudiados presentaron un xilema de tipo mesomórfico, este tipo de xilema ya ha sido reportado para $M$. bahamensis Benth., M. hexandra M. Micheli., M. leucaenoides, M. tejupilcana R. Grether \& A. MartínezBernal y M. tenuiflora (Willd.) Poir.; sin embargo, el valor de IM de M. luisana es más parecido con $M$. leucaenoides (276.77) debido a que son taxa que habitan en ambientes secos. El valor de IM de $M$. aculeaticarpa var. aculeaticarpa se parece al de M. tejupilcana (727.76), ya que ambos taxa crecen el ambientes subhúmedos.

El xilema mesomórfico en conjunto con valores de IV menores a cinco, sugiere que los taxa estudiados tienen un sistema de conducción seguro y eficaz para el movimiento del agua (León-H., 2001, 2001-2002).

\section{CONCLUSIONES}

Los taxa estudiados tienen un xilema adaptado para resistir periodos de escasez de agua que les permite vivir y adaptarse a los ambientes en los que habitan. Se reconoce que la presencia de elementos vasculares de diámetro tangencial pequeño, longitud corta, con placa de perforación simple, punteaduras intervasculares ornamentadas y traqueidas vasicéntricas, contribuyen a la seguridad en la conducción de agua y son caracteres distintivos de taxa con capacidad de adaptación a diferentes tipos de hábitats. 
La estructura de la madera es sólo una de las múltiples estrategias adaptativas (P. ej. caducifolias, hojas pequeñas) que tienen los taxa estudiados para resistir o tolerar los periodos de escasez de agua.

Asimismo, la comparación de estos resultados con relación a lo reportado para otros taxa del género Mimosa, revela que los taxa, tanto de climas templados como secos, presentan estrategias adaptativas semejantes, lo que explica su capacidad de colonizar ambientes desfavorables; es decir, aquellos hábitats en los que existen condiciones extremas de temperatura y/o precipitación.

Es preciso mencionar que, a pesar de que se ha estudiado la anatomía de la madera de 41 taxa de Mimosa, son pocos los trabajos que tienen un enfoque ecoanatómico y/o ecofisiológico (Barajas-Morales, 1985; Barajas-Morales y LeónGómez, 1989), lo que pone de manifiesto la necesidad de avanzar en esta línea para una evaluación comparativa que permita sugerir los taxa idóneos para diferentes ambientes en México. Algunas de las descripciones anatómicas llegan a ser ambiguas, ya que en ellas no se mencionan algunos caracteres o no dan una explicación de la característica encontrada lo que impide llegar a una conclusión ecoanatómica que integre a todos los taxa estudiados hasta ahora. No obstante, los resultados aquí presentados, son útiles para sugerir la factibilidad de la reforestación de ecosistemas secos y mésicos. Se propone a $M$. aculeaticarpa var. aculeaticarpa para lugares mésicos y a $M$. luisana para restaurar ambientes secos. 


\section{LITERATURA CITADA}

Aguilar-Rodríguez, S. y Barajas-Morales J. 2005. Anatomía de la madera de especies arbóreas de un bosque mesófilo de montaña: un enfoque ecológicoevolutivo. Boletín de la Sociedad Botánica de México 77: 51-58.

Aguilar-Rodríguez, S., Terrazas T. y López-Mata L. 2006. Anatomical wood variation of Buddleja cordata (Buddlejaceae) along its natural range in Mexico. TreesStructure and Function 20: 253-261.

Alves, E.S. y Angyalossy-Alfonso V. 2002. Ecological trends in the wood anatomy of some Brazilian species. 2. Axial parenchyma, rays and fibers. International Association of Wood Anatomists Journal 23: 391-418.

Amano, E. 2007. Pau-brasil, madeira e casca: formação, desenvolvimento e estrutura. Tese (Doutorado em Ciências, área Botânica). Instituto de Biociências, Universidade de São Paulo, São Paulo. 101 p.

Araque, A. y León H.W. 2006. Anatomía comparada del leño de Spondias mombin L. (Anacardiaceae) que crecen en zonas de banco y bajío en la Reserva Forestal Caparo (Barinas, Venezuela). Revista. Forestal Venezolana 50: 9-17.

Arias, S. y Terrazas T. 2001. Variación en la anatomía de la madera de Pachycereus pecten-aboriginum (Cactaceae). Anales del Instituto de Biología Universidad Nacional Autónoma de México, Serie Botánica 72: 157-169.

Baas, P. 1973. The wood anatomical range in llex (Aquifoliaceae) and its ecological and phylogenetic significance. Blumea 21: 193-258. 
Baas, P. y Carlquist S. 1985. A comparison of ecological wood anatomy of the floras of southern California and Israel. International Association of Wood Anatomists Journal 8: 245- 274.

Barajas-Morales, J. 1985. Wood structural differences between trees of two tropical forests in Mexico. International Association Wood Anatomy Bulletin 6: 355-365.

Barajas-Morales, J. y León-Gómez C. 1989. Anatomía de maderas de México: especies de una selva baja caducifolia. Instituto de Biología, UNAM, México, Publicaciones Especiales 1: 79-80.

Baretta-Kuipers, T. 1981. Wood anatomy of Leguminosae: its relevance to taxonomy. En: Polhill R.M. y Raven P.H. (eds.). Advances in Legume Systematics. Royal Botanic Gardens, Kew 2: 677-705.

Bernal-Salazar, S. y Terrazas T. 2000. Influencia climática sobre la variación radial de caracteres anatómicos de la madera en Abies religiosa. Madera y Bosques 6: 73-86.

Bissing, D.R. 1982. Variation in qualitative anatomical features of the xylem of selected dicotyledonous woods in relation to water availability. Bulletin of the Torrey Botanical Club 109: 371-384.

Camargo-Ricalde, S.L., Grether R., Martínez-Bernal A., García-García V. y Barriosdel-Rosal S. 2001. Especies útiles del género Mimosa (Fabaceae-Mimosoideae) en México. Boletín de la Sociedad Botánica de México 68: 33-44.

Camargo-Ricalde, S.L., Dhillion S.S. y Grether R. 2002. Community structure of endemic Mimosa species and environmental heterogeneity in a semi-arid Mexican valley. Journal of Vegetation Science 13: 697-704. 
Camargo-Ricalde, S.L., Reyes-Jaramillo I. y Montaño N.M. 2010a. Forestry insularity effect of four Mimosa L. species (Leguminosae-Mimosoideae) on soil nutrients of a Mexican semiarid ecosystem. Agroforestry Systems 80: 385-397.

Camargo-Ricalde, S.L., Montaño N.M., Reyes-Jaramillo I., Jiménez-González C. y Dhillion S.S. 2010b. Effect of mycorrhizae on seedlings of six endemic Mimosa L. species (Leguminosae-Mimosoideae) from the semi-arid Tehuacán-Cuicatlán Valley, Mexico. Trees-Structure and Function 24: 67-78.

Carlquist, S. 1975. Ecological strategies of xylem evolution. University of California Press, Berkeley, California, USA. 259 pp.

Carlquist, S. 1977. Ecological factors in wood evolution: a floristic approach. American Journal of Botany 64: 887-896.

Carlquist, S. 1982. Wood anatomy of Onagraceae: further species, root anatomy, significance of vestured pits and allied structures in dicotyledons. Annals of the Missouri Botanical Garden 69: 755-769.

Carlquist, S. 2001. Comparative wood anatomy. Systematic, ecological and evolutionary aspects of dicotyledon wood. Springer Verlag. Berlín. 457 pp.

Carlquist, S. y Hoekman D. 1985. Ecological wood anatomy of the woody southern California Flora. International Association Wood Anatomy Bulletin 6: 319-347.

Carnieletto, C. y Marchiori, J.N.C. 1993. Anatomia da madeira de Mimosa eriocarpa Benth. Ciência Florestal, Santa Maria 3: 107-120.

Chattaway, M. 1956. Crystals in wood tissues II. Tropical Woods 104: 100-124. 
Chávez-Romero, D.M., Aguilar-Rodríguez S. y Terrazas T. 2010. Variación anatómica en la madera de Quercus obtusata (Fagaceae). Madera y Bosques 16: 69-87.

Chehaibar, M. y Grether R. 1990. Anatomía de la madera de algunas especies del género Mimosa (Leguminosae). Boletín de la Sociedad Botánica de México 50: 3-17.

Choat, B., Jansen S., Zwieniecki M.A., Smets E. y Holbrook N.M. 2004. Changes in pit membrane porosity due to deflection and stretching: the role of vestured pits. Journal of Experimental Botany 55: 1569-1575.

Christensen, J.H., Hewitson B., Busuioc A., Chen A., Gao X., Held I., Jones R., Kolli R.K., Kwon W.-T., Laprise, R. Magaña Rueda V., Mearns L., Menéndez C.G., Räisänen J., Rinke A., Sarr A. y Whetton P. 2007. Regional climate projections. En: Solomon S., Qin D., Manning M., Chen Z., Marquis M., Averyt K.B., Tignor M. y Miller H.L. Eds. Climate Change: The physical science basis. Contribution of working group I to the fourth assessment report of the Intergovernmental Panel on Climate Change (IPCC), pp.1-94, Cambridge University Press, Cambridge, UK and New York, NY, USA.

Cline, W.R. 2007. Global warming and agriculture: impact estimates by country. Center for Global development, Washington DC.

Cozzo, D. 1951. Anatomia del leno secundario de las Leguminosas Mimosoideas y Caesalpinoideas Argentinas, silvestres y cultivadas. Revista del Instituto Nacional de Investigación de las Ciencias naturales. Ciencias Botánicas 2: 63146. 
Cozzo, D. y Cristiani L.Q. 1950. Los géneros de fanerógamas argentinas con estructura leñosa estratificada. Revista del Museo Argentino de Ciencias Naturales, Bernardino Rivadavia, Ciencias Botánicas 1: 363-405.

da Silva-Pereira, A.C., Siegloch A.M. y Marchiori J.N.C. 2013. Anatomia do lenho de Mimosa micropteris Benth. Balduinia 40: 18-22.

De la Barrera, E. y Andrade A. 2005. Challenges to plant megadiversity: how environmental physiology can help. New Phytologist 167: 5-8.

de Lima, R.S., De Oliveira P.L. y Rodrigues L.R. 2009. Anatomia do lenho de Enterolobium contortisiliquum (Vell.) Morong (Leguminosae- Mimosoideae) ocorrente em dois ambientes. Revista Brasileira de Botânica 32: 361-374.

Evans, J.A., Gasson P.E. y Lewis G.P. 2006. Wood anatomy of the Mimosoideae (Leguminosae). International Association of Wood Anatomists Journal Supplement 5. $117 \mathrm{p}$.

Espinoza de Pernía, N. y Melandri J.L. 2006. Wood anatomy of the tribe Caesalpinieae (Leguminosae, Caesalpinioideae) in Venezuela. International Association of Wood Anatomists Journal 27: 99-114.

Figueroa, M.E., Giménez A.M., Hernández P., Gaillard de Benítez C. y Lorenz G. 2011. Ecological wood anatomy of Allenrolfea vaginata [Griseb.] Kuntze [Chenopodiaceae] in saline environments in Santiago del Estero. Ecología Austral 21: 339-352.

Fisher, B.J., Goldstein G., Jones T.J. y Cordell S. 2007. Wood vessel diameter is related to elevation and genotype in the Hawaiian tree Metrosideros polymorpha (Myrtaceae). American Journal of Botany 94: 709-715. 
García, E. 1987. Modificaciones al Sistema de Clasificación climática de Köppen (para adaptarlo a las condiciones de la República Mexicana). Instituto de Geografía, Universidad Autónoma de México, México, D.F.

Giménez, A.M. 2004. Anatomía comparada de leño y corteza de Geoffroea striata y Geoffroea decorticans. Madera y Bosques 10: 55-68.

Giménez, A.M., Calatayu F., Figueroa M.E. y Díaz-Zirpolo J. 2012. Anatomía de leño de Maytenus vitis-idaea y M. viscifolia (Celastraceae). Boletín de la Sociedad Argentina de Botánica 47: 351-362.

Grether, R., Camargo-Ricalde S.L. y Martínez-Bernal A. 1996. Especies del género Mimosa (Leguminosae) presentes en México. Boletín de la Sociedad Botánica de México 58: 149-152.

Grether, R., Martínez-Bernal A., Camargo-Ricalde S.L. 2007. Mimosa. En: Rzedowski J. y G. Calderón de Rzedowski (eds.). Flora del Bajío y de regiones adyacentes. Instituto. Ecología, Centro Regional del Bajío, México. Fascículo 150: 1-229.

Heringer, E.P. y De Paula J.E. 1979. Um novo par vicariante: Mimosa schomburgkii Benth. e Mimosa artemisiana Heringer \& Paula sp. Nov- (Floresta Atlántica). En: Anais Congresso Nacional de Botanica do Brasil 30, Campo Grande, Ms. Sociedad Botánica de Brasil, Anais da Sociedade Botanica do Brasil 30: 75-82.

Hintze, J. 2001. Number cruncher statistical system (NCSS). Realease 2001.

IAWA. 1989. IAWA list of microscopic features for hardwood identification. International Association Wood Anatomy Bulletin new series 10: 219-332.

Jansen, S., Baas P., Gasson P. y Smets E. 2003. Vestured pits: do they promote safer water transport? International Journal of Plant Sciences 164: 405-413. 
Jansen, S., Baas P., Gasson P., Lens F. y Smets E. 2004. Variation in xylem structure from tropics to tundra: evidence from vestured pits. Proceedings of the National Academy of Sciences of the USA 101: 8833-8837.

Johansen, D.A. 1940. Plant Microtechnique. Mc Graw Hill. Nueva York. 523 pp.

Jono, V. 2009. Anatomia ecológica do Lenho e actividade cambial de Roupala rhombifolia (Proteaceae) na Serra do Cipó (MG). Dissertação de Mestrado, área Botânica. Instituto de Biociências, Universidade de São Paulo, São Paulo, Brasil. 75 p.

Kribs, D.A. 1968. Commercial foreign woods on the American marquet. Dover Pub. Inc. New York. 241 p.

León, H.W. 2001. Anatomía del leño, aspectos ecológicos y filogenia en mangles de Venezuela. Revista Forestal Venezolana 45: 191-203.

León, H.W. 2001-2002. Anatomía xilemática del tronco de Pereskia guamacho (Cactaceae) procedente de Mérida-Venezuela. Pittieria 31: 41-49.

León, H.W. 2005. Anatomía ecológica del xilema secundario de un bosque seco tropical de Venezuela. Acta Botánica Venezolana 28: 257-274.

Lindorf, H.1994. Eco-anatomical wood features of species from a very dry tropical forest. International Association Wood Anatomy Journal 15: 361-376.

Luchi, A.E. 1998. Periodicidade de crescimento em Hymenaea courbaril L. e anatomia ecológica do lenho de espécies de mata ciliar. Tesis de Doctorado. Universidade de São Paulo, São Paulo, Brasil. 236 p. 
Maccari, A. y Marchiori J.N.C. 1994. Estudo anatômico do xilema secundário de Mimosa sparsa Benth. Ciência Florestal, Santa Maria 4: 145-155.

Marchiori, J.N.C. 1982. A estrutura do xilema secudário de Mimosa daleoides Benth. (Leguminosae-Mimosaoideae). Ciência e Natura, Santa Maria 4: 107-113.

Marchiori, J.N.C. 1985. Anatomia da madeira de Mimosa cruenta Benth. (Leguminosae Mimosoideae). Ciência e Natura, Santa Maria 7: 73-81.

Marchiori, J.N.C. 1993. Anatomia da madeira e casca do maricá, Mimosa bimucronata (DC.) O. Kuntze. Ciência Florestal 3: 85-106.

Marchiori, J.N.C. 1996. Anatomia do xilema secundário de Mimosa incana (Spreng.) Benth. Ciência Florestal, Santa Maria 6: 53-63.

Marchiori, J.N.C y Muñiz B.G. 1997. Estudo anatômico do xilema secundário de Mimosa trachycarpa Benth. Ciência Rural, Santa Maria 27: 223-228.

Martínez-Bernal, A. y Grether R. 2006. Mimosa. En: Novelo A. y Medina-Lemus R. (eds.). Flora del Valle de Tehuacán-Cuicatlán. Fascículo 44. Instituto de Biología, Universidad Nacional Autónoma de México, México. 1-108p.

Merino, E.G. 2009. La dendrocronología: métodos y aplicaciones. En: Nieto X. y Cau M.A. (eds.) Arqueologia nàutica mediterránia CASC, Museo de Arqueología de Catalunya, España. 309-322 p.

Miller, H. 1975. Anatomical characteristics of some woody plants of the Angmassalik district of southeast Greenland. Meddelanden Groenlandia 198: 1-30.

Moglia, G. y Giménez A. 1998. Rasgos anatómicos característicos del hidrosistema de las principales especies arbóreas de la región chaqueña argentina. Investigación Agraria 7: 53-71. 
Moglia, J. y López C. 2001. Tendencias de variación radial del leño en Aspidosperma Quebracho Blanco. Investigación Agraria. Sistema y Recursos Forestales 10: 69-79.

Montaño-Arias, S.A. 2010. Anatomía comparada de la madera de especies arbóreas mexicanas del género Mimosa sección Batocaulon (Leguminosae). Tesis de Maestría. Universidad Autónoma Metropolitana, Unidad Iztapalapa. México, D.F. 141 p.

Montaño-Arias, S.A., Camargo-Ricalde S.L., Grether R. y De la Paz Pérez-Olvera C. 2011. La madera en función del ambiente: un análisis ecoanatómico. Revista Elementos Ciencia y Cultura (Benemérita Universidad Autónoma de Puebla, $B U A P)$ 18: 19-24.

Montaño-Arias, S.A., Camargo-Ricalde S.L. y De la Paz Pérez-Olvera C. 2013. Ecoanatomía de los elementos de vaso de la madera de cinco especies del género Mimosa L. (Leguminosae-Mimosoideae). Botanical Sciences 91: 1-10.

Moya, R. y Tomazello F.M. 2008. Variation in the wood anatomical structure of Gmelina arborea (Verbenaceae) trees at different ecological conditions in Costa Rica. Revista de Biología Tropical 56: 689-704.

Novaes, F., Callado Ch., Pereira-Moura M.V. y Lima H.R.P. 2010. Wood anatomy of Mollinedia glabra (Spreng.) Perkins (Monimiaceae) in two Restinga Vegetation Formations at Rio das Ostras, RJ, Brazil. Anais da Academia Brasileira de Ciências 82: 915-924 
Parra, M.J. 2010. Determinación de índices de vulnerabilidad y mesomorfia en especies de laurales de la selva San Eusebio (Mérida, Venezuela). Pittieria, 34: 13-22.

Polanco, T.C. y Grande P.D.C. 2009. Análisis ecoanatómico, evolutivo y comparativo de la madera de 40 especies de dos asociaciones del Bosque alto andino colombiano. Revista Colombia Forestal 12: 183-203.

Ribeiro, M.L.R. y Barros C.F. 2006. Variação intraspecífica do lenhoff de Pseudopiptadenia contorta (DC.) GP Lewis \& M.P. Lima (LeguminosaeMimosoideae) de populações ocorrentes em dois remanescentes de Floresta Atlântica. Acta Botanica Brasilica 20: 839-844.

Rzedowski, J. 1978. Vegetación de México. Limusa. México, D.F. 482 p.

Rzedowski, J. 1991. Diversidad y orígenes de la flora fanerogámica de México. Acta Botánica Mexicana 14: 3-21.

Sidiyasa, K. y Baas P. 1998. Ecological and systematic wood anatomy of Alstonia (Apocynaceae). International Association Wood Anatomy Journal 19: 207-229.

Silva, A., Blanco C., y Lindorf H. 1989. Anatomia de la madera de nueve leguminosas de Venezuela. Acta Botanica Brasilica 2: 115-134.

Silva, L.B.D., Santos F.D.A.R.D., Gasson P. y Cutler D. 2011. Comparative study of Mimosa ophthalmocentra Mart. ex Benth and Mimosa tenuiflora (Willd.) Poir. (Fabaceae-Mimosoideae) wood in the caatinga of Northeast Brazil. Acta Botanica Brasilica 25: 301-314. 
Simon, M.F., Grether R., de Queiroz L.P., Sarkinen T.E., Dutra V.F. y Hughes C.E. 2011. The evolutionary history of Mimosa (Leguminosae): towards a phylogeny of the sensitive plants. American Journal of Botany 78: 1201-1221.

Sokal, R. y Rohlf F. 1995. Biometry. Freeman and Company, San Francisco, C.A. $887 \mathrm{pp}$.

Sosa, V. y Dávila P. 1994. Una evaluación del conocimiento florístico de México. Annals of the Missouri Botanical Garden 81: 749-757.

Wodzicki, T.J. 2001. Natural factors affecting wood structure. Wood Science and Technology 35: 5-26.

Woodcock, D.W. 1994. Occurrence of woods with a gradation in vessel diameter across the ring. International Association Wood Anatomy Journal 15:377-385.

Yaman, B. 2008. Variation in quantitative vessel element features of Juglans regia wood in the western black sea region of Turkey. Agrociencia 42: 357-365.

Zimmermann, M. 1978. Vessel ends and the disruption of water flow in plants. Phytopathology 68: 253-255.

Zweypfenning, R.C.V.J. 1978. A hypothesis on the function of vestured pits. International Association Wood Anatomy Bulletin 1: 3-15. 


\section{DISCUSIÓN GENERAL}

Una manera de aproximarse a las respuestas de los taxa a las condiciones ambientales es a través del modelado de su distribución, ya sea conocida o potencial. Lo anterior, permite visualizar sus patrones de distribución y generar hipótesis sobre las posibles respuestas adaptativas que pudiesen tener ante distintos factores ambientales. No obstante, este punto de vista es parcial, por lo que éste debe enriquecerse con otros aspectos como los biológicos que aportan información y datos relacionados con la morfología y anatomía de los taxa, y la capacidad de germinación de sus semillas; así como con aspectos ecológicos que contribuyen con información sobre la tasa de reproducción, interacciones bióticas y abióticas, dispersión y adaptación, entre otros, que sustenten los modelos de distribución (Buckley et al., 2010; González et al., 2003).

Aunque en este trabajo no se elaboraron escenarios de cambio climático, sino modelos de "nicho ecológico" para los dos taxa de Mimosa en estudio, es importante considerar que estos aspectos (biológicos y ecológicos) pueden modificarse como parte de los efectos del cambio climático y, por ende, modificar la distribución de los taxa. De acuerdo con las predicciones climáticas propuestas por el Panel Intergubernamental de Cambio Climático (IPCC), se espera que para finales del siglo XXI haya cambios en la temperatura que variarían geográficamente. Además, se espera que las sequías aumenten en algunos ecosistemas; mientras que en otros, se 
considera que habrá una mayor precipitación (Dirmeyer y Shukla, 1996; Rind et al., 1990; Peñuelas et al., 2004). Bajo estos pronósticos, la distribución de los taxa, independientemente de su tipo (amplia o restringida), se verá afectada, ya sea positiva (incrementándose) o negativamente (reduciéndose); por lo que es importante considerar los atributos intrínsecos de los taxa que permitan evaluar y predecir sus respuestas $y$, de esta forma, precisar sobre los efectos que puede tener el cambio climático en su distribución (Buckley et al., 2010; Lavergne et al., 2010).

De acuerdo con Hill et al. (2001), la distribución y persistencia de muchos taxa está delimitada por el clima. En este estudio, se consideró a la temperatura y la precipitación como los elementos del clima que afectan directamente la biología y la ecología de cualquier taxon vegetal.

En este caso, la distribución de ambos taxa del género Mimosa, se sustentó en los análisis sobre su biología y ecología, abarcando la morfología y la germinación de las semillas, así como la anatomía de la testa y de la madera; ya que, de acuerdo con Walck et al. (2011), estos temas influyen en la distribución de los taxa. Asimismo, estos temas ofrecen datos a diferentes niveles; por ejemplo, poblacional (natalidad, mortalidad y migración), de comunidad (interacciones: depredación, competencia, distribución) y ecosistémico (flujos de materia y energía), entre otros (Figura 1).

En Mimosa, existen varios trabajos enfocados en la morfología de sus semillas (Boelcke, 1946; Bravato, 1974; Lima, 1985) y la germinación de éstas (De Souza y De Castro, 1983; Camargo-Ricalde et al., 2004; Orozco-Almanza et al., 2003; Pavón 
et al., 2011), y en la anatomía de su madera (Maccari y Marchiori, 1994; Marchiori, 1996; Marchiori y Muñiz, 1997); mientras que de distribución, hasta ahora, sólo se han detectado dos (Camargo-Ricalde, 2015; Grether et al. 2015).

De manera general, aunque se ha mencionado que los factores que determinan la distribución de los taxa en el planeta son: I) la ecología y ii) la historia evolutiva de los taxa (Brown, 1995), así como iii) el establecimiento de los mecanismos y iv) la capacidad de dispersión de cada taxon (Soberón y Peterson, 2005), estos factores se consideran de forma aislada, por lo que es importante cambiar este enfoque, ya que están ligados y se requieren ver de manera conjunta (Figura 1), con el fin de brindarle mayor robustez y precisión a los modelos y, de esta forma, continuar siendo útiles en el reconocimiento de áreas de conservación (Thuiller et al., 2008) y en la detección de sitios con potencial para reintroducir taxa o para su posible restauración ambiental (Kumar y Stohlgren, 2009).

De acuerdo con Dalgleish et al. (2010), las primeras etapas del desarrollo de las plantas son más vulnerables comparadas con la etapa adulta y representan un obstáculo para el reclutamiento. Por lo anterior, en este estudio, se determinó la distribución conocida y potencial (Capítulo I) reconociendo a la semilla como la primera etapa vulnerable. Por lo anterior, se abordó la morfología de la semilla y la anatomía de su testa (Capítulo II), y la germinación de éstas (Capítulo III). Asimismo, la etapa adulta está representada con el estudio ecoanatómico de la madera de los dos taxa (Capítulo IV). 
Las semillas de ambos taxa presentan características propias de la familia Leguminosae como son: I) Hilo, ii) Lente y iii) Línea fisural o pleurograma irregular, con brazos de igual o diferente longitud (Corner, 1976; Gunn, 1984, 1991) y, específicamente, características de la subfamilia Mimosoideae: I) Hilo, posición apical o sub-apical, ii) Lente, conspicua, iii) Línea fisural presente en ambas caras y vi) Endospermo vítreo (Boelcke ,1946; Bravato, 1974; Lima, 1985).

Anatómicamente, la testa de las semillas de $M$. aculeaticarpa var. aculeaticarpa presenta una capa de macroesclereidas y la línea lúcida se localiza en la parte superior de esta capa. En el caso de las semillas de M. luisana, éstas presentan una capa de macrosesclereidas con la línea lúcida ubicada en la parte media de ésta y una capa de osteoesclereidas. La posición de la línea lúcida y la presencia de osteoesclereidas permiten diferenciar a los dos taxa; sin embargo, estos caracteres ya han sido reportados en otros géneros de mimosoideas como Leucaena leucocephala (Serrato-Valenti et al., 1994) y Prosopis velutina Woot. (Irving, 1984).

De acuerdo con Smith et al. (2002) y con Radchuk y Borisjuk (2014), la función del esclerénquima es fungir como una barrera que evita la entrada de agua y gases, por lo que los resultados sugieren que la semilla de $M$. luisana está más protegida contra la desecación (Radchuk y Borisjuk, 2014), y esto podría indicar que presenta un mayor grado de latencia física (Baskin y Baskin, 2004) y una mayor longevidad (Arambarri, 2002; De Souza y Marcos-Filho, 2001). 
Asimismo, Martín-Gómez y Saco-Sierra (2012) consideran que las capas de esclerénquima le confieren rigidez a la testa y dureza a la semilla, por lo que las semillas de ambos taxa requieren de un proceso de escarificación, el cual eleva el porcentaje de germinación (Chahuan y Johnson, 2008; Jayasuriya et al., 2013; Leal y Biondi, 2007; Pavón et al., 2011; Silveira y Fernandes, 2006); en este caso, $M$. aculeaticarpa var. aculeaticarpa elevó su germinación de 1.2\% (semillas sin escarificar) a $70.2 \%$ (semillas escarificadas) y $M$. luisana de $6.3 \%$ (semilla sin escarificar) a $79.6 \%$ (semillas escarificadas).

Aunque el proceso de escarificación aumenta el porcentaje de germinación de las semillas en ambos taxa, la temperatura y la identidad del taxon juegan un papel fundamental en el porcentaje de germinación alcanzado, aumentándolo o disminuyéndolo, según sea el caso. En este estudio, M. aculeaticarpa var. aculeaticarpa, a $5^{\circ} \mathrm{C}$ alcanzó $10 \%$ de germinación; mientras que M. luisana alcanzó el 50\%; asimismo, a $45^{\circ} \mathrm{C}, M$. aculeaticarpa var. aculeaticarpa alcanzó el $35 \%$ y $M$. luisana el $27 \%$ de germinación. Estas variantes en los porcentajes de germinación también han sido observadas en otros taxa de Mimosa; por ejemplo, M. tenuiflora (Willd.) Poir., a 25C alcanza el 95\% de germinación (Camargo-Ricalde y Grether, 1998; Parra, 1984). Igualmente, Camargo-Ricalde et al. (2004) reportaron que en $M$. calcicola B. L. Rob., germina el $100 \%$ de las semillas entre los 25 y $30^{\circ} \mathrm{C}, \mathrm{M}$. polyantha Benth. alcanzó el 100\% de germinación a una temperatura de 35드 y en M. lacerata Rose, se alcanza el 100\% de germinación entre los 15 y 25ㄷ․

Debido a que las semillas de ambos taxa germinan en una gama amplia de temperaturas $\left(5^{\circ} \mathrm{C}\right.$ a $45^{\circ} \mathrm{C}$, con intervalos de $\left.5^{\circ} \mathrm{C}\right)$ se sugiere que, aunque la 
germinación de las semillas es una etapa vulnerable, la temperatura no representa un obstáculo para su germinación; no obstante, deben considerarse otros aspectos relacionados con el papel que juegan los brúquidos como posibles escarificadores naturales (Romero-Nápoles et al., 2005), así como otros aspectos relacionados con el establecimiento de las plántulas (depredación, nodrizaje, etc).

En la etapa adulta, los taxa estudiados se diferencian porque $M$. aculeaticarpa var. aculeaticarpa presenta una madera con porosidad anular y la madera de $M$. luisana tiene porosidad difusa; estos caracteres ya han sido observados en otros taxa como M. acantholoba (H. \& B. ex Willd.) Poir. var. eurycarpa (B.L. Rob.), M. benthamii J.F. Macbr. var. benthamii, M. lacerata Rose, M. texana (A. Gray) Small var. filipes (Britton \& Rose) Barneby (Montaño-Arias, 2010), y M. polyantha (Montaño-Arias et al., 2016).

El análisis en conjunto de los trabajos arriba mencionados con los resultados obtenidos en este estudio, muestra que los taxa de Mimosa tienen elementos vasculares de diámetro tangencial pequeño, longitud corta, con placa de perforación simple, punteaduras intervasculares ornamentadas y traqueidas vasicéntricas (da Silva-Pereira et al., 2013; Montaño-Arias et al. 2013), caracteres que contribuyen a la seguridad en la conducción de agua y son caracteres distintivos de los taxa con capacidad de adaptación a diferentes tipos de hábitats. Por lo tanto, de manera general, los taxa de Mimosa tienen un xilema adaptado para resistir períodos de escasez de agua que les permite vivir y adaptarse a los ambientes en los que habitan, esto se robustece con el valor del Índice de Vulnerabilidad (IV) de cada 
taxon (Carlquist, 1977; Montaño-Arias et al., 2013). M. aculeaticarpa var. aculeaticarpa presentó un IV de 4.05; mientras que el IV de M. luisana es de 1.42, lo que sugiere que esta última es más resistente a la sequía.

Es relevante mencionar que las respuestas ecoanatómicas y ecofisiológicas que presentan los dos taxa estudiados, permiten sugerir que las variaciones en la precipitación y en la temperatura no afectarían ni su biología ni su ecología y, por lo tanto, aumentaría la posibilidad de que ambos taxa pudiesen ampliar su distribución (nicho ecológico).

Finalmente y desde una perspectiva utilitaria bio-ecológica, algunos autores han propuesto, entre otras especies de Mimosa, a M. aculeaticarpa (Pavón et al., 2011) y a M. luisana (Camargo-Ricalde y García-García, 2001) como taxa con potencial para la restauración ambiental. Al respecto, el conjunto de los resultados obtenidos apoyan, de manera contundente, la propuesta de dichos autores; sin embargo, existen otros aspectos que deben ser considerados; por ejemplo, la producción de frutos, las interacciones bióticas, la biología reproductiva y la capacidad de invasividad de los taxa. Asimismo, se hace énfasis en que es importante respetar sus respectivas áreas de distribución para no alterar la dinámica ecosistémica. 


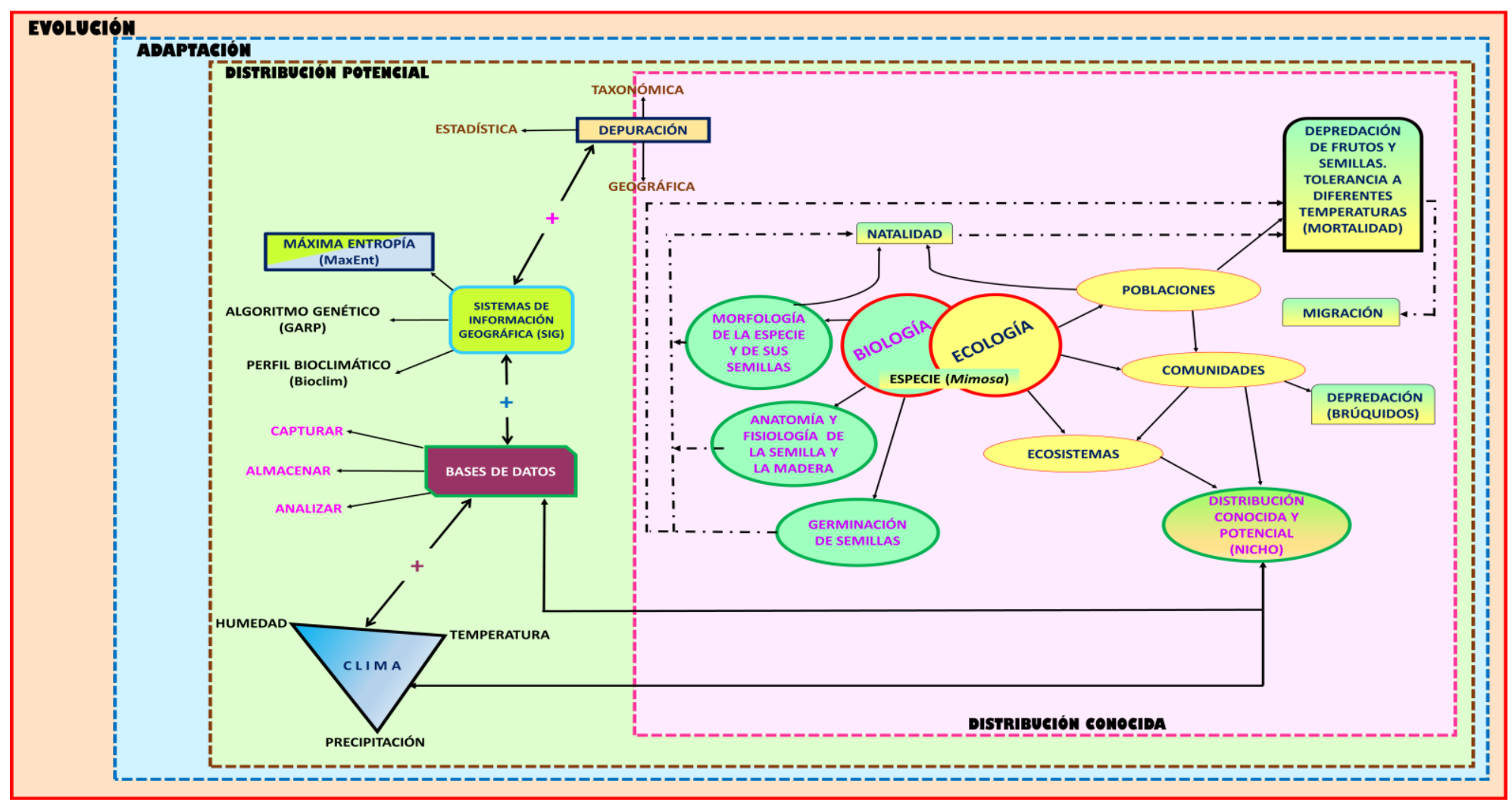

Figura 1. Modelo de integración basado en elementos biológicos y ecológicos de $M$. aculeaticarpa var. aculeaticarpa y $M$. luisana, y aspectos ambientales (y logísticos) que determinan tanto la distribución conocida como la potencial de ambos taxa. Los aspectos estudiados en esta tesis (círculos con contorno verde), contribuyen con información biológica y ecológica de cada taxon, ya sea de forma directa (flechas continuas) o indirecta (flechas punteadas). El cuadro de distribución conocida contiene, para este estudio en particular, la integración de los elementos biológico-ecológicos que se requieren estudiar para establecerla. En la distribución potencial, se incorporan los sistemas de información geográfica, algoritmos y la distribución conocida. Asimismo, mediante el conocimiento tanto de la distribución conocida como de la potencial, en conjunto con otros aspectos aquí no estudiados ( $P$. ej. establescimiento, desarrollo, etc.), se pueden inferir procesos de adaptación, aportando información que permite comprender los procesos evolutivos de ambos taxa. 


\section{LITERATURA CITADA}

Arambarri, A.M. 2002. Morfología, Anatomía y formaciones cristalinas en especies del género Senna, sección Chamaefistula de la Argentina (LeguminosaeCaesalpinioideae-Cassieae-Cassinae). Doctoral dissertation, Facultad de Ciencias Exactas. Universidad Nacional de La Plata, Argentina. 205 p.

Baskin, J.M. y Baskin C.C. 2004. A classification system for seed dormancy. Seed Science Research 14: 1-16.

Boelcke, O. 1946. Estudio morfológico de las semillas de Leguminosas, Mimosoideas y Caesalpinoideas de interés agronómico en la Argentina. Darwiniana 7: 240321.

Bravato, M. 1974. Estudio morfológico de frutos y semillas de las Mimosoideae (Leguminosae) de Venezuela. Acta Botanica Venezuelica 9: 317-361.

Brown, J.H. 1995. Macroecology. University of Chicago Press, Illinois. 269 p.

Buckley, L.B., Urban M.C., Angilletta M.J., Crozier L.G., Rissler L.J. y Sears M.W. 2010. Can mechanism inform species' distribution models? Ecology letters 13: 1041-1054.

Camargo-Ricalde, S.L. y Grether R. 1998. Germinación, dispersión y establecimiento de plántulas de Mimosa tenuiflora (Leguminosae) en México. Revista de Biología Tropical 46: 1-12.

Camargo-Ricalde, S.L., y García-García V. 2001. El género Mimosa L. (Fabaceae) y la restauración ecológica. Contactos 39: 34-42.

Camargo-Ricalde, S.L., Dhillion S.S. y García-García V. 2004. Phenology, and seed production and germination of seven endemic Mimosa species (Fabaceae- 
Mimosoideae) of the Tehuacán-Cuicatlán Valley, Mexico. Journal of Arid Environments 58: 423-437.

Camargo-Ricalde, S.L. 2015. Modelación de la distribución real y potencial de especies de dos géneros de Mimosoideae: Mimosa y Prosopis (Leguminosae) en México. Universidad Autónoma Metropolitana. Unidad Iztapalapa. Informe Final SNIB_CONABIO proyecto No. JM050. México, D.F.

Carlquist, S. 1977. Ecological factors in wood evolution: a floristic approach. American Journal of Botany 64: 887-896.

Chauhan, B.S. y Johnson D.E. 2008. Seed germination and seedling emergence of giant sensitive plant (Mimosa invisa). Weed Science 56: 244-248.

Corner, E. 1976. The seeds of Dicotyledons. Vol. I. Cambridge University. Madingley Road, Cambridge, England. 309 p.

da Silva-Pereira, A.C., Siegloch A.M. y Marchiori J.N.C. 2013. Anatomia do lenho de Mimosa micropteris Benth. Balduinia 40: 18-22.

Dalgleish, H.J., Koons D.N. y Adler P.B. 2010. Can life-history traits predict the response of forb populations to changes in climate variability? Journal of Ecology 98: 209-217.

De Souza, A.M. y De Castro G.A. 1983. Métodos para superar a dormÊncia tegumentar em sementes de Jurema- preta (Mimosa hostilis Benth.). Boletim de Pesquisa Florestal, Colombo 6/7: 26-32.

De Souza, F.H.D y Marcos-Filho J. 2001. The seed coat as a modulator of seedenvironment relationships in Fabaceae. Revista Brasileira de Botânica 24: 365375. 
Dirmeyer, P.A. y Shukla J. 1996. The effect on regional and global climate of expansion of the worl's deserts. Quart. J. Royal Meteorol. Soc. 122: 451-482.

González, E.M., Jurado E., González E.S., Aguirre C.O., Jiménez P.J. y Navar J. 2003. Cambio climático mundial: origen y consecuencias. Ciencia UANL 6: 377385.

Grether, R. Camargo-Ricalde S.L., Martínez-Bernal A., Montaño-Arias S. y. Fraile Ma.E. 2015. Diversity and geographical distribution patterns of the genus Mimosa (Mimosoideae) in the United States, Mexico, and Central America. En: V Conferencia Internacional de Leguminosas (VILC). R. Fortunato (ed.). Fundación CICCUS. 224 p.

Gunn, C.R. 1984. Fruits and seeds of genera in the subfamily Mimosoideae (Fabaceae). Technical Bulletin no. 1681. Agricultural Research Service. United States Departament of Agriculture, Washington DC. 194 p.

Gunn, C.R. 1991. Fruits and seeds of genera in the subfamily Caesalpinoideae (Fabaceae). Technical Bulletin no. 1755. Agricultural Research Service. United States Departament of Agriculture, Washington DC. 408 p.

Hill, J.K., Collingham Y.C., Thomas C.D., Blakeley D.S., Fox R., Moss D. y Huntley B. 2001. Impacts of landscape structure on butterfly range expansion. Ecology Letters 4: 313-321.

Irving, D.W. 1984. Seed structure and histochemistry of Prosopis velutina (Leguminosae). Botanical Gazette 145: 340-345. 
Jayasuriya, G.K. Wijetunga A.S., Baskin J.M. y Baskin C.C. 2013. Seed dormancy and storage behavior in tropical Fabaceae: a study of 100 species from Sri Lanka. Seed Science Research 23: 257-269.

Kumar, S. y Stohlgren T.J. 2009. Maxent modelling for predicting suitable habitat for threatened and endangered tree Canacomyrica monticola in New Caledonia. Journal of Ecology and Natural Environment 1: 94-98.

Lavergne, S., Mouquet N., Thuiller W. y Ronce O. 2010. Biodiversity and climate change: integrating evolutionary and ecological responses of species and communities. Annual Review of Ecology, Evolution, and Systematics. 41: 321 350.

Leal, L. y Biondi D. 2007. Comportamento germinativo de sementes de Mimosa dolens Vell. Publ UEPG Exact Earth Sci Agr Sci Eng Ponta Grossa 13: 37-43.

Lima, M.P.M. 1985. Morfologia dos frutos e sementes dos gêneros da tribo Mimoseae (Leguminosae-Mimosoideae) aplicada à Sistemática. Rodriguésia 37: 53-78.

Maccari, A. y Marchiori J.N.C. 1994. Estudo anatômico do xilema secundário de Mimosa sparsa Benth. Ciência Florestal, Santa Maria 4: 145-155.

Marchiori, J.N.C y Muniz B.G. 1997. Estudo anatômico do xilema secundário de Mimosa trachycarpa Benth. Ciência Rural, Santa Maria 27: 223-228.

Marchiori, J.N.C. 1996. Anatomia do xilema secundário de Mimosa incana (Spreng.) Benth. Ciência Florestal, Santa Maria 6: 53-63. 
Martín-Gómez, S. y Saco-Sierra, D. 2012. Estudio de los tejidos para la caracterización de las plantas. REDUCA 4: 1-26.

Montaño-Arias, S.A. 2010. Anatomía comparada de la madera de especies arbóreas mexicanas del género Mimosa sección Batocaulon (Leguminosae). Tesis de Maestría. Universidad Autónoma Metropolitana, Unidad Iztapalapa. México, D.F. 141 p.

Montaño-Arias, S.A., Camargo-Ricalde S.L. y De la Paz Pérez-Olvera C. 2013. Ecoanatomía de los elementos de vaso de la madera de cinco especies del género Mimosa L. (Leguminosae-Mimosoideae). Botanical Sciences 91: 1-10.

Montaño-Arias, S.A., Camargo-Ricalde S.L. y Grether R. 2016. Anatomía de la madera de tres especies de Mimosa (Leguminosae, Mimosoideae) distribuidas en México. Madera y Bosques (en prensa).

Orozco-Almanza, S., Ponce De León-García L., Grether R. y García-Moya E. 2003. Germination of four species of the genus Mimosa (Leguminosae) in a semi-arid zone of Central Mexico. Journal of Arid Environments 55: 75-92.

Parra, G.P. 1984. Estudio de la morfología externa de plántulas de Calliandra gracilis, Mimosa albida, Mimosa arenosa, Mimosa camporum y Mimosa tenuiflora. Revista de la Facultad de Agronomía (Maracay) 13: 311-350.

Pavón, N.P., Ballato-Santos J. y Pérez-Pérez C. 2011. Germinación y establecimiento de Mimosa aculeaticarpa var. biuncifera (FabaceaeMimosoideae). Revista Mexicana de Biodiversidad 82: 653-661.

Peñuelas, J., Sabaté S., Fidella I. y Gracia C. 2004. Efectos del cambio climático sobre los ecosistemas terrestres: observación, experimentación y simulación. 
En: Valladares, F. 2004. Ecología del bosque mediterráneo en un mundo cambiante. 425-460. Ministerio de Medio Ambiente, EGRAF, S. A., Madrid.

Radchuck, V. y Borisjuk L. 2014. Physical, metabolic and developmental functions of the seed coat. Frontiers in Plant Science 5: 1-17.

Rind, D., Goldberg R., Hansen J., Rosenzweig C. y Ruedy R. 1990. Potential evapotranspiration and the likelihood of future drought. Journal of Geophysical Research 95: 9983-10004.

Romero-Nápoles, J., Grether R., Camargo-Ricalde S.L. y Jonson C.D. 2005. Método para la evaluación de daño de semillas por brúquidos (Insecta, Coleoptera), en el campo con nuevos registros de hospederos y distribución para el grupo. Entomología Mexicana 4: 107-111.

Serrato-Valenti, G., Cornara L., Ghisellini P. y Ferrando M. 1994.Testa structure and histochemistry related to water uptake in Leucaena leucocephala Lam. (De Wit). Annals of Botany 73: 531-537.

Silveira, F.A. y Fernandes G.W. 2006. Effect of light, temperature and scarification on the germination of Mimosa foliolosa (Leguminosae) seeds. Seed Science and Technology 34: 585-592.

Smith, M.T., Wang B.S.P. y Msanga H.P. 2002. Dormancy and germination. 149-176 p. In Vozzo, J.A. (ed.) Tropical tree seed manual. Agriculture Handbook 721. Washington DC, USDA Forest Service.

Soberón, J. y Peterson A.T. 2005. Interpretation of models of fundamental ecological niches and species' distributional areas. Biodiversity Informatics 2: 110. 
Thuiller, W., Albert C., Araujo M.B., Berry P.M., Cabeza M., Guisan A., Hickler T., Midgely G.F., Paterson J., Schurr F.M., Sykes M.T. y Zimmermann N.E. 2008. Predicting global change impacts on plant species' distributions: future challenges. Perspectives in Plant Ecology, Evolution and Systematics 9: 137152.

Walck, J.L., Hidayati S.N., Dixon K.W., Thompson K. y Poschlod P. 2011. Climate change and plant regeneration from seed. Global Change Biology 17: 21452161. 


\section{CONCLUSIONES GENERALES}

Los resultados de la distribución conocida (o "nicho realizado") indicaron que Mimosa aculeaticarpa var. aculeaticarpa se distribuye en 16 estados de la República Mexicana; mientras que M. luisana se restringe al Valle de Tehuacán-Cuicatlán, en los estados de Puebla y Oaxaca.

Respecto al modelado de la distribución potencial (o "nicho ecológico") de ambos taxa, éste indicó que existen las condiciones de temperatura y precipitación para que M. aculeaticarpa var. aculeaticarpa amplíe su distribución desde el centro del país hacia la región del Altiplano Sur (Zacatecano-Potosino); también este taxon podría extender su distribución hacia el noroeste del Eje Volcánico y hacia la parte sur de la Sierra Madre del Sur. En el caso de M. luisana esta podría ampliar su distribución hacia la región noreste del Eje Volcánico, las regiones suroeste y sureste de la Sierra Madre del Sur, y abarcar, en su totalidad, la provincia biogeográfica de Oaxaca y extenderse hacia una pequeña porción del oeste de la provincia del Golfo de México (Capítulo I). Dichos modelos están sustentados con los atributos intrínsecos de cada taxon como son la morfología y anatomía de la testa de las semillas (Capítulo II); así como con su germinación (Capítulo III), y, finalmente, con la anatomía de su madera (Capítulo IV).

En el caso de las semillas (Capítulo II), en ambos taxa la testa presenta caracteres que les confieren impermeabilidad, en el caso de $M$. aculeaticarpa var. 
aculeaticarpa presentó tres caracteres: i) Cutícula, ii) Macroesclereidas, y iii) Línea lúcida; mientras que $M$. luisana tiene cuatro: i) Cutícula, ii) Macroesclereidas, iii) Línea lúcida, y iv) Osteoesclereidas; estos caracteres, además de prevenir la germinación inicial, elevan la longevidad de la semilla, ya que tienen relación directa con la latencia.

Asimismo, sus semillas pueden germinar (Capítulo III) en una amplia gama de temperaturas $\left(5^{\circ}\right.$ a $45^{\circ} \mathrm{C}$, con intervalos de $\left.5^{\circ} \mathrm{C}\right)$; sin embargo, éstas deben escarificarse, para alcanzar porcentajes de germinación superiores al $70 \%$. No obstante, la temperatura juega un papel fundamental en la germinación de las semillas ya que a $5^{\circ} \mathrm{C} M$. aculeaticarpa var. aculeaticarpa alcanza el $10 \%$ de germinación y $M$. luisana el $50 \%$; mientras que a $45^{\circ} \mathrm{C}$, se alcanza el $35 \%$ y el $27 \%$, respectivamente. Cabe señalar que a 25 y $30^{\circ} \mathrm{C} M$. aculeaticarpa var. aculeaticarpa alcanza el $88 \%$ de germinación, mientras que M. luisana alcanza el 100\%.

Por otro lado, los taxa estudiados (Capítulo IV), tienen un xilema adaptado para resistir periodos de escasez de agua que les permite vivir y adaptarse a los ambientes en los que habitan. Ambos taxa presentaron elementos vasculares de diámetro tangencial pequeño, longitud corta, con placa de perforación simple, punteaduras intervasculares ornamentadas y traqueidas vasicéntricas, estos caracteres contribuyen a la seguridad en la conducción de agua y son distintivos de taxa con capacidad de adaptación a diferentes tipos de hábitats. 
De manera adicional, el índice de vulnerabilidad obtenido en la madera de $M$. aculeaticarpa var. aculeaticarpa (4.05), supera casi tres veces el de M. luisana (1.42). El análisis de este índice en conjunto con los caracteres anatómicos de cada taxon indica que esta última es la más resistente a periodos de escasez de agua.

Por lo anterior, es factible señalar que existen las condiciones ambientales (climáticas: temperatura y precipitación) para que ambos taxa amplíen su distribución. Aunado a lo anterior y considerando sus atributos biológicos y ecológicos, es factible proponer que ambos taxa puedan ser utilizados en proyectos de restauración ambiental. 


\section{PERSPECTIVAS}

Con base en los resultados de esta tesis, se plantean diferentes aspectos de experimentos tanto de campo como bajo condiciones controladas, que necesitan ser considerados para poder ampliar el conocimiento sobre la distribución de Mimosa aculeaticarpa var. aculeaticarpa y de M. luisana.

Los modelos mostrados en el Capítulo I, son una aproximación de como es y será la distribución de los taxa estudiados, y que están sustentados con aspectos biológicos y ecológicos de los mismos. Se propone que una forma de ampliar y enriquecer el conocimiento sobre su distribución (o la distribución de cualquier taxon vegetal), sobre todo de la potencial, es generar los modelos bajo escenarios de cambio climático que consideren no sólo la temperatura y la precipitación, sino también a la pendiente del terreno y al cambio de uso de suelo, sin perder de vista, la relevancia del estudio de la biología de estos taxa.

Además, considerando el ciclo reproductivo de cada taxon (P. ej. semilla, plántula, planta joven o adulta, etc.), sería posible la utilización de sus diferentes etapas como modelos biológicos de estudio; es decir, sería factible llevar a cabo experimentos controlando diferentes concentraciones de bióxido de carbono $\left(\mathrm{CO}_{2}\right)$; así como con interacciones entre $\mathrm{CO}_{2}$, temperatura y precipitación, ya que éstas se consideran algunas de las variables más importantes en cuestiones de cambio climático y, sin duda, son variables que influyen en la distribución de los taxa. 
Otro aspecto relevante a considerar, estaría enfocado en ampliar el conocimiento de las semillas de estos taxa. Sin bien, la morfología queda definida en el Capítulo II, sería conveniente profundizar el análisis anatómico e histoquímico de la semilla en su totalidad (testa, embrión y endospermo) e implementar otras técnicas (P. ej. microscopia confocal, electrónica de barrido y de transmisión) que no generen artificios, que corroboren lo planteado en esta tesis (P. ej. presencia de cutícula y de lignina) y que brinden información detallada sobre la microestructura de la semilla.

En el Capítulo III, se demostró que las semillas de ambos taxa requieren de un proceso de escarificación para germinar; en este punto se propone que, una vez conocida la anatomía e histoquímica de la semilla, se prueben otros métodos de escarificación para determinar el mejor método para cada taxon, con el fin de promover su germinación y evitar cualquier tipo de daño morfológico, anatómico o de desarrollo al embrión, de manera que su desarrollo y crecimiento ocurran en forma adecuada, ya sea en condiciones controladas y/o naturales. Una vez reconociendo que la anatomía de la semilla influye en la selección del método de escarificación, entonces, se sugiere realizar estudios de establecimiento de plántulas, para evaluar la mortalidad de los taxa, dato importante, ya que mediante observaciones en campo, se ha documentado la presencia de muy pocas plántulas de ambos taxa y que, además, la mayoría de éstas no sobrevive a la estación de secas.

Por otro lado, la anatomía de la madera muestra que ambos taxa tienen un xilema adaptado para resistir períodos de escases de agua; sin embargo, 
considerando que $M$. aculeaticarpa var. aculeaticarpa tiene una distribución en ecosistemas templados y secos, cuyo rango altitudinal varía entre 1,900 y 2,700 msnm y que $M$. luisana se distribuye únicamente en el Valle semiárido de Tehuacán-Cuicatlán, teniendo un rango de altitud entre 500 y 1,760 msnm, sería interesante llevar a cabo un estudio ecoanatómico de ambos taxa (o de cualquier otro taxon vegetal) en un gradiente altitudinal que mostrara la variación a nivel intraespecífico y que revelara información sobre cuáles son los caracteres genéticos y cuáles los caracteres influenciados por el ambiente, para entender cuáles son los procesos adaptativos y evolutivos de estos taxa.

Los aspectos señalados conllevan a generar nuevos estudios a corto, mediano y largo plazo que permitirán conocer, entender y robustecer los modelos de distribución de los taxa. Por último, se considera que los estudios sobre distribución potencial que no aborden los aspectos biológicos y ecológicos de los taxa son frágiles, y posiblemente, poco precisos. 
RESPUESTAS ECOANATOMICAS Y ECOFISIOLOGICAS DE DOS ESPECIES DEL GENERO Mimosa (Leguminosae) ANTE EL CAMBIO CLIMATICO

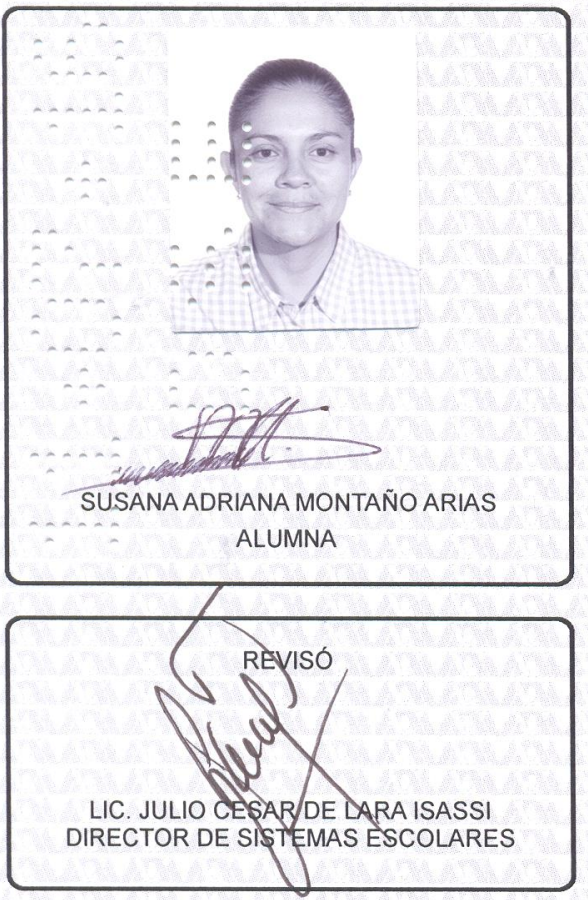

DIRECTORA DE LA DIVISIÓN DE CBS

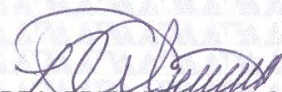

DRA. EDITHA PONCE ALQUICIRA

En la Ciudad de México, se presentaron a las 10:00 horas del día 15 del mes de junio del año 2016 en la Unidad Iztapalapa de la Universidad Autónoma Metropolitana, los suscritos miembros del jurado:

DRA. SARA LUCIA CAMARGO RICALDE

DR. DAVID MANUEL DIAZ PONTONES

DR. SILVIA CASTILLO ARGÜERO

DRA. MARIA HILDA FLORES OLVERA

DRA. ROSAURA GRETHER GONZALEZ

Bajo la presidencia de la primera y con carácter de Secretaria la última, se reunieron a la presentación de la Disertación Pública cuya denominación aparece al margen, para la obtención del grado de:

DOCTORA EN CIENCIAS BIOLOGICAS Y DE LA SALUD

DE: SUSANA ADRIANA MONTAÑO ARIAS

y de acuerdo con el artículo 78 fracción IV del Reglamento de Estudios Superiores de la Universidad Autónoma Metropolitana, los miembros del jurado resolvieron:

\section{aprobar}

Acto continuo, la presidenta del jurado comunicó a la interesada el resultado de la evaluación $y$, en caso aprobatorio, le fue tomada la protesta.

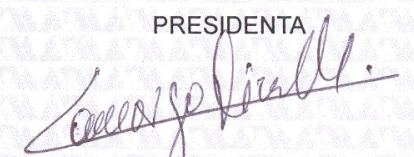

DRA. SARA LUGIA CAMARGO RICALDE

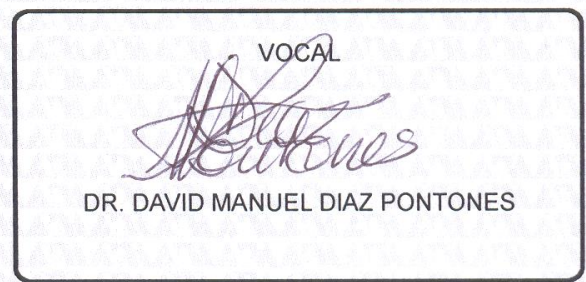

SECRETARIA

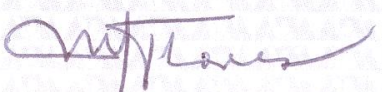

DRA. MARIA HILDA FLORES OLVERA

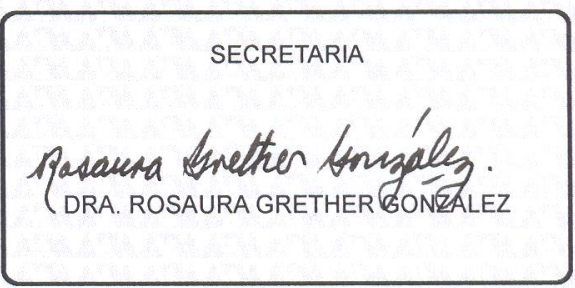

